\title{
Studies on mendelian disorders of cornification
}

Citation for published version (APA):

Nellen, R. G. L. (2017). Studies on mendelian disorders of cornification. [Doctoral Thesis, Maastricht University]. Maastricht University. https://doi.org/10.26481/dis.20170119rn

Document status and date:

Published: 01/01/2017

DOI:

10.26481/dis.20170119rn

Document Version:

Publisher's PDF, also known as Version of record

\section{Please check the document version of this publication:}

- A submitted manuscript is the version of the article upon submission and before peer-review. There can be important differences between the submitted version and the official published version of record.

People interested in the research are advised to contact the author for the final version of the publication, or visit the DOI to the publisher's website.

- The final author version and the galley proof are versions of the publication after peer review.

- The final published version features the final layout of the paper including the volume, issue and page numbers.

Link to publication

\footnotetext{
General rights rights.

- You may freely distribute the URL identifying the publication in the public portal. please follow below link for the End User Agreement:

www.umlib.nl/taverne-license

Take down policy

If you believe that this document breaches copyright please contact us at:

repository@maastrichtuniversity.nl

providing details and we will investigate your claim.
}

Copyright and moral rights for the publications made accessible in the public portal are retained by the authors and/or other copyright owners and it is a condition of accessing publications that users recognise and abide by the legal requirements associated with these

- Users may download and print one copy of any publication from the public portal for the purpose of private study or research.

- You may not further distribute the material or use it for any profit-making activity or commercial gain

If the publication is distributed under the terms of Article $25 \mathrm{fa}$ of the Dutch Copyright Act, indicated by the "Taverne" license above, 
Studies on

\section{Mendelian}

disorders of

cornification

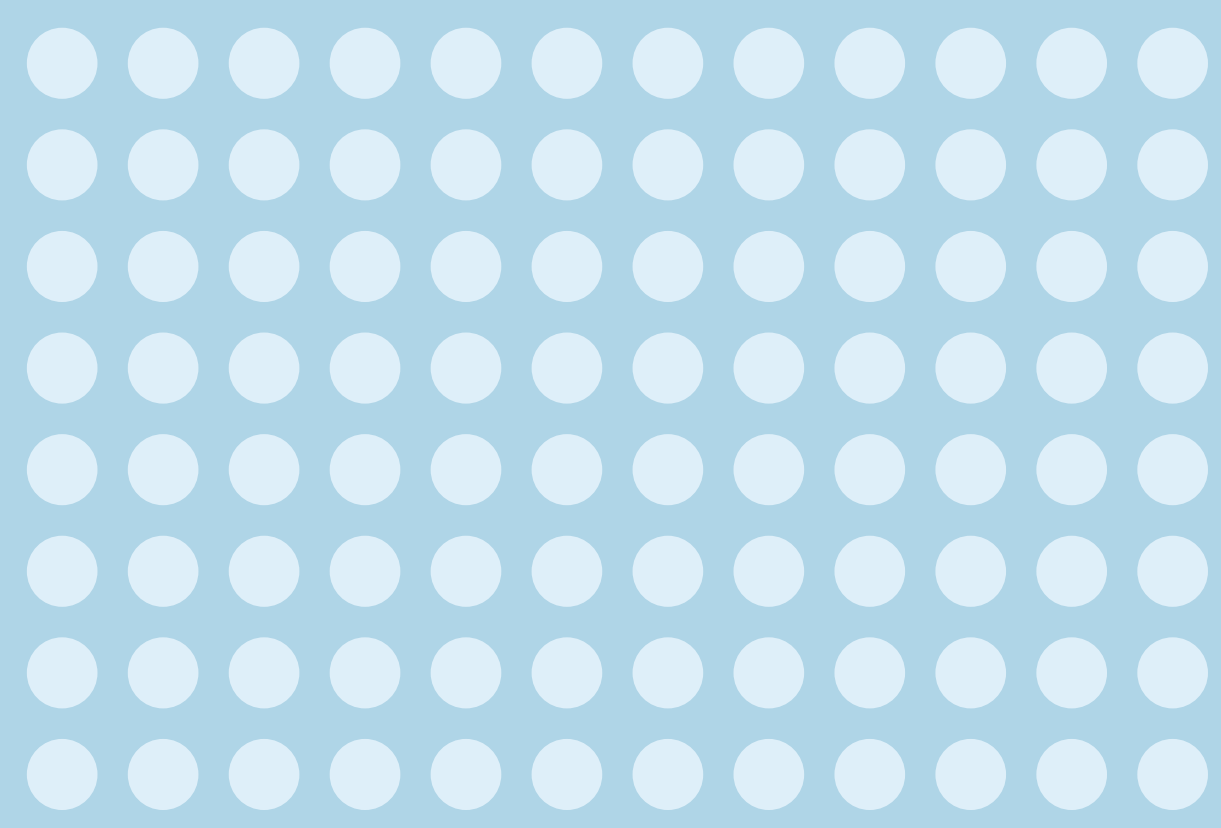

R.G.L. Nellen 



\section{STUDIES ON MENDELIAN DISORDERS OF CORNIFICATION}


Publicatie van dit proefschrift is mede mogelijk gemaakt door een financiële bijdrage van de Raad van Bestuur van het IJsselland Ziekenhuis, Capelle aan den IJssel.

$\begin{array}{ll}\text { Cover design } & \text { AdriaanTV } \\ \text { Layout } & \text { Renate Siebes | Proefschrift.nu } \\ \text { Printed by } & \text { Proefschriftmaken.nl } \\ \text { ISBN } & 978-90-9030071-9\end{array}$

\section{Copyright 2017 (c) R.G.L. Nellen, Rotterdam, The Netherlands}

All rights reserved. No part of this thesis may be reproduced, stored or transmitted in any form or by any means without prior permission of the author. 


\section{STUDIES ON MENDELIAN DISORDERS OF CORNIFICATION}

\section{PROEFSCHRIFT}

ter verkrijging van de graad van doctor aan de Universiteit Maastricht,

op gezag van de Rector Magnificus, prof. dr. Rianne M. Letschert

volgens het besluit van het College van Decanen,

in het openbaar te verdedigen

op donderdag 19 januari 2017 om 14.00 uur

door

Ruud Gerard Leonard Nellen

Geboren 12 juli 1980 te Roosendaal en Nispen 


\section{Promotores}

Prof. dr. P.M. Steijlen

Prof. dr. M.A.M. van Steensel

\section{Copromotores}

Dr. M. van Geel

Prof. dr. J. Frank (Heinrich Heine Universität Dusseldorf, Duitsland)

\section{Beoordelingscommissie}

Prof. dr. C.T.R.M. Stumpel (voorzitter)

Prof. dr. S.G.M.A. Pasmans (Erasmus MC, Rotterdam)

Dr. A.M.G. Pasmooij (UMCG, Groningen)

Prof. dr. H.J.M. Smeets 
Les études ça vous change, ça fait l'orgueil d'un homme. Il faut bien passer par là pour entrer dans le fond de la vie. Avant, on tourne autour seulement. On se prend pour un affranchi mais on bute dans des riens. On rêve de trop. On glisse sur tous les mots. Ça n'est pas ça. Ce n’est rien que des intentions, des apparences. Faut autre chose au résolu.

Louis-Ferdinand Céline, Voyage au bout de la nuit.

Aan Annieke Aan mijn ouders 



\section{Contents}

Chapter I Introduction 9

$\begin{array}{ll}\text { Chapter II } \quad \text { Mal de Meleda } & 15\end{array}$

Chapter III Epidermolytic Ichthyosis $\quad 51$

$\begin{array}{lll}\text { Chapter IV Darier disease and Hailey-Hailey disease } & 67\end{array}$

$\begin{array}{lr}\text { Chapter V } \quad \text { Conclusions, discussion and valorisation } & \mathbf{1 2 5}\end{array}$

$\begin{array}{lll}\text { Chapter VI Summary } & 152\end{array}$

Samenvatting $\quad 155$

$\begin{array}{lll}\text { Appendix } & \text { Curriculum vitae } & 164\end{array}$

List of publications $\quad 165$

Dankwoord (Acknowledgements) 168 


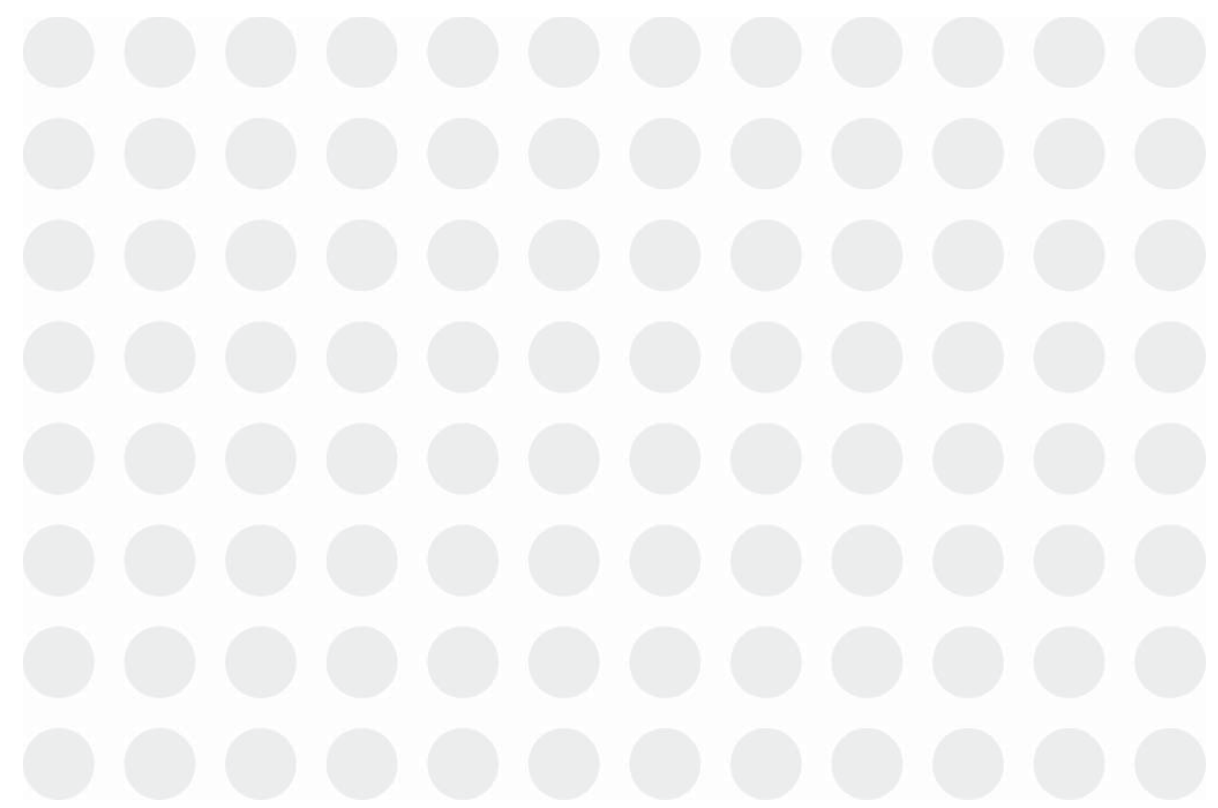


Chapter I

Introduction 


\subsection{Introduction}

The Mendelian disorders of cornification (MEDOC) encompass the hereditable monogenic skin diseases caused by mutations in genes responsible for homeostasis of the epidermis, in particular the development of the cornified envelope $\mathrm{e}^{1,2}$. Disruption of keratinocyte physiology can yield strikingly different skin diseases. This is reflected in the most commonly used classification of MEDOC, in which syndromes are grouped according to clinical phenotype. The phenotypes distinguished are the ichthyoses ${ }^{1}$, palmoplantar keratodermas (PPK) $)^{3}$, Darier disease (DD) and Hailey-Hailey disease (HHD). A classification based on genotype or aetiology has also been proposed, which divides MEDOC into diseases of epidermal lipid metabolism, corneocyte physiology, cell-cell junctions and keratinocyte homeostasis ${ }^{1,2}$. Most PPKs are classified either according to the mode of inheritance or the occurrence of associated symptoms (syndromic and non-syndromic PPKs) ${ }^{3}$.

In most MEDOC as well as other inherited disorders, genetic variants in the associated gene will cause a uniform phenotype, i.e. a phenotype that is more or less the same in each individual patient. This the case for homozygous or compound heterozygous mutations in SLURP1 in Mal de Meleda (MDM) ${ }^{4}$. However, this uniformity is not always present, as the phenotype of certain MEDOC can be highly variable. In some diseases, this variance is associated with a strong genotype-phenotype correlation, i.e. specific variations in the genomic sequence can be associated with a specific phenotype. For example, the severe phenotype of Epidermolytic Ichthyosis (EI) is associated with mutations in a relatively small area of the sequence of $K R T 1$ or $K R T 10^{5}$, in this case coding for the helix boundary motifs. The mild phenotype, on the other hand, is linked to mutations in the linker L12 domain of $K R T 1^{6,7}$. Sometimes, an extensive phenotypic variation is observed with no apparent genotype-phenotype correlations. This variation includes differences in disease severity, as well as the presence or absence of specific symptoms. For example, in Darier disease (DD) and Hailey-Hailey disease (HHD), ATP2A2 and ATP2C1 mutations inherit with complete penetrance. However, clinical symptoms and disease severity may be variable, even within families affected by the same disease causing variant ${ }^{8-10}$.

Variability in associated clinical features or severity may pose problems in identifying these syndromes. Unclear genotype-phenotype correlations make predicting disease course difficult. This ultimately interferes with patient care: without a diagnosis and 


\section{CHAPTER 1 INTRODUCTION}

prognosis, effective treatment and provision of adequate (genetic) counselling is impaired. There is therefore a dire need for studies that describe the clinical and genetic variation in MEDOC. This thesis addresses the problem of genotypic and phenotypic variation in four MEDOC with a relatively high prevalence and associated with impaired quality of life for patients: mal de Meleda (MDM), Epidermolytic Ichthyosis (EI), Darier disease (DD) and Hailey-Hailey disease (HHD).

\subsection{Aims and outline}

The aims of this thesis can be formulated as follows:

1. What is the clinical and genetic variability in MDM, EI, DD and HHD?

2. Is it possible to assess genotype-phenotype correlations in MDM, EI, DD and HHD?

To answer these questions, this thesis describes clinical and molecular studies in patients with MDM, EI, DD or HHD.

Part I describes patients with MDM. We identified new mutations in the causative gene for MDM, SLURP1, in Dutch and Indian patients. Several mutations in SLURP1 recur in different populations. We investigated whether the p.(Trp15Arg) mutation recurred in the Western European population due to a founder effect. With regard to clinical variation in MDM, we discuss whether palmoplantar keratoderma of the Gamborg-Nielsen type (PPK-GN) should be considered as a separate disease entity.

Part II considers the clinical variability of EI. We describe patients from a family with variable severity of symptoms due to mutation p.(Met339Lys) in the linker L12 domain KRT1. This observation shows that the genotype-phenotype correlations in KRT1-associated skin disease are not as strict as has been previously suggested. We provide clinical and functional evidence for the pathogenicity of variant p.(Met339Lys) in EI and add a novel variant to the mutation spectrum in EI.

Part III describes two distinct clinical presentations of DD and a comprehensive review of all reported mutations in $A T P 2 A 2$ and $A T P 2 C 1$. To expand the clinical variability in DD, we report a patient with type II segmental distribution of DD and an unusually mild phenotype of DD in a Sinhalese patient with skin type V. In the former patient, we were able to provide molecular evidence for the loss of heterozygosity that 


\section{CHAPTER 1 INTRODUCTION}

underlies the type II segmental presentation. This evidence has so far only been provided for one instance ${ }^{11}$. Furthermore, we present data on a large cohort of patients with DD and $\mathrm{HHD}$ and report several new mutations in $A T P 2 A 2$ and $A T P 2 C 1$, respectively. We created a database for all mutations in ATP2A2 and ATP2C1 using the Leiden Open Variation Database (LOVD v3.0), for variants reported in the literature as well as to allow future inclusions. This enables us to fully quantify genetic variability in DD and HHD. It allows us to address the question of a genotype-phenotype correlation, which has not been noted unequivocally in DD and HHD. 


\section{CHAPTER 1 INTRODUCTION}

\section{References}

1 Oji, V., Tadini, G., Akiyama, M. et al. Revised nomenclature and classification of inherited ichthyoses: results of the First Ichthyosis Consensus Conference in Soreze 2009. J Am Acad Dermatol 2010; 63: p. 607-41.

2 Schmuth, M., Martinz, V., Janecke, A.R. et al. Inherited ichthyoses/generalized Mendelian disorders of cornification. Eur J Hum Genet 2013; 21: p. 123-33.

Itin, P.H., Fistarol, S.K. Palmoplantar keratodermas. Clin Dermatol 2005; 23: p. 15-22.

4 Fischer, J., Bouadjar, B., Heilig, R. et al. Mutations in the gene encoding SLURP-1 in Mal de Meleda. Hum Mol Genet 2001; 10: p. 875-80.

5 Arin, M.J., Oji, V., Emmert, S. et al. Expanding the keratin mutation database: novel and recurrent mutations and genotype-phenotype correlations in 28 patients with epidermolytic ichthyosis. Br J Dermatol 2011; 164: p. 442-7.

6 Bolling, M.C., Bladergroen, R.S., van Steensel, M.A. et al. A novel mutation in the L12 domain of keratin 1 is associated with mild epidermolytic ichthyosis. Br J Dermatol 2010; 162: p. 875-9.

$7 \quad$ Kremer, H., Lavrijsen, A.P., McLean, W.H. et al. An atypical form of bullous congenital ichthyosiform erythroderma is caused by a mutation in the L12 linker region of keratin 1. J Invest Dermatol 1998; 111: p. 1224-6.

8 Ikeda, S., Shigihara, T., Mayuzumi, N. et al. Mutations of ATP2C1 in Japanese patients with Hailey-Hailey disease: intrafamilial and interfamilial phenotype variations and lack of correlation with mutation patterns. J Invest Dermatol 2001; 117: p. 1654-6.

9 Ruiz-Perez, V.L., Carter, S.A., Healy, E. et al. ATP2A2 mutations in Darier's disease: variant cutaneous phenotypes are associated with missense mutations, but neuropsychiatric features are independent of mutation class. Hum Mol Genet 1999; 8: p. 1621-30.

10 Wang, C.C., Chao, S.C., Tsai, T.H. Hailey-Hailey disease: a novel mutation of the ATP2C1 gene in a Taiwanese family with divergent clinical presentation. J Eur Acad Dermatol Venereol 2008; 22: p. 1145-6.

11 Poblete-Gutierrez, P., Wiederholt, T., Konig, A. et al. Allelic loss underlies type 2 segmental Hailey-Hailey disease, providing molecular confirmation of a novel genetic concept. J Clin Invest 2004; 114: p. 1467-74. 


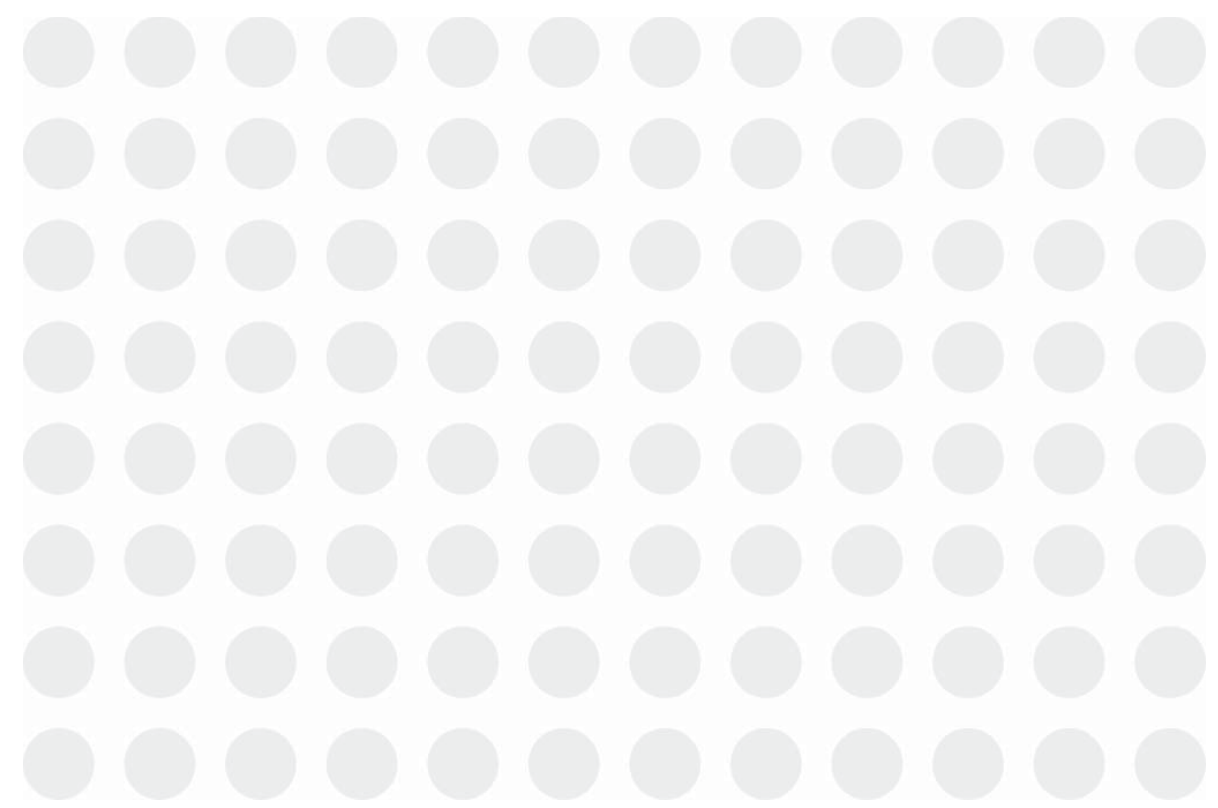




\section{Chapter II}

Mal de Meleda

Adapted from

Compound heterozygosity for ARS Component B mutations in a Dutch patient with Mal de Meleda. R.G.L. Nellen, M. van Geel, P.M. Steijlen, M.A.M. van Steensel. Br J Dermatol. 2009 Apr;160(4):878-80

Haplotype analysis in Western European patients with Mal de Meleda: founder effect for the p.(Trp15Arg) mutation in the SLURP1 gene. R.G.L. Nellen, P.M. Steijlen, H.C. Hennies, J. Fischer, C.S. Munro, M.F. Jonkman, M.A.M. van Steensel, M. van Geel. Br J Dermatol. 2013 Jun;168(6):1372-4

A novel mutation in SLURP1 in patients with mal de Meleda from the Indian subcontinent. R.G.L. Nellen, T. Claessens, P.S.S. Ranugha, J. Betkerur, A. Prashanth, P.M. Steijlen, M. van Geel. J Dermatol Sci. 2015 Oct;80(1):76-8

Comment on "Palmoplantar Keratoderma of the Gamborg-Nielsen Type is Caused by Mutations in the SLURP1 Gene and Represents a Variant of Mal de Meleda", Acta Derm Venereol. 2014; 94: 707-710. R.G.L. Nellen, P.M. Steijlen, M. van Geel, M.A.M. van Steensel. Acta Derm Venereol. 2015 Nov;95(8):1034-5 
Mal de Meleda (MDM, OMIM \#248300), caused by mutations in SLURP1, is an autosomal recessive genodermatosis defined by transgredient palmoplantar keratoderma, hyperhidrosis and malodourous scent due to bacterial superinfection. The spectrum of causative mutations is expanding, and the most prevalent mutations show a distribution confined to distinct geographical and ethnical demarcations. Haplotype analysis shows some of those mutations have arisen from a common ancestor.

This chapter is divided into four parts. After a general introduction, the second part describes the clinical and genetic characteristics of four Dutch patients and an Indian family with MDM. The third part discusses the research we performed to test whether a founder effect for the p.(Trp15Arg) mutation in SLURP1 exists. This mutation is found in all Western European patients with MDM. We performed haplotype analysis and SNP sequencing in all MDM patients with the p.(Trp15Arg) mutation from the Netherlands, Germany and Scotland. In the fourth part, we discuss palmoplantar keratoderma of the Gamborg-Nielsen type (PPK-GN) and propose that PPK-GN should be abandoned as a separate disease entity and should be considered as a mild clinical presentation of MDM. 


\subsection{Introduction}

\subsubsection{Historical aspects}

The name "mal de Meleda" is derived from the Italian name for the isle of Mljet. It is one of the larger islands in the Adriatic Sea boarding the Dalmatian region in Croatia ${ }^{1,2}$. The island was discovered by Greek explorers in the sixth century BC, and it is said to feature as the island Ogygia in Homer's Odysseia ${ }^{1}$, where Odysseus is held captive by Calypso, as well as the location of the shipwreck of St. Paul (Acts of the Apostles, 27:39$28: 11)^{\text {a }}$. It was subsequently ruled by the Roman Empire and the Byzantines. In the $12^{\text {th }}$

${ }^{a}$ Unfortunately, both claims are most likely untrue. The origin of confusion lies in the name given to Mljet by Scyllax Caryandensis, the first cartographer to describe the island: Melite, or, in Latin, Melita ${ }^{3,4}$. The name is used ubiquitously in Antiquity. Most importantly, Melite was used to describe modern day Malta. It further refers to a neighborhood in Athens, a lake on the border of the Aetolia and Acarnania region in North-Western Greece, a city in Ionia (present day Anatolia, Turkey) and several female characters in ancient Greek mythology, such as an Oceanid, part of the entourage of Persephone, and a Naiad, who gave birth to a son of Hercules ${ }^{4}$.

In the Odysseia, Odysseus was captured on Ogygia by Calypso5: "In a wave-girt isle, the navel of the sea That woodland isle where hath her home a goddess - Daughter of Atlas wise of heart who knows - The depths of all the sea and himself sustains - The lofty pillars propping earth and heaven." (Odysseia I:50-53) ${ }^{6}$. The vague description of Ogygia's location in the Odysseia has led to numerous hypotheses on the precise location of Ogygia. Most authors consider "the navel of the sea" as the most important clue to the precise location of Ogygia, but it seems obvious that this formulation is interpretable in many different ways. Therefore, many islands in the Mediterranean Sea and beyond are said to be Ogygia. Strabo, by citing Callimachus of Cyrene, introduces the most common hypothesis that points out Malta (then known as Melite), or more precisely Gozo, in the Maltese archipelago, as the location of Ogygia ${ }^{7.8}$. A confusion between both "Melites" is, of course, easily imaginable, and indeed one source mentions Melita in the Adriatic Sea as the location of Ogygia ${ }^{5}$. This notion is not widely accepted, however. The images of Google Street View quickly confirm the impressive and epic natural beauty of Mljet, but the actual geographical location of Mljet is hardly compatible with Ogygia's character of a remote island where Homerian heroes are likely to shipwreck. Other authors place Ogygia as far away as the Atlantic Ocean; it is identified with Madeira, or even with Atlantis. Nowadays, common opinion is that the exact location of Ogygia cannot be precisely set. Instead, the meaning of Ogygia is metaphorical: it is Paradise on earth, a place of otherworldly beauty and peace that not really belongs to our everyday world. It confronts the reader with the question whether it is more preferable to remain in a blissful place absent of all things evil or accept to live in the real but imperfect world with its pleasures as well as its disappointments. As a true hero, Odysseus does not ponder for long on this question: although Calypso tries to seduce him with the promise of eternal youth and immortality during his 7 year captivity, Odysseus resists the temptation due to his sense of duty towards his wife and kingdom. He returns to Ithaka only to find his wife Penelope fending off suitors usurping his possessions, and his son Telemachos, who is unable to turn the tide of events, but is heartily welcomed by his loyal canine companion Argos, who dies after greeting his long-lost master.

As described in the Acts of the Apostles, St. Paul is shipwrecked en route from Crete on the island Melite, in the Adria or Adriatic Sea. There has been much debate on which Melite is referred to, Mljet or Malta. The $8^{\text {th }}$ century writer Constantinus Porphyrogenitus was the first to identify Mljet as the place of shipwreck and mentioned that Mljet was also known as Kephallenia'. Renaissance and early modern humanists such as Erasmus and Grotius are quite unequivocal in their support of Malta (for an overview of early modern exegetical comments on Acts 27:27 and 28:1 see ${ }^{10}$ ). Nowadays, it is thought that Kephallenia, an island approximately $30 \mathrm{~km}$ from the Peloponnesian shore, is the most presumable island on which St. Paul was stranded ${ }^{11}$. 


\section{CHAPTER 2 MAL DE MELEDA}

century, the Benedictine Order founded a monastery on an island in one of Mljet's lakes, the Veliko Jezero (Big Lake). The monastery functioned as a leper colony throughout the medieval period and a hospital for sufferers from the Plague ${ }^{1}$.

Before the first scientific descriptions of MDM, various legends have arisen that link Mljet to the particular palmoplantar skin disease that afflicts a substantial part of Mljet's inhabitants ${ }^{1}$. Once, Meledan pirates captured a Turkish trade vessel, and executed its leprous crew. The murderers, as well as their offspring, were inflicted with skin disease as punishment for their cruelty and lack of charity. The second legend is more customary among the inhabitants of Mljet. Its origin can probably be traced to the use of Mljet as a leper colony. In the monastery on the island in the Veliko Jezero, the chapel devoted to the Holy Virgin was said to hold a relic of a female hand, severely damaged by a skin disease. One day, a local desecrated the shrine and destroyed the relic. He and his progeny suffer from diseased skin on the hands and feet from that moment on ${ }^{1}$. It is important to notice that this folk lore recognises the hereditary nature of the disease.

The first scientific report of mal de Meleda was given by the Ragusan physician Luca Stulli in $1826^{13}$. He was the first to distinguish the "endemic leprosy of the island of Mljet" from infectious leprosy and described the hereditary, autosomal-recessive and non-contagious nature of MDM. Reports by Hovorka and Ehlers $(1897)^{14}$ and Neumann $(1898)^{15}$ confirmed the findings of Stulli, although they did not refer to the 1826 paper.

One of the main arguments supporting the claim from Malta is the fact that, in Antiquity, the term Adriatic Sea (Adria) was used to describe both the Adriatic Sea (Inner Adriatic Sea) and the Ionian Sea (Outer Adriatic Sea) including the seas surrounding Malta, as can be found in the works of viri eruditi ${ }^{12}$ such as Strabo, Ovid, Statius and Ptolemy ${ }^{10}$. Although others agree with the existence of an Inner and Outer Adriatic Sea in classical literature, they point out that the borders of the Outer Adriatic Sea did not extend further south than the imaginary border between Sicily and Methoni (Messenia region, Greece), which excludes the waters surrounding Malta as part of the Adriatic Sea ${ }^{3}$.

There are three arguments in favor of Mljet $^{3,11}$, apart from the fact that Mljet is unambiguously located in the Adriatic Sea. Firstly, the natives of Melita are described as Barbaroi (Acts Apost 28:11). Although Mljet was part of the Roman Empire, the inhabitants were not considered Roman citizens, and were therefore Barbarians. The Maltese population had Roman civil rights in the times of St. Paul's journeys and was thus considered to be civilized, instead of Barbaroi. Secondly, the Apostle is bitten by a sand viper, which are not present on Malta, but do occur on Mljet. Last, the sea currents in the Mediterranean Sea are mostly from West to East, which would enhance the chances of a ship with lowered sails (described in the Acts of the Apostles) drifting towards Mljet, at least away from the other Melita, Malta. However, Mljet is located too far to the North in the Inner Adriatic Sea to be a likely place of a shipwreck of a vessel on a journey from Crete to Italy.

The arguments in favor of Kephallenia are mainly the arguments in opposition to Mljet and Malta: it is located in the Eastern part of the current Ionian Sea that would be recognized as the Outer Adriatic Sea in ancient times, but not too far away north, sand vipers were part of the local fauna and its inhabitants were not granted Roman citizenship ${ }^{11}$. It is interesting to note that, according to Constantinus Porphyrogenitus, Melite is synonymous with Kephallenia ${ }^{9}$. There are no further sources, however, that confirm this statement. It remains therefore unlikely that, by accident, the evangelist Luke made the mistake of confusing Melite and Kephallenia. 


\section{CHAPTER 2 MAL DE MELEDA}

\subsubsection{Clinical characteristics}

The major symptoms of MDM are hyperkeratosis of the palms and soles (palmoplantar keratoderma, PPK), complicated by hyperhidrosis and malodourous scent due to bacterial superinfection (all reports are summarised in table 2.3, see also paragraph 2.2 and 2.3, figure 2.3, 2.4 and 2.6). The disease develops during infancy, with most patients developing a PPK in the first year of life ${ }^{16,17}$. The hyperkeratosis extends to the dorsal sides of hands and feet (transgrediens) and is slowly progressive over the years (progrediens). The hyperkeratosis usually starts on the dorsal sides of fingers and toes, progresses to the dorsa of hands and feet and finally may extend to the forearms and lower legs. Mechanical trauma (manual labor) and heat cause exacerbations of hyperkeratosis and hyperhidrosis ${ }^{18}$. The distal phalanges of the fingers may acquire a conical shape. Later in life, annular constriction of digital skin (pseudo-ainhum) may develop. Nail changes such as a pale, pink discoloration, subungual hyperkeratosis, koilonychia and dystrophy occur in a significant number of patients, but are not as widespread as some authors suggest (see table 2.3 and ${ }^{19-21}$ ). Although most symptoms are on hands and feet, the skin on other parts of the body may be affected as well: some patients suffer from ichthyosiform hyperkeratosis and perioral erythema and scaling ${ }^{22,23}$. On rare instances, MDM has been found concurrently with (congenital) cataract ${ }^{24,25}$, Bowen's disease ${ }^{26}$ or malignant melanoma in affected skin ${ }^{27-29}$.

Other PPKs feature in the differential diagnosis of MDM. They can be divided into several groups that may overlap: the syndromes with a diffuse PPK (non-syndromic PPKs), some diffuse PPKs with associated features (syndromic PPKs), autosomal recessive diffuse PPKs and diffuse PPKs with transgredient hyperkeratosi ${ }^{30,31}$. Table 2.1 lists the PPKs with transgrediens and associated genes. PPK Gamborg Nielsen will be discussed separately below (paragraph 2.4).

As in most PPK, therapeutic options are limited. General measures are routine baths that cleanse the skin and facilitate keratolysis by the regular application of keratolytic ointments, (urea containing ointments in a concentration up to $10 \%$ are better tolerated than salicylic acid containing externa), if possible under occlusion of gloves or mechanical keratolysis with, for instance, pumice stone ${ }^{32,33}$. It is sometimes necessary to start maintenance therapy with topical antifungals to treat concurrent fungal infection. Systemic therapy with oral retinoids (acitretin, isotretinoin, alitretinoin) is effective in diminishing hyperkeratosis, but is associated with side effects (such as dry skin, 
TABLE 2.1

\begin{tabular}{|c|c|c|c|}
\hline Disease & $\begin{array}{c}\text { Mode of } \\
\text { inheritance }\end{array}$ & $\begin{array}{l}\text { Associated } \\
\text { gene }\end{array}$ & Differential symptoms \\
\hline \multirow[t]{3}{*}{ Greither disease $^{78}$} & \multirow[t]{3}{*}{$\mathrm{AD}$} & KRT1 & $\begin{array}{l}\text { Hyperkeratosis on knees, elbows, shins, } \\
\text { flexures, Achilles tendon. Fading course }\end{array}$ \\
\hline & & GJB3/GJB4 & On one instance associated with \\
\hline & & & Erythrokeratodermia variabilis ${ }^{79}$ \\
\hline PPK of Sybert ${ }^{80}$ & $\mathrm{AD}$ & unknown & $\begin{array}{l}\text { Natal cleft, groin, elbows, knees, posterior } \\
\text { aspects of forearms, and anterior aspects } \\
\text { of legs }\end{array}$ \\
\hline Acral Keratoderma ${ }^{81}$ & $\mathrm{AR}$ & unknown & $\begin{array}{l}\text { Hyperkeratosis on knees, elbows, ankles, } \\
\text { Achilles tendon }\end{array}$ \\
\hline Bothnian PPK ${ }^{82,83}$ & $\mathrm{AD}$ & AQP5 & $\begin{array}{l}\text { Marked change of affected skin upon } \\
\text { water exposure. No other associated } \\
\text { symptoms }\end{array}$ \\
\hline $\begin{array}{l}\text { Papillon-Lefevre } \\
\text { syndrome }^{84,85}\end{array}$ & $\mathrm{AR}$ & CTSC & Periodontitis, premature loss of dentition \\
\hline Haim-Munk syndrome $e^{75}$ & $\mathrm{AR}$ & CTSC & $\begin{array}{l}\text { periodontitis, arachnodactyly, acro- } \\
\text { osteolysis, atrophic changes of the nails, } \\
\text { radiographic deformities of the fingers }\end{array}$ \\
\hline Nagashima-PPK ${ }^{31}$ & $\mathrm{AR}$ & SERPINB7 & $\begin{array}{l}\text { Mild phenotype compared to MDM, } \\
\text { hyperkeratosis on elbows and knees }\end{array}$ \\
\hline Olmsted syndrome ${ }^{86}$ & $\mathrm{AD} / \mathrm{AR}$ & $\begin{array}{l}\text { TRPV3/ } \\
\text { MBTPS2 }\end{array}$ & $\begin{array}{l}\text { Periorificial plaques, painful PPK } \\
\text { interfering with daily activities, hair } \\
\text { abnormalities, corneal dystrophy }\end{array}$ \\
\hline PPK-Gamborg Nielsen ${ }^{56}$ & $\mathrm{AR}$ & SLURP1 & $\begin{array}{l}\text { No separate entity, should be classified } \\
\text { as MDM }\end{array}$ \\
\hline
\end{tabular}

Differential diagnosis of PPK with transgrediens.

teratogenesis) ${ }^{34-37}$. In two patients, surgical excision of keratoderma and reconstruction with full thickness skin grafts yielded long term resolution of hyperkeratosis ${ }^{28,38}$.

\subsubsection{Pathophysiology}

In 2001, mutations in the SLURP1 gene, encoding the Secreted Ly-6/uPar related protein-1, were identified as the cause of Mal de Meleda ${ }^{39}$. SLURP1 is a member of the leukocyte antigen-6 (Ly6)/urokinase-type plasminogen activator (uPAR) protein family, which is characterised by 1 or more repetitive domains containing 10 cysteins in a distinct disulfide-bonded arrangement ${ }^{40}$. The amino-acid sequence of SLURP1 shows a high 


\section{CHAPTER 2 MAL DE MELEDA}

degree of structural similarity with snake venom toxins that target the acetylcholine receptor. In contrast to other members of the Ly6/uPAR family, SLURP1 is a secreted protein, mainly expressed at high levels in keratinocytes, especially in the palms and soles $^{41}$. SLURP1 is also found in plasma and urine ${ }^{42,43}$ and rat spinal cord neurons ${ }^{44}$.

Mutations in SLURP1 severely affect secretion. No SLURP1 protein was detected in frozen skin biopsies of patients with the p.(Cys28fs32*) and p. $\left(\operatorname{Arg} 96^{*}\right)$ mutations $^{41}$. No or low levels of SLURP1 were detected in sweat from MDM patients with the p.(Trp15Arg), p.(Cys28fs32*) and p.(Arg71His) mutation ${ }^{41}$. Transfection studies for mutations p.(Trp15Arg) and p.(Arg71His) showed absence of secretion of SLURP1 ${ }^{41}$. Another study that examined mutations p.(Trp15Arg), p.(Arg71His), p.(Arg71Pro), p.(Cys77Arg), p.(Pro82Ser), p.(Gly86Arg), p.(Leu98Pro), p.(Cys94Ser) and p.(Cys99Tyr) found impaired secretion of SLURP1 in all transfected cells except for those cells transfected with the p.(Pro82Ser) and p.(Gly86Arg) mutated SLURP1, which was secreted at levels comparable to wild type SLURP1. Furthermore, mutated SLURP1 formed aberrant di- and multimers except for the p.(Pro82Ser) and p.(Gly86Arg) mutated SLURP1. SLURP1 mutant p.(Pro82Ser) formed predominantly monomeric SLURP1, albeit in lower levels compared to wild type SLURP1 and mutant p.(Gly86Arg) levels of SLURP1 monomers, indicating that this variant may exert its effect through improper SLURP1 functioning, rather than absence of SLURP1 protein as in the other variants ${ }^{45}$.

Experimental evidence suggests that SLURP1 exerts its effect on epidermal homeostasis by enhancing the function of the nicotinic acetylcholine receptor $\alpha 7$ (nAChR $\alpha 7$ ) in epidermal keratinocytes, thereby potentiating acetylcholine signalling in the stratum granulosum ${ }^{43,46,47}$. SLURP1 significantly increased expression of keratinocyte differentiation markers transglutaminase type I, cytokeratin 10, p21, and caspase-3 and pro-apoptotic enzymes caspase 3 and $8^{47}$. Other experiments found that downstream effects of nAChRa7 signalling enhanced by SLURP1 include upregulation of nuclear factor- $\kappa B(N F-\kappa B)$ gene expression due to activation of the Raf-1/MEK1/ERK1/2 cascade $^{48}$. This cascade is initiated by two synergistic pathways. The first pathway involves activation $\mathrm{Ca}^{2+} /$ calmodulin-dependent kinase II (CaMKII) and protein kinase $\mathrm{C}(\mathrm{PKC})$ following $\mathrm{nAChR} \alpha 7$ mediated $\mathrm{Ca}^{2+}$ influx. The other pathway involves $\mathrm{Ca}^{2+}$ independent phosphorylation of JAK $2^{48}$. Inhibition of the $\mathrm{nAChRa} 7$ signalling pathway blocks nicotine-induced influx of calcium and inhibited terminal differentiation ${ }^{49}$. It is 


\section{CHAPTER 2 MAL DE MELEDA}

possible that impaired keratinocyte differentiation is a consequence of inhibited NF$\kappa \mathrm{B}$ function, as NF- $\kappa \mathrm{B}$ inhibition is associated with epidermal hyperplasia and tumor necrosis factor- $\alpha(\mathrm{TNF} \alpha)$ dependent skin inflammation ${ }^{50}$. The latter may account for the inflammatory component of the PPK seen in MDM.

SLURP1 knockout mice exhibit similar PPK compared to MDM patients, a defective epidermal water barrier and increased number of lipid droplets in murine stratum corneum. Corneal lipid droplets are also found in ultrastructural examination of skin and nails of MDM patients ${ }^{51-53}$. The formation of lipid droplets and a defective epidermal water barrier is likely due to improper hydrolysis of triglycerides ${ }^{54}$. Oxidation of improperly processed lipids by micro-organisms may yield the malodorous skin that accompanies the PPK in $\mathrm{MDM}^{54}$. Furthermore, SLURP1 knockout mice showed neurological and marked metabolic abnormalities (reduced body weight and adiposity, increased oxygen consumption, and lowered plasma lipid and insulin levels) ${ }^{54}$. This metabolic phenotype is possibly due to increased lipid metabolism, although the precise mechanisms are not clear. To date, metabolic and neurological abnormalities have not been reported in MDM patients. The difference in human and murine phenotypes might indicate differences in SLURP1 function between humans and mice, but also indicates the need of detailed neurological and metabolic investigation in MDM patients.

\subsubsection{SLURP1 mutations}

Up to 18 different mutations in SLURP1 associated with MDM have been described since the first report by Fischer et al., including the p.(Arg71Pro) and c.58+5G>T mutations, discussed in parts 2.2.1 and 2.2.2. They are summarized in table 2.2. Of the 18 mutations, $11(61 \%)$ were missense, 2 (11\%) were nonsense, $4(22 \%)$ were intronic changes leading to aberrant splicing and $1(6 \%)$ was a frameshift deletion leading to a predicted premature stop codon. Most patients were homozygous for SLURP1 mutations. Four people were found to be compound heterozygous: a Scottish patient with the p. (Trp15Arg) and p.(Cys28fs32*) mutations ${ }^{22}$, a Dutch patient with the p.(Trp15Arg) and p.(Arg71Pro) mutations ${ }^{55}$, who will be discussed in greater detail in part 2.2.1, a Swedish patient with the p.(Trp15Arg) and p.(Cys94Ser) mutations ${ }^{56}$ and a Korean patient with the p.(Gly86Arg) and p. (Arg96*) mutations ${ }^{23}$.

Interestingly, the prevalence of two of the most common mutations, p.(Cys28fs $32^{\star}$ ) and p. $\left(\operatorname{Arg} 96^{*}\right)$, has a sharp geographical demarcation (figure 2.1, table 2.2) 22,23,39,57-61. 


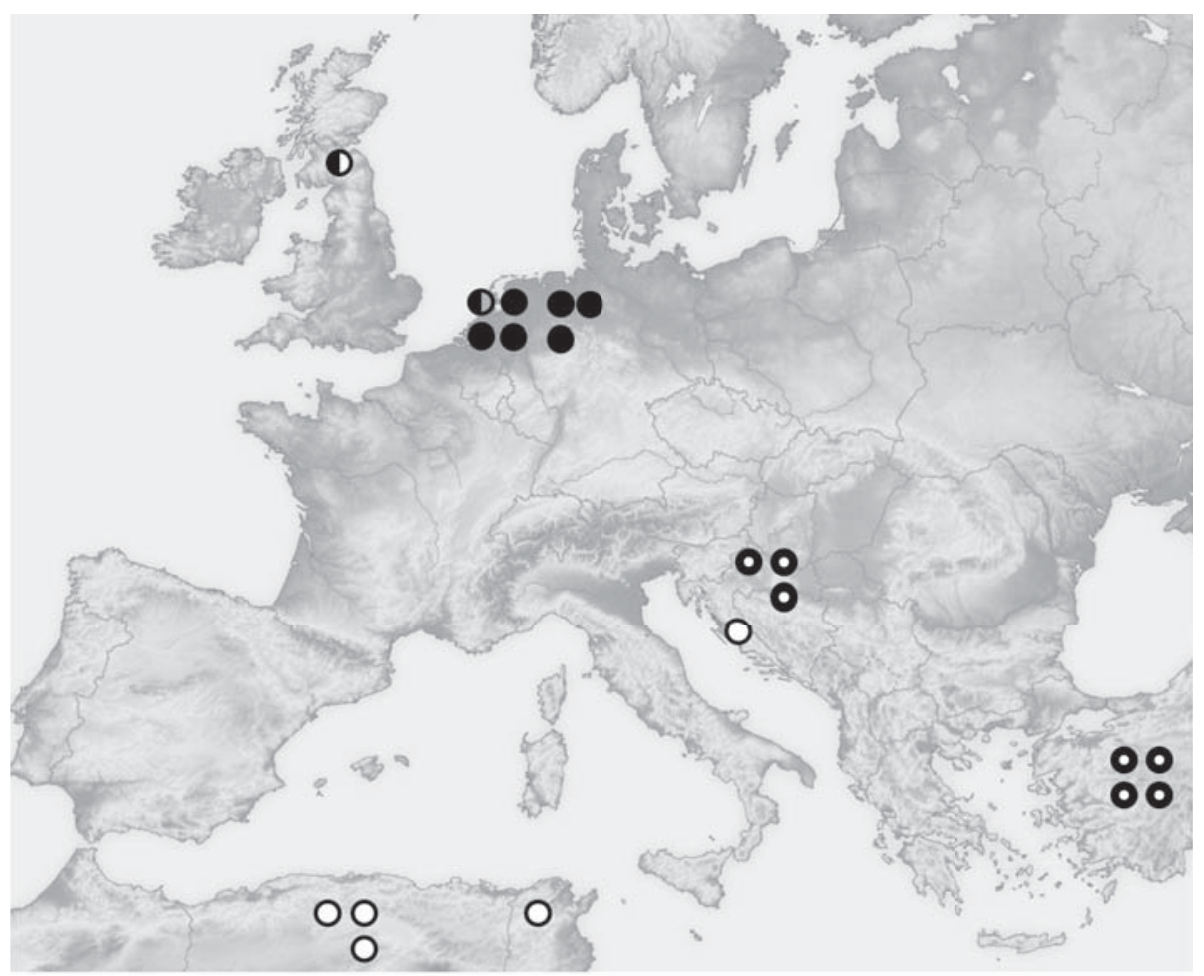

FIGURE 2.1

Geographical distribution of the most prevalent mutations in MDM in Europe: p.(Trp15Arg) ( ), p.(Cys28fs32*) ( $\bigcirc)$, p. $($ Arg96*) ( $($ ), compound heterozygous p.(Trp15Arg)/p.(Arg71Pro) ( ( ) ), compound heterozygous p. (Trp15Arg)/p. $\left(\right.$ Cys28fs $\left.32^{*}\right)$ ( D ).

The p.(Cys28fs32*) mutation is most prevalent around the Western part of the Mediterranean Sea and was reported in Algerian, Tunisian, Croatian and Turkish families, as well as in a compound heterozygous Scottish patient ${ }^{22,39,57,59,60}$. In two studies, the p. $\left(\right.$ Cys28fs $\left.32^{*}\right)$ mutation co-segregates with a shared haplotype in all carriers of this variant, strongly suggesting a founder effect for this mutation ${ }^{22,39}$. The p.(Arg96*) mutation was reported in Turkish, Croatian and Pakistani families, as well as in a sporadic compound heterozygous Korean MDM patient ${ }^{23,39,58,59,61}$. Haplotype analysis showed an ancestral haplotype suggestive of a founder effect in four Turkish families ${ }^{59}$. Given the tight historical relationship and consequent cultural and demographical exchange between the two regions, it is tempting to speculate that this founder effect can be extended to the Croatian families, although this analysis was not performed in 
CHAPTER 2 MAL DE MELEDA

TABLE 2.2

\begin{tabular}{|c|c|c|c|c|c|}
\hline $\begin{array}{l}\text { Nucleotide } \\
\text { change }\end{array}$ & $\begin{array}{l}\text { Amino acid } \\
\text { change }\end{array}$ & Consequence & Exon & $\begin{array}{l}\text { Reported } \\
\text { patients }\end{array}$ & $\begin{array}{c}\text { Geographical } \\
\text { location }\end{array}$ \\
\hline c. $1 \mathrm{~A}>\mathrm{C}$ & p.Met1? & Missense & Exon 1 & sporadic & $\begin{array}{c}\text { United Arab } \\
\text { Emirates }^{18}\end{array}$ \\
\hline \multirow[t]{7}{*}{ c. $43 \mathrm{~T}>\mathrm{C}$} & p.(Trp15Arg) & Missense & Exon 1 & 1 family & Germany $^{18}$ \\
\hline & & & & 1 family & Germany $^{22}$ \\
\hline & & & & compound $^{\mathrm{a}}$ & Scotland ${ }^{22}$ \\
\hline & & & & compound $^{\mathrm{b}}$ & The Netherlands ${ }^{55}$ \\
\hline & & & & 4 families & The Netherlands ${ }^{76}$ \\
\hline & & & & 2 families & Germany $^{76}$ \\
\hline & & & & $\begin{array}{l}9 \text { families/ } \\
\text { compound }^{\mathrm{c}}\end{array}$ & Sweden $^{56}$ \\
\hline c. $.58+1 \mathrm{G}>\mathrm{A}$ & & Altered splice site & Intron 1 & 1 family & Pakistan $^{58}$ \\
\hline c. $58+1 \mathrm{G}>\mathrm{C}$ & & Altered splice site & Intron 1 & sporadic & $\operatorname{Japan}^{20}$ \\
\hline c. $58+5 \mathrm{G}>\mathrm{T}$ & & Altered splice site & Intron 1 & sporadic & India \\
\hline \multirow[t]{8}{*}{ c.82delT } & p. $\left(\right.$ Cys $\left.28 \mathrm{fs} 32^{\star}\right)$ & Frame shift deletion & Exon 2 & 9 families & Algeria $^{39}$ \\
\hline & & & & 4 families & Croatia $^{39}$ \\
\hline & & & & 4 families & Tunisia $^{57}$ \\
\hline & & & & 1 family & Algeria $^{22}$ \\
\hline & & & & 1 family & Tunisia $^{22}$ \\
\hline & & & & compound $^{\mathrm{a}}$ & Scotland ${ }^{22}$ \\
\hline & & & & 1 family & Kurdistan $^{59}$ \\
\hline & & & & 2 families & Tunisia $^{60}$ \\
\hline \multirow[t]{2}{*}{ c. $178+1 \mathrm{G}>\mathrm{A}$} & & Altered splice site & Intron 2 & 3 families & Algeria $^{39}$ \\
\hline & & & & 3 families & Algeria $^{22}$ \\
\hline c. $129 \mathrm{C}>\mathrm{A}$ & p. $\left(\right.$ Cys $\left.43^{*}\right)$ & Nonsense & Exon 3 & sporadic & Turkey $^{87}$ \\
\hline c. $212 \mathrm{G}>\mathrm{A}$ & p.(Arg71His) & Missense & Exon 3 & sporadic? & France $?^{41}$ \\
\hline c. $212 \mathrm{G}>\mathrm{C}$ & p.(Arg71Pro) & Missense & Exon 3 & compound $^{\mathrm{b}}$ & The Netherlands ${ }^{55}$ \\
\hline c. $229 \mathrm{C}>\mathrm{T}$ & p.(Cys77Ala) & Missense & Exon 3 & 2 families & Tunisia $^{57}$ \\
\hline c. $244 \mathrm{C}>\mathrm{T}$ & p.(Pro82Ser) & Missense & Exon 3 & sporadic & Germany $^{34}$ \\
\hline \multirow[t]{9}{*}{ c. $256 \mathrm{G}>\mathrm{A}$} & p.(Gly86Arg) & Missense & Exon 3 & 1 family & Palestina $^{18}$ \\
\hline & & & & sporadic & Libya $^{62}$ \\
\hline & & & & sporadic & Taiwan $^{64}$ \\
\hline & & & & sporadic & Taiwan $^{63}$ \\
\hline & & & & 1 family & Pakistan $^{58}$ \\
\hline & & & & sporadic & Taiwan $^{65}$ \\
\hline & & & & compound $^{\mathrm{d}}$ & South Korea ${ }^{23}$ \\
\hline & & & & sporadic & Indonesia $^{66}$ \\
\hline & & & & 2 families & China $^{67}$ \\
\hline c. $256 \mathrm{G}>\mathrm{C}$ & p.(Gly86Arg) & Missense & Exon 3 & 2 families & Turkey $^{18}$ \\
\hline c. $280 \mathrm{~T}>\mathrm{A}$ & p.(Cys94Ser) & Missense & Exon 3 & compound $^{c}$ & Sweden ${ }^{56}$ \\
\hline \multirow[t]{2}{*}{ c. $286 \mathrm{C}>\mathrm{T}$} & p. $\left(\operatorname{Arg} 96^{*}\right)$ & Nonsense & Exon 3 & 3 families & Croatia $^{39}$ \\
\hline & & & & 4 families & Turkey $^{61}$ \\
\hline
\end{tabular}

Table 2.2 continues on next page 
TABLE 2.2 - Continued

\begin{tabular}{cccccc}
\hline Mutation & $\begin{array}{c}\text { Predicted AA } \\
\text { change }\end{array}$ & Consequence & Exon & $\begin{array}{c}\text { Reported } \\
\text { patients }\end{array}$ & $\begin{array}{c}\text { Geographical } \\
\text { location }\end{array}$ \\
\hline & & & & 1 family & Turkey $^{59}$ \\
& & & 1 family & Pakistan $^{58}$ \\
& & & & compound & South Korea $^{23}$ \\
c.293T>C & p.(Leu98Pro) & Missense & Exon 3 & sporadic & Turkey $^{77}$ \\
c.296G $>$ A & p.(Cys99Tyr) & Missense & Exon 3 & 2 families & Tunisia $^{57}$ \\
& & & & 1 family & Tunisia $^{22}$ \\
& & & & sporadic & Tunisia $^{24}$ \\
& & & & sporadic & Tunisia $^{60}$ \\
\hline
\end{tabular}

An overview of all reported mutations in SLURP1, with predicted amino acid change, characteristics of reported patients and families, and geographic origin of patients. There are four patients with compound heterozygous mutations in SLURP1: a a Scottish patient with the p.(Trp15Arg) and p.(Cys28fs $\left.32^{*}\right)$ mutation, ba Dutch patient with the p.(Trp15Arg) and p.(Arg71Pro) mutation, ${ }^{c}$ a Swedish patient with the p.(Trp15Arg) and p.(Cys94Ser) mutation and ${ }^{d}$ a Korean patient with the p.(Gly86Arg) and p.(Arg96 $6^{*}$ mutation.

the Croatian carriers. Data from mutation reports of Western European patients with MDM show a similar geographical clustering of the p.(Trp15Arg) mutation prevalent in this population and is suggestive of a similar founder effect seen in the populations described above. This hypothesis is tested and discussed in part 2.3 of this chapter. Of note, the mutation most often described, c.256G $>$ A, p. (Gly86Arg) ${ }^{\mathrm{b}}$, has been found in patients from Libya ${ }^{62}$, Palestina ${ }^{18}$, Pakistan $^{58}$, Korea $^{23}$, Taiwan ${ }^{63-65}$, Indonesia ${ }^{66}$ and China ${ }^{67}$. The wide distribution of this mutation argues against an introduction by a common ancestor, although it is speculated that a founder effect may be possible for the Eastern Asian patients ${ }^{66}$. Spontaneous methylation-mediated deamination of 5-methylcytosine of $\mathrm{CpG}$ dinucleotides may be a more likely explanation of the widespread prevalence of this variant ${ }^{68}$.

\subsubsection{Genotype-phenotype relation}

No clear genotype-phenotype relation in MDM could be identified. Differences in clinical variety is thought to be mainly dependent on age, with most authors noting gradual progression during life ${ }^{24,39,56,60,67}$, and exacerbations after mechanical trauma (manual labor, heat) ${ }^{18,23,67}$. To see if these observations are supported by the literature,

${ }^{b}$ Not to be confused with the $c .256 \mathrm{G}>C$ mutation, that also leads to a substitution of a glycine to an arginine residue (p.(Gly86Arg) $)^{18}$. 


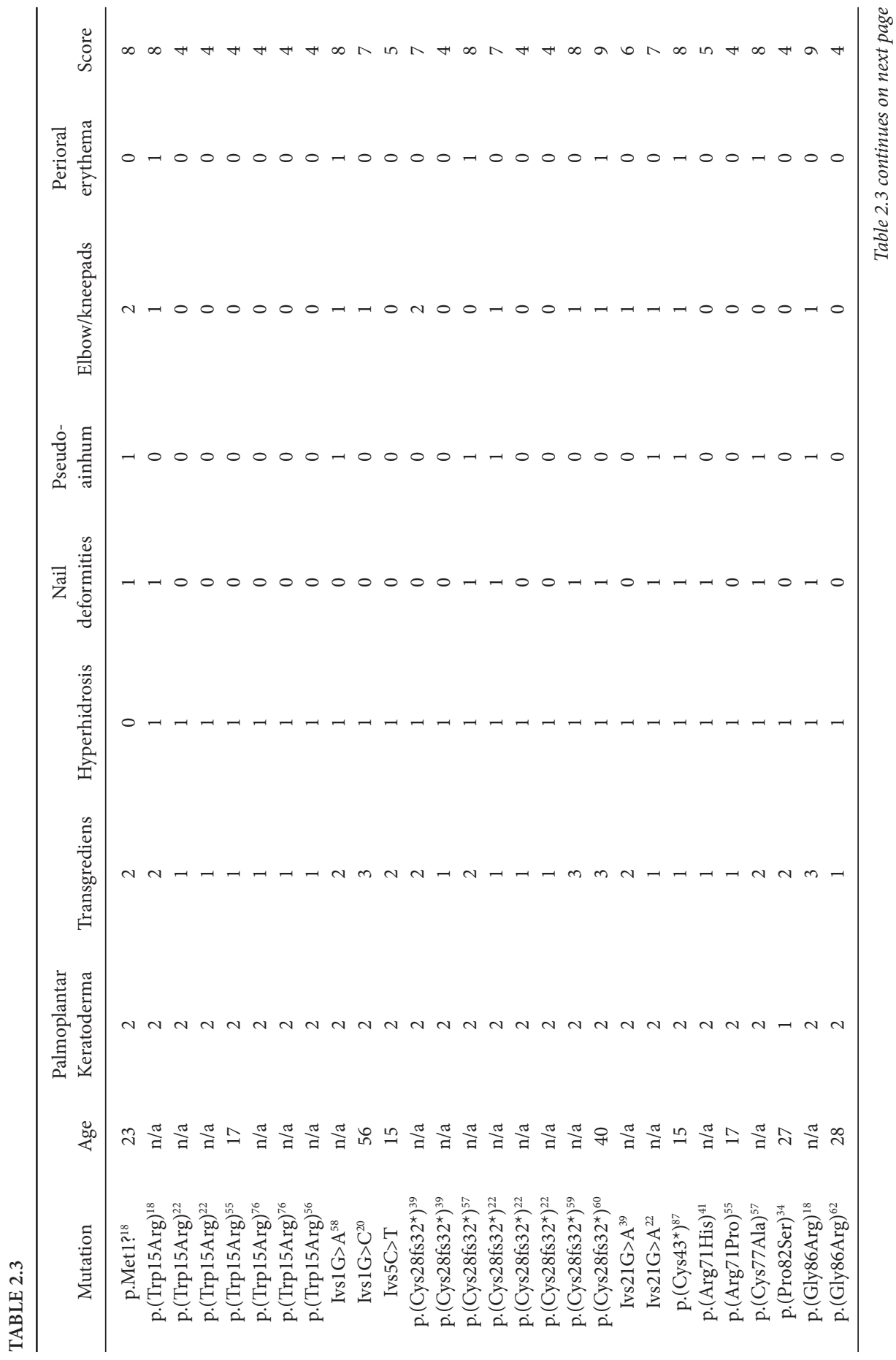




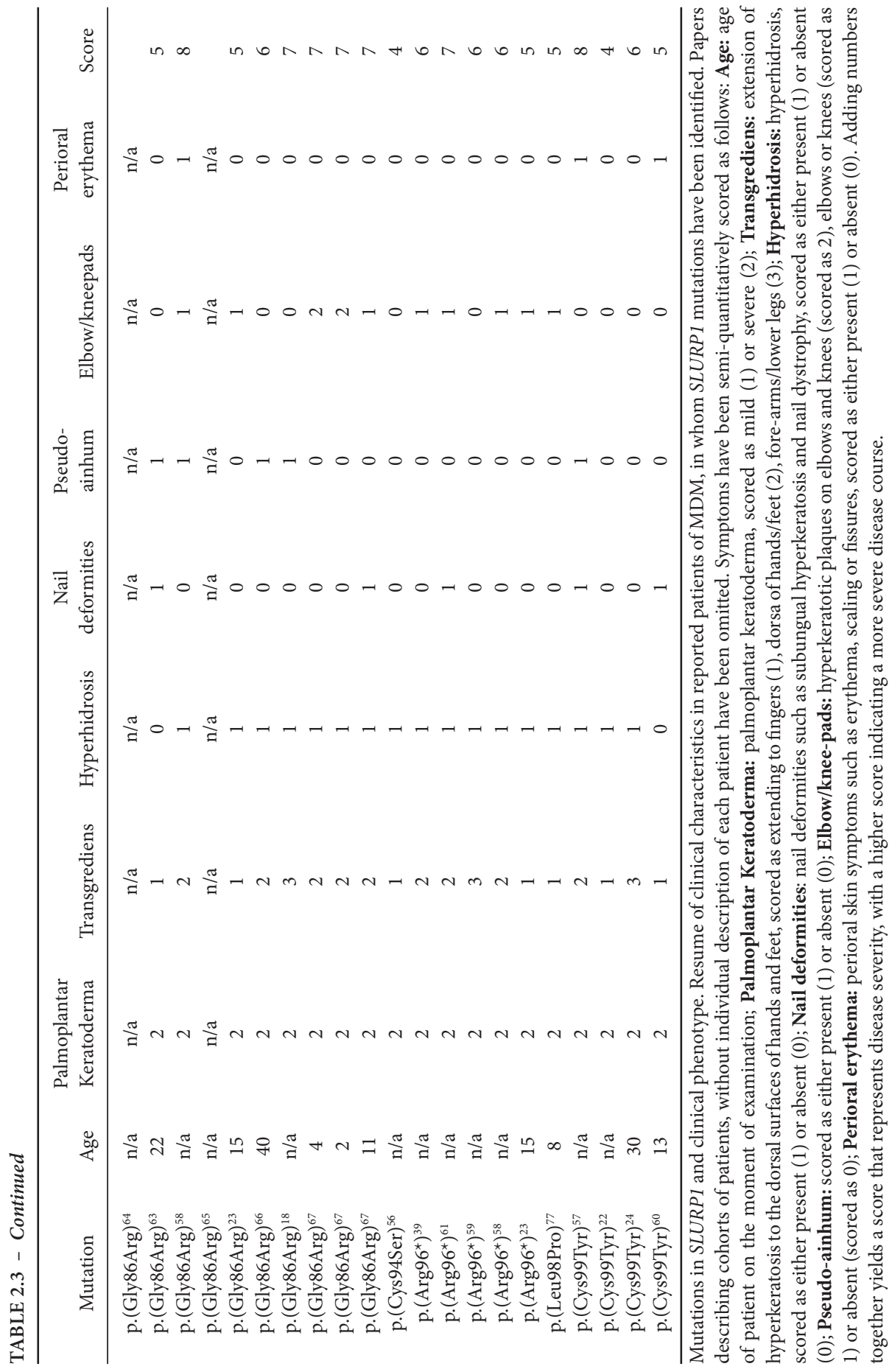


CHAPTER 2 MAL DE MELEDA

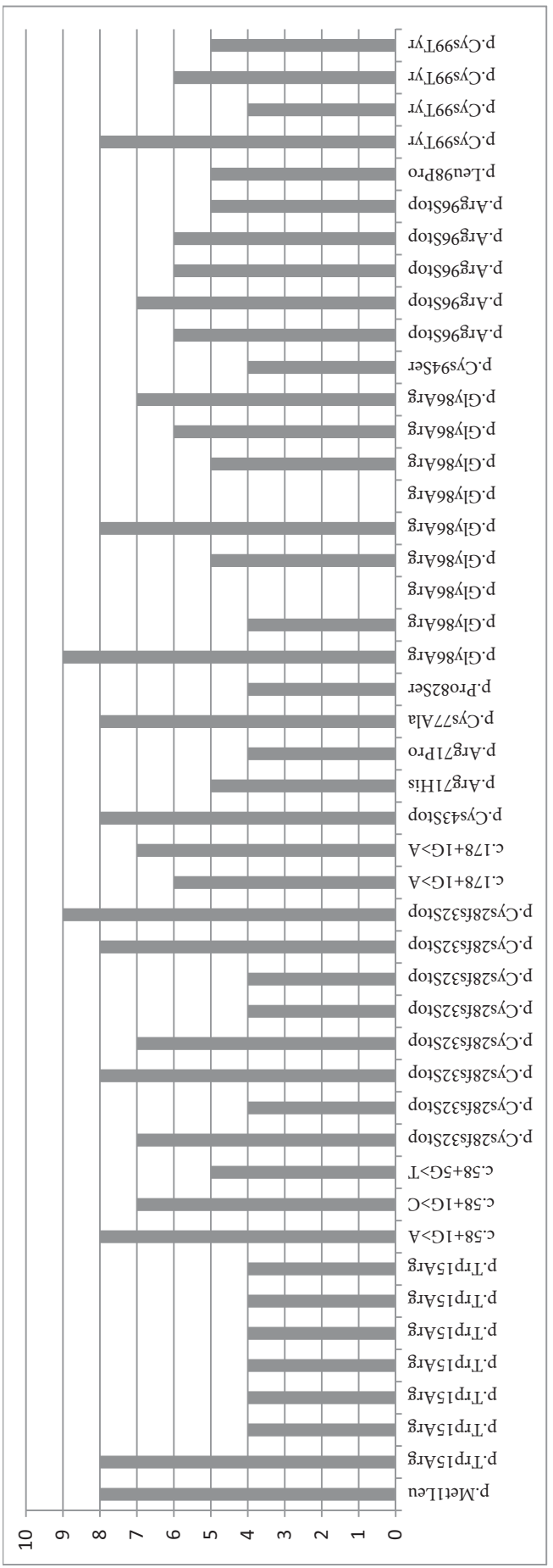

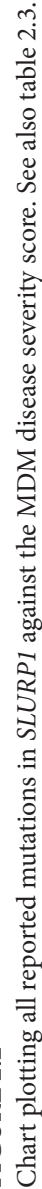




\section{CHAPTER 2 MAL DE MELEDA}

we reviewed all reports on MDM and SLURP1 mutations. Table 2.3 and figure 2.2 semi-quantitatively summarizes the clinical phenotypes reported in patients with MDM, with a description of disease course, including age, clinical characteristics and SLURP1 mutations. From these data, we derived a disease severity score, which is further explained in the legend of table 2.3. At a glance, there seems to be a tendency to a more severe course in elderly patients, and a less severe course in patients with a missense mutation in the coding sequence of SLURP1 compared to patients with a frame shift or nonsense mutation. We are aware, however, that drawing conclusions from these data is difficult; the assessment of disease severity in large groups of patients is not very accurate and we acknowledge the fact that it is not possible to objectively score MDM severity. Still, there seems to be a tendency to a more severe course in elderly patients. We feel the data is not robust enough to conclude that other factors, such as mutation type, can be associated with a specific disease course. Therefore, we were not able to identify a genotype-phenotype correlation in MDM.

\subsection{Mutation analysis}

\subsubsection{Compound heterozygosity in a Dutch patient}

We examined a 17-year-old boy of Dutch descent who developed transgredient palmoplantar keratosis on palms and soles shortly after birth (figure 2.3a). Of note, his skin lesions produced a penetrant malodorous scent. No nail abnormalities, perioral erythema, pseudoainhum or skin changes elsewhere on the body were present at the time of examination. He did not suffer from hearing loss. The parents did not show any skin symptoms, were otherwise healthy and, to the best of their knowledge, were not related. The family history did not reveal any hereditary skin disorders or abnormalities. Based on clinical symptoms, we diagnosed the patient as having mal de Meleda.

After obtaining informed consent from the patient and his parents, we extracted DNA from peripheral blood leucocytes using methods described elsewhere ${ }^{69}$. We analysed the SLURP1 gene of the propositus and his parents by direct sequencing using primers and reaction conditions as previously described ${ }^{70}$. The index patient was compound heterozygous for the mutations c.43T $>C$ and $c .212 \mathrm{G}>\mathrm{C}$ leading to the substitutions p.(Trp15Arg) and p.(Arg71Pro), respectively (figure 2.3b). The patient's mother was 


\section{CHAPTER 2 MAL DE MELEDA}

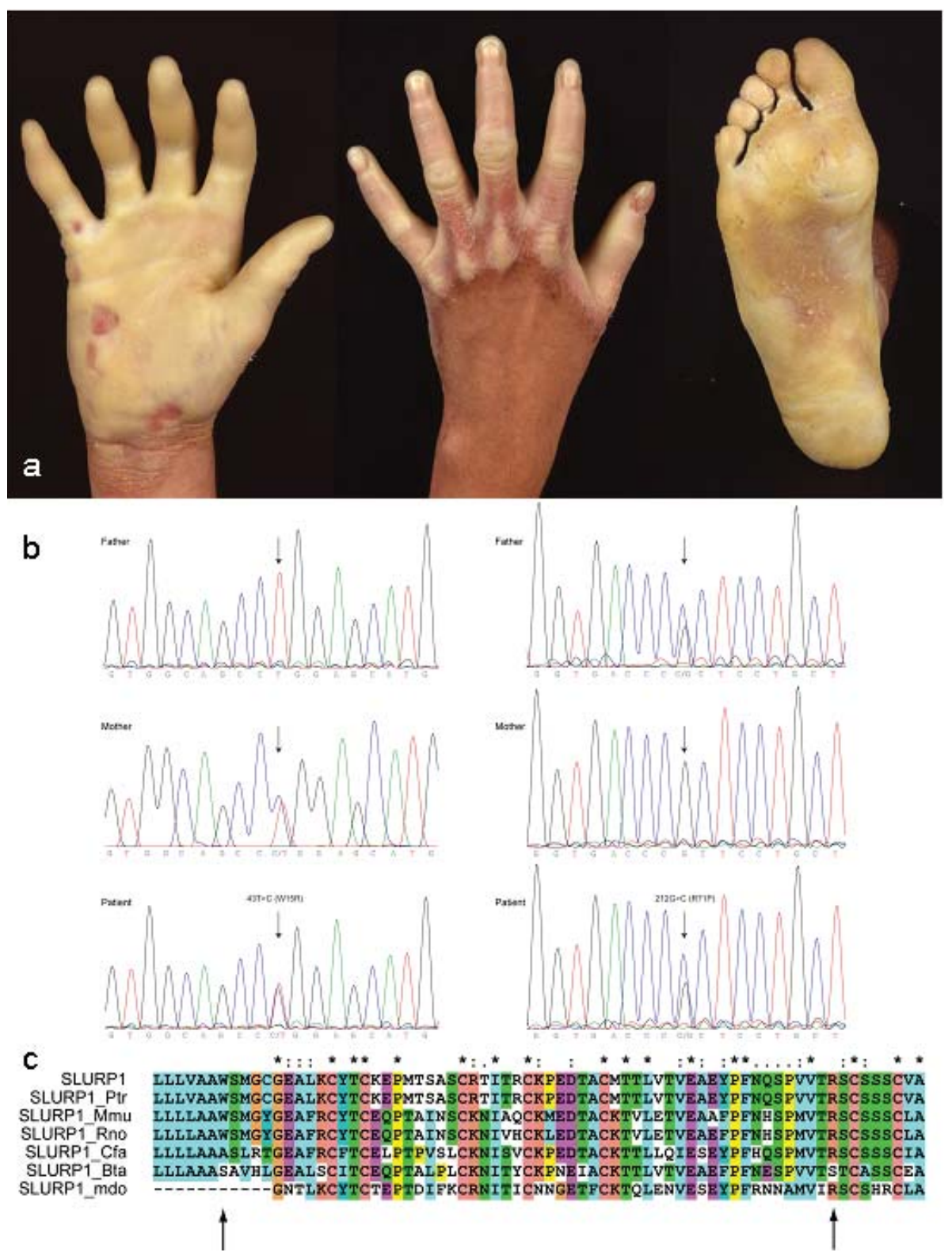

FIGURE 2.3 A Dutch patient with MDM.

a. Palms and soles of our patient, showing transgredient palmoplantar keratosis. b. Sequence analysis of the patient's father, his mother and our patient, respectively. Mutations have been indicated with an arrow. c. Alignment of amino acid sequence of SLURP-1 and its analogs in mammals. The position of both mutations shows a remarkable conservation among different species. 


\section{CHAPTER 2 MAL DE MELEDA}

heterozygous for p.(Trp15Arg), his father was heterozygous for p.(Arg71Pro) (figure 2.3b). The p.(Arg71Pro) mutation was not detected in 100 ethnically matched healthy controls by BsrBI restriction analysis.

Since the identification of mutations in SLURP1 gene as the cause of MDM, a limited number of mutations have been identified. Our patient is heterozygous for p.(Trp15Arg), the most prevalent SLURP1 mutation in the Western Europe population ${ }^{18,22}$. This mutation replaces a hydrophobic arginine with a hydrophilic tryptophan at the border of the core hydrophobic region. This region is known to be important for secretion of SLURP1 $1^{71,72}$. Thus, secretion may be impaired. Transfection experiments with p.(Trp15Arg)-SLURP1 in human embryonic kidney 293T cells showed no production of SLURP1 at all, indicating that this mutation also may exert a dominant negative effect on expression of the wild type allele ${ }^{41}$. However, the absence of features of MDM in the heterozygous mother of our index patient is not compatible with such a dominant negative effect.

To the best of our knowledge, the p.(Arg71Pro) mutation has not yet been described and is as such the second SLURP1 gene mutation reported in the North Western European population. Transfection studies showed that the p.(Arg71Pro) mutation impairs SLURP1 secretion and yields increased numbers of SLURP1 di- and monomers ${ }^{45}$. Interestingly, another mutation affecting this residue, p.(Arg71His), has been previously described by Favre et al. They could not detect SLURP1 in sweat of patients with the p.(Arg71His) mutation, further indicating impairment of SLURP1 secretion as a disease mechanism in $\mathrm{MDM}^{41}$. In addition, both residues described here are well conserved between mammalian species (figure 2.3c).

\subsubsection{A novel mutation in Intron 1 in an Indian family}

A fifteen year old girl developed a diffuse palmoplantar keratoderma in the first year of life (figure 2.4a, b). The hyperkeratosis slowly advanced to the dorsal side of her wrists, hands and feet and developed a malodorous scent, with a relatively extensive progredient hyperkeratosis at the moment of first consultation. The distal phalanges gradually acquired a conical shape without development of pseudo-ainhum. Nail changes other than a pinkish-pale hue, perioral erythema or skin changes elsewhere were not noted. Her 6 year old brother developed similar but less severe symptoms starting in infancy, with a comparable course over time. Parents were consanguineous (figure 

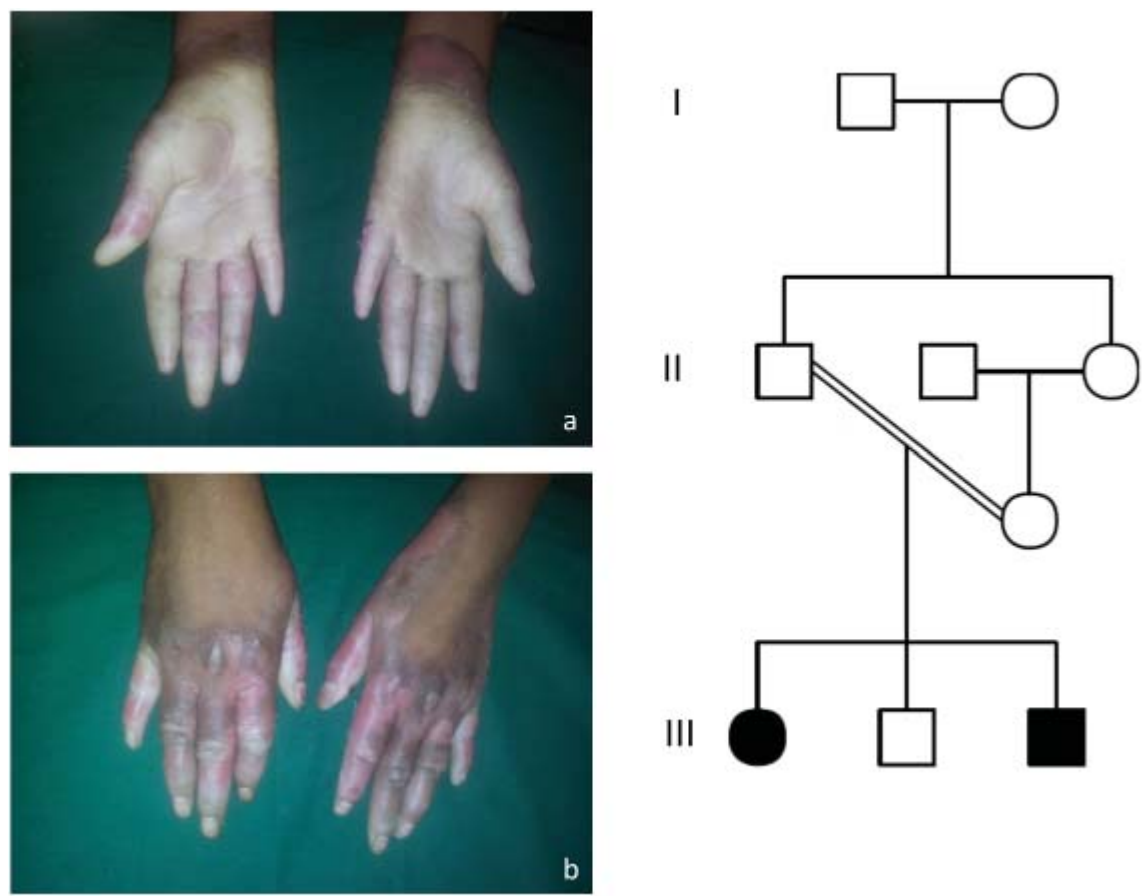

FIGURE 2.4

Phenotype of the Indian index patient: a. Diffuse palmar keratoderma, extending to the dorsal side of the fingers and hands (panel b) and wrists and forearm, with scattered desquamated erythematous patches. The distal phalanges show a remarkable conical shape. The nails show "pale and pink" discoloration. The feet showed similar symptoms. c. Genealogical tree. The index patient is designated III-1, her affected brother III-3.

2.4c). Probands and their parents gave written informed consent to further molecular analysis. Mutation analysis of SLURP1 revealed a homozygous c.58+5G>T splice site mutation in intron 1 in both index patients (figure 2.5a, methods are discussed in paragraph 2.2.1). The parents were heterozygous for this mutation. Splice site prediction software tools (integrated in Alamut 2.4) showed reduced scores of the variant splice donor site, which means that it could give rise to aberrant RNA splicing. To test this prediction, whole blood RNA was isolated from the patient and analysed with reverse transcriptase-PCR. The SLURP1 transcript was not detected in patient or control blood (data not shown) suggesting SLURP1 is not expressed in blood. Since a skin biopsy was not available, we used a SLURP1 minigene construct to determine if aberrant splicing occurs by the variant. HEK293 cells were transfected with either a plasmid 

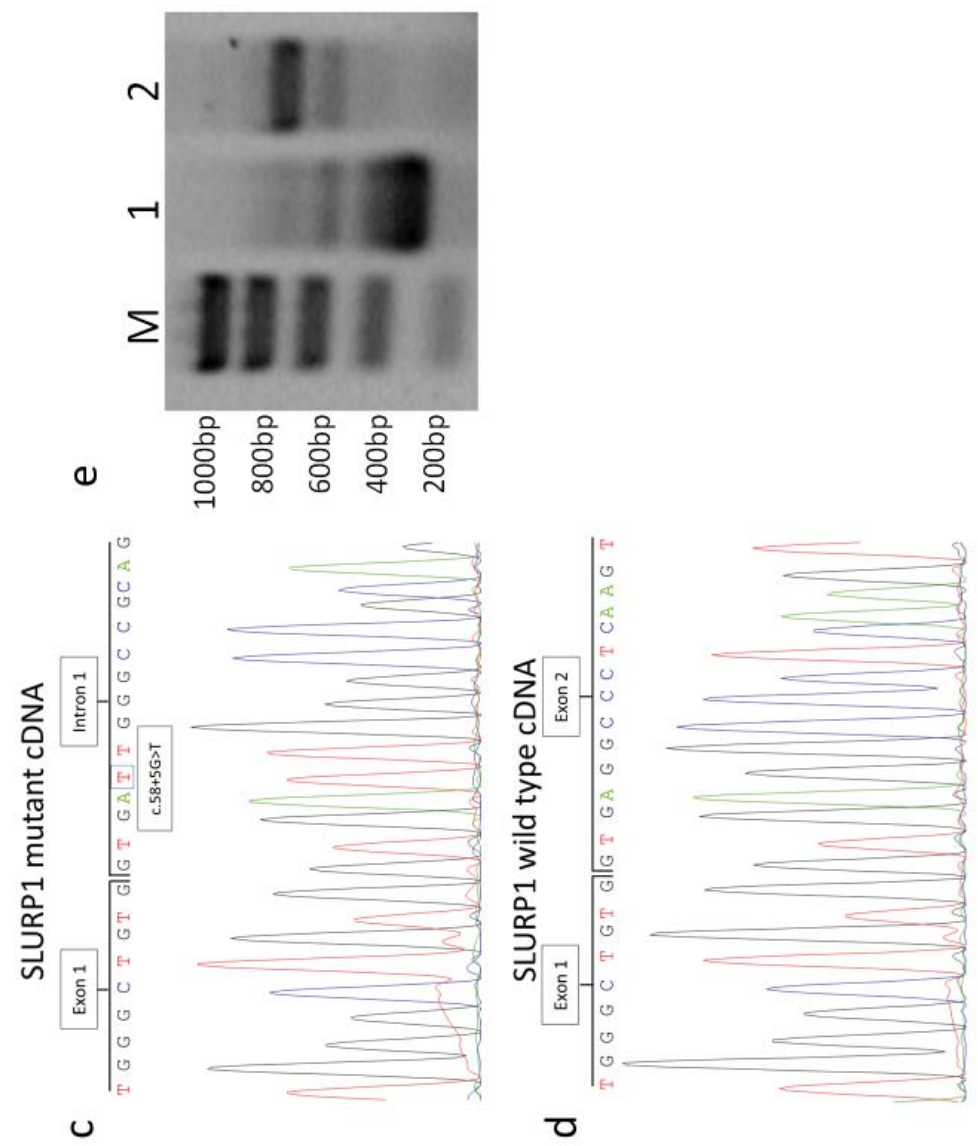

설 ్ㅡㄹ

in
क
in

宛

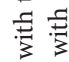

范

วิ

节

苯骂

크

(⿹)

宕

艺

岕艺

굴

仓ิ

옹

䒕 品

궁

仓

क

ป

I

疍

范苞

.

छี
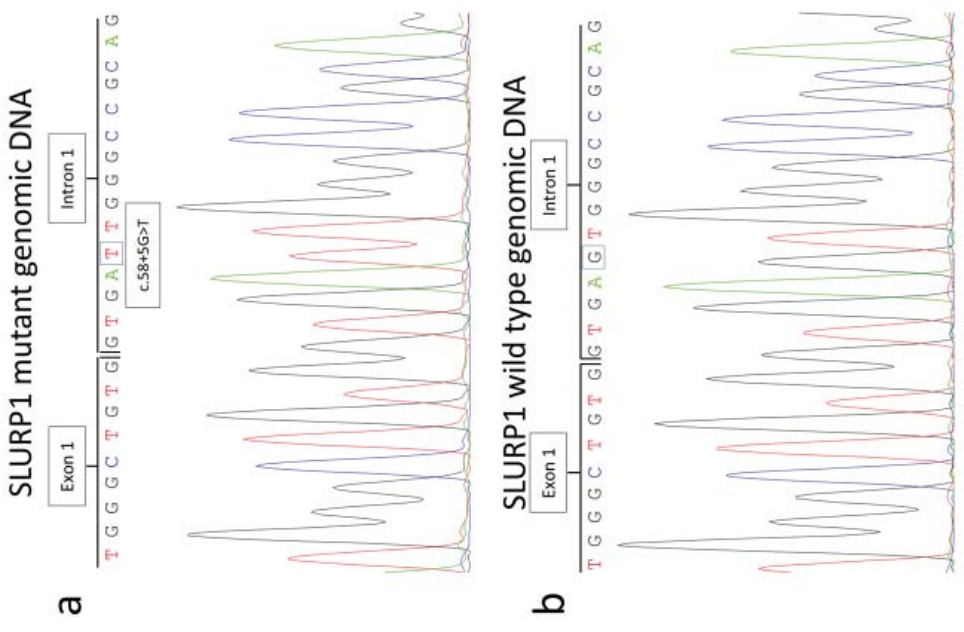

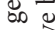

)ิ

艺

空

药苗艺

荧.

$\infty$

芯苛总

글

菏

品曋

更

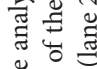

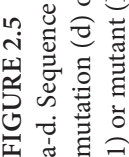


containing the wild type genomic DNA sequence of SLURP1 or the sequence with the c. $58+5 \mathrm{G}>\mathrm{T}$ variation. RNA was isolated from the HEK293 cells $24 \mathrm{~h}$ after transfection with either construct and cDNA was synthesized. SLURP1 cDNA was amplified using primers SLURP1cF1 5'-CCTCTCGCTGGGCTGTGCAG-3 and SLURP1cR3 5'AGGTCTCGGAAGCAGCAGAAG-3'. PCR amplification of wild type cDNA yielded a correctly spliced product of $289 \mathrm{bp}$, and cDNA with the c.58+5G $>$ T variant yielded an aberrant 694 bp product retaining intron 1 in the otherwise correctly spliced product (figure 2.5e). Sanger sequencing in both directions of the mutant cDNA PCR product showed retention of the full sequence of intron 1, excluding the activation of a cryptic splice acceptor site in the intronic sequence. Thus, the consequence of the c.58+5G>T mutation is aberrant splicing of mRNA (r.58_59ins58+1_59-1) putatively leading to a frameshift and premature protein truncation (p.(Val17Metfs $\left.{ }^{\star} 16\right)$ ).

Up to 18 different mutations in SLURP1 associated with MDM have been previously reported in the literature, three of which were intronic missense mutations in the introns $(\text { c. } 58+1 \mathrm{G}>\mathrm{A}, \mathrm{c} .58+1 \mathrm{G}>\mathrm{C}, \mathrm{c} .178+1 \mathrm{G}>\mathrm{A})^{18,39,58}$. The c.58+5G>T mutation found in our patients adds a new mutation to the spectrum of SLURP1 mutations associated with MDM. We show that this intron 1 mutation leads to aberrant splicing and intron retention, which probably leads to non-functioning protein. These results strongly indicate pathogenicity of the $c .58+5 \mathrm{G}>\mathrm{T}$ mutation. Intron retention was also reported with the $c .58+1 \mathrm{G}>\mathrm{C}$ mutation in a minigene assay ${ }^{58}$.

No clear genotype-phenotype relation in MDM could be identified, as reviewed in the introduction. As noted before, the main factors influencing the course of MDM seem to be age (more severe symptoms reported in elderly patients, especially the progredient nature of hyperkeratosis) and mechanical traumata (exacerbation of symptoms after prolonged periods of manual labor and/or heat exposure $)^{18,73}$. The fact that the older index patient has a slightly more severe progredient PPK for their age seems to contradict the first statement. We think this observation is attributable either to normal phenotypic variation in MDM or environmental factors, since the patients are from a rural area with a subtropical climate ${ }^{18,73}$. 


\subsection{Haplotype analysis in patients with the p.(Trp15Arg) mutation}

\subsubsection{Geographical clustering of SLURP1 mutations}

As pointed out in the introduction, the prevalence of three of the most common mutations, p.(Cys28fs32*), p.(Arg96 $\left.6^{*}\right)$ and p.(Trp15Arg), has a sharp geographical demarcation (figure 2.1). The p.(Cys28fs $\left.32^{*}\right)$ mutation was reported in Tunisian, Algerian and Croatian families as well as in a Scottish patient ${ }^{22,39,57}$, and co-segregates with a shared haplotype, suggesting a founder effect ${ }^{22}$. Shared haplotypes were also found in Turkish ${ }^{61}$ and Croatian ${ }^{39}$ families homozygous for the p.(Arg96 $6^{*}$ ) mutation, in a German family and in a Scottish patient harbouring the p. (Trp15Arg) mutation ${ }^{59}$.

We found the p.(Trp15Arg) mutation in four Dutch and a German patient with MDM. We hypothesised that this mutation could have arisen in a common ancestor. We tested this by haplotype analysis in our patients and the previously reported cases with the p.(Trp15Arg) mutation ${ }^{18,22}$. The total group thus consisted of four unrelated Dutch patients and a German patient, together with a previously reported German family (the affected mother and three affected children), a German family with one affected proband and one Scottish patient ${ }^{18,22}$.

\subsubsection{Methods}

For the mutation analysis, we studied four index patients of Dutch descent and their parents. The cohort of Western European patients with MDM consisted of a German family with an affected mother and three affected children, two German families, each with one affected proband and their parents, and one Scottish patient. Two of the German families and the Scottish patient had been previously reported ${ }^{18,22}$ and all were included in our study. The parents of the Scottish patient were deceased, and thus, no material was available for further analysis. The parents of one Dutch patient did not consent to further analysis and we excluded this family from our investigations.

All affected Dutch subjects showed the cardinal features of MDM, such as the development of transgredient palmoplantar keratoderma shortly after birth, hyperhydrosis and bacterial superinfection with concurrent malodour (figure 2.6). One patient developed nail deformities, consisting of mild nail dystrophy and distal onycholysis. We did not note perioral erythema, ichthyosis, scaling of elbows and knees 


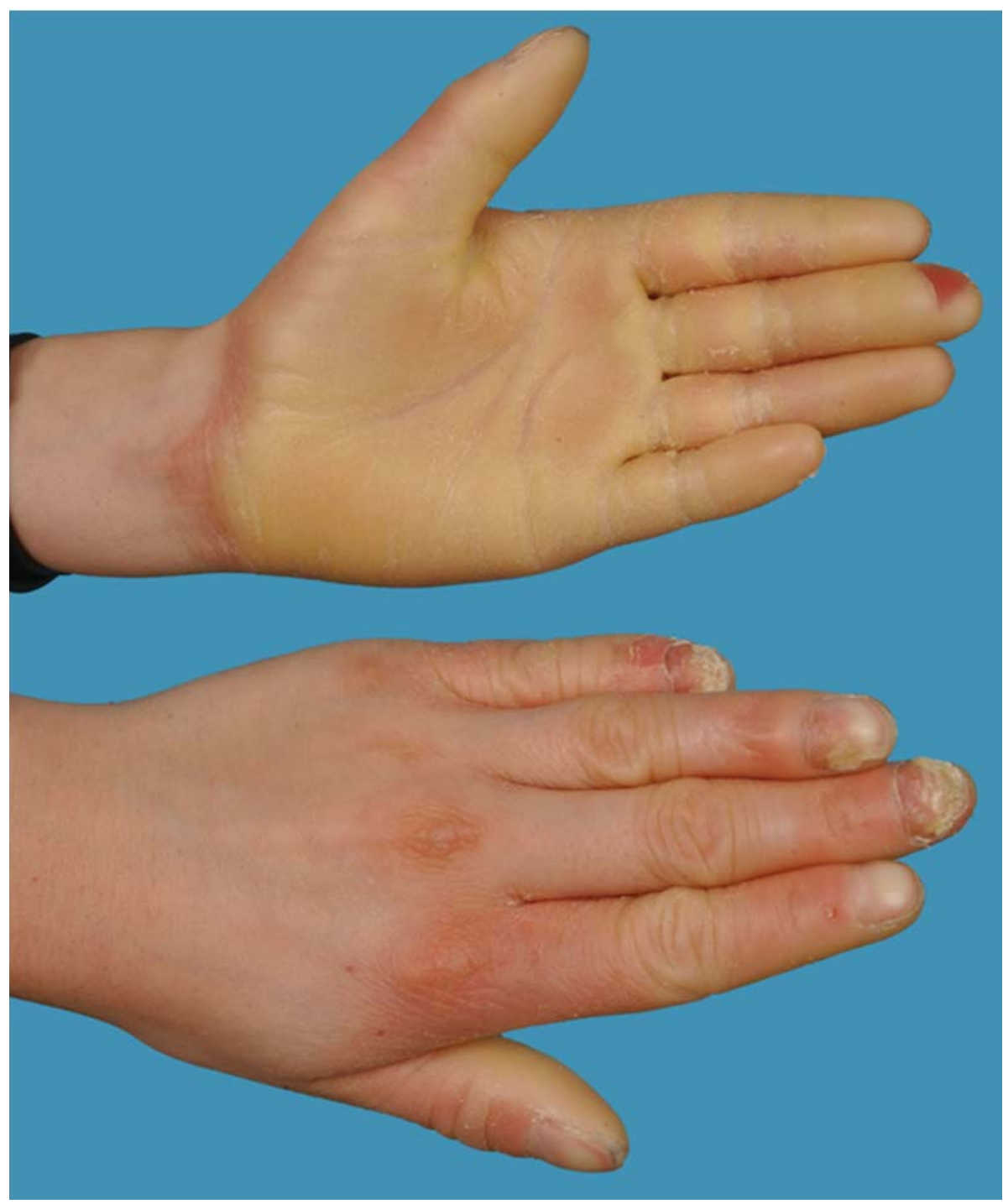

\section{FIGURE 2.6}

Clinical characteristics of unreported patients with MDM described in the haplotype study: progressive transgredient hyperkeratosis of the palms. The soles showed a similar keratoderma.

and pseudo-ainhum in any of our patients. The parents of the index patients were unaffected, and no consanguinity was indicated. Clinical characteristics of the German and Scottish patients and their family members have been previously reported ${ }^{18,22}$, but did not significantly differ from the Dutch and German patients. 


\section{CHAPTER 2 MAL DE MELEDA}

After obtaining informed consent from all patients and their parents, we performed mutation analysis of SLURP1 on DNA extracted from peripheral blood leucocyte, as is discussed in greater detail in paragraph 2.2.1.

We analysed haplotypes of all subjects and parents by amplifying a set of microsatellites surrounding SLURP1 on chromosome 8 (table 2.4). We used primers previously reported by Fischer et al. ${ }^{39}$, and reaction conditions described by Schuelke ${ }^{74}$. To further specify the haplotype, we also analysed SNPs at -55 and -60 bp upstream from the initiation codon of exon 1 (rs2572914 and rs 13254346, respectively) and two sets of SNPs in an interval at 20.8 (rs7005423, rs7005613, rs7005927, rs7822193, rs7812623, rs7825980, rs7816480, rs1075542) and $51.5 \mathrm{kbp}$ (rs2572919, rs2572918, rs2585159, rs749129, rs892842) distal of SLURP1 (build GRch37/hg19 and dbSNP132).

\subsubsection{Results}

Three of four Dutch patients were homozygous for the c.43T $>C$ mutation, leading to a substitution of a tryptophan to arginine at codon 15 (p. (Trp15Arg)). Their parents were heterozygous for the $\mathrm{p}$.(Trp15Arg) mutation. One patient was compound heterozygous for the p.(Trp15Arg) and p.(Arg71Pro) mutations (see paragraph 2.2) ${ }^{55}$. The unreported German proband was homozygous for the p.(Trp15Arg) mutation, and his parents were both heterozygous carriers. We confirmed homozygosity for p.(Trp15Arg) in the affected family members of the 2 previously reported German families and the carrier status of their parents and non-affected siblings ${ }^{18,22}$. The Scottish patient was compound heterozygous for the p.(Trp15Arg) and p.(Cys28fs $\left.32^{\star}\right)$ mutations $^{22}$.

The results of the haplotype analysis are shown in table 2.4. In all carriers of the p.(Trp15Arg) mutation, the mutation co-segregated with a core haplotype between and including the proximal marker D8S1836 and the two sets of SNPs telomeric to SLURP1, spanning approximately $125 \mathrm{Kbp}$. This core haplotype could be extended in three Dutch families, one German family and the Scottish patient to an area of $474 \mathrm{Kbp}$ between and including markers D8S1836 and D8S373. In the Dutch families the haplotype could be extended further to an area of $476 \mathrm{Kbp}$ between and including markers D8S1751 and D8S373. The parents of the homozygous p.(Trp15Arg) patients were all heterozygous for the mutation and for the p.(Trp15Arg) linked haplotype. 


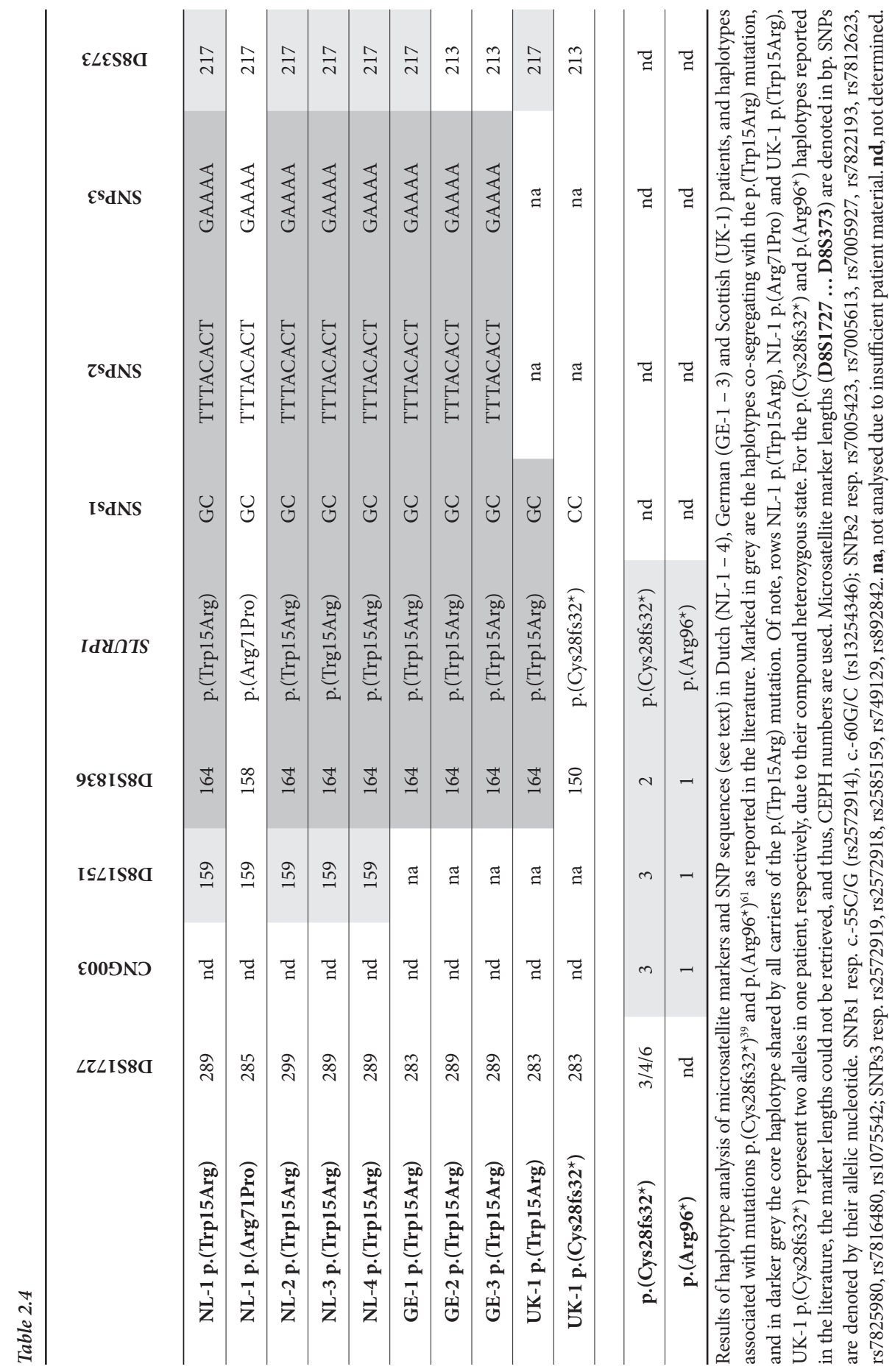




\section{CHAPTER 2 MAL DE MELEDA}

\subsubsection{Discussion}

Apart from the previously reported families, we describe one previously unreported German family and three unreported Dutch families with MDM, caused by a homozygous p.(Trp15Arg) mutation in SLURP1. Furthermore, we found a shared haplotype of at least $125 \mathrm{Kbp}$ surrounding the SLURP1 gene locus. An extended haplotype of at least 474 Kbp was shared by one German and three Dutch families. The Dutch families shared a haplotype that could be extended to an area of at least $476 \mathrm{Kbp}$. We could not analyse all markers in each patient due to insufficient patient material. We were thus not able to precisely specify the size of the shared haplotype. We confirmed the reported haplotype associated with p.(Trp15Arg) in the previously analysed German family (see table 2.1, GE-1 p.(Trp15Arg), Eckl et al. $\left.{ }^{18}\right)$.

As expected, the parents heterozygous for the p.(Trp15Arg) mutation were also heterozygous for the haplotype linked to the p.(Trp15Arg) mutation. This shows that the shared haplotypes are identical by descent from parent to children. The smallest common interval, $125 \mathrm{Kbp}$, is defined by polymorphic marker D8S1836, two SNPs upstream and two sets of SNPs upstream (telomeric) from SLURP1. Arguably, any linkage between the mutation and only one microsatellite marker and three set of SNPs may be attributable to coincidence. However, the size of microsatellite marker D8S1836 is highly variable in the general population but was the same in all investigated subjects. Also, the sets of SNPs we analysed revealed a strong linkage of a specific SNP-nucleotide to the mutation (see table 2.4). Although we cannot rule out the possibility of chance, we feel that our data is strong enough to suggest a founder effect for this mutation by a common ancestor.

The small size of the shared ancestral haplotype suggests that this mutation was not a recent event. We lacked sufficient data to estimate how many generations in the past the most recent common ancestor introduced the p.(Trp15Arg) mutation into the population. In table 2.4 , we displayed the reported results of the haplotype analysis performed for the p.(Cys28fs $\left.32^{*}\right)^{22,39}$ and p.(Arg96 $6^{*}$ mutation ${ }^{22,39,61}$. Both mutations link to marker set CNG003, D8S1751 and D8S1836, spanning an area of $32 \mathrm{Kbp}$. All three markers are located on the centromeric side of SLURP1. Marker D8S373 was not tested. Both shared haplotypes are relatively small as well. Given the small size of the reported haplotypes, all three mutations were not recent events and may have occurred around the same time. Also, the likelihood of recombination events may be increased due to the location of SLURP1, at the telomeric end of chromosome 8q. 


\section{CHAPTER 2 MAL DE MELEDA}

The founder effect described for the p.(Cys28fs32*) and p. $\left(\operatorname{Arg}^{*} 6^{\star}\right)$ mutation $^{22,59}$ is reported in families with a high incidence of consanguinity and thus contributes to the high incidence of MDM in these families. In our families, no consanguinity was reported. However, the four Dutch patients were members of a homogenous population, i.e. uninfluenced by migration and we hypothesise that this accounts for the high incidence of the p.(Trp15Arg) mutation. This may also account for the fact that the p.(Arg71Pro) mutation occurred in the same genetic haplotype as p.(Trp15Arg) in the compound heterozygous Dutch patient (see table 2.4). The spread of the mutation in parts of Northern Europe may be caused by incidental migration due to trade or other economic reasons, although we have no demographical data to support this statement. It remains therefore uncertain if the p.(Trp15Arg) variant recently reported in Swedish patients with MDM was introduced by the same common ancestor as the other Northern European MDM patients, or if this variant occurred as an independent event in the Swedish population ${ }^{56}$.

From the observation of a geographical demarcation of certain mutations and the evidence for a founder effect for the three most prevalent mutations in SLURP1 we conclude that there are population specific mutations that cause MDM. Therefore, this data may provide a first screening tool in molecular diagnostic strategies for MDM.

The major symptoms and course of the disease in our patients did not differ from earlier reports. All patients developed a slowly extending transgredient diffuse palmoplantar keratoderma within the first six months after birth, with hyperhidrosis and malodorous scent. However, in the four reviewed Dutch patients, we did not find pseudoainhum, perioral erythema or squamous plaques on the elbows. It is tempting to speculate that these differences are caused by the fact that our patients have a mutation in the first exon of SLURP1, whereas most other patients have mutations in exon 2 or 3. However, according to the data reported on clinical features in MDM, this variety in phenotype may not be unique. First of all, clinical symptoms may vary between patients with MDM, even between family members harbouring the same mutation ${ }^{19,57}$. Furthermore, in general, no correlation between the genotype and the phenotype has been observed ${ }^{18,22,39}$, whether mutations occur in exon 2 or 3 . Finally, some clinical signs, most notably the pseudoainhum, only occur later in life ${ }^{19}$. Three of four Dutch patients were children when first examined and have not reached the age when pseudoainhum occurs, and thus, this symptom may still develop in the future (for further discussion on genotype-phenotype relations, see paragraph 2.1.5 and 2.4). 


\section{CHAPTER 2 MAL DE MELEDA}

In conclusion, our data further extend the spectrum of mutations in SLURP1 in MDM and suggest a founder effect for p.(Trp15Arg) in the Western European population. Being the most prevalent mutation, Western European patients with MDM can first be screened for p.(Trp15Arg).

\subsection{Palmoplantar keratoderma of the Gamborg-Nielsen type}

In issue 94:6 of Acta Dermato-Venereologica, Zhao et al. identified mutations in the SLURP1 gene, encoding the secreted lymphocyte antigen 6/urokinase-type plasminogen activator receptor related protein-1 in patients with palmoplantar keratoderma of the Gamborg-Nielsen type (PPK-GN) ${ }^{56}$. They describe 15 patients suffering from a marked, sharply demarcated, and waxy, usually yellowish PPK with an erythematous base, involvement of the dorsal sides of fingers and toes, interspersions of erythematous skin in the hyperkeratosis and pseudo-ainhum. The clinical phenotype was complicated by hyperhidrosis and foul odor due to fungal superinfection. Symptoms began in the first year of life. The authors did not report skin changes on other parts of the body or mucosal symptoms. They suggest that, given the relatively mild phenotype, PPK-GN should be considered as a distinct entity allelic to Mal de Meleda (MDM) which is also caused by mutations in SLURP1 $1^{39}$.

We disagree with this conclusion. To classify a disease as allelic to another genetic disease caused by mutations in the same gene, symptoms need to be distinct and (partly) non-overlapping, not demonstrate varying severity. For instance, Papillon-Lefèvre syndrome (PLS, MIM \#245000) and Haim-Munk syndrome (HMS, MIM \#245010) are both caused by mutations in the gene coding for Cathepsin C (CTSC) ${ }^{75}$. Their phenotypes overlap to include PPK and periodontitis, but in Haim-Munk syndrome, arachnodactyly, acro-osteolysis, and onychogryphosis develop as well. Because of this, HMS is considered a distinct entity allelic to PLS. Clearly, the situation for PPK-GN and MDM is quite different. These two represent a spectrum of disease severity, as is seen in most genetic disorders. The cases described by Zhao et al. are not remarkable for being especially mild or otherwise distinct from classic MDM.

To illustrate the point, we recently reported a series of Dutch MDM-patients with a phenotype comparable to the patients reported by Zhao et al. The characteristics of these patients are discussed in greater detail in paragraph 2.3.2. In short, all subjects 


\section{CHAPTER 2 MAL DE MELEDA}

had PPK with transgredient hyperkeratosis, pseudo-ainhum and hyperhidrosis with bacterial superinfection, without skin symptoms elsewhere or mucosal changes ${ }^{76}$. All patients had the p.(Trp15Arg) mutation in SLURP1, the same as found in the majority of patients in the study by Zhao et al. A relatively mild phenotype has been reported in a significant number of other studies on MDM, with varying severity of symptoms reported even within families harbouring the same mutation in SLURP1 18,24,62,67,77. Table 2.3 semi-quantitatively summarizes the phenotypes reported so far in individual patients with MDM, with a description of disease course, including age, clinical characteristics and SLURP1 mutations. We added the data from the Dutch and Swedish cohorts. We are aware that drawing firm conclusions from these data is difficult; there are no reports describing large cohorts of patients and we acknowledge that there are no objective measures of MDM severity. That said, there seems to be a wide range of symptom severity, with previously reported cases of MDM being similar to the patients reported by Zhao et al. The data do suggest a tendency to a more severe course in older patients, which is consistent with earlier reports that note gradual progression during life. It would be of interest to follow disease progression and variation in a larger cohort of patients in order to get a more complete view of phenotypic variation in MDM.

In conclusion, it is our opinion that PPK-GN merely represents the mild end of the MDM spectrum. We therefore propose that the classification of PPK-GN as a separate genodermatosis should be abandoned. 


\section{CHAPTER 2 MAL DE MELEDA}

\section{References}

1 Fatovic-Ferencic, S., Holubar, K. Mal de Meleda: from legend to reality. Dermatology 2001; 203: p. 7-13.

2 Fatovic-Ferencic, S., Holubar, K. The portrait and paper of a forgotten hero--Luca Stulli (1772-1828) and the Mal de Meleda of yesteryear: a 175-year anniversary. J Invest Dermatol 2001; 116: p. 198-9.

3 Bryant, J. A New System: Or, An Analysis of Ancient Mythology: Wherein an Attempt is Made to Divest Tradition of Fable, and to Reduce the Truth to Its Original Purity. London: J. Walker; W.J. and J. Richardson; R. Faulder. 1807; p. 357-424.

Van der Kolf, M.C., Honigmann, E., Kroll, W. et al. Melite. In: Paulys Realencyclopädie der classischen Altertumswissenschaft (Pauly F, Wissowa G, Kroll W et al., eds), Vol. XV, 1. Stuttgart: Metzler, Stuttgart. 1893-1980; p. 540-9.

Schmidt, J., Von Geisau, H., Kees, H. Ogygia. In: Paulys Realencyclopädie der classischen Altertumswissenschaft (Pauly F, Wissowa G, Kroll W et al., eds), Vol. XVII, 2. Stuttgart: Metzler, Stuttgart. 1893-1980; p. 2066-76.

Bigge-Wither, L. A Nearly Literal Translation of Homer's Odyssey Into Accentuated Dramatic Verse. Oxford - London: J. Parker and Company. 1869; p. 2.

Strabo. Geographica, Vol. 1, Book I Chapter 2.37. Boston: Harvard University Press. 1917; p. 163.

Strabo. Geographica, Vol. 3, Book VII Chapter 3.6. Boston: Harvard University Press. 1924; p. 193.

Barrett, C.K. A critical and exegetical commentary on the Acts of the Apostles, Vol. 2. Edinburgh: T\&T Clark. 1998; p. 1219-25.

10 Gürtler, N., Pearson, J. Critici Sacri: Sive Clarissimorum Virorum In Sacro-Sancta Utriusque Foederis Biblia, Doctissimae Annotationes Atque Tractatus Theologico-Philologici., Vol. 4. Francofurti ad Moenum: Balthazar Wustius, Johannes Phillipus \& Johannes Nicolaus Andreas 1696; p. 2437-2464.

11 Warnecke, H., Schirrmacher, T. War Paulus wirklich auf Malta? Neuhausen bei Stuttgart Hänssler-Verlag. 1992.

12 Grotius, H. Annotationes in Novum Testamentum, Annotationes ad Acta Apostolorum, 27:27, Vol. 2. Paris: Guillaume Pelé. 1646; p. 156.

13 Stulli, L. Di una varieta cutanea. Lettera al direttore dell'antologia. Estratti dall'Antologia di Firenze, Firenze 1826; 71-72: p. 1-3.

14 Hovorka, O., Ehlers, E. Mal de Meleda. Arch Dermatol Syphilis 1897; 44: p. 251-6.

15 Neumann, I. Über Keratoma hereditarium. Arch Dermatol Syphilis 1898; 42: p. 163-74. 


\section{CHAPTER 2 MAL DE MELEDA}

16

Fischer, J., Bouadjar, B., Heilig, R. et al. Genetic linkage of Meleda disease to chromosome 8qter. Eur J Hum Genet 1998; 6: p. 542-7.

Schnyder, U.W., Franceschetti, A., Ceszarovic, B. et al. La maladie de Meleda autochtone. Ann Derm Syph 1969; 96: p. 517-30.

Eckl, K.M., Stevens, H.P., Lestringant, G.G. et al. Mal de Meleda (MDM) caused by mutations in the gene for SLURP-1 in patients from Germany, Turkey, Palestine, and the United Arab Emirates. Hum Genet 2003; 112: p. 50-6.

Bouadjar, B., Benmazouzia, S., Prud'homme, J.F. et al. Clinical and genetic studies of 3 large, consanguineous, Algerian families with Mal de Meleda. Arch Dermatol 2000; 136: p. 1247-52.

Sakabe, J., Kabashima-Kubo, R., Kubo, A. et al. A Japanese case of Mal de Meleda with SLURP1 mutation. J Dermatol 2014; 41: p. 764-5.

Bakija-Konsuo, A., Basta-Juzbasic, A., Rudan, I. et al. Mal de Meleda: genetic haplotype analysis and clinicopathological findings in cases originating from the island of Mljet (Meleda), Croatia. Dermatology 2002; 205: p. 32-9.

Marrakchi, S., Audebert, S., Bouadjar, B. et al. Novel mutations in the gene encoding secreted lymphocyte antigen-6/urokinase-type plasminogen activator receptor-related protein-1 (SLURP-1) and description of five ancestral haplotypes in patients with Mal de Meleda. J Invest Dermatol 2003; 120: p. 351-5.

3 Oh, Y.J., Lee, H.E., Ko, J.Y. et al. A Sporadic Case of Mal de Meleda Caused by Gene Mutation in SLURP-1 in Korea. Ann Dermatol 2011; 23: p. 396-9.

Bchetnia, M., Merdassi, A., Charfeddine, C. et al. Coexistence of mal de Meleda and congenital cataract in a consanguineous Tunisian family: two case reports. J Med Case Reports 2010; 4: p. 108.

5 Sethi, A., Janda, J.K., Sharma, N. et al. Mal de Meleda with Congenital Cataract: A Novel Case Report. Indian J Dermatol 2015; 60: p. 524.

Tourlaki, A., Bentivogli, M., Boneschi, V. et al. Genetically proven Mal de Meleda complicated by Bowen's disease of the sole. Eur J Dermatol 2011; 21: p. 292-4.

7 Mozzillo, N., Nunziata, C.A., Caraco, C. et al. Malignant melanoma developing in an area of hereditary palmoplantar keratoderma (Mal de Meleda). J Surg Oncol 2003; 84: p. 229-33.

8 Sartore, L., Bordignon, M., Bassetto, F. et al. Melanoma in skin affected with keratoderma palmoplantaris hereditaria (Mal de Meleda): Treatment with excision and grafting. J Am Acad Dermatol 2009; 61: p. 161-3.

9 Vilas-Sueiro, A., Roson, E., Suarez-Penaranda, J.M. et al. Malignant melanoma in a patient with mal de Meleda. Clin Exp Dermatol 2016; 41: p. 437-9.

Itin, P.H., Fistarol, S.K. Palmoplantar keratodermas. Clin Dermatol 2005; 23: p. 15-22. 


\section{CHAPTER 2 MAL DE MELEDA}

Kubo, A., Shiohama, A., Sasaki, T. et al. Mutations in SERPINB7, encoding a member of the serine protease inhibitor superfamily, cause Nagashima-type palmoplantar keratosis. Am J Hum Genet 2013; 93: p. 945-56.

Braun-Falco, M. Hereditary palmoplantar keratodermas. J Dtsch Dermatol Ges 2009; 7: p. 971-84; quiz 84-5.

Schiller, S., Seebode, C., Hennies, H.C. et al. Palmoplantar keratoderma (PPK): acquired and genetic causes of a not so rare disease. J Dtsch Dermatol Ges 2014; 12: p. 781-8.

Gruber, R., Hennies, H.C., Romani, N. et al. A novel homozygous missense mutation in SLURP1 causing Mal de Meleda with an atypical phenotype. Arch Dermatol 2011; 147: p. 748-50.

Reed, M.L., Stanley, J., Stengel, F. et al. Mal de Meleda treated with 13-cis retinoic acid. Arch Dermatol 1979; 115: p. 605-8.

Park, H.K., Kim, E.J., Ko, J.Y. Alitretinoin: treatment for refractory palmoplantar keratoderma. Br J Dermatol 2016; 174: p. 1143-4.

van de Kerkhof, P.C., van Dooren-Greebe, R.J., Steijlen, P.M. Acitretin in the treatment of mal de Meleda. Br J Dermatol 1992; 127: p. 191-2.

Marchac, A., Blanchet-Bardon, C., Revol, M. et al. Peut-on traiter chirurgicalement le Mal de Meleda (kératodermie palmoplantaire diffuse de Siemens)? Ann Chir Plast Esthet 2009; 54: p. 152-5.

Fischer, J., Bouadjar, B., Heilig, R. et al. Mutations in the gene encoding SLURP-1 in Mal de Meleda. Hum Mol Genet 2001; 10: p. 875-80.

Galat, A., Gross, G., Drevet, P. et al. Conserved structural determinants in three-fingered protein domains. FEBS J 2008; 275: p. 3207-25.

Favre, B., Plantard, L., Aeschbach, L. et al. SLURP1 is a late marker of epidermal differentiation and is absent in Mal de Meleda. J Invest Dermatol 2007; 127: p. 301-8.

Adermann, K., Wattler, F., Wattler, S. et al. Structural and phylogenetic characterization of human SLURP-1, the first secreted mammalian member of the Ly-6/uPAR protein superfamily. Protein Sci 1999; 8: p. 810-9.

Mastrangeli, R., Donini, S., Kelton, C.A. et al. ARS Component B: structural characterization, tissue expression and regulation of the gene and protein (SLURP-1) associated with Mal de Meleda. Eur J Dermatol 2003; 13: p. 560-70.

Moriwaki, Y., Watanabe, Y., Shinagawa, T. et al. Primary sensory neuronal expression of SLURP-1, an endogenous nicotinic acetylcholine receptor ligand. Neurosci Res 2009; 64: p. 403-12. 


\section{CHAPTER 2 MAL DE MELEDA}

45 Adeyo, O., Oberer, M., Ploug, M. et al. Heterogeneity in the properties of mutant secreted lymphocyte antigen 6/urokinase receptor-related protein 1 (SLURP1) in Mal de Meleda. $\mathrm{Br}$ J Dermatol 2015; 173: p. 1066-9.

46 Chimienti, F., Hogg, R.C., Plantard, L. et al. Identification of SLURP-1 as an epidermal neuromodulator explains the clinical phenotype of Mal de Meleda. Hum Mol Genet 2003; 12: p. 3017-24.

47 Arredondo, J., Chernyavsky, A.I., Webber, R.J. et al. Biological effects of SLURP-1 on human keratinocytes. J Invest Dermatol 2005; 125: p. 1236-41.

48 Chernyavsky, A.I., Arredondo, J., Galitovskiy, V. et al. Upregulation of nuclear factor-kappaB expression by SLURP-1 is mediated by alpha7-nicotinic acetylcholine receptor and involves both ionic events and activation of protein kinases. Am J Physiol Cell Physiol 2010; 299: p. C903-11.

49 Arredondo, J., Nguyen, V.T., Chernyavsky, A.I. et al. Central role of \{alpha\}7 nicotinic receptor in differentiation of the stratified squamous epithelium. J Cell Biol 2002; 159: p. 325-36.

50 Pasparakis, M. Role of NF-kappaB in epithelial biology. Immunol Rev 2012; 246: p. 346-58.

51 Kuster, W., Melnik, B., Traupe, H. et al. Lipid composition of outer stratum corneum in hereditary palmoplantar keratodermas. Dermatology 2003; 206: p. 131-5.

52 Salamon, T. Sudan-IV-positive material in fingernails of patient affected with mal de Meleda. Dermatologica 1986; 173: p. 199-200.

53 Salamon, T., Plavsic, B., Nikulin, A. Electron microscopic study of fingernails in the disease of Mljet (Mal de Meleda). Acta Derm Venereol 1984; 64: p. 302-7.

54 Adeyo, O., Allan, B.B., Barnes, R.H., 2nd et al. Palmoplantar keratoderma along with neuromuscular and metabolic phenotypes in Slurp1-deficient mice. J Invest Dermatol 2014; 134: p. 1589-98.

55 Nellen, R.G.L., van Geel, M., Steijlen, P.M. et al. Compound heterozygosity for ARS component B mutations in a Dutch patient with mal de Meleda. Br J Dermatol 2009; 160: p. 878-80.

56 Zhao, L., Vahlquist, A., Virtanen, M. et al. Palmoplantar Keratoderma of the GamborgNielsen Type is Caused by Mutations in the SLURP1 Gene and Represents a Variant of Mal de Meleda. Acta Derm Venereol 2014; 94: p. 707-10.

57 Charfeddine, C., Mokni, M., Ben Mousli, R. et al. A novel missense mutation in the gene encoding SLURP-1 in patients with Mal de Meleda from northern Tunisia. Br J Dermatol 2003; 149: p. 1108-15.

58 Wajid, M., Kurban, M., Shimomura, Y. et al. Mutations in the SLURP-1 gene underlie Mal de Meleda in three Pakistani families. J Dermatol Sci 2009; 56: p. 27-32. 


\section{CHAPTER 2 MAL DE MELEDA}

Ward, K.M., Yerebakan, O., Yilmaz, E. et al. Identification of recurrent mutations in the ARS (component B) gene encoding SLURP-1 in two families with mal de Meleda. J Invest Dermatol 2003; 120: p. 96-8.

Bchetnia, M., Laroussi, N., Youssef, M. et al. Particular Mal de Meleda phenotypes in Tunisia and mutations founder effect in the Mediterranean region. Biomed Res Int 2013; 2013: p. 206803.

Hu, G., Yildirim, M., Baysal, V. et al. A recurrent mutation in the ARS (component B) gene encoding SLURP-1 in Turkish families with mal de Meleda: evidence of a founder effect. $J$ Invest Dermatol 2003; 120: p. 967-9.

Bchetnia, M., Bozgia, M., Laroussi, N. et al. The first Mal de Meleda case in Libya: identification of a SLURP1 mutation. Int J Dermatol 2015; 54: p. 1426-8.

Chao, S.C., Huang, C.Y., Lai, F.J. et al. Pseudodominant inheritance with the G86R mutation in the ARS gene in Mal de Meleda. Int J Dermatol 2006; 45: p. 1456-8.

Chao, S.C., Lai, F.J., Yang, M.H. et al. Mal de Meleda in a taiwanese. J Formos Med Assoc 2005; 104: p. 276-8.

Tjiu, J.W., Lin, P.J., Wu, W.H. et al. SLURP1 mutation-impaired T-cell activation in a family with mal de Meleda. Br J Dermatol 2011; 164: p. 47-53.

(1)

Taylor, J.A., Bondavalli, D., Monif, M. et al. Mal de Meleda in Indonesia: Mutations in the SLURP1 gene appear to be ubiquitous. Australas J Dermatol 2016; 57: p. e11-3.

(1)

Zhang, J., Cheng, R., Ni, C. et al. First Mal de Meleda report in Chinese Mainland: two families with a recurrent homozygous missense mutation in SLURP-1. J Eur Acad Dermatol Venereol 2016; 30: p. 871-3.

Gruenbaum, Y., Stein, R., Cedar, H. et al. Methylation of CpG sequences in eukaryotic DNA. FEBS Lett 1981; 124: p. 67-71.

van Steensel, M.A., van Geel, M., Nahuys, M. et al. A novel connexin 26 mutation in a patient diagnosed with keratitis-ichthyosis-deafness syndrome. J Invest Dermatol 2002; 118: p. 724-7.

van Steensel, M.A., van Geel, M.V., Steijlen, P.M. Mal de Meleda without mutations in the ARS coding sequence. Eur J Dermatol 2002; 12: p. 129-32.

Izard, J.W., Kendall, D.A. Signal peptides: exquisitely designed transport promoters. Mol Microbiol 1994; 13: p. 765-73.

2 Izard, J.W., Rusch, S.L., Kendall, D.A. The amino-terminal charge and core region hydrophobicity interdependently contribute to the function of signal sequences. J Biol Chem 1996; 271: p. 21579-82.

Nellen, R.G.L., Steijlen, P.M., van Geel, M. et al. Comment on Zhao et al. "Palmoplantar keratoderma of the Gamborg-Nielsen type is caused by mutations in the SLURP1 gene and represents a variant of Mal de Meleda”. Acta Derm Venereol 2015; 95: p. 1034-5. 


\section{CHAPTER 2 MAL DE MELEDA}

74 Schuelke, M. An economic method for the fluorescent labeling of PCR fragments. Nat Biotechnol 2000; 18: p. 233-4.

75 Hart, T.C., Hart, P.S., Michalec, M.D. et al. Haim-Munk syndrome and Papillon-Lefevre syndrome are allelic mutations in cathepsin C. J Med Genet 2000; 37: p. 88-94.

76 Nellen, R.G.L., Steijlen, P.M., Hennies, H.C. et al. Haplotype analysis in western European patients with mal de Meleda: founder effect for the W15R mutation in the SLURP1 gene. $\mathrm{Br}$ J Dermatol 2013; 168: p. 1372-4.

77 Yerebakan, O., Hu, G., Yilmaz, E. et al. A novel mutation in the ARS (component B) gene encoding SLURP-1 in a family with Mal de Meleda. Clin Exp Dermatol 2003; 28: p. 542-4.

78 Gach, J.E., Munro, C.S., Lane, E.B. et al. Two families with Greither's syndrome caused by a keratin 1 mutation. J Am Acad Dermatol 2005; 53: p. S225-30.

79 Wollina, U., Knopf, B., Schaaschmidt, H. et al. [Familial coexistence of erythrokeratodermia variabilis and keratosis palmoplantaris transgrediens et progrediens]. Hautarzt 1989; 40: p. 169-72.

80 Sybert, V.P., Dale, B.A., Holbrook, K.A. Palmar-plantar keratoderma. A clinical, ultrastructural, and biochemical study. J Am Acad Dermatol 1988; 18: p. 75-86.

81 Nesbitt, L.T., Jr., Rothschild, H., Ichinose, H. et al. Acral keratoderma. Arch Dermatol 1975; 111: p. 763-8.

82 Cao, X., Yin, J., Wang, H. et al. Mutation in AQP5, encoding aquaporin 5, causes palmoplantar keratoderma Bothnia type. J Invest Dermatol 2014; 134: p. 284-7.

83 Blaydon, D.C., Lind, L.K., Plagnol, V. et al. Mutations in AQP5, encoding a water-channel protein, cause autosomal-dominant diffuse nonepidermolytic palmoplantar keratoderma. Am J Hum Genet 2013; 93: p. 330-5.

84 Hart, T.C., Hart, P.S., Bowden, D.W. et al. Mutations of the cathepsin C gene are responsible for Papillon-Lefevre syndrome. J Med Genet 1999; 36: p. 881-7.

85 Toomes, C., James, J., Wood, A.J. et al. Loss-of-function mutations in the cathepsin C gene result in periodontal disease and palmoplantar keratosis. Nat Genet 1999; 23: p. 421-4.

86 Duchatelet, S., Hovnanian, A. Olmsted syndrome: clinical, molecular and therapeutic aspects. Orphanet J Rare Dis 2015; 10: p. 33.

87 Muslumanoglu, M.H., Saracoglu, N., Cilingir, O. et al. A novel mutation in the ARS (component B) gene encoding SLURP-1 in a Turkish family with mal de Meleda. Br J Dermatol 2006; 155: p. 467-9. 
CHAPTER 2 MAL DE MELEDA 


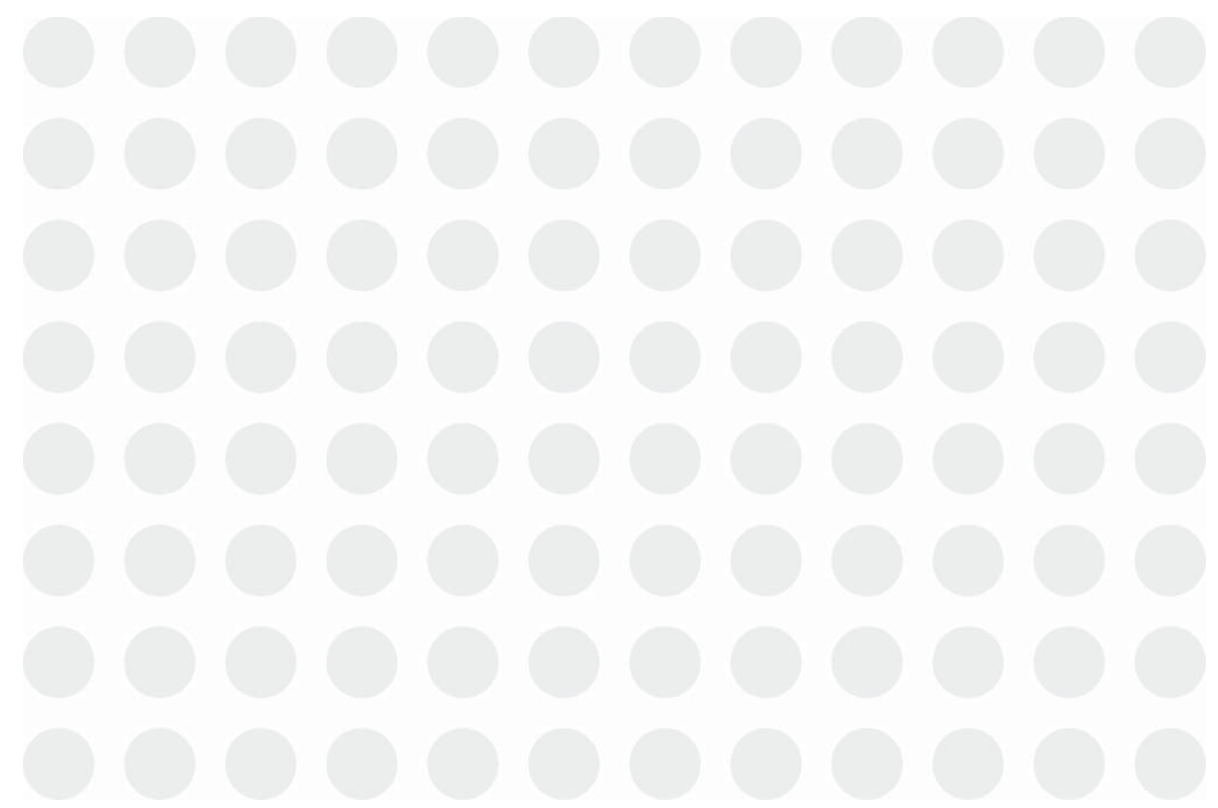




\section{Chapter III}

\section{Epidermolytic Ichthyosis}




\section{CHAPTER 3 EPIDERMOLYTIC ICHTHYOSIS}

Epidermolytic Ichthyosis (EI) is a rare inherited skin disorder caused by autosomal dominant mutations in keratin 1 or keratin 10. The symptoms of EI are either widespread blistering and erythroderma during infancy that develops into generalized ichthyosis, often more pronounced in the flexural areas (severe phenotype) or blistering upon mechanical trauma, but no ichthyosis (mild phenotype). If KRT1 mutations are the cause of EI, a palmoplantar keratoderma will develop as well. We describe patients from a family with variable severity of symptoms due to mutation p.(Met339Lys) in the linker L12 domain KRT1. This observation shows that the genotype-phenotype correlation in KRT1-associated skin disease are not as strict as has been suggested before. We provide clinical and functional evidence for the pathogenicity of variant p.(Met339Lys) in EI and add a novel variant to the mutation spectrum in EI. 


\section{CHAPTER 3 EPIDERMOLYTIC ICHTHYOSIS}

\subsection{Introduction}

Epidermolytic Ichthyosis (EI), formerly known as bullous congenital ichthyosiform erythroderma or epidermolytic hyperkeratosis, is a rare autosomal dominant skin disorder caused by mutations in $K R T 1$ and $K R T 10^{1}$. Both genes code for the major components of the intermediate filaments in suprabasal keratinocytes, keratins 1 (K1) and $10(\mathrm{~K} 10)^{2}$. The consequences of these mutations are beginning to be understood (reviewed in ${ }^{2-6}$ ). It is thought that, due to improper keratin processing, desmosome formation is impaired. This, in turn, leads to sequelae such as increased skin fragility, increased epidermal thickness and increased proliferation of keratinocytes ${ }^{7,8}$. It is suggested that the epidermal hyperproliferation is secondary to cytokines released from rupturing suprabasal keratinocytes 5 . Mice heterozygous for truncated K10 show epidermolysis and large keratin aggregates in suprabasal keratinocytes ${ }^{7,8}$. Experiments in type II keratin negative (KtyII-/-) mice and murine keratinocytes had a decreased number of desmosomes due to protein kinase C- $\alpha$ (PKC- $\alpha$ ) induced desmoplakin (DP) phosphorylation $^{9-11}$. It is thought that keratins are able to inhibit PKC- $\alpha$ via RACK1 sequestration, thereby inhibiting DP phosphorylation ${ }^{9}$. Although the murine KtyII-/genotype differs from the genetic defects in EI in humans, it is interesting to note that KtyII-/- mice suffered from hyperkeratotic lesions reminiscent of skin symptoms occasionally found in EI patients in areas exposed to natural strain, e.g. limb and neck folds ${ }^{10}$.

Classical features of EI are widespread blistering and erythroderma during infancy. In subsequent years, symptoms slowly develop into generalized ichthyosis, often more pronounced in the flexural areas. If KRT1 mutations are the cause of EI, a palmoplantar keratoderma will also develop ${ }^{1}$, although severe EI with PPK has been associated with KRT10 mutations in several patients ${ }^{12-14}$. Interestingly, there is extensive phenotypic variation in patients harbouring a KRT1 mutation, and strong genotype-phenotype correlations have been reported. Mutations associated with the severe and widespread phenotype mainly occur in the helix boundary motifs (HBM, helix initiation and termination motifs (HIM, HTM)) or the non-helical H1 domain of the K1 protein ${ }^{15,16}$. Mutations causing milder phenotypes occur in non-HBM areas such as linker (L12) domain. For instance, Kremer et al. and Bolling et al. both reported families with only mild neonatal blistering. Adult features included PPK and mild blistering upon mechanical trauma, but no ichthyosis. They identified mutations in the linker L12 


\section{CHAPTER 3 EPIDERMOLYTIC ICHTHYOSIS}

domain at codon 340, p.(Asp340Val) and p.(Asp340Gly) respectively ${ }^{17,18}$. Genotypephenotype correlation seem less well defined for mutations in areas adjacent to the HBMs, such as the 2B domain of KRT1 and KRT10 $0^{19-21}$. However, in an in silico model of 2B domain K1-K10 dimers, mutations in amino acid residues localized at the surface of K1-K10 dimers were associated with a mild phenotype, whereas mutations in amino acid residues localized at the interface domain (i.e. where K1 and K10 monomers interact and where the secondary structure is further stabilised) are associated with more severe EI phenotypes, though ${ }^{20,22}$. This indicates that the genotype-phenotype correlation for mutations in the $2 \mathrm{~B}$ domain is dependent on the specific position of the affected amino acid in the $2 \mathrm{~B}$ helix.

We now present data suggesting that L12 mutations can be associated with EI phenotypes of varying severity, thus further weakening the reported genotype-phenotype correlations for KRT1. We have identified several patients with a p.(Met339Lys) change in the linker L12 domain of K1. Of note, their phenotypes are quite variable; in one of the index patients the skin abnormalities are much more severe compared to previously reported patients with mutations in the L12 domain. We performed functional studies to assess the functional consequences of the p.(Met399Lys) mutation. Similar to keratinocytes with the p.(Asp340Gly/Val) mutation ${ }^{12,13}$, mutant keratins formed globular aggregates which became more pronounced when cells were subjected to osmotic stress.

\subsection{Methods}

\subsubsection{Clinical characteristics}

A four-year-old boy (figure 3.10, VI-4) presented to our outpatient clinic with a diffuse palmoplantar keratoderma and extensive warty thickening of the skin in several areas. The skin on the trunk and extremities showed mild ichthyosiform hyperkeratosis with scaling (figure 3.1a-c). Removal of scaling revealed a tender, erosive base. All symptoms developed in the first four years of life and worsened in the course of the following years (figure 3.1d-h).

Hair, nails, teeth and mucosae were not affected. Blistering or erythroderma during the neonatal period had not been noted. His father had a diffuse palmoplantar keratoderma, although his phenotype was mild compared to that of our index patient. 


\section{CHAPTER 3 EPIDERMOLYTIC ICHTHYOSIS}
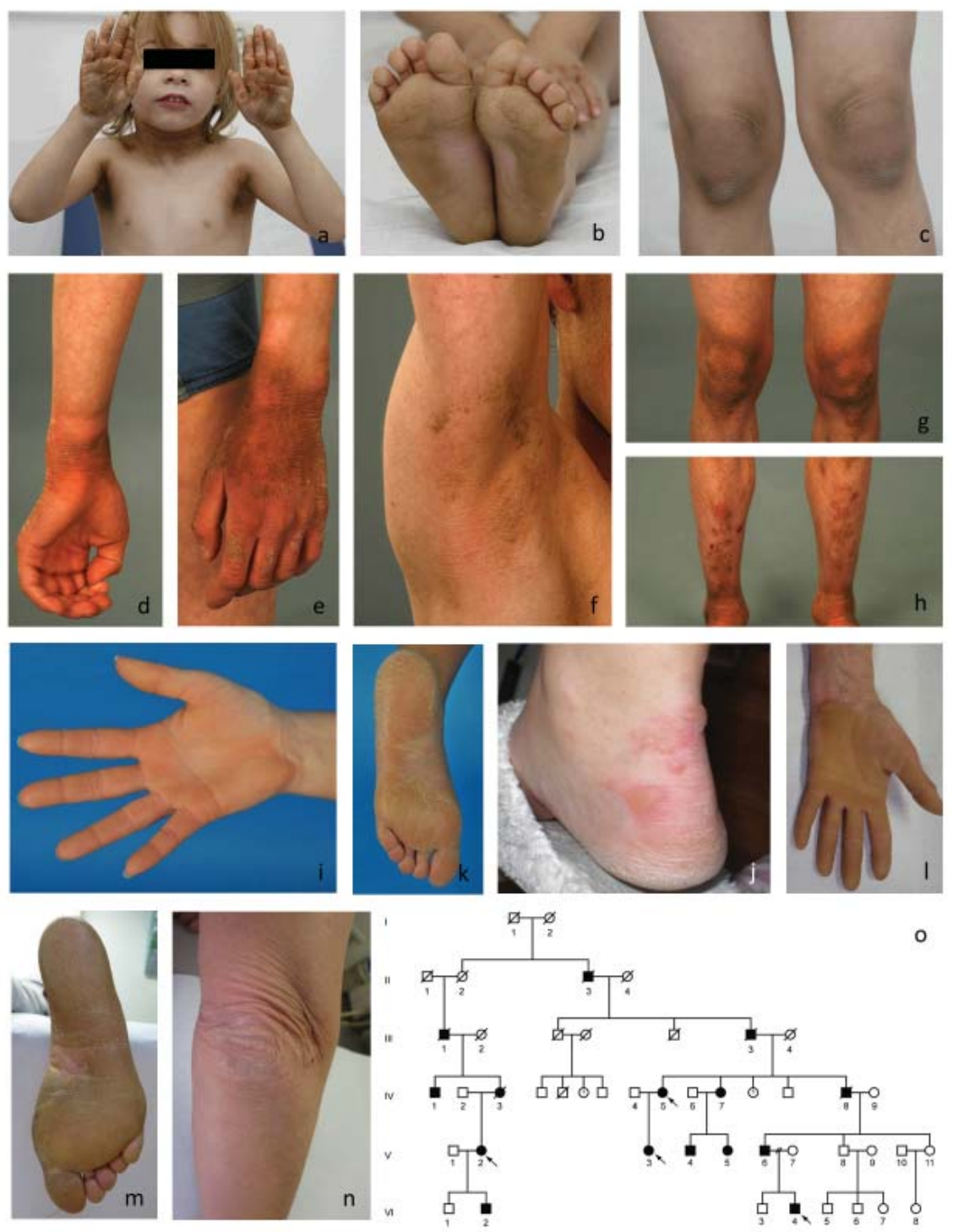

$\stackrel{0}{1} T_{2}^{\infty}$

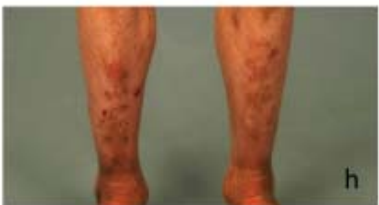

FIGURE 3.1 Clinical and genealogical data.

a-c: Clinical features of the first index patient (VI-4), showing a diffuse palmoplantar keratoderma (a, c) and extensive warty thickening of the neck and axillae (a) and knees (b). d-h: Clinical features of the same patient (VI-4) four years later: aggravation of the palmoplantar keratoderma (d), warty thickening of the skin on the dorsum of the hands and wrists (e), elbows, and knees (g). A generalized ichthyosis developed, with superficial erosions on the shins (h). Flexural areas such as the axillae and knee pits showed cobblestone like hyperkeratosis in a striate configuration (f). i-k: The second and third index patients (IV-5, $\mathrm{V}-3$ resp.) showed a diffuse palmoplantar keratoderma (i, $\mathrm{k}$ ) and intra-epidermal blisters upon mechanical traumata (j). The phenotype of the fourth patient (V-2): diffuse palmoplantar keratoderma $(1, n)$ and mild erythematous scar-like macules with mild scaling on sites exposed to friction $(\mathrm{m})$. o: Genealogical tree showing the described patients (solid arrows) and the common ancestors (I-1,2) five generations in the past. 


\section{CHAPTER 3 EPIDERMOLYTIC ICHTHYOSIS}

The index patient's great-aunt (figure 3.1o, IV-5) and her daughter (figure 3.10, V-3) suffered from mild superficial blistering starting in infancy, which developed into erosive blistering induced by mechanical stress (shoes, tight underwear, figure 3.1i-k). They developed a diffuse palmoplantar keratoderma at 15 years of age and during childhood, respectively. Both patients reportedly had not had congenital erythroderma. The greataunt showed mild brownish hyperkeratosis in her neck and elbow pits.

A fourth patient (figure 3.10, V-2) presented with a diffuse palmoplantar keratoderma, with an onset in the first decade of her life. She suffered from mild blistering of skin exposed to mechanical friction, such as the elbows (figure 3.11-n). Lesions healed with superficial, erythematous scar-like macules (figure 3.1m). Her history and clinical examination did not reveal any other skin symptoms.

\subsubsection{Mutation analysis}

Mutation analysis of KRT1 was performed on DNA derived from peripheral blood lymphocytes as described elsewhere ${ }^{23}$.

\subsubsection{EGFP constructs}

EGFP constructs were generated and transfection experiments performed as previously described by Bolling et al. ${ }^{17,23}$. The wild-type (WT) human KRT1 cDNA was previously cloned into the pEGFP-C3 (Invitrogen, San Diego, CA, U.S.A.) vector (kindly provided by Prof. W.H.I. McLean, Dundee, U.K.). Next, we used sitedirected mutagenesis to introduce the mutation c.1016T $>$ A (p.(Met339Lys)) into the WT EGFP-K1 construct (QuickChange SDM kit; Stratagene, La Jolla, CA, U.S.A.), according to the manufacturer's protocols (primer sequences: KRT1_M339K_F; 5'-ATGTCATCCTCTCTAAGGACAACAACCGCAG-3', KRT1_M339K_R ; 5’-CTGCGGTTGTTGTCCTTAGAGAGGATGACAT-3’).

\subsubsection{Transfection}

We transfected HaCaT cells with WT and mutant KRT1:p.Met339Lys (Met339Lys) fusion constructs using FuGENE-HD reagent (Roche, Lewis, U.K) ${ }^{17,23}$. We stressed keratinocytes by immersion in $150 \mathrm{mmol} / \mathrm{l}^{-1}$ urea (hypo-osmotic shock) for 5 minutes at $37^{\circ} \mathrm{C}$. This experiment was performed on half of the cultures from each of the groups 


\section{CHAPTER 3 EPIDERMOLYTIC ICHTHYOSIS}

of transfected cells. Keratin filaments were analysed on a Leica DM4000B fluorescence microscope (Leica, Heidelberg, Germany). Nuclei were stained with 4,6-diamidino-2phenyl-indole, which allowed for selection of non-apoptotic cells. We scored presence or absence of keratin clumping as either 'normal filaments' (figure 3.2e) or 'abnormal filaments' (figure 3.2d; differing from the standard filament network as in figure 3.2e).

\subsubsection{Statistical analysis of results}

We repeated the experiment three times on 100 cells from each group (WT vs. Met339Lys, both stressed and non-stressed) and scored for formation of protein aggregates. We used Microsoft Excel for all statistical analysis. The proportion of transfected cells showing cytoskeleton disruption for the stressed and non-stressed $\mathrm{K} 1$ constructs was expressed as a percentage $\pm 95 \%$ confidence interval. The different groups were compared using the chi- squared test.

\subsection{Results}

\subsubsection{Mutation analysis}

Index patients were heterozygous for the missense mutation $c .1016 \mathrm{~T}>\mathrm{A}$ in exon 5 of KRT1 (figure 3.2a), leading to substitution of a methionine to lysine at codon 339 (p.(Met339Lys)). This region codes for the linker L12 domain of K1 and is highly conserved among species, as well as other type II keratins and desmin (figure 3.2b). Genealogical analysis revealed a common ancestor at least four generations in the past, linking all index patients (figure 3.10).

\subsubsection{Transfection experiments}

Keratinocytes transfected with the p.(Met339Lys) mutation showed diminished keratin filament formation and a larger percentage of keratin clumping compared to wildtype keratinocytes $(\Delta 16 \%, \mathrm{p}<0.001)$ (figure $3.2 \mathrm{~d}$, e). This difference increased after hyperosmotic shock $\left(\Delta 29 \%, \mathrm{p}<1 \times 10^{-9}\right)$ (figure 3.2c). Of note, stressed WT keratinocytes did not form more aggregates than their non-stressed counterparts $(\Delta 6 \%, \mathrm{p}=0.19)$. This was not the case for p.(Met339Lys)-keratinocytes, where stressed cells had significantly more clumping than non-stressed cells $\left(19 \%, \mathrm{p}<1 \times 10^{-4}\right)$. 

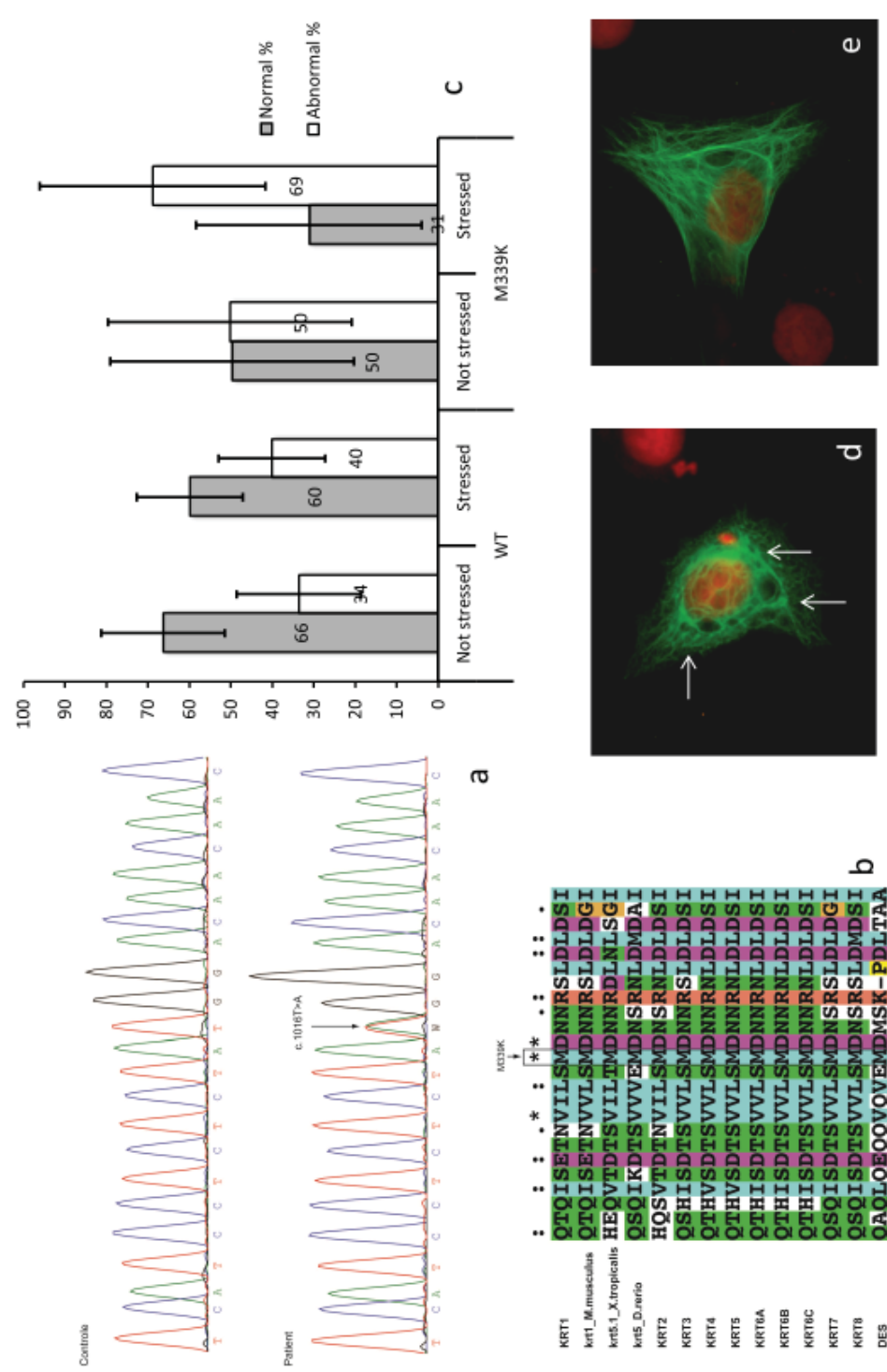

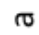

م

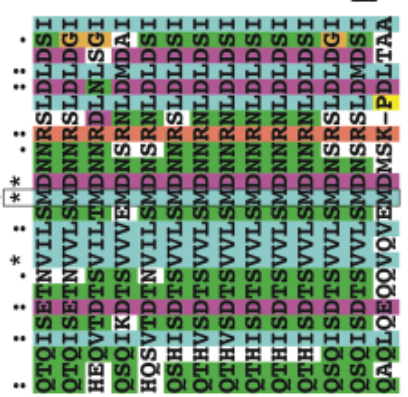

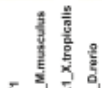

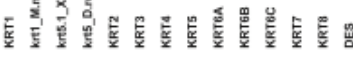

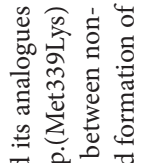

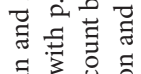

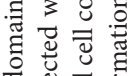

总

군

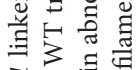

赵

运㻤

艺离

पु

षै की की

可记

政寻

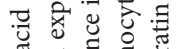

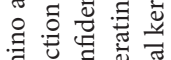

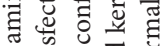

प艹

苟佥

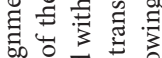

से

을을

उิ

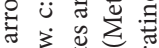

类

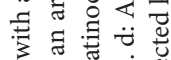

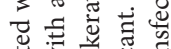

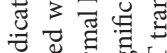

吾

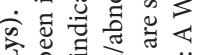

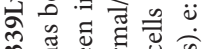

氜

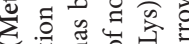

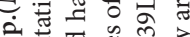

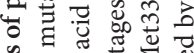

क

F.झ 巳

䒕

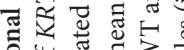

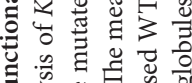

象罂

灵立总寻

ஸे

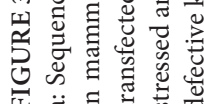




\section{CHAPTER 3 EPIDERMOLYTIC ICHTHYOSIS}

\subsection{Discussion}

We report several patients with a varying disease severity of EI, associated with a novel p.(Met339Lys) mutation in KRT1. The variant co-segregates with the disease phenotype and was not detected in clinically unaffected controls. Genealogical analysis revealed a relation between the patients and strongly suggests a common ancestor who introduced the mutation approximately 180 years ago. Transfection studies showed similar disruption of keratin formation and function compared to previous studies discussing KRT1 mutations in the linker L12 domain ${ }^{17}$. In addition, at the equivalent position in KRT5 (p.Met327), a similar mutation p.(Met327Lys) was found in a patient with epidermolysis bullosa simplex of the hands and feet ${ }^{24}$. Collectively, these findings support pathogenicity of the p.(Met339Lys) mutation. Our data suggest a role for formation of clumped mutant keratin in the development of the clinical phenotype mentioned above.

The mild clinical phenotype of EI caused by mutations in the KRT1 L12 domain usually consists of diffuse palmoplantar keratoderma and blistering on areas exposed to mechanical trauma. A severe phenotype (congenital blistering and erythroderma, developing into generalized ichthyosis) is associated with mutations in the $\alpha$-helical rod domain. A few exceptions to this rule have been published in recent literature $\mathrm{e}^{2,19,25}$ and our data provide further evidence that the genotype-phenotype correlation in KRT1related disease is not always as strong as has been suggested. In our series, one patient presented with a diffuse palmoplantar keratoderma, severe ichthyosis with a cobblestone appearance in flexural areas and distal parts of the extremities and mild ichthyosis on the trunk, in absence of congenital blistering and erythroderma. On the other hand, our other patients, harbouring the same mutation and sharing a common ancestor with the first patient, only developed a diffuse palmoplantar keratoderma and occasionally friction blisters. Although intrafamilial clinical heterogeneity in EI has been reported for the p.(Ser185Pro) mutation in the rod 1A domain of $K R T 1^{26}$ and p.(Leu153Met) mutation in the rod $1 \mathrm{~A}$ domain of $K R T 10^{27}$, to the best of our knowledge, this phenotypic variation has not been reported before in EI patients with mutations in the L12 domain.

The mechanisms that underlie the differences in the phenotype are poorly understood. There are no experimental models in which a comparable defect in KRT1 is analysed. In KtyII-/- mice., a phenotype develops reminiscent of the phenotype of our severely affected patient VI- $4^{10}$. However, we think that the data of a knockout 


\section{CHAPTER 3 EPIDERMOLYTIC ICHTHYOSIS}

model cannot readily be extrapolated to our patients, in whom one KRT1 allele is mutated instead of both alleles absent. The functional consequences of K1 aggregates as seen in our study remain unclear. Experimental data suggests that mutations alter the dynamics of filament formation and reduce expression of desmosome components and cytoskeletal linker proteins, giving rise to a keratin network that is less stable ${ }^{3}$. In $\mathrm{K} 1$ associated EI, the suprabasal keratinocytes are affected, leading to intra-epidermal blister formation and PPK. Environmental factors (mechanical strain) may contribute to development of specific symptoms, as is seen in the development of PPK. However, we think that environmental factors cannot explain the substantial differences seen in our index patient VI-4 compared to patients IV-5, V-2, V-3 and V-5. The ichthyosiform changes observed in patient VI-4 are found on parts of the body not subject to excessive mechanical strain. Evaluation of daily activities did not reveal any triggering effects (for example, swimming, sporting activities).

Other genetic factors (keratin or non-keratin related) that influence K1 filament assembly may contribute to the phenotypic variability, in a comparable manner to filaggrin $(F L G)$ mutations in X-linked ichthyosis ${ }^{28}$. We did not identify the 5 most frequently found Western European FLG mutations (c.1501C>T (p.Arg501*), c.2282_2285del4, c.3702delG, c.7339C>T (p.Arg2447*) and c.9740C>A (p.Ser3247*)) in our index patient with the severe phenotype (data not shown), excluding FLG mutations as explanation for the observed difference in phenotypes ${ }^{29}$. One study found five cis-regulatory single nucleotide polymorphisms (SNP) that greatly influenced binding of transcription factors and KRT1 promoter activity, thereby causing dramatic differences in KRT1 allele expression in leukocytes ${ }^{30}$. However, this study did not provide further information on probable pathologic relevance in EI. It is imaginable that the observed phenotypic differences in our family may be attributable to segregation of the p.(Met339Lys) KRT1 allele with the SNPs favouring high expression and segregation of the wild type KRT1 allele with SNPs favouring low expression in our index patient. In the less severely affected patients, the p.(Met339Lys) mutation segregates with the SNPs favouring low expression and the wild type KRT1 allele with SNPs favouring high expression. Although the probability of an "allelic switch" of the high expression SNP allele due to a genetic recombination event such as a (double) chromosomal crossover is very low, this may provide a theoretical explanation for the observed familial phenotypic variation. Other factors influencing post-translational processing of mutated $\mathrm{K} 1$, such 


\section{CHAPTER 3 EPIDERMOLYTIC ICHTHYOSIS}

as differences in phosphorylation in reaction to mechanical stress may vary between individuals ${ }^{3,31,32}$. It remains highly speculative to apply this experimental data as an explanation for the difference in disease severity.

In conclusion, we report a novel missense mutation p.(Met339Lys) in KRT1 in several patients with remarkable variation in clinical presentation. Symptoms vary from palmoplantar keratoderma and occasional friction blistering in less severely affected patients to severe palmoplantar keratoderma, friction blistering and generalized ichthyosis with flexural accentuation, all in the absence of congenital symptoms. Functional testing of p.(Met339Lys) indicates pathogenicity, but does not provide an explanation for the phenotypic variation. 


\section{CHAPTER 3 EPIDERMOLYTIC ICHTHYOSIS}

\section{References}

1 Oji, V., Tadini, G., Akiyama, M. et al. Revised nomenclature and classification of inherited ichthyoses: results of the First Ichthyosis Consensus Conference in Soreze 2009. J Am Acad Dermatol 2010; 63: p. 607-41.

2 Chamcheu, J.C., Siddiqui, I.A., Syed, D.N. et al. Keratin gene mutations in disorders of human skin and its appendages. Arch Biochem Biophys 2011; 508: p. 123-37.

Haines, R.L., Lane, E.B. Keratins and disease at a glance. J Cell Sci 2012; 125: p. 3923-8.

Lane, E.B., McLean, W.H. Keratins and skin disorders. J Pathol 2004; 204: p. 355-66.

McLean, W.H., Moore, C.B. Keratin disorders: from gene to therapy. Hum Mol Genet 2011; 20: p. R189-97.

Knobel, M., O’Toole, E.A., Smith, F.J. Keratins and skin disease. Cell Tissue Res 2015; 360: p. 583-9.

7 Porter, R.M., Leitgeb, S., Melton, D.W. et al. Gene targeting at the mouse cytokeratin 10 locus: severe skin fragility and changes of cytokeratin expression in the epidermis. J Cell Biol 1996; 132: p. 925-36.

8 Reichelt, J., Bauer, C., Porter, R. et al. Out of balance: consequences of a partial keratin 10 knockout. J Cell Sci 1997; 110 (Pt 18): p. 2175-86.

9 Kroger, C., Loschke, F., Schwarz, N. et al. Keratins control intercellular adhesion involving PKC-alpha-mediated desmoplakin phosphorylation. J Cell Biol 2013; 201: p. 681-92.

10 Bar, J., Kumar, V., Roth, W. et al. Skin fragility and impaired desmosomal adhesion in mice lacking all keratins. J Invest Dermatol 2014; 134: p. 1012-22.

11 Wallace, L., Roberts-Thompson, L., Reichelt, J. Deletion of K1/K10 does not impair epidermal stratification but affects desmosomal structure and nuclear integrity. J Cell Sci 2012; 125: p. 1750-8.

12 Arin, M.J., Longley, M.A., Anton-Lamprecht, I. et al. A novel substitution in keratin 10 in epidermolytic hyperkeratosis. J Invest Dermatol 1999; 112: p. 506-8.

13 Morais, P., Mota, A., Baudrier, T. et al. Epidermolytic hyperkeratosis with palmoplantar keratoderma in a patient with KRT10 mutation. Eur J Dermatol 2009; 19: p. 333-6.

14 Virtanen, M., Gedde-Dahl, T., Jr., Mork, N.J. et al. Phenotypic/genotypic correlations in patients with epidermolytic hyperkeratosis and the effects of retinoid therapy on keratin expression. Acta Derm Venereol 2001; 81: p. 163-70.

15 Syder, A.J., Yu, Q.C., Paller, A.S. et al. Genetic mutations in the K1 and K10 genes of patients with epidermolytic hyperkeratosis. Correlation between location and disease severity. J Clin Invest 1994; 93: p. 1533-42. 


\section{CHAPTER 3 EPIDERMOLYTIC ICHTHYOSIS}

Porter, R.M., Lane, E.B. Phenotypes, genotypes and their contribution to understanding keratin function. Trends Genet 2003; 19: p. 278-85.

Bolling, M.C., Bladergroen, R.S., van Steensel, M.A. et al. A novel mutation in the L12 domain of keratin 1 is associated with mild epidermolytic ichthyosis. Br J Dermatol 2010; 162: p. 875-9.

Kremer, H., Lavrijsen, A.P., McLean, W.H. et al. An atypical form of bullous congenital ichthyosiform erythroderma is caused by a mutation in the L12 linker region of keratin $1 . J$ Invest Dermatol 1998; 111: p. 1224-6.

Arin, M.J., Oji, V., Emmert, S. et al. Expanding the keratin mutation database: novel and recurrent mutations and genotype-phenotype correlations in 28 patients with epidermolytic ichthyosis. Br J Dermatol 2011; 164: p. 442-7.

Mirza, H., Kumar, A., Craiglow, B.G. et al. Mutations Affecting Keratin 10 Surface-Exposed Residues Highlight the Structural Basis of Phenotypic Variation in Epidermolytic Ichthyosis. J Invest Dermatol 2015; 135: p. 3041-50.

Hotz, A., Oji, V., Bourrat, E. et al. Expanding the Clinical and Genetic Spectrum of KRT1, KRT2 and KRT10 Mutations in Keratinopathic Ichthyosis. Acta Derm Venereol 2016; 96: p. 473-8.

Sung, J.Y., Oh, S.W., Kim, S.E. et al. Mild phenotype of epidermolytic hyperkeratosis mimicking ichthyosis bullosa of Siemens is related to specific mutation in 2B domain of KRT1. J Dermatol Sci 2013; 70: p. 220-2.

Terron-Kwiatkowski, A., van Steensel, M.A., van Geel, M. et al. Mutation S233L in the 1B domain of keratin 1 causes epidermolytic palmoplantar keratoderma with "tonotubular" keratin. J Invest Dermatol 2006; 126: p. 607-13.

Muller, F.B., Kuster, W., Bruckner-Tuderman, L. et al. Novel K5 and K14 mutations in German patients with the Weber-Cockayne variant of epidermolysis bullosa simplex. J Invest Dermatol 1998; 111: p. 900-2.

Terron-Kwiatkowski, A., Terrinoni, A., Didona, B. et al. Atypical epidermolytic palmoplantar keratoderma presentation associated with a mutation in the keratin 1 gene. Br J Dermatol 2004; 150: p. 1096-103.

McLean, W.H., Eady, R.A., Dopping-Hepenstal, P.J. et al. Mutations in the rod 1A domain of keratins 1 and 10 in bullous congenital ichthyosiform erythroderma (BCIE). J Invest Dermatol 1994; 102: p. 24-30.

Abdul-Wahab, A., Takeichi, T., Liu, L. et al. Intrafamilial phenotypic heterogeneity of epidermolytic ichthyosis associated with a new missense mutation in keratin 10. Clin Exp Dermatol 2016; 41: p. 290-3.

28 Liao, H., Waters, A.J., Goudie, D.R. et al. Filaggrin mutations are genetic modifying factors exacerbating X-linked ichthyosis. J Invest Dermatol 2007; 127: p. 2795-8. 


\section{CHAPTER 3 EPIDERMOLYTIC ICHTHYOSIS}

29 Chen, H., Common, J.E., Haines, R.L. et al. Wide spectrum of filaggrin-null mutations in atopic dermatitis highlights differences between Singaporean Chinese and European populations. Br J Dermatol 2011; 165: p. 106-14.

30 Tao, H., Cox, D.R., Frazer, K.A. Allele-specific KRT1 expression is a complex trait. PLoS Genet 2006; 2: p. e93.

31 Pan, X., Hobbs, R.P., Coulombe, P.A. The expanding significance of keratin intermediate filaments in normal and diseased epithelia. Curr Opin Cell Biol 2013; 25: p. 47-56.

32 Snider, N.T., Omary, M.B. Post-translational modifications of intermediate filament proteins: mechanisms and functions. Nat Rev Mol Cell Biol 2014; 15: p. 163-77. 
CHAPTER 3 EPIDERMOLYTIC ICHTHYOSIS 


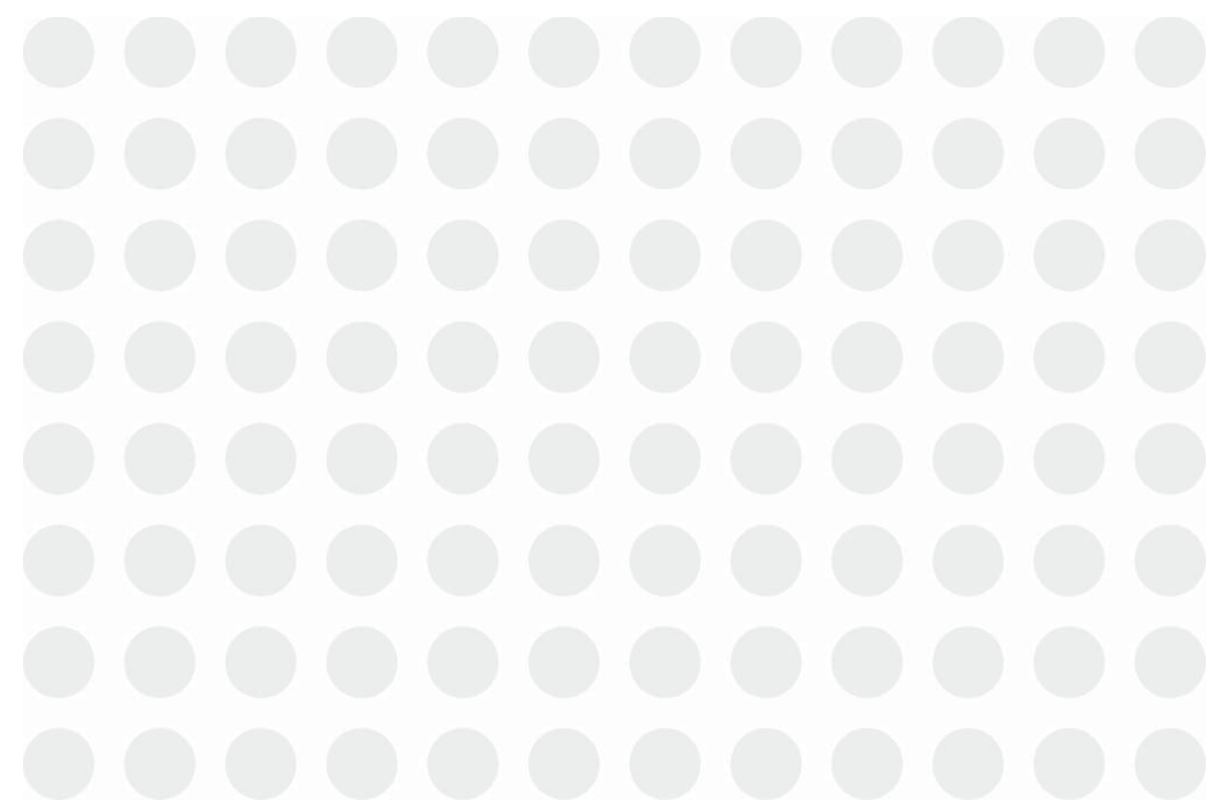




\section{Chapter IV}

\section{Darier disease and Hailey-Hailey disease}

R. Fölster-Holst*, R.G.L. Nellen*, J.M. Jensen, P. Poblete-Gutiérrez, P.M. Steijlen, T. Schwarz, R. Happle, M. van Geel, J. Frank. Molecular genetic support for the rule of dichotomy in type 2 segmental Darier disease. Br J Dermatol. 2012 Feb;166(2):464-6

${ }^{*}$ Both authors contributed equally to this work.

R.G.L. Nellen, A.H.M.M. Arits, M. van Geel, P.M. Steijlen, M.A.M. van Steensel.

Darier disease: discrete phenotype in a Sinhalese patient with Darier disease.

J Eur Acad Dermatol Venereol. 2015 Aug;29(8):1641-2

R.G.L. Nellen, M. van Geel, K.M.L. Huijbregts. Response to 'Darier disease in Israel: combined evaluation of genetic and neuropsychiatric aspects'.

Br J Dermatol. 2016 Jul;175(1):223-4

R.G.L. Nellen, P.M. Steijlen, M.A.M. van Steensel, M. Vreeburg, European professional contributors", J. Frank, M. van Geel. Mendelian disorders of cornification caused by defects in intracellular calcium pumps: mutation update and database for variants in ATP2A2 and ATP2C1 associated with Darier disease and Hailey-Hailey disease. Under revision for publication in Human Mutation. 
Darier disease (DD) and Hailey-Hailey disease (HHD) are disorders of cornification associated with mutations in genes coding for intracellular calcium pumps. DD is caused by mutations in the ATP2A2 gene, while the ATP2C1 gene is associated with HHD. Both are inherited as autosomal dominant traits. DD is mainly defined by warty papules in seborrheic and flexural areas, whereas the major symptoms of HHD are vesicles and erosions in flexural skin. Both phenotypes are highly variable. In 12 to $40 \%$ of DD patients and $12-55 \%$ of HHD patients, no mutations in $A T P 2 A 2$ or $A T P 2 C 1$ are found.

This chapter provides the first comprehensive review of the clinical and genetic variability in DD and HHD. To further delineate the clinical variability in DD, we describe a patient with type II segmental DD and a DD patient with skin type $\mathrm{V}$ and an unusually mild phenotype. Both disease phenotypes are caused by novel mutations in ATP2A2. Furthermore, we comment on a recent report on neuropsychiatric disease associated with DD. Last, we provide detailed clinical data of $52 \mathrm{DD}$ and $13 \mathrm{HHD}$ patients, which, combined with results from the literature, enables us to address genotype-phenotype relations in DD and HHD. To assess genetic variability, we present data on a large cohort of patients with DD and $\mathrm{HHD}$ and report several new mutations in $A T P 2 A 2$ and $A T P 2 C 1$, respectively. We created a database for all mutations in ATP2A2 and ATP2C1 using the Leiden Open Variation Database (LOVD v3.0) for variants reported in the literature and future inclusions. Having the entire spectrum of ATP2A2 and ATP2C1 variants allows us to address the question of a genotype-phenotype-correlation, which has so far remained equivocal in both DD and HHD. This data may promote further research on treatment of DD and HHD. 


\subsection{Introduction}

Calcium homeostasis in keratinocytes is essential for many epidermal functions, such as differentiation, barrier repair, cell-cell-adhesion and keratinocyte motility. Darier disease (DD, MIM \#124200) and Hailey-Hailey disease (HHD, MIM \#169600) are autosomal dominantly inherited disorders of cornification caused by defective functioning of intracellular calcium pumps in keratinocytes. The defective gene in DD, ATP2A2, encodes the sarcoplasmic/endoplasmic reticulum $\mathrm{Ca}^{2+}$-ATPase isoform 2 protein $(\text { SERCA2 })^{1}$, which is located in the endoplasmic reticulum (ER). HHD is associated with mutations in the ATP2C1 gene, encoding the secretory pathway $\mathrm{Ca}^{2+}$-ATPase 1 protein (SPCA1). SPCA1 is located in the membrane of the Golgi-apparatus and regulates $\mathrm{Ca}^{2+}$ and $\mathrm{Mn}^{2+}$ uptake in the Golgi-apparatus ${ }^{2,3}$. Although defects in SERCA2 and SPCA1 are both associated with disruption of suprabasal keratinocyte adhesion (acantholysis), DD and HHD show remarkably different phenotypes.

In $\mathrm{DD}$, the classical features are warty papules in seborrheic and flexural areas, palmoplantar pits and nail changes such as longitudinal leukonychia and V-shaped notches at the distal end of the nail plate (figure 4.1). Cobblestone-like lesions can be found on the oral and genital mucosa ${ }^{4}$. Less common subtypes of DD are guttate leukoderma (small depigmented macules on the trunk and extremities, seen more often in patients with skin type IV-VI ${ }^{4,5}$ ), acral haemorrhagic DD (haemorrhagic vesicles on the hands and feet ${ }^{6}$ ) and comedonal DD (predominantly comedones and acne-like lesions $\left.{ }^{7,8}\right)$. Acrokeratosis Verruciformis of Hopf (AKV) consists of verrucous papules on the dorsum of the hands, which can be found either together with classic DD or as a separate entity. AKV is considered to be allelic to DD, since ATP2A2 mutations have been found in patients with $\mathrm{AKV}^{9}$. Exacerbations of classic DD can be triggered by external factors such as UV radiation, heat and sweating, but can develop spontaneously as well. Epidemiological data suggests that the incidence of neurological and psychiatric disease may be slightly elevated in DD patients. This will be further discussed in paragraph 4.2.3. Bone cysts were found in a small number of DD patients (reviewed by Castori et al..$^{10}$ ).

In $\mathrm{HHD}$, painful blisters and vesicles that develop into erosions and scaly erythematous plaques occur at the axillae, groins, neck and perineum (figure 4.2) ${ }^{11}$. This may possibly be due to friction of flexural skin. Longstanding disease may progress to hypertrophic and malodorous patches with painful fissures that limit mobility and can mimic flexural DD. Longitudinal leukonychia can be found in some patients. Blistering 

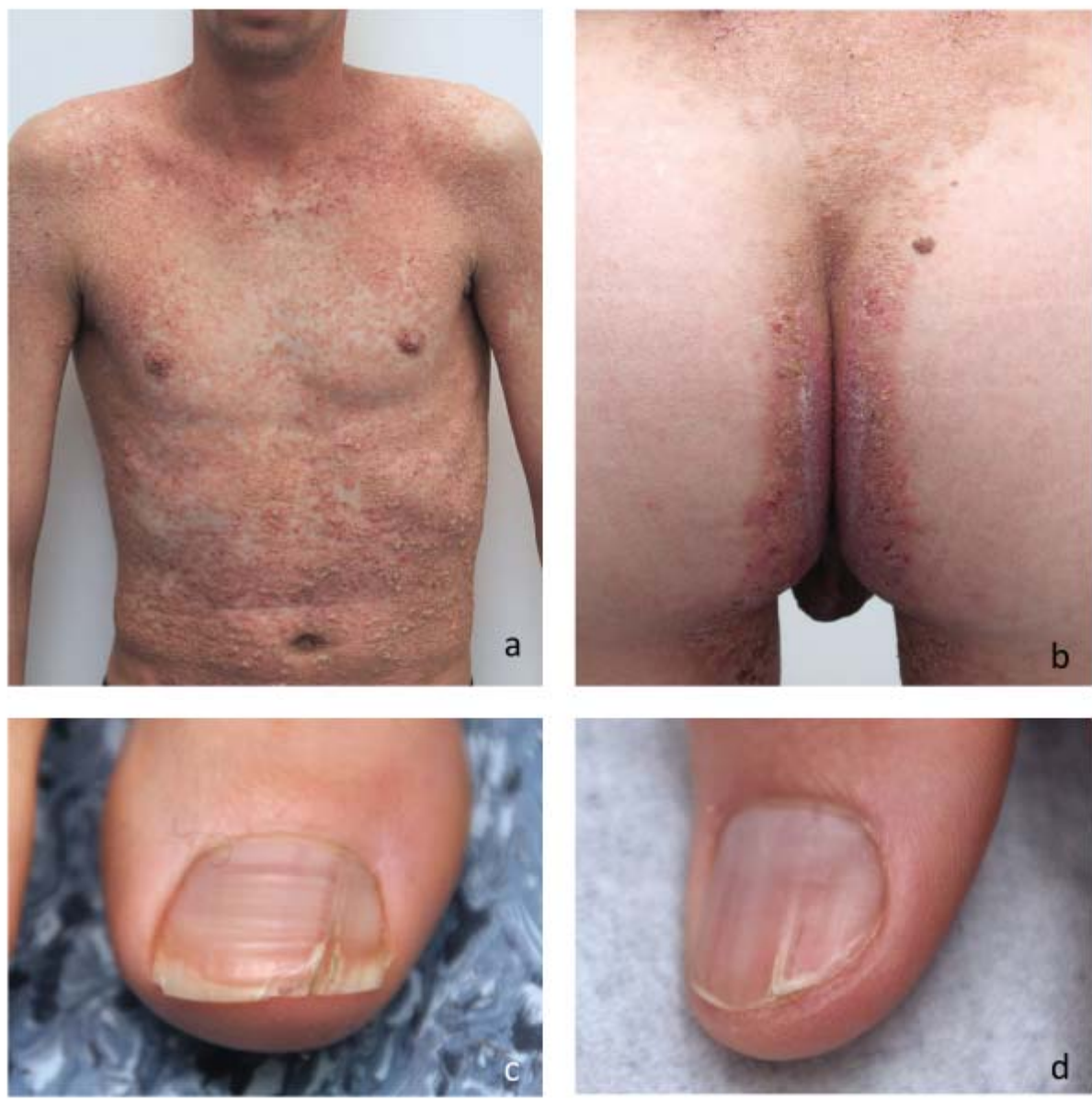

FIGURE 4.1 Clinical features of classic Darier disease.

a. and b. Greasy, warty papules, in this case not limited to the seborrheic areas (upper torso) but covering the chest, abdomen and upper extremities, as well as extending to the flexural areas (b.).

c. V-shaped notch: indentations of the distal side of the nail plate of digitus I of the right foot.

d. Longitudinal leukonychia: a longitudinal white band on the nail plate of digitus I of the left hand.

and erosions of oral, esophageal, vaginal and conjunctival mucosa have been described ${ }^{3}$. Similar external influences as seen in DD can aggravate the disease course.

Diagnosis of both diseases is primarily based on clinical criteria. Mutation analysis of ATP2A2 or ATP2C1 can confirm the clinical diagnosis. Both DD and HHD usually develop in the second decade of life and have a chronic relapsing course. Even mild disease can severely affect quality of life $^{12}$. Prevalences are estimated at 1:30,000-55,000 

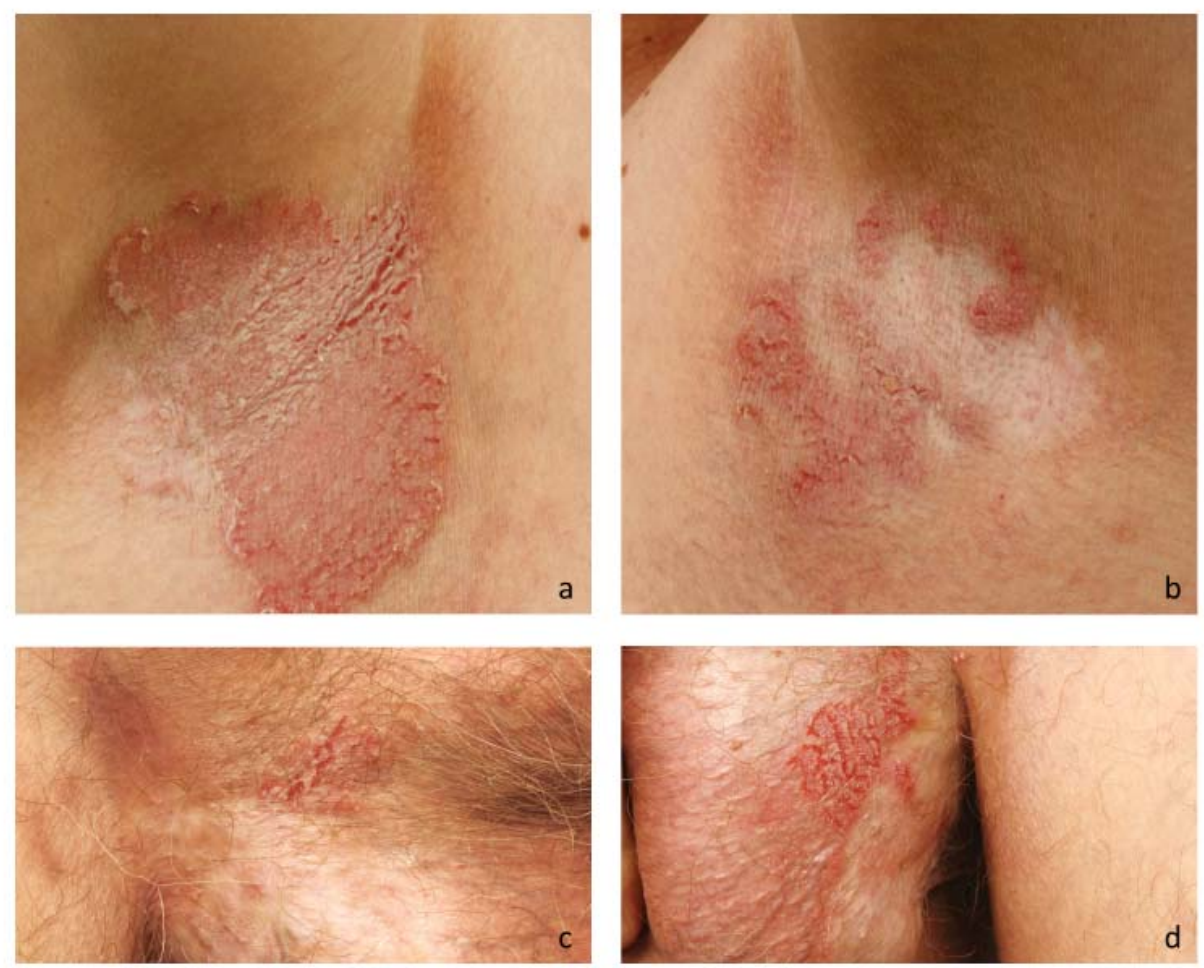

FIGURE 4.2 Clinical features of Hailey-Hailey disease.

a.-d. Erosions and scaly erythematous plaques in the axillae (a. and b.) and groins (c. and d.). More extensive, vegetating hyperkeratosis may develop in long standing disease (a.). Diseased skin may be interspersed with healed, hypopigmented or scarred areas (b. and c.).

for DD and 1:50,000 for $\mathrm{HHD}^{4,11,13-15}$. Penetrance is complete, but expressivity is highly variable; the phenotype may vary between unrelated patients affected by the same variant as well as among family members harboring the same mutation ${ }^{6,16,17}$. Patients with skin type IV-VI tend to have a relatively mild phenotype of $\mathrm{DD}^{4,5}$. DD and HHD may occur in a segmental distribution, either due to a post-zygotic somatic mutation (type I segmental disease) ${ }^{18-20}$ or post-zygotic loss of heterozygosity for the wild type allele in a patient heterozygous for a germline ATP2A2 or ATP2C1 mutation (type II segmental disease $)^{21,22}$. A case of type II segmental DD will be discussed in greater detail in paragraph 4.2.1. 


\subsection{Clinical variability in $D D$}

\subsubsection{Type II segmental DD}

According to Happle's rule of dichotomy, two types of segmental manifestation can be distinguished in autosomal dominant skin disorders ${ }^{23,24}$. Type 1 reflects heterozygosity for a de novo postzygotic mutation. This leads to a segmental cutaneous manifestation of the respective disease with a severity comparable to the ordinary, non-segmental trait. Heterozygous somatic ATP2A2 gene mutations were identified in several patients with so-called acantholytic dyskeratotic nevi, confirming that this nevi represented type I segmental $\mathrm{DD}^{18,20}$.

Type II segmental autosomal dominant skin diseases are caused by postzygotic loss of heterozygosity ( $\mathrm{LOH})$, i.e. loss of the wild type allele in heterozygous individuals. This results in either homozygosity or hemizygosity for the underlying mutation. Rather pronounced segmental lesions are superimposed on the ordinary non-segmental phenotype. Usually, the segmental manifestation precedes the diffuse, nonsegmental disease. In 2004, Poblete-Gutiérrez et al. confirmed this hypothesis for the type II segmental manifestation in Hailey-Hailey disease for the first time ${ }^{22}$. Recently, the type II segmental DD phenotype has been reported on several instances ${ }^{25,26}$. To the best of our knowledge though, molecular genetic support for this theory has not yet been delivered in DD.

Here, we report on an otherwise healthy one-year-old German Caucasian boy (individual III-2 in figure 4.3a) who developed sharply demarcated erosive patches confined to the right abdomen shortly after birth. In the course of the following months, the lesions extended to the rest of his abdomen while following the lines of Blaschko (figure 4.3b). His mother, a maternal uncle and his maternal grandmother were previously diagnosed with classical DD, affecting the seborrheic areas on the trunk, and palmar pits on hands and feet (figure 4.3c). A skin biopsy showed focal hyperkeratosis, acanthosis of the epidermis and elongated rete ridges as well as suprabasal clefting, multiple dyskeratotic cells, and a mild dermal interstitial infiltrate consisting of lymphocytes and histiocytes (data not shown). Based on the family history, clinical and histopathologic features we made the tentative diagnosis of type 2 segmental DD.

After obtaining informed consent we extracted genomic DNA from peripheral blood leucocytes using standard procedures ${ }^{22}$. Mutation analysis was carried out with specific 


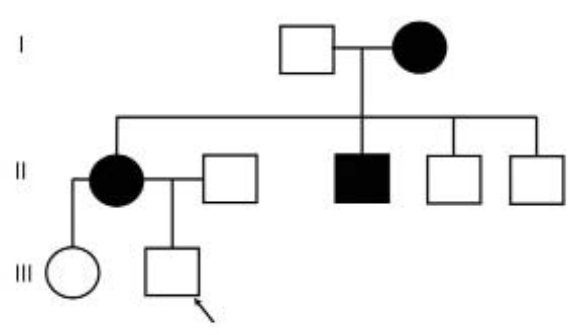

A
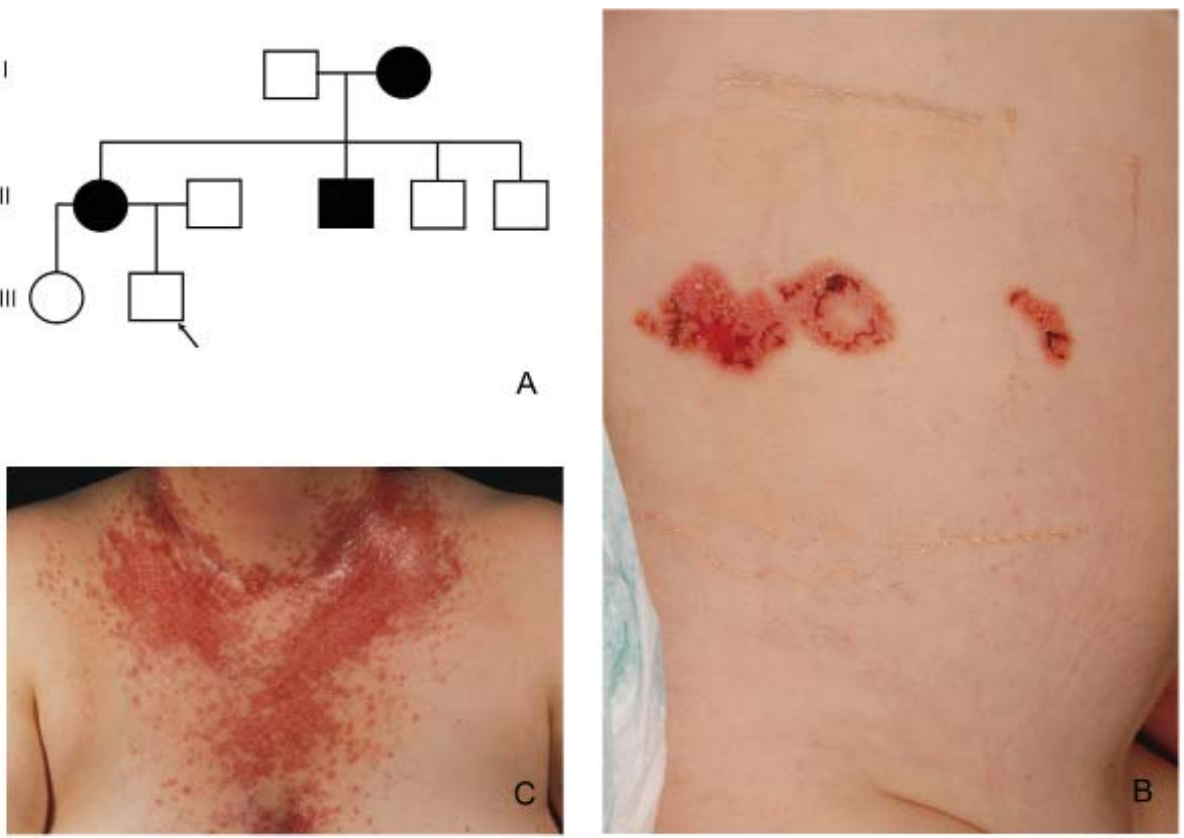

FIGURE 4.3 Clinical features of type II segmental Darier disease.

a. Pedigree of the family with Darier disease (DD). The index patient (individual III-2) is indicated with an arrow. His mother, maternal uncle and grandmother (individuals II-1, II-2 and I-2, respectively) were diagnosed with DD. b. Sharply demarcated erosive plaques confined to the right side of the index patient's trunk and abdomen. c. Warty papules and plaques in the seborrhoeic areas of the trunk in the index patient's grandmother.

primers amplifying the entire coding region and adjacent splice sites of the ATP2A2 gene (primer sequences and annealing conditions available from the authors upon request). Direct sequencing in the index patient and his mother revealed a sequence deviation in exon 8, c.1030G $>\mathrm{A}$, that is predicted to cause substitution of a glycine by an aspartate residue, designated p.(Gly343Asp) (figure 4.4; mid panel). This novel missense mutation creates a new cleavage site for the restriction endonuclease EcoRI. Restriction analysis of the PCR product containing exon 8 of the ATP2A2 gene performed in 100 ethnically matched control individuals indicated that p.(Gly343Asp) is not a common polymorphism (data not shown).

The parents of the index patient consented to a $3 \mathrm{~mm}$ biopsy of the segmentally affected skin for diagnostic purposes. Thus, we were not able to obtain further material for in-depth molecular studies or cell culture as previously performed in Hailey-Hailey 

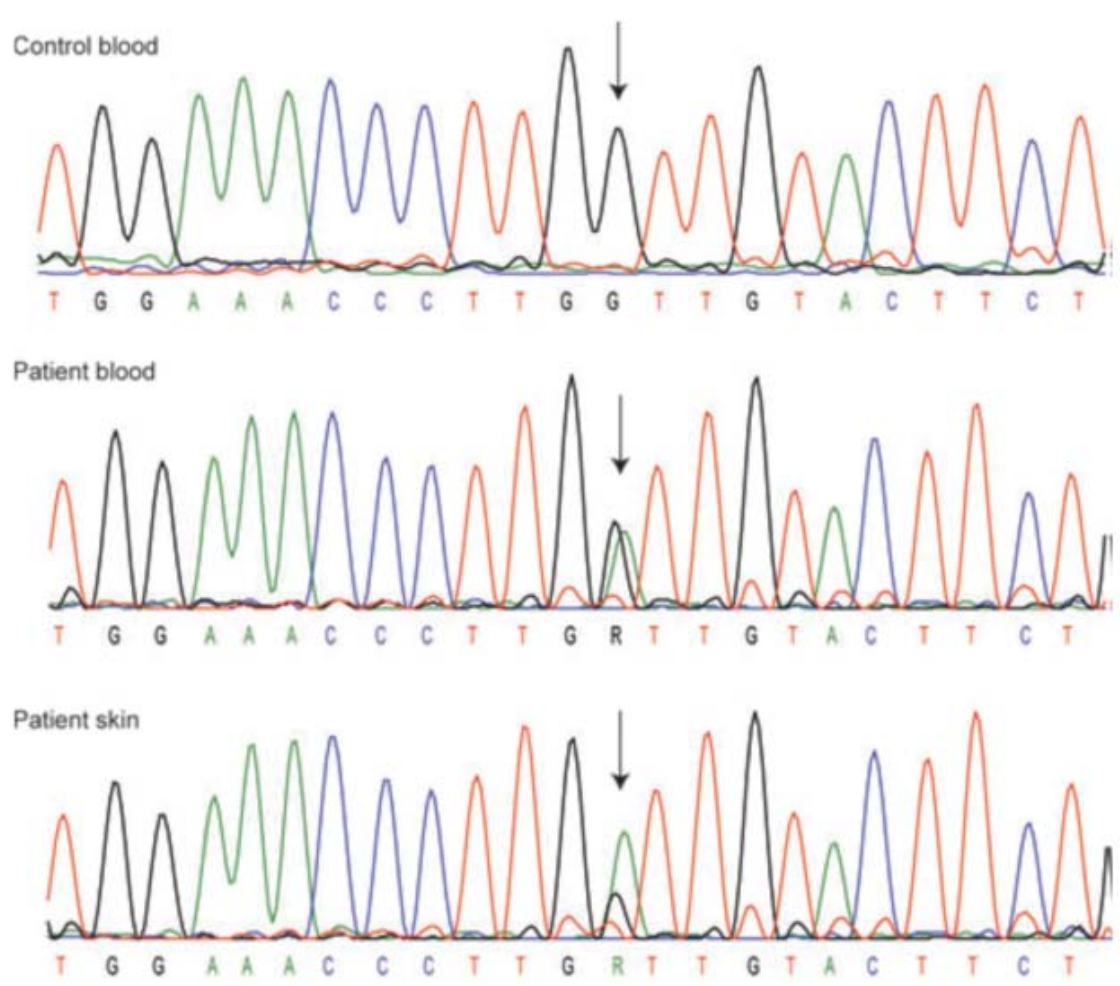

FIGURE 4.4 Results of mutation analysis in individual III-2 with type II segmental Darier disease. In the top panel, the wild-type sequence is depicted. The middle panel shows the germline mutation p.(Gly343Asp) in exon 8 of the ATP2A2 gene that consists of a G>A transition, indicated by an arrow. The bottom panel reflects the result of mutation analysis in paraffin-embedded epidermal tissue from a segmental plaque obtained by laser-captured microdissection. Note the overrepresentation of the mutated A-allele whereas the wild-type G-signal is markedly reduced, compared with the germline mutation (top panel) and the heterozygous germline mutation (middle panel).

disease $^{22}$. Following routine diagnostic microscopy, we isolated DNA from the paraffin embedded tissue by laser assisted microdissection using the PALM Robot MicroBeam system (PALM GmbH, Munich, Germany) and the QIAamp DNA FFPE Tissue kit according to the manufacturer's instructions.

In the PCR product of exon 8 of the ATP2A2 gene derived from the paraffin material we saw a marked decrease of the wildtype G-signal when compared to the heterozygous germline mutation (figure 4.4; bottom panel), indicative of $\mathrm{LOH}$. To further characterize the nature of $\mathrm{LOH}$, we performed haplotype analysis using microsatellite markers D12S1339 and D12S1343, flanking a chromosomal region of approximately 
$6 \mathrm{Mbp}$ harboring the ATP2A2 gene. This experiment did not reveal marker loss (data not shown). Subsequently, we excluded a second somatic mutation by direct DNA sequencing analysis. Unfortunately, we were not able to elucidate the precise mechanism of $\mathrm{LOH}$ in our patient because there was not enough tissue material.

Our results indicate loss of the wildtype ATP2A2 allele in the segmentally affected skin region. Presumably, the $\mathrm{LOH}$ region on chromosome 12 is not bigger than $6 \mathrm{Mbp}$, because we found both the centromeric marker D12S1339 and the telomeric marker D12S1343 in the diploid state.

The possible mechanisms of $\mathrm{LOH}$ in this patient remain unclear. Both somatic deletion of a small DNA fragment containing the coding sequence of the ATP2A2 gene and gene conversion could account for a decrease of the wildtype signal in the DNA electropherogram, reflecting either a hemizygous or homozygous state of the mutation $^{27,28}$. Deletion of a fragment smaller than exon 8 presumably would have resulted in a frameshift that we could have detected in the electropherogram. Interestingly, the wildtype G-signal was not completely absent in the electropherogram. Thus it is tempting to hypothesize that $\mathrm{LOH}$ could also be the result of postzygotic crossing-over. This would give rise to two different daughter cells, one of them being homozygous for the underlying mutation, whereas the other cell would be homozygous for the wild-type allele, which could account for the still detectable wildtype signal ${ }^{29}$. As the DNA extracted from the biopsy specimen necessarily may contain material from cells of different lineages and, possibly, disease status, the presence of the wild-type allele in the skin sample has no influence on the likelihood of any of the three mechanisms of LOH proposed by us. Although our results do not provide unequivocal molecular proof of the concept of type II segmental involvement in the patient described here, they are compatible with the assumption of an early postzygotic event of LOH that may have originated at the ATP2A2 locus from various postzygotic mechanisms such as deletion, gene conversion or crossover. The clinical features noted in this case in the form of a segmental and rather pronounced involvement manifesting shortly after birth, the occurrence in a family with classic DD and the histological findings may be taken as indirect supporting evidence in favour of the proposed aetiological concept of type 2 mosaicism. 


\subsubsection{Discrete phenotype in a DD patient with skin type $V$}

Most clinical reports on DD patients describe the classical features of DD in patients of white descent (Fitzpatrick skin type I-III) (selection of references ${ }^{4,6,14,30,31}$ ) and Far Eastern Asians (Chinese, Taiwanese or Japanese, Fitzpatrick skin type IV) (idem ${ }^{32-34}$ ). Patients of Indian (Fitzpatrick type V) or African origin (Fitzpatrick type VI) are more likely to develop leukoderma guttata than classic DD and are hardly described in the literature ${ }^{34,35}$. We believe this apparent lack of reports is due to a much subtler disease course in patients with skin types V and VI. We illustrate this hypothesis with the following case report of a Singalese patient with DD.

Our 25-year-old female index patient, born in Sri Lanka, developed a diffuse palmoplantar keratoderma during childhood. During puberty, she noted the gradual occurrence of small papules on her trunk. Her mother, half-brother and half-sister developed similar features in the second decade of life. Only the index patient was available for clinical and molecular studies. Clinical examination revealed a diffuse palmoplantar keratoderma with palmar pits. We noted V-shaped notches and longitudinal white bands in two finger nails and flat, skin-coloured papules on the dorsum of her hands. On her trunk we found a small number of discrete, disseminated, slightly pigmented papules and depigmented macules 5-7 mm in diameter (figure 4.5ad). Histologic examination of a skin biopsy taken from one of the papules on the trunk showed hyperkeratosis, acantholysis of the epidermis and multiple dyskeratotic cells (figure 4.5e). Based on these findings, we diagnosed the patient with DD. Our clinical diagnosis was confirmed by mutation analysis of the ATP2A2 gene. We found a novel missense mutation c.1769T $>C$, which is predicted to lead to an amino acid substitution p.(Leu590Pro) in the ATP binding region of SERCA2 (figure 4.6a). The leucine residue is highly conserved between species but also among other SERCA proteins (figure 4.6b). This highly conserved region is necessary for protein conformational change upon ATP binding and $\mathrm{Ca}^{2+}$ release into the ER lumen after ATP hydrolysis. We did not find the mutation in 50 ethnically matched controls.

It is tempting to speculate on the possible mechanisms underlying the mild phenotype of our patient. The observed clinical picture could be an example of the normal variability of symptoms in $\mathrm{DD}^{1}$. The phenotype of our patient, especially the flat-topped, skin-coloured papules on the dorsa of the hands, is reminiscent of AKV. This will be further discussed in paragraph 4.5.1. However, the relatively indolent course of DD in 

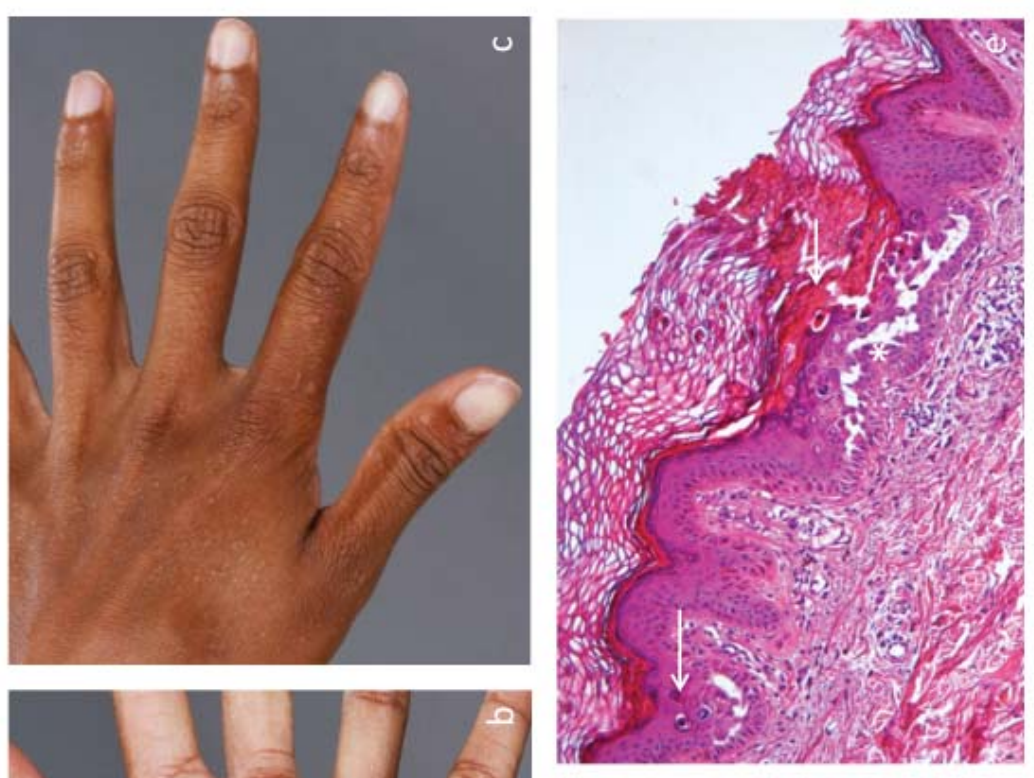

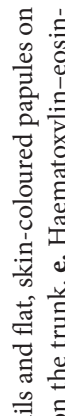

클

范惑

灵

药

$\Xi \Xi$

青趻

震

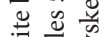

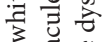

สี

콜

क्.

도을

चี 흠

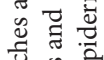

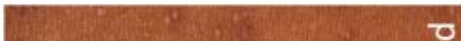

\%

웡

言焉

要

它氙

荘的喆

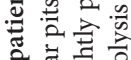

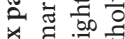

击

$\exists$ तैं

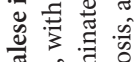

जี हี

需

प च

范

可

\&

吾证

递安

नี एี

芢 氜 氙

0 : के

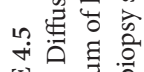

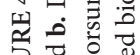

它 웡

的管 

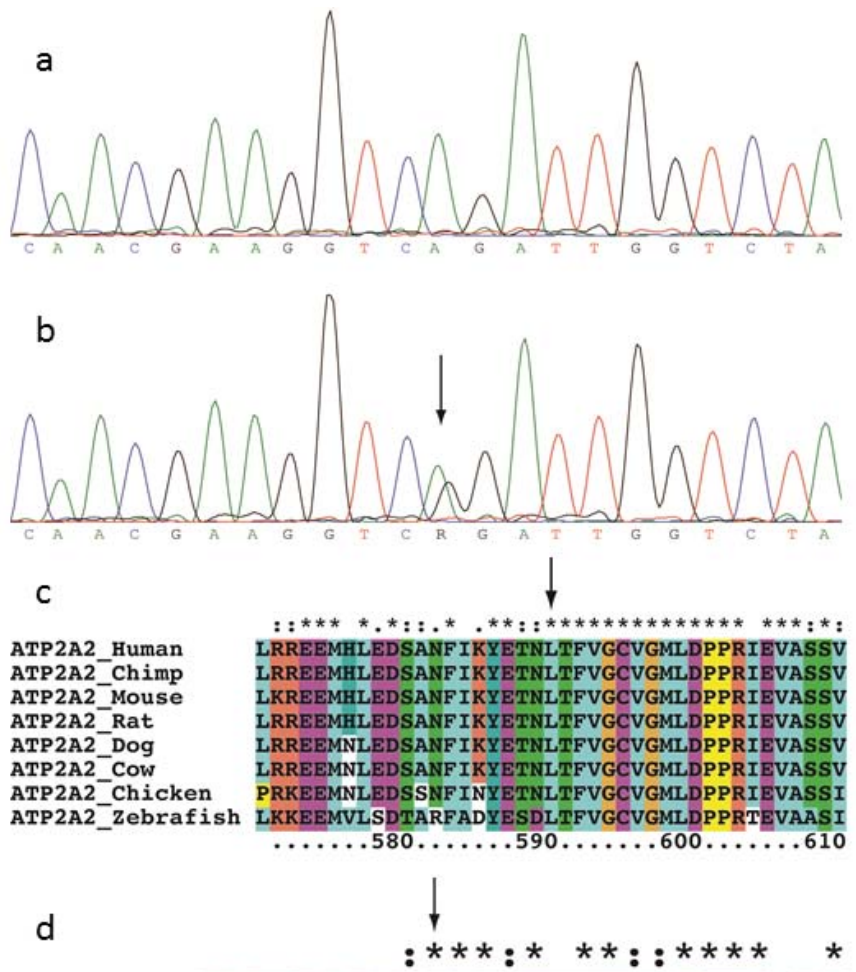

ATP2A1 ARFLEYETDLTFVGVVGMLDPPRKEV ATP2A2 ANFIKYETNLTFVGCVGMLDPPRIEV ATP2A3 SKFVQYETDLTFVGCVGMLDPPRPEV ATP2C1 --------QLTFLGLVGIIDPPRTGV

FIGURE 4.6 Sequence analysis and alignment in the Sinhalese index patient.

a. Sequence analysis of a healthy subject (top) and the index patient (bottom), showing the substitution c. $1769 \mathrm{~T}>\mathrm{C}$ (arrow) in the ATP2A2 gene. b. Alignment of amino acid sequence of the highly conserved ATP binding region and affected leucine (arrow) of SERCA2 and its analogues in other species and other human proteins of the SERCA family. This region is necessary for protein conformational change upon ATP binding and $\mathrm{Ca}^{2+}$ release into the ER lumen after ATP hydrolysis.

our patient, the absence of exacerbations and the non-development of "classic" warty lesions caused by extensive dyskeratosis suggest other constitutional factors that make up for the consequences of the ATP2A2 mutation.

We think the skin type of our patient holds the key to the mild manifestation of the disease. First, DD can be exacerbated by the stress condition UVB-irradiation, mechanical trauma and infection. Skin types V-VI provide protection to UVB radiation, 
likely resulting in less UVB induced exacerbations of DD. Moreover, patients with darker skin types are at risk of developing Vitamin D3 deficiency and disrupted calcium physiology ${ }^{36}$. Although in vitro and in vivo data do not support this hypothesis ${ }^{37,38}$, it is possible that extracellular hypocalcemia may influence intracellular calcium homeostasis and alter the clinical features of DD. We do not think that our patient is less exposed to other external stressors (mechanical trauma, infection).

Second, the desmosomal adhesion of keratinocytes of DD patients with Fitzpatrick skin type $\mathrm{V}$ might differ from that of patients with skin type I-III. A larger number of desmosomes could lead to increased structural integrity of the epidermis and subsequent resistance to the negative effects of $A T P 2 A 2$ mutations. In support of this notion, the incidence of blistering diseases such as bullous pemphigoid, essentially a desmosomal disease, seems to be lower in patients from the Indian subcontinent ${ }^{39}$. However, we are unable to provide further data supporting this hypothesis.

In conclusion, we report a Sinhalese patient with $\mathrm{DD}$, with a relatively mild phenotype, caused by a novel missense mutation in the ATP $2 A 2$ gene. In contrast to the abundant reports on DD in patients with skin type I-IV, the literature on DD patients with skin type $\mathrm{V}$ is scarce. We suggest that this may be due to DD having a mitigated course in dark skin, leading to under-diagnosis.

\subsubsection{The neuropsychiatric phenotype in DD}

Several neuropsychiatric disorders such as depression, bipolar disorder, schizophrenia, epilepsy and learning disabilities, have been thought to be more prevalent in DD patients $^{40-42}$. Given the fact that $A T P 2 A 2$ is expressed in brain neurons ${ }^{1,43}$, a relation between ATP2A2 variants and neuropsychiatric disease seems plausible. In the most comprehensive study to date, DD patients were found to have high lifetime prevalence rates of depression (30\%), bipolar disorder (4\%), suicide attempts (13\%), suicidal thoughts $(31 \%)$ and epilepsy (3\%) compared with the general population ${ }^{41}$. Similar prevalence rates were found in a recent study of DD in Israel ${ }^{44}$. In a matched cohort study in 770 Swedish DD patients, DD patients had a six-fold increased risk of having intellectual disability ( $2 \%$ of DD patients), a four-fold increased risk of developing bipolar disorder (2\% of DD patients) and a two-fold increased risk of being diagnosed with schizophrenia ( $1 \%$ of DD patients) compared to matched controls from the general population $^{45,46}$. However, other studies did not find this correlation ${ }^{47}$. It is interesting 
to note that there are only incidental reports on HHD associated with depression and bipolar disorder ${ }^{48-50}$. HHD has not been linked to any other specific neurologic, cognitive or psychiatric problems, although ATP2C1 is expressed in brain neuronal cells ${ }^{2,51,52}$.

It remains difficult to establish a causal relationship between $A T P 2 A 2$ variants and any associated neuropsychiatric phenotype. There are no pathological mechanisms explaining the occurrence of these symptoms in individuals with DD, although there is experimental evidence that implies a role for (aberrant) calcium signaling in the development of bipolar disorder, schizophrenia and intellectual disability ${ }^{46}$. Furthermore, psychological disorders can be the result of having a chronic skin disease. The latter seems to be a more likely explanation for the occurrence of depression and depressive symptoms in DD. Lifetime depression prevalence in DD is not remarkably different from psoriasis or other chronic diseases ${ }^{53}$ (5.4\% for clinical depression, $22.9 \%$ for depressive symptoms in $\mathrm{DD}^{44}$, vs. $10 \%$ and $28 \%$ in psoriasis, respectively), suggesting that having a chronic, extensive and debilitating skin disease is the major determinant of mood disorders in DD. Therefore, one can assume that a large percentage of DD patients would have developed depressive symptoms, regardless of their ATP2A2 mutation status. One study states that depressive symptoms are not the result of the psychological effect of having a chronic skin disease, since this variable does not correlate well with disease severity ${ }^{44}$. However, there are no reliable measures to quantify disease severity and disease course in DD and therefore, the data presented in this study merely represents an assumption of DD severity. Moreover, in psoriasis, the occurrence of depressive symptoms is not correlated with PASI scores ${ }^{53}$. The latter observation indicates that having a chronic skin disease is more important in developing depression than the extent of the disease. The data presented by Dodiuk-Gad et al. ${ }^{44}$ do not, in our view, warrant a different conclusion for DD.

We therefore believe that the role of ATP2A2 variants in the development of psychiatric disease in DD remains uncertain. Nonetheless, psychiatric problems clearly are an important aspect of DD. This warrants the need for adequate psychiatric care and neuropsychological evaluation for cognitive symptoms such as learning difficulties for DD patients. There are some excellent examples of integrated care in psoriasis ${ }^{54}$ and for chronic physical conditions in general $^{55}$. This may be the way forward to more effective treatment of psychiatric disorders in DD. 


\subsection{Variants}

\subsubsection{Methods of mutation detection and literature search}

Patients were either referred for clinical and molecular evaluation to our outpatient clinic for genetic skin disorders, or DNA was sent to our department/laboratory after the diagnosis of DD or HHD had been made elsewhere. The described individuals originated from the Netherlands, Germany, Austria, Belgium, Cyprus, Finland, Norway and the UK. Patients were diagnosed based on clinical and histological features, either in our department or by the referring dermatologist. When DNA was sent for molecular analysis, referring physicians were asked to provide data on clinical symptoms. For DD, phenotypes were classified as "mild", "moderate" or "severe" when clinical data was available. Mild DD was defined as sparsely distributed keratotic papules on predilection areas, moderate DD as extension of symptoms beyond predilection areas. Patients with widespread hypertrophic patches or vegetating flexural disease were considered to have severe $\mathrm{DD}^{4,56}$. For $\mathrm{HHD}$, such criteria have not been developed. We classified patients with mild disease when relatively mild symptoms such as superficial blistering and erythema developed and only flexural areas were affected, moderate disease when symptoms such as hyperkeratotic patches developed and severe disease when symptoms extended to other parts than flexural areas.

Mutation analysis was performed on DNA derived from peripheral blood leucocytes using standard procedures ${ }^{57}$. We performed polymerase chain reaction (PCR) to amplify all exons and flanking intron boundaries of ATP2A2 or ATP2C1. PCRproducts were analysed by direct sequencing (Big Dye Terminator Sequence Kit) using standard protocols. Sequences were evaluated and compared with the reference sequence (ATP2A2: NM_001681.3 and NM_170665.3, ATP2C1:NM_014382.3) using the Mutation Surveyor DNA Variant Analysis Software version 4.0 (SoftGenetics LLC, USA). The nomenclature standards of the Human Genome Variation Society (HGVS) were used for designation on the nucleotide and protein level; additionally the denomination of mutations was verified using Mutalyzer 2.0.beta-21 (https://mutalyzer. $\mathrm{nl} /)^{58,59}$. Pathogenicity of all variants was checked with Alamut Visual Version 2.7.1, a software tool which integrates pathogenicity prediction (Align GVGD, MutationTaster, PolyPhen-2, SIFT) and in silico prediction of hypothesized splice site mutations, (SpliceSiteFinder-like, MaxEntScan, NNSPLICE, GeneSplicer, Human Splicing Finder). 
Protein alignment was created using ClustalW2 (http://www.ebi.ac.uk/Tools/msa/ clustalw2/) and BLOSUM62- Matrix.

In one DD patient, in whom we did not find an ATP2A2 variant using the aforementioned methods, we performed RNA analysis (see also paragraph 4.5.3).

\subsubsection{Database}

We created a locus specific database (LSDB) in the Leiden Open Variation Database (LOVD) for each gene (ATP2A2: http://lovd.nl/ATP2A2; ATP2C1: http://lovd.nl/ ATP2C1, figure 4.7a and 4.7b: QR codes for quick access to the database). We recorded all previously published mutations after we performed a literature search for patients with DD or HHD in whom a variant in the corresponding gene had been reported. We recorded $A T P 2 A 2$ or ATP2C1 genotypes and geographic details from the original publications when data were available. We adjusted the nomenclature of certain variations in older reports to be concordant with the current ATP2A2 and ATP2C1 cDNA reference sequence (ATP2A2: NM_001681.3 and NM_170665.3, ATP2C1: NM_014382.3). Reported variations were classified by mutation type according to predicted amino acid sequence changes: missense or nonsense variations, duplications, insertions and/or deletions and intronic mutations leading to alternate splicing.

To check whether the variants found in our own cohort were unique, the results were compared with the data in the LSDBs for ATP2A2 and ATP2C1. Two patients had been previously reported by our group (indicated in the results table).

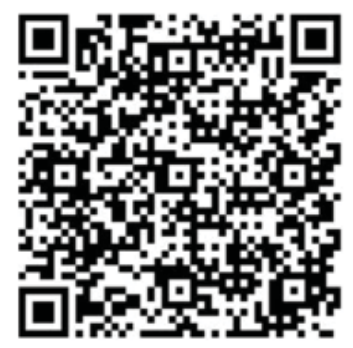

a: $A T P 2 A 2$

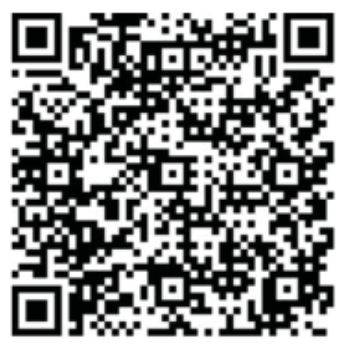

b: $A T P 2 C 1$

FIGURE 4.7 QR-code for URL and direct access to the Locus Specific Database of a: ATP2A2 and b: ATP2C1. 


\subsubsection{ATP2A2}

The ATP2A2 gene is located on chromosome 12q24.11. The coding region spans $64 \mathrm{~kb}$ and consists of 20 or 21 exons, depending on the isoform. Alternative splicing of the primary mRNA transcript in the $3^{\prime}$ region yields four different tissue-specific isoforms of SERCA2 ( $\mathrm{a}-\mathrm{d}$ ). Isoform 2a is mainly expressed in the sarcoplasmatic (SR) reticulum of heart muscle, slow-twitch skeletal muscle and smooth muscle. Isoform $2 b$ is found in the endoplasmatic reticulum (ER) of all non-muscle cells, particularly in keratinocytes, isoform $2 \mathrm{c}$ in the SR of heart muscle and ER of haematopoietic cells and isoform $2 \mathrm{~d}$ in muscle cells ${ }^{1,43,60}$. The secondary structure of SERCA2 is homologous to SERCA $1^{61}$ and consists of four major domains: a transmembrane $(\mathrm{M})$ domain, composed of 10 (SERCA2a) or 11 (SERCA2b) transmembrane helices, and three cytosolic domains: the actuator $(\mathrm{A})$ and the phosphorylation $(\mathrm{P})$ domain, both connected to the transmembrane and the nucleotide-binding $(\mathrm{N})$ domain, connected to the $\mathrm{P}$ domain. The two $\mathrm{Ca}^{2+}-$ binding sites are located in the M domain. The ATP-binding site is located in the $\mathrm{N}$ domain $^{1,62,63}$.

\subsubsection{Novel mutations in ATP2A2}

We analysed 80 patients with DD, 40 of whom were sporadic while 39 patients had a positive family history. Of these familial cases, we had only the index patients available for analysis in 20 families. In the other 7 families, a total of 20 family members with DD were analysed. Three patients were thought to have type I segmental DD. Variants are summarised in table 4.1 and figure $4.8 \mathrm{a}$.

In the 80 patients with DD, we found 43 different mutations in 60 patients (75\%). In the 40 sporadic patients analysed, 24 different mutations in 28 patients were found, and no ATP2A2 mutations in 12 sporadic DD patients. De novo inheritance was demonstrated in 4 sporadic DD patients. In the 20 index patients with a positive family history, we found 13 unique mutations in 15 patients, and no variants in 4 patients. In the 7 families with DD, we found 5 different ATP2A2 variants in 6 families with 16 patients and did not find variants in one family with 4 patients. All affected members within the same family harbored the same mutation. In three families, four unaffected family members were available for analysis. We did not detect ATP2A2 mutations in these individuals. We did not find germline mutations in the patients with segmental disease. Mutation analysis on affected skin from these patients was not performed, since 
CHAPTER 4 DARIER DISEASE AND HAILEY-HAILEY DISEASE

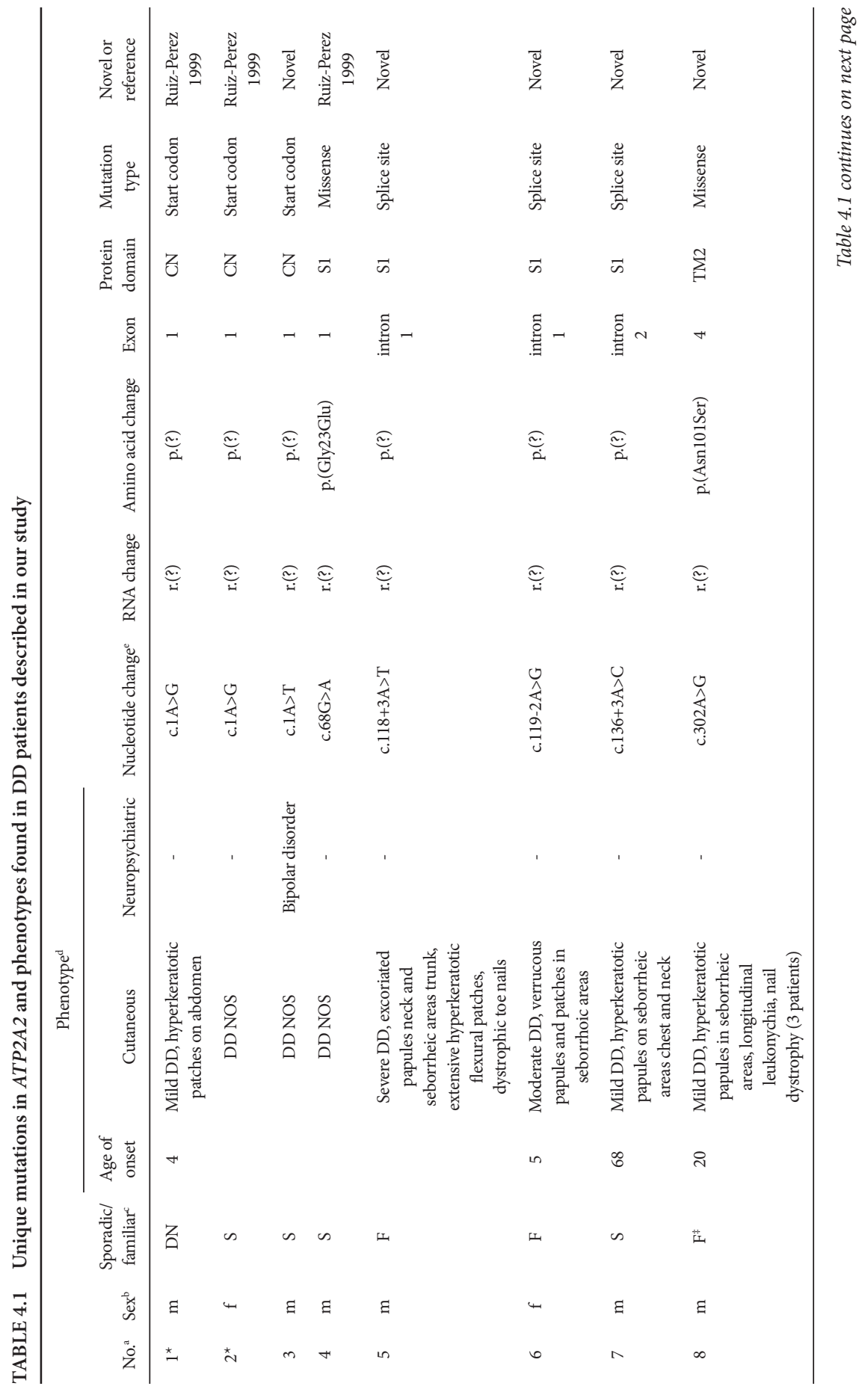




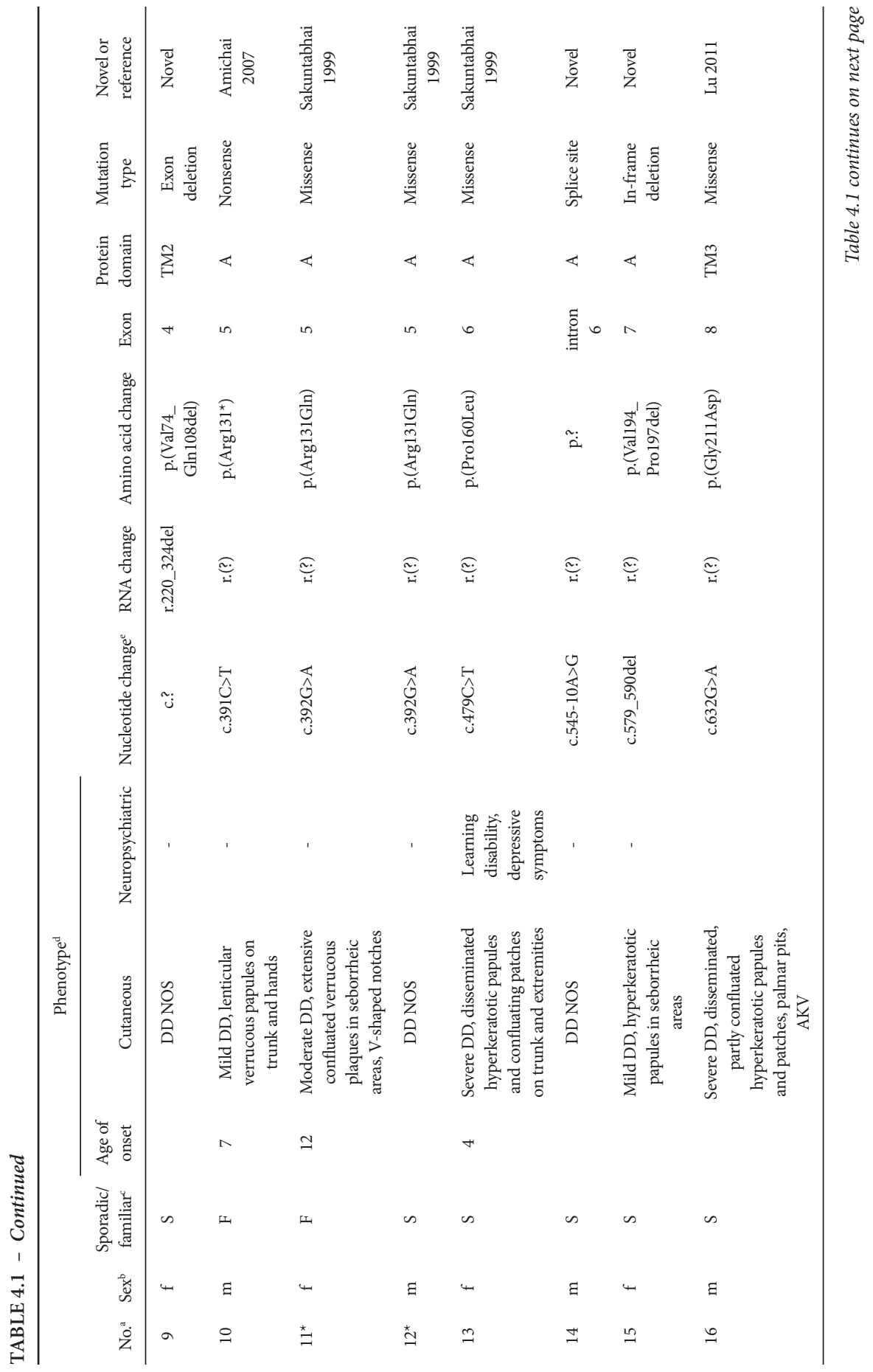




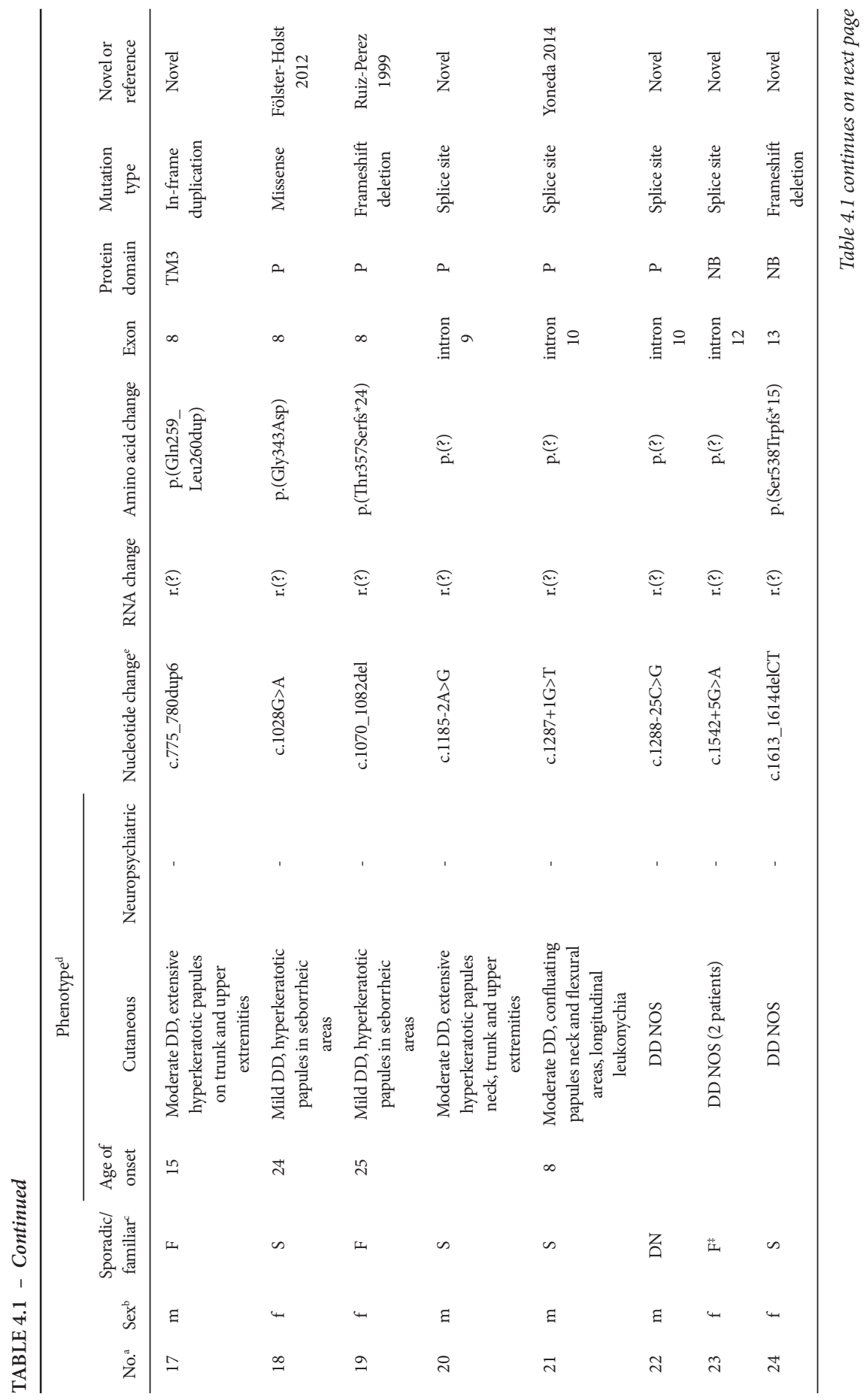




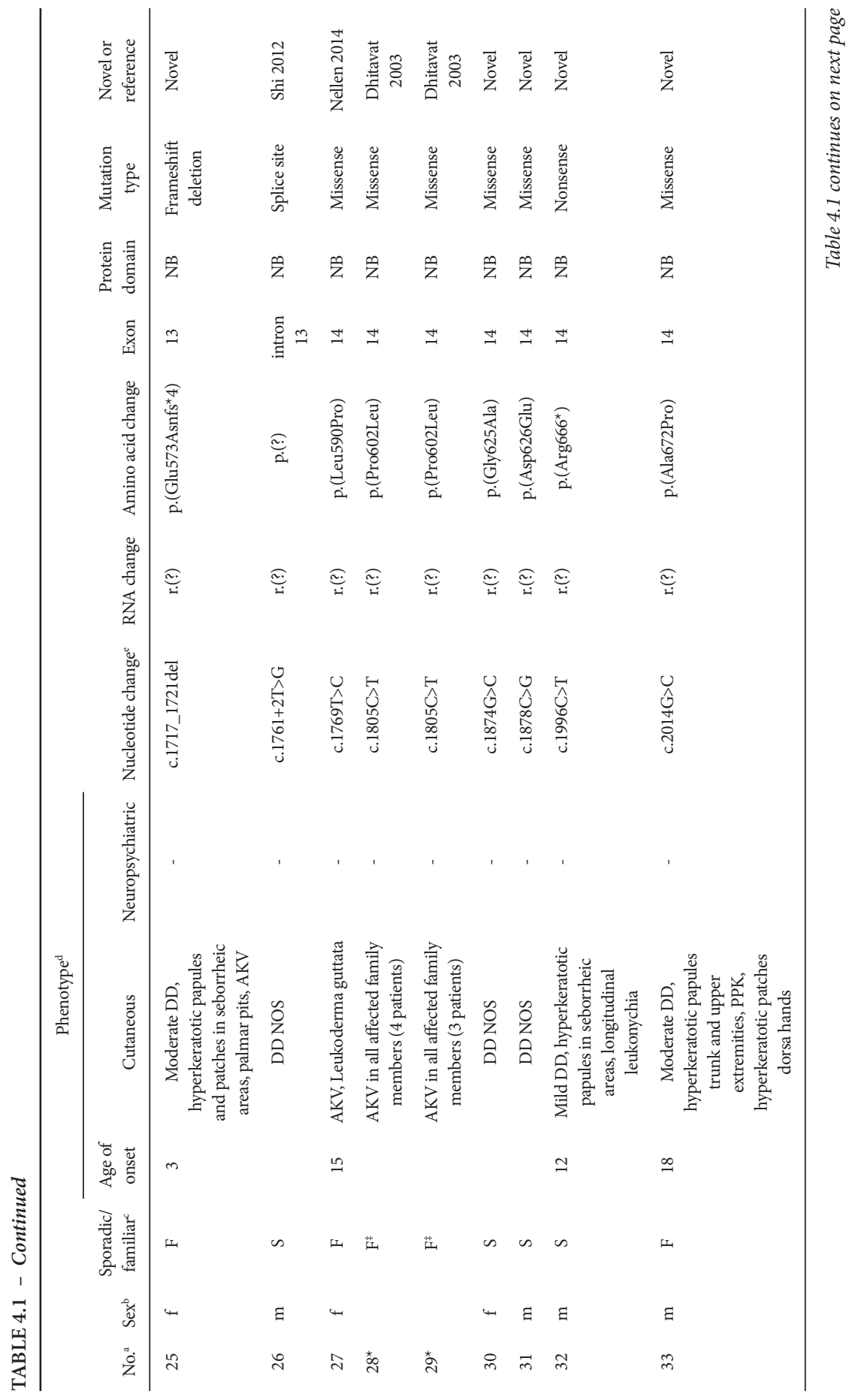




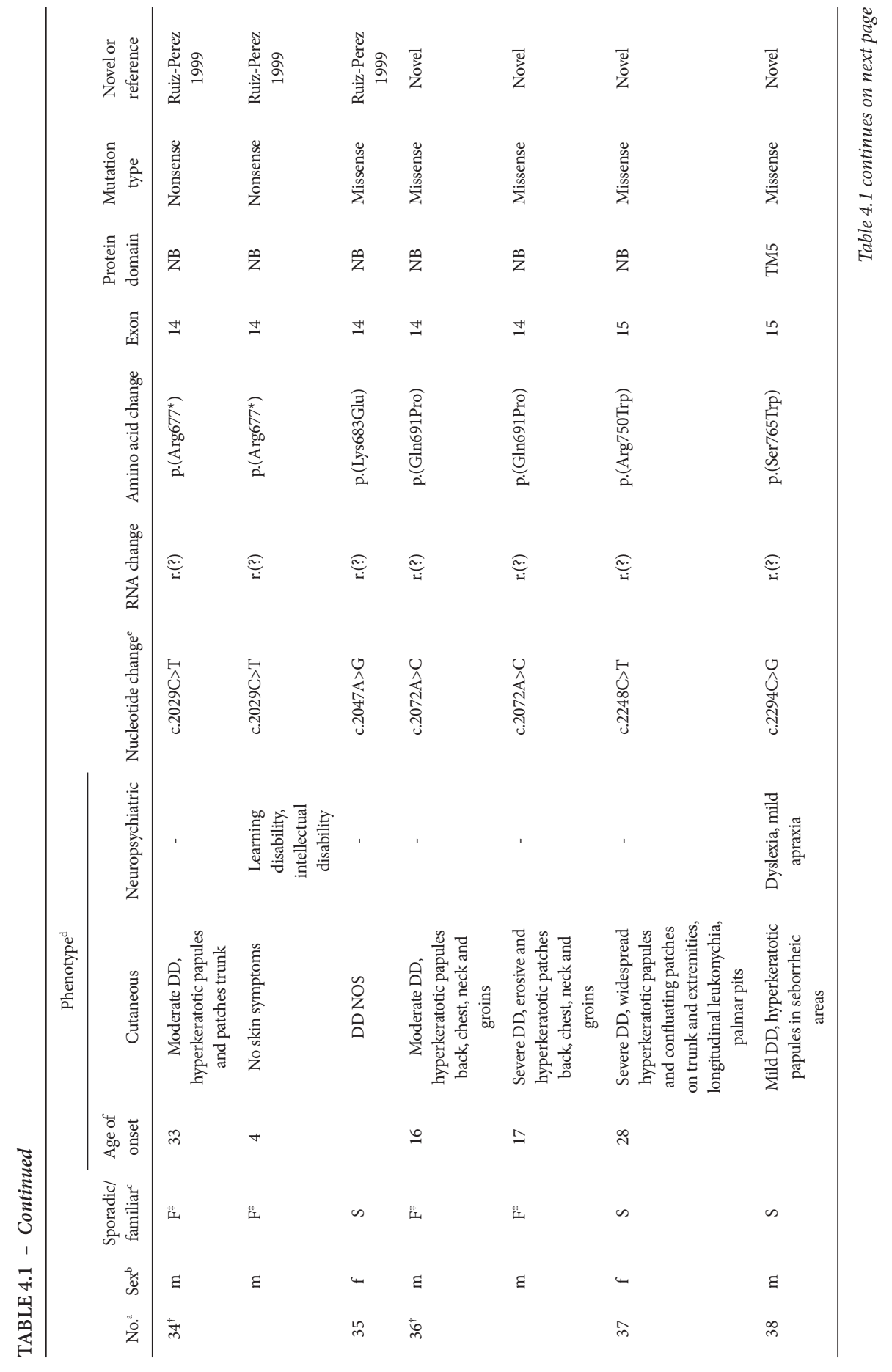


CHAPTER 4 DARIER DISEASE AND HAILEY-HAILEY DISEASE

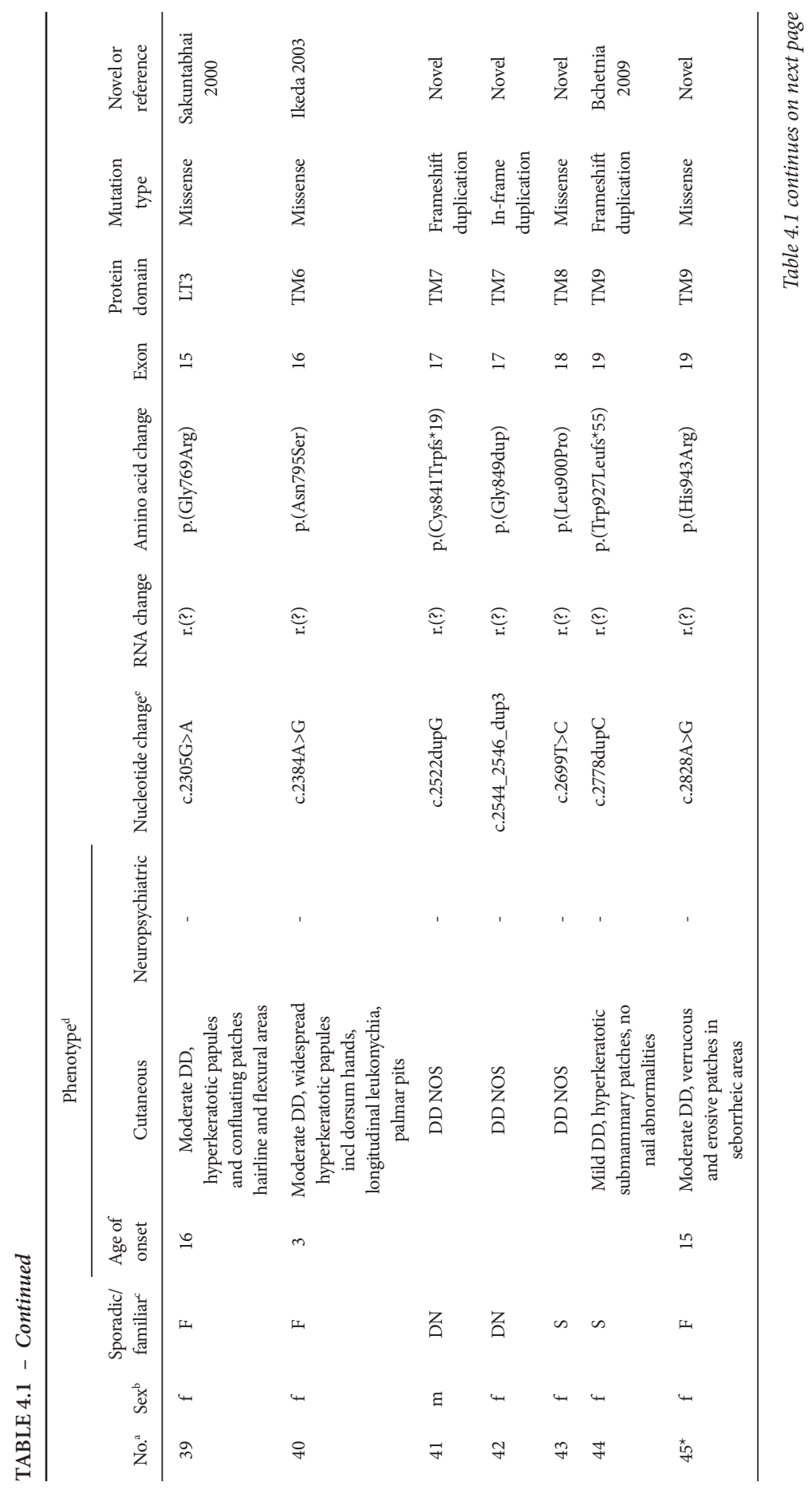




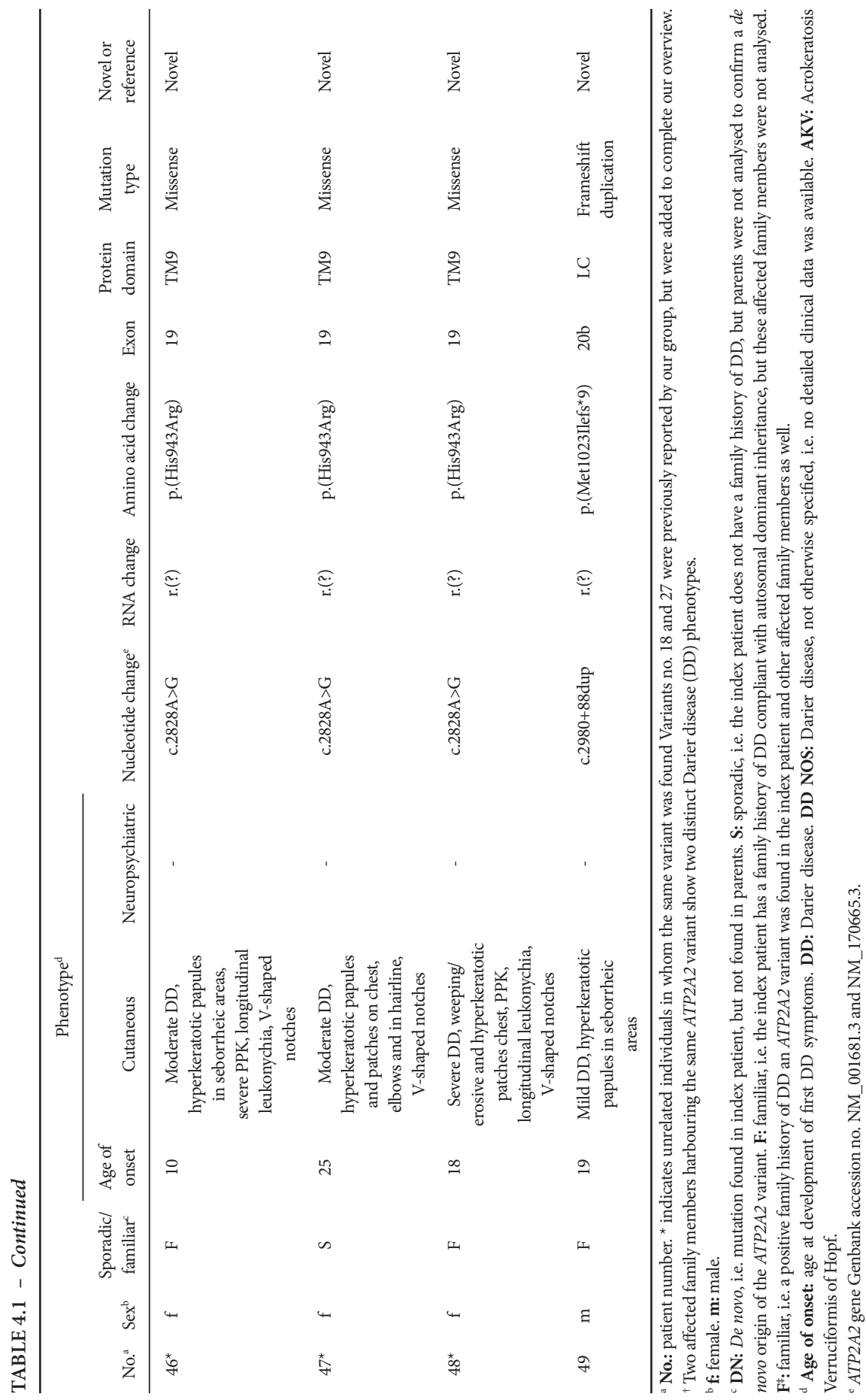



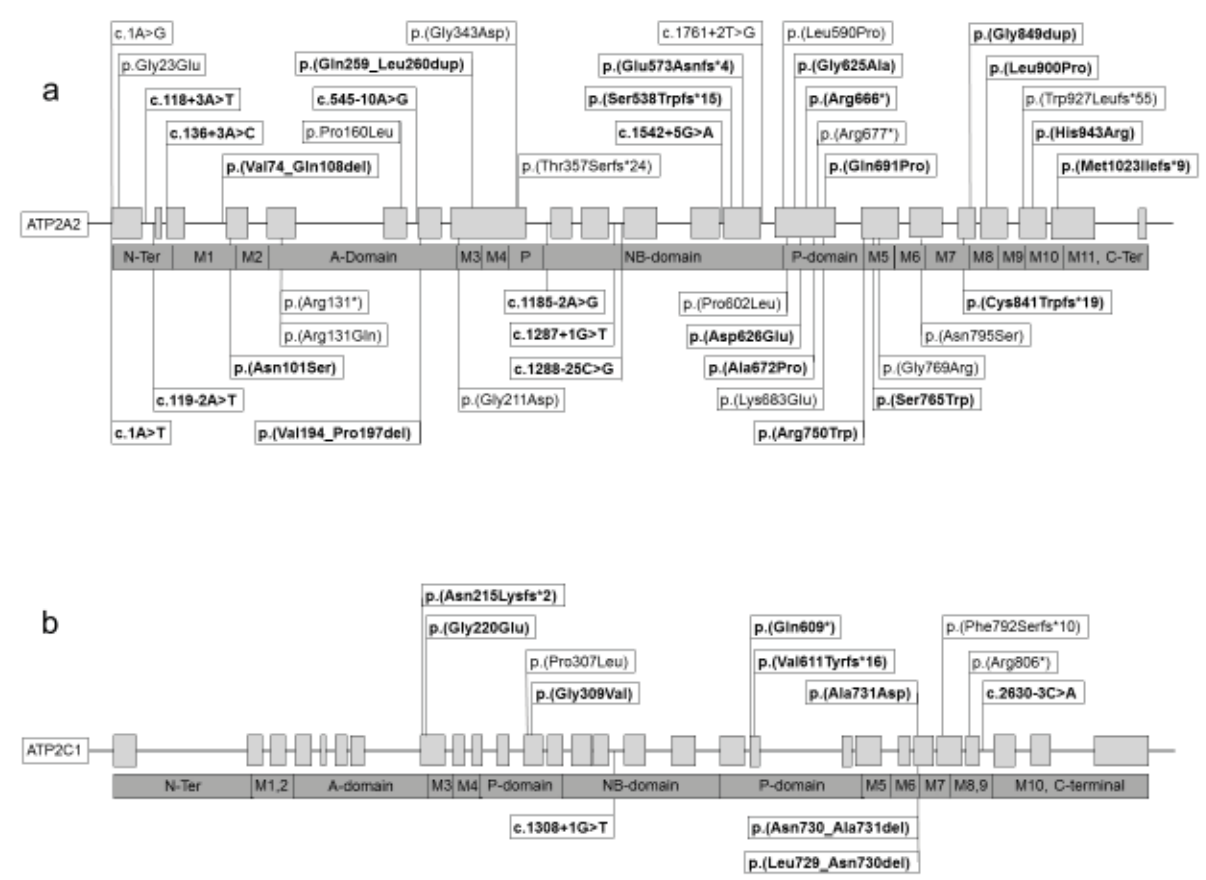

FIGURE 4.8 Novel variants in ATP2A2 and ATP2C1.

a. Schematic representation of the coding sequence of $A T P 2 A 2$ with the variants found in our DD patient sample shown. Bold markings denote novel variants.

b. Schematic representation of the coding sequence of ATP2C1 with the variants found in our HHD patient sample shown. Bold markings denote novel variants.

no material was available for further analysis. We found 22 (51\%) missense and 3 (7\%) nonsense mutations, 3 (7\%) frameshift deletions, 3 (7\%) frameshift duplications, 1 (2\%) in-frame deletion, $2(5 \%)$ in-frame duplications and $9(21 \%)$ splice site variants. In one DD patient in whom no ATP2A2 mutation was found, RNA analysis showed deletion r.220_324del, which is predicted to lead to deletion of exon 4 (p.(Val74_Gln108del)). We did not find mutations in the introns flanking exon 4, however. All variants were identified as either "pathogenic" or "likely to be pathogenic" by analysis with Alamut ${ }^{64}$. Of the 43 unique mutations found in our patients, 24 variants were not found in the literature and can thus be considered as novel.

All mutations found are scattered throughout the sequence of ATP2A2, in accordance with other studies. For three novel mutations (c.1A>T, c. $1761+2 \mathrm{~T}>\mathrm{G}$, c. $2699 \mathrm{~T}>\mathrm{C}$ (p.(Leu900Pro))), different variants at the same position were described previously 
(c.1A>G, c.1761+2T>C, c.2699T>G (p.(Leu900Arg)), respectively) ${ }^{6,65-69}$. We found c. $1 \mathrm{~A}>\mathrm{G}$ in two of our patients as well, so that mutations at position 1 have been described on six instances up to date $e^{6,66-68}$. Variant p.(His943Arg) in exon 19 was found in four unrelated individuals. We found 9 (24\%) unique variants in exon 14, which is slightly more when compared with data from the LOVD database $(24$ (10\%) unique mutations in exon 14). We think this distribution is a coincidence, since exon 14 is one of ATP2A2's largest exons $(336 \mathrm{bp})^{1}$.

\subsubsection{Reported variants in ATP2A2}

Since the first report of mutations in ATP2A2 in 1999, 253 unique variants have been found in 350 families or sporadic patients with DD (http://lovd.nl/ATP2A2, figure 4.7a). These include 118 missense and 20 nonsense mutations, 20 duplications, 9 insertions, 51 deletions, 27 splice site alterations and 3 insertion/deletion mutations. Variants are dispersed throughout the coding sequence. Relatively more variants are found in exon 8 and 14, the two largest exons of ATP2A2.

It is interesting to note that the most prevalent recurrent mutations in ATP2A2 are base substitutions resulting in missense mutations: c.2300A $>\mathrm{G} / \mathrm{p}$.(Asn767Ser), reported 12 times, c. $1 \mathrm{~A}>\mathrm{G}$ reported 6 times (including patients in current study), c.68G>A/p. (Glu23Gly), c.392G>A/p.(Arg131Gln), c.1484C>T/p.(Ser495Leu) and c.2047A>G/p. (Lys683Glu) and c.2104G>A/p. (Asp702Asn) reported 5 times and c.2249G>A/p. (Arg750Glu) reported 4 times $^{1,6,14,42,44,56,65-68,70-78}$. Furthermore, at amino acid positions 131 and 495, variants c.392G >T/p.(Arg131Leu) and c.1484C>A/p.(Ser495*) are reported as well ${ }^{67,79}$.

It remains unclear which mechanisms are responsible for the occurrence of these more prevalent variants. Most mutations occur de novo. Together with the widespread geographical distribution of the recurrent variants, this strongly argues against a founder effect. For instance, one Scottish and two unrelated Italian DD patients with the p.(Asn767Ser) variant all had different disease haplotypes were different, largely excluding a common ancestor for this mutation ${ }^{6}$. A founder effect for recurrent mutations in more homogenous populations cannot be completely ruled out (for instance, p.(His943Arg) in four Dutch (this study) and p.(Asn767Ser) in four British DD patients ${ }^{66}$ ).

The fact that all variants are base substitutions suggests a higher sensitivity for these alterations at these specific positions in the ATP2A 2 coding sequence. Experimental data 
suggests that mutation-generating mechanisms may not occur completely at random and are, for instance, dependent on specific DNA sequences ${ }^{80,81}$. Spontaneous $\mathrm{C}>\mathrm{T}$ or $\mathrm{G}>\mathrm{A}$ substitutions occur six- to sevenfold more often compared to the common base mutation rate due to methylation-mediated deamination of 5-methylcytosine in $\mathrm{CpG}$ dinucleotides ${ }^{81-84}$. Furthermore, the occurrence of $\mathrm{CpG}$ dinucleotide base pair substitutions depends on neighbouring base pairs. Especially TGCA and TCGG, but TCGC and CCGC tetranucleotides as well, were found to be more prone to mutation, although frequencies varied between different genes ${ }^{85,86}$. Studies on somatic

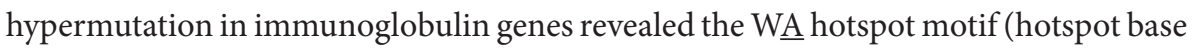
underlined, $\mathrm{W}=\mathrm{A}$ or $\mathrm{T}$ ), with a preferential DNA polymerase $\eta$-mediated incorporation of an $A>G$ in $66 \%$ of mutations ${ }^{86,87}$.

Variants c.392G>A/p.Arg131Glu, c.1484C>T/p.(Ser495Leu), c.2104G>A/p. (Asp702Asn) and c.2249G>A/p.(Arg750Glu) were associated with CG dinucleotides and TGCA, TGCG, TCGC and CCGC tetranucleotides in the ATP2A2 coding sequence (see table 4.3). In variants c.2047A>G/p.(Lys683Glu) and c.2300A>G/p.(Asn767Ser), an adenosine base within the context of an AA motif is substituted with a guanine (see table 4.3). Thus, context-specific hypermutability of certain hotspots may be an explanation for the high prevalence of the aforementioned mutations, although the occurrence of mutation hotspots is dependent on a large number of other factors ${ }^{80}$.

\subsubsection{ATP2C1}

The ATP2C1 gene is located on chromosome 3q22.1, spans $166 \mathrm{~kb}$ and consists of 28 exons. Currently, four ATP2C1 mRNA isoforms are known $(1 \mathrm{a}-\mathrm{d})^{3,88}$. The encoded protein, SPCA1, is expressed predominantly in keratinocytes, skeletal and heart muscle, brain tissue and kidney. It localises to the Golgi apparatus ${ }^{2,51,52}$. The primary structure of SPCA1 shares $37 \%$ homology with SERCA2 ${ }^{3}$. Comparable to SERCA2, SPCA1 contains an actuator $(\mathrm{A})$, nucleotide-binding $(\mathrm{N})$, and phosphorylation $(\mathrm{P})$ domain extending into the cytosol, and 10 hydrophobic transmembrane helices (M1-M10) ${ }^{89}$.

\subsubsection{Novel mutations in ATP2C1}

We analysed 20 patients with HHD, 6 of which were sporadic cases, 14 had a positive family history of HHD. Of the familial cases, 12 index patients were available for analysis. We analysed one family with two HHD patients. In the 20 patients with HHD, we found 


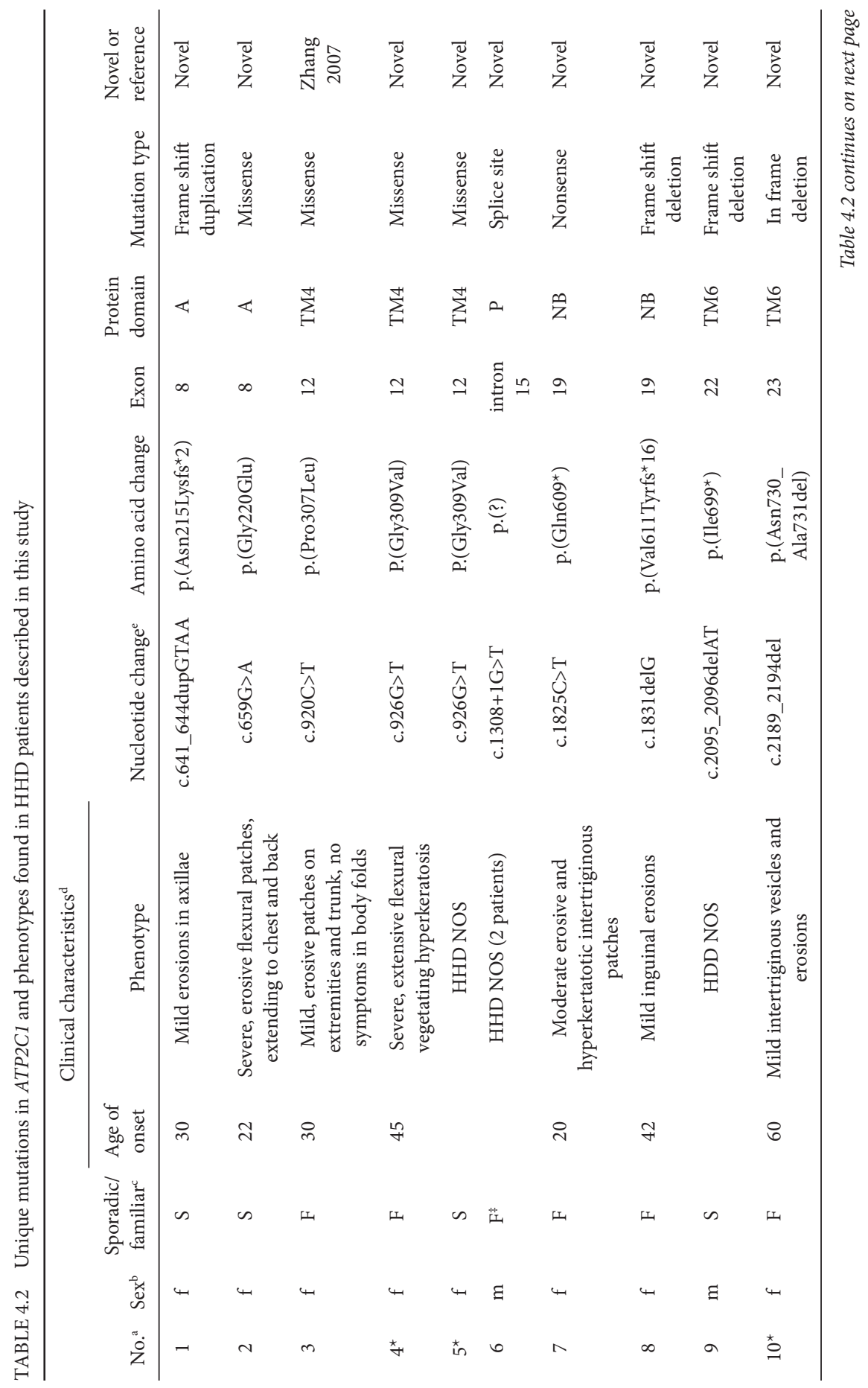




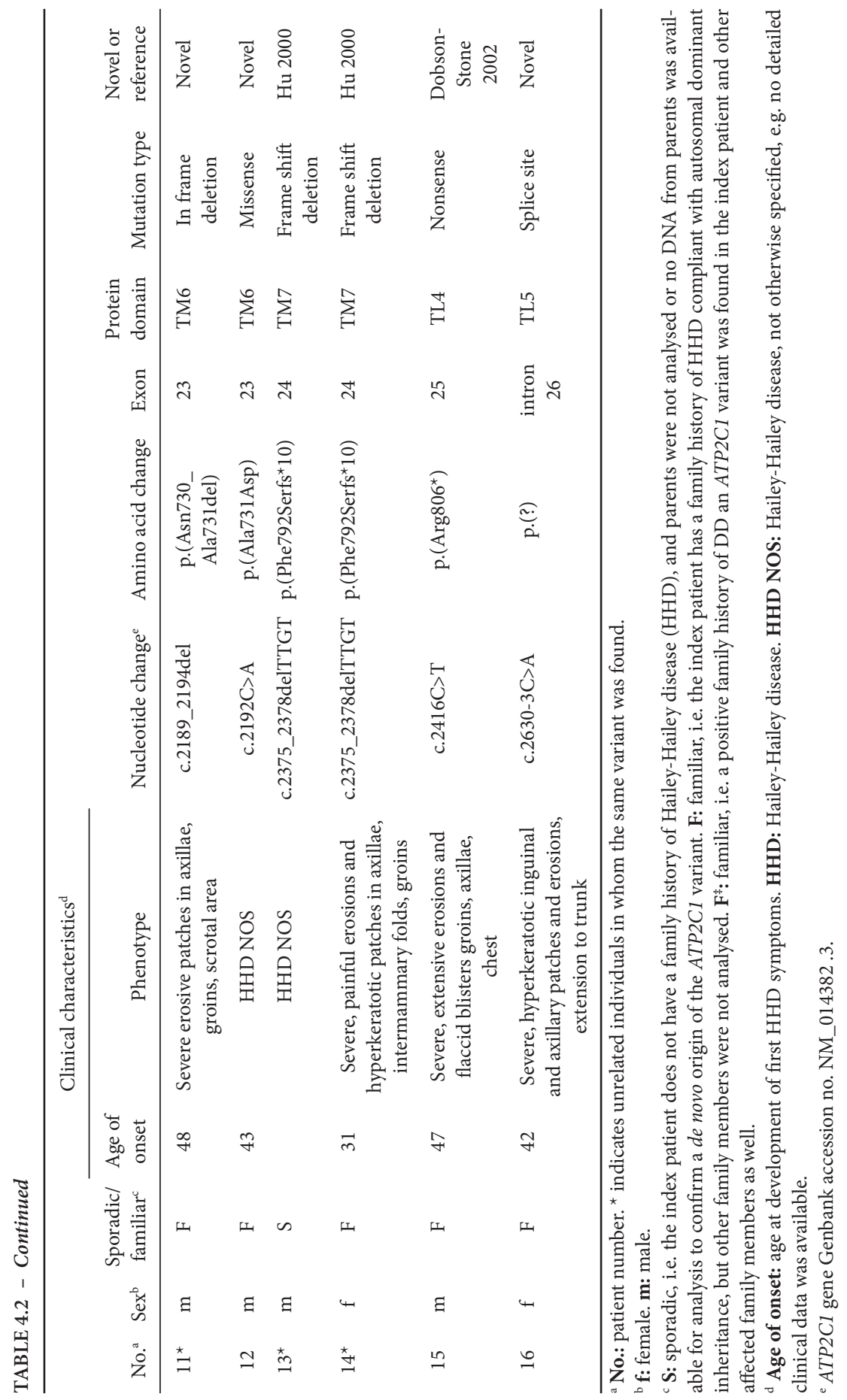


13 different mutations in 17 (85\%) patients (table 4.2, figure 4.8b. In the 16 sporadic patients analysed, 12 different mutations in 13 patients were found, whereas in three of those we did not find any ATP2C1 mutation. The two affected members of the analysed family had the same c.1308+1G>T mutation. We found 4 (29\%) missense and $2(14 \%)$ nonsense mutations, 3 (21\%) frameshift deletions, 1 (7\%) frameshift duplication, 2 (14\%) in-frame deletions and 2 (14\%) splice site mutations. All variants were identified as either "pathogenic" or "likely to be pathogenic" by analysis with Alamut ${ }^{64}$.

Of the 13 unique mutations found in our patients, 10 were not found in the literature and can thus be considered as novel: one of these was found in the familial case, the other 9 in the sporadic patients.

In line with other studies, we found mutations dispersed throughout all regions of the ATP2C1 gene ${ }^{90-92}$. Interestingly, seven of 13 unique variants were located in the transmembrane domain of SPCA1, raising the question if this region is particularly mutation-prone. However, the sample size of our series is too small to draw firm conclusions as to whether there are any mutation hot-spots in ATP2C1.

\subsubsection{Reported variants in ATP2C1}

Between 2000 up to now, 167 unique ATP2C1 variants were reported in 209 families or sporadic patients with HHD (http://lovd.nl/ATP2C1, figure 4.7b). Of these mutations, 46 were missense and 21 nonsense mutations, 8 duplications, 41 deletions, 31 splice site alterations and one insertion/deletion mutation.

Variant c. $163 \mathrm{C}>\mathrm{T} / \mathrm{p}$. $\left(\right.$ Arg $\left.55^{\star}\right)$ was reported in 6 unrelated individuals, c. $457 \mathrm{C}>\mathrm{T} / \mathrm{p}$. $\left(\operatorname{Arg} 153^{*}\right)$ and c.2395C $>$ T/p. $\left(A r g 799^{\star}\right)$ in 5 patients, and c.2375_2378delTTGT/p. (Phe792Serfs $\left.{ }^{\star} 10\right)$ was reported 12 times, including two unrelated patients in our case series. All missense mutations were base substitutions consisting of a $\mathrm{C}>\mathrm{T}$ transition within a CpG motif, suggesting methylated cytosine hypermutability. We did not find that tetranucleotide motifs were associated with a higher mutation rate (see table 4.3). Deletions are usually the result of slipped strand mispairing in the context of neighbouring direct repeat sequences, inverted repeats and mirror repeats (selected references $\left.{ }^{93-96}\right)$. Variant c.2375_2378delTTGT occurs within a context of a repeated TTTGTTTGTCTTCT (deleted base pairs in bold) motif, which renders this sequence prone to slipped mispairing (table 4.3). 


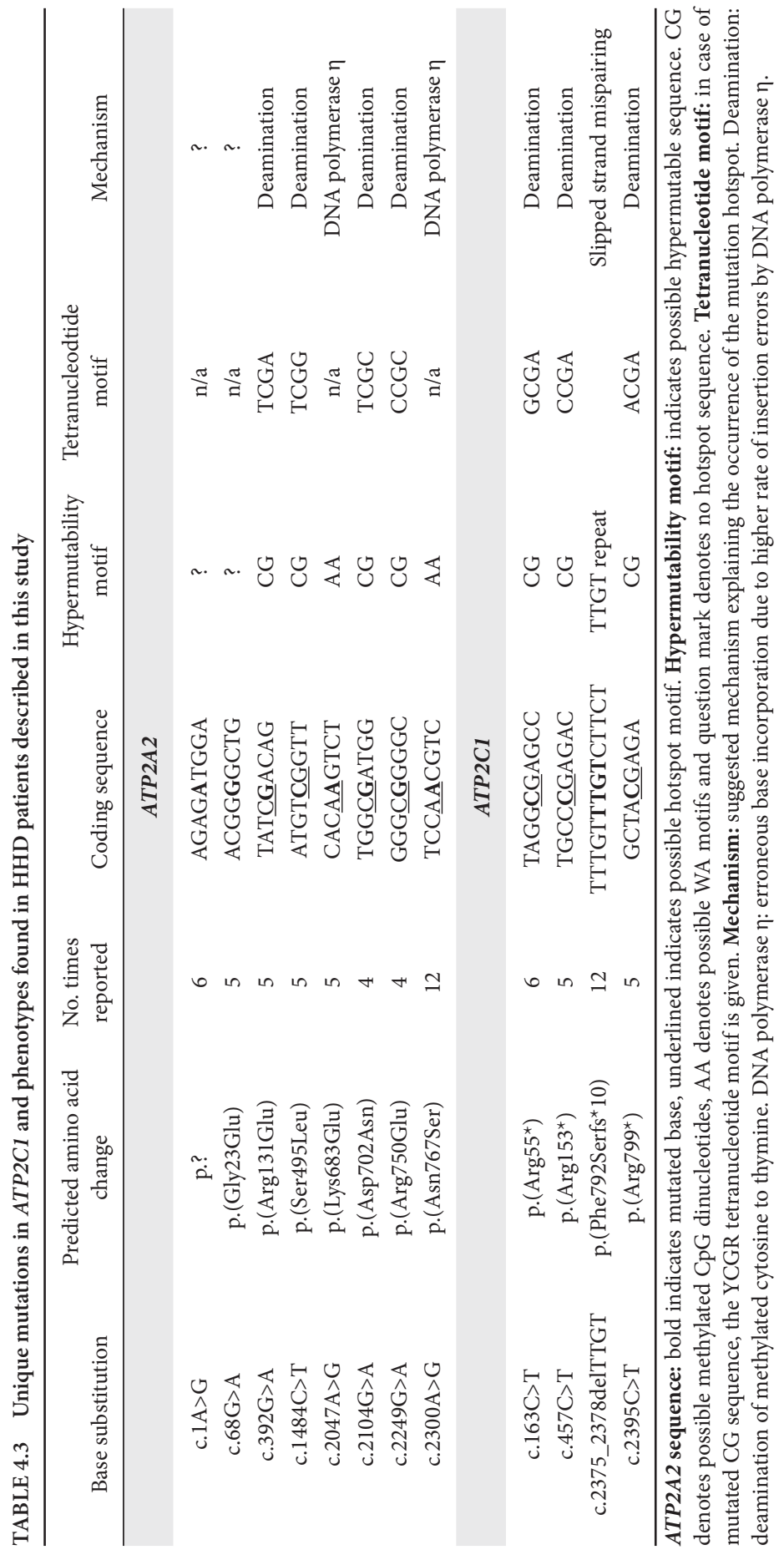




\subsection{Biological relevance}

\subsection{1 АТР2A2}

Analysis of several missense mutations and in-frame deletions found in patients with DD indicates different levels of SERCA2 dysfunction. Mutants showed normal to reduced SERCA2 expression (compared to wild type). The mutant SERCA2 with normal or slightly reduced levels of expression showed either normal to reduced $\mathrm{Ca}^{2+}$ ATPase activity, and/ or reduced levels of $\mathrm{Ca}^{2+}$ transport rate and/or reduced phosphorylation at the catalytic site independent of mutation type and location ${ }^{62,97-99}$. Three mutations (p.(Ile274Val), p.(Leu321Phe), and p.(Met719Ile)) showed normal levels of protein expression, $\mathrm{Ca}^{2+}$ ATPase activity, $\mathrm{Ca}^{2+}$ transport rate and phosphorylation, but reduced $\mathrm{Ca}^{2+}$ affinity at binding sites. Furthermore, markedly decreased sensitivity to feedback inhibition by luminal $\mathrm{Ca}^{2+}$ was found ${ }^{98}$. SERCA2 affected by nonsense mutations and frame shift deletions was subject to increased proteasomal degradation ${ }^{97}$. These findings indicate that symptoms occur independently of mutation type or which aspect of SERCA2 functionality is compromised. Thus, ATP2A2 mutations might exert their deleterious effect through haploinsufficiency. Interestingly, five of six analysed missense mutations inhibited the activity of the coexpressed wild-type SERCA2. Co-immunoprecipitation experiments showed that mutant SERCA2 monomers interacted with and downregulated wild-type SERCA2, although this could not be linked to a specific DD phenotype ${ }^{97}$. Thus, a dominant negative effect of some ATP2A2 mutations may also underlie the phenotype, instead of haploinsufficiency.

Experiments with several missense, nonsense and deletion variants showed depleted ER calcium stores in affected keratinocytes, again independently of variant type $e^{37,100}$. However, the effects on cytosolic $\mathrm{Ca}^{2+}$ levels remain equivocal, as both increased ${ }^{100}$ and decreased levels ${ }^{37}$ of intracellular $\mathrm{Ca}^{2+}$ have been found. Upregulation of SPCA1 and transient receptor potential canonical channel 1 (TRPC1) was shown to compensate decreased SERCA2 activity with regard to intracellular $\mathrm{Ca}^{2+}$ concentration ${ }^{37}$.

The further consequences of specific variants or mutations at specific loci in ATP2A2 on calcium homeostasis are even less clear. It was shown in cultured cells from DD patients that i) due to depleted $\mathrm{ER} \mathrm{Ca}^{2+}$ stores, post-translational protein trafficking was impaired and ER stress responses were induced ${ }^{101,102}$, ii) due to chronic ER stress, desmosome and adherens junctions formation and trafficking to the plasma membrane were abrogated ${ }^{101,103,104}$, iii) upon ER stress, keratinocyte differentiation was upregulated 
through XBP1 activation ${ }^{105}$. All of these pathologic changes can be related to the observed clinical and histological phenotype, but it remains uncertain if distinct mutation types exert specific influences on disease mechanisms of DD.

\subsubsection{ATP2C1}

Analysis of ATP2C1 missense mutations showed marked changes in SPCA1 function. Most variants showed decreased SPCA1 expression, reduced $\mathrm{Ca}^{2+} / \mathrm{Mn}^{2+}$ transport and reduced phosphorylation, in spite of correct localization to the Golgi membrane $e^{88,106,107}$. The p.(Pro201Leu) mutation showed normal expression, localisation to the Golgi membrane and phosphorylation of mutant SPCA1 compared to wild type SPCA1, but a reduced $\mathrm{Ca}^{2+}$ transport rate ${ }^{88}$. Nonsense and intronic splice site mutations, as well as frame shift deletions or insertions are thought to result in premature termination codons, eventually resulting in reduced expression of SPCA1 due to nonsense mediated RNA decay or ER mediated protein degradation of truncated SPCA1, as was shown for the p. $\left(\mathrm{Gln} 504^{\star}\right)$ mutation ${ }^{2,88,106,108}$. A dominant negative effect on wild type hSCPA1 protein function was not found for ATP2C1 mutations ${ }^{88}$. Therefore, haploinsufficiency of SPCA1 seems to be the explanation for the autosomal dominant inheritance of the HHD phenotype, in a manner (mostly) comparable to DD.

The disruption of calcium homeostasis in the Golgi has detrimental consequences for keratinocyte biology, as shown in ample research on HHD keratinocytes. Haploinsuffiency of ATP2C1 causes a reduction in both the rate of $\mathrm{Ca}^{2+}$ sequestration and the levels of $\mathrm{Ca}^{2+}$ in Golgi vesicles ${ }^{51}$. In turn, both $\mathrm{N}$-linked glycosylation and trafficking of proteins in the Golgi are impaired by loss of SPCA1 function and likely contribute to the observed misfolding and mislocalisation of proteins in the Golgi apparatus and ER, which renders cells hypersensitive to ER stress due to accumulation and impaired degradation of misfolded proteins ${ }^{109-111}$. SPCA1-deficient cultured keratinocytes showed delayed translocation of desmoplakin and desmoglein 3 in desmosomes and increased intracellular pools of tight junctions and desmosomal components, which might account for the observed phenotype of acantholysis in $\mathrm{HHD}^{112}$. However, theses consequences of SPCA1 dysfunction were not examined in relation to specific variants of ATP2C1. Finally, it is proposed that alteration of epidermal rather than keratinocyte calcium homeostasis, thus, tissue calcium homeostasis rather than cellular calcium homeostasis, is the main contributing factor in the pathogenesis of $\mathrm{HHD}^{113,114}$. 


\section{CHAPTER 4 DARIER DISEASE AND HAILEY-HAILEY DISEASE}

\subsubsection{Animal models}

Yeast does not have a SERCA2 ortholog. Instead, they express Pmr1 to regulate Golgi $\mathrm{Ca}^{2+}$ levels ${ }^{115,116}$. Homozygous SERCA2 knockout mice were not observed, indicating that SERCA2 is mandatory for cell survival ${ }^{117}$. Heterozygous Serca2 KO mice show remarkable differences from DD patients. Instead of DD-like lesions, they develop squamous cell carcinomas with age, possibly due to improper adaptation to prolonged ER stress ${ }^{118,119}$. In contrast, the incidence of cutaneous malignancies is not elevated in DD patients. Furthermore, in mice with an inducible cardiomyocyte-specific knockout of SERCA2 as well as in SERCA2+/- mice, mild impairment of cardiac contractility and subsequent heart failure was observed ${ }^{117,120}$. Such cardiac phenotypes are not observed in DD patients, though ${ }^{121,122}$.

SPCA1 orthologs have been intensively studied in other organisms. Although these studies yielded much data on SPCA1 homologue function, results cannot be readily extrapolated to the pathophysiologic mechanisms in HHD. The yeast homolog Pmr1 locates to the Golgi apparatus where it plays an important role in $\mathrm{Ca}^{2+}$ and $\mathrm{Mn}^{2+}$ homeostasis. Yeast cells with mutated or deleted pmr1 are more sensitive to $\mathrm{Mn}^{2+}$ accumulation and $\mathrm{Mn}^{2+}$ toxicity and depletion of Golgi $\mathrm{Ca}^{2+}$ stores. They further show impaired protein glycosylation, trafficking and degradation of improperly folded proteins and a failure in exporting misfolded proteins from the ER to the cytosol. This, in turn, leads to ER stress and activation of the unfolded protein response $\mathrm{e}^{123-127}$. Part of the pathological phenotype in pmr1 mutants can be alleviated by upregulation of exogenous SERCA1, which has been shown to overcome growth impairment of affected yeast cells ${ }^{126}$.

Caenorhabditis elegans Pmr-1 plays an essential role in embryogenesis. Embryos with defective Pmr-1 show ventral and anterior enclosure failure, body morphogenesis defects, and an unattached pharynx, which are caused by earlier defects during gastrulation. Migration rates are significantly reduced for cells moving along the embryo surface, such as ventral neuroblasts, C-derived, and anterior-most blastomeres ${ }^{128}$.

Spca1(-/-)) mouse embryos showed growth defects such as an open neural tube due to increased apoptosis and died on gestation day 10.5. Ultrastructural changes included increased numbers of dilated Golgi membranes and Golgi-associated vesicles, indicating increased Golgi stress ${ }^{129}$. Adult heterozygous mice did not show a phenotype comparable to HHD. Instead, they had an increased incidence of squamous cell tumours of keratinized epithelial cells of the skin and oesophagus ${ }^{129}$. 
It is interesting to note that the phenotypes observed in mice are quite different from the DD and HHD phenotypes. It is thought, however, that the underlying pathologic mechanism is the same in both organisms: variants in both genes eventually cause ER stress, which elicits adaptive stress responses that lead either to cell survival or apoptosis, dependent on the cell's ability to overcome the ER stress. It is hypothesized that differences in either pro-survival responses or pro-apoptosis responses between mouse and human keratinocytes may lead to a cancer-phenotype (pro-survival) or an acantholysis-phenotype (pro-apoptotic) ${ }^{130}$.

\subsection{Clinical and diagnostic relevance}

It is well established that variants in ATP2A2 are associated with DD and variants in ATP2C1 with HHD. Although diagnosis of DD and HHD is established on clinical criteria, analysis for mutations in these genes is a valuable tool in confirmation of respective diagnoses. Furthermore, mutation analysis provides necessary information for genetic counseling. However, not all patients with DD and DD have variants in ATP2A2 and $A T P 2 C 1$ and a genotype-phenotype-correlation has so far not been established in DD or HHD.

To better define a genotype-phenotype correlation in DD and HHD, we reviewed clinical data from all newly reported individuals, if available. We were able to retrieve clinical information in 52 (65\%) DD and 13 (65\%) HHD patients. The relation of phenotypes in relation to the $A T P 2 A 2$ or $A T P 2 C 1$ variant are summarised in table 4.1 and 4.2, respectively. Phenotypes of DD and HHD patients in whom no variant in $A T P 2 A 2$ or $A T P 2 C 1$ was found are summarised in table 4.4. Penetrance of specific features is tabulated in table 4.5 for both diseases.

\subsubsection{Genotype-phenotype-correlation in DD}

Of the 52 patients for whom clinical data was available, 7 (13\%) patients had severe, 15 (29\%) moderate and 21 (40\%) mild disease. Of the latter, 1 patient had only guttate leukoderma (see table 4.1, 4.3 and 4.4). One patient, harbouring the same p. $\left(\operatorname{Arg} 677^{\star}\right)$ variant as his father, did not have apparent skin disease, but was diagnosed with learning difficulties and mild intellectual disability. AKV without DD symptoms was found in 


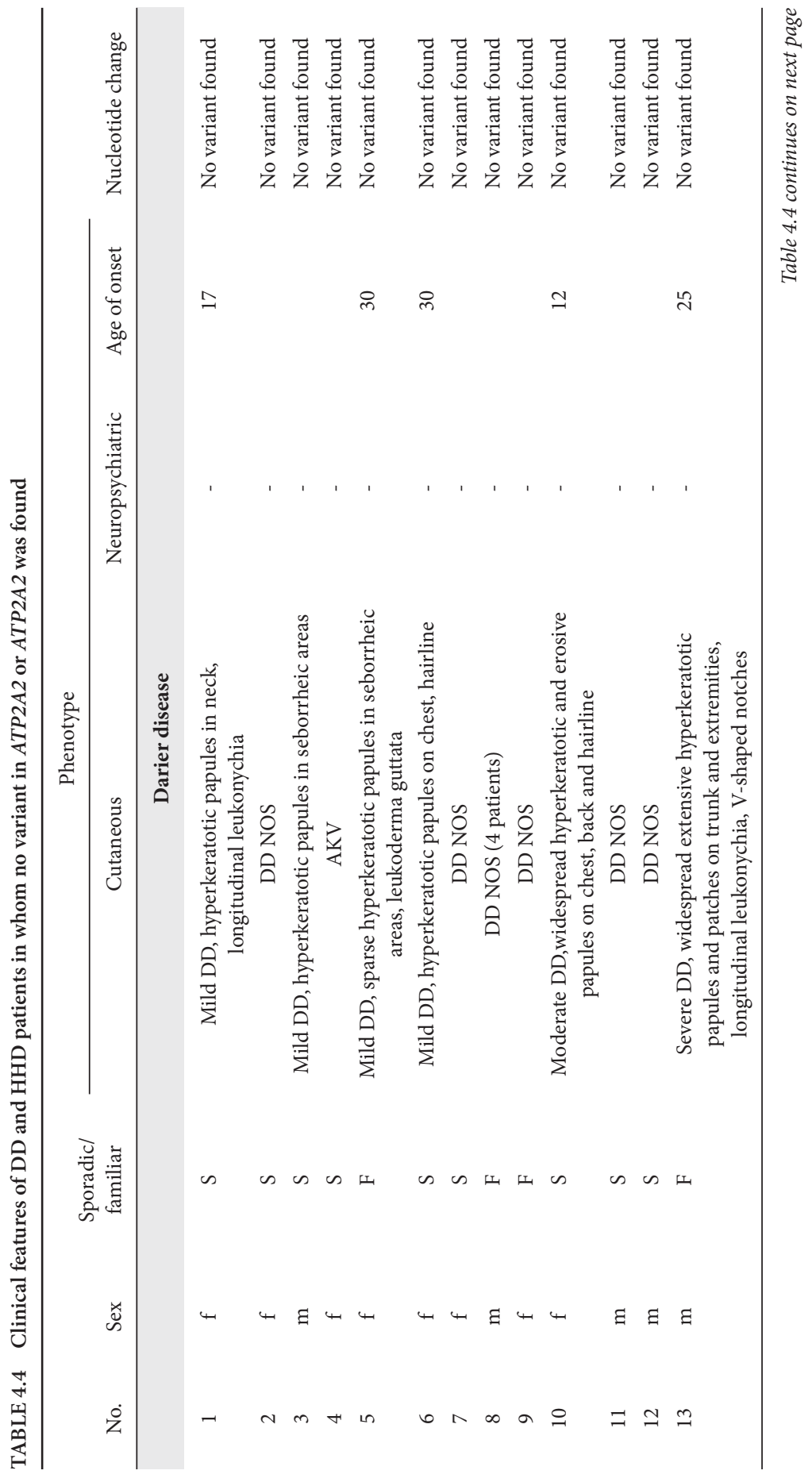




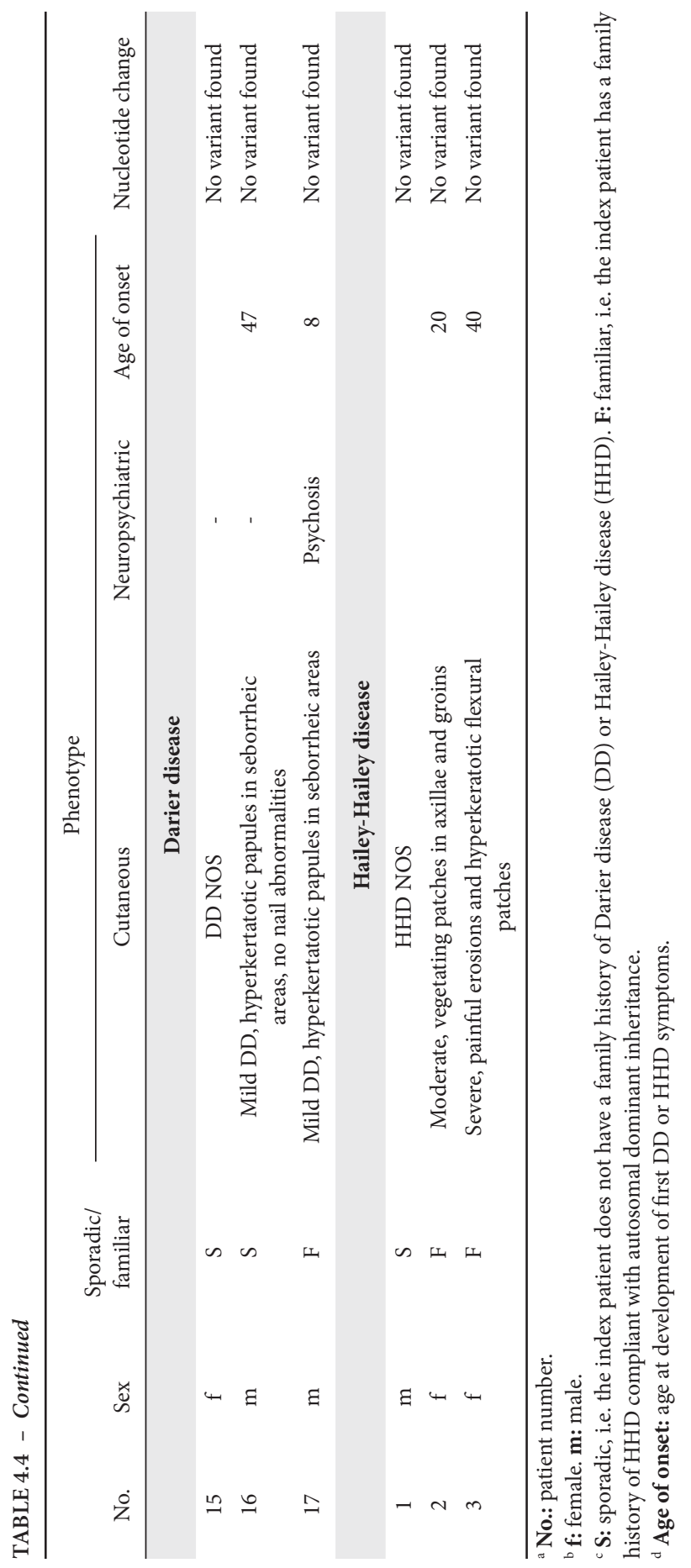




\section{CHAPTER 4 DARIER DISEASE AND HAILEY-HAILEY DISEASE}

TABLE 4.5 Clinical characteristics DD and HHD patients

\begin{tabular}{|c|c|c|c|}
\hline \multicolumn{4}{|c|}{ Darier disease } \\
\hline & Total $(\mathrm{n}=52)$ & Variant $+(\mathrm{n}=42(81 \%))^{\mathrm{a}}$ & Variant $-(\mathrm{n}=10(19 \%))^{\mathrm{b}}$ \\
\hline \multicolumn{4}{|c|}{ Disease severity $^{c}$} \\
\hline Mild & $21(40 \%)$ & $14(27 \%)$ & $7(13 \%)$ \\
\hline Moderate & $15(29 \%)$ & $14(27 \%)$ & $1(2 \%)$ \\
\hline Severe & $7(13 \%)$ & $6(11 \%)$ & $1(2 \%)$ \\
\hline No skin symptoms & $1(2 \%)$ & $1(2 \%)$ & 0 \\
\hline $\mathrm{AKV}$ & $8(15 \%)$ & $7(13 \%)$ & $1(2 \%)$ \\
\hline \multicolumn{4}{|c|}{ Associated skin symptoms } \\
\hline AKV and DD symptoms & $3(6 \%)$ & $3(6 \%)$ & 0 \\
\hline Longitudinal leukonychia & $13(25 \%)$ & $10(19 \%)$ & $3(6 \%)$ \\
\hline V-shaped notches & $5(10 \%)$ & $4(8 \%)$ & $1(2 \%)$ \\
\hline Palmar pits & $5(10 \%)$ & $4(8 \%)$ & $1(2 \%)$ \\
\hline Palmoplantar keratoderma & $3(6 \%)$ & $3(6 \%)$ & 0 \\
\hline Leukoderma guttata & $2(4 \%)$ & $1(2 \%)$ & $1(2 \%)$ \\
\hline \multicolumn{4}{|c|}{ Neuropsychiatric symptoms } \\
\hline Learning disability & $3(6 \%)$ & $3(6 \%)$ & 0 \\
\hline Dyslexia & $1(2 \%)$ & $1(2 \%)$ & 0 \\
\hline Psychosis & $1(2 \%)$ & 0 & $1(2 \%)$ \\
\hline Depressive symptoms & $1(2 \%)$ & $1(2 \%)$ & 0 \\
\hline Bipolar disorder & $1(2 \%)$ & $1(2 \%)$ & 0 \\
\hline \multicolumn{4}{|c|}{ Hailey-Hailey disease $^{d}$} \\
\hline & Total $(n=13)$ & Variant $+(\mathrm{n}=11)^{\mathrm{a}}$ & Variant $-(\mathrm{n}=2)^{\mathrm{b}}$ \\
\hline Mild & $4(31 \%)$ & $4(31 \%)$ & 0 \\
\hline Moderate & $2(15 \%)$ & $1(8 \%)$ & $1(8 \%)$ \\
\hline Severe & $7(54 \%)$ & $6(46 \%)$ & $1(8 \%)$ \\
\hline
\end{tabular}

${ }^{a}$ Variant +: Patients in whom a mutation in ATP2A2, resp. ATP2C1 was found.

${ }^{\mathrm{b}}$ Variant -: Patients in whom no mutation in ATP2A2, resp. ATP2C1 was found.

'Disease severity in Darier disease: phenotypes were classified as "mild", "moderate" or "severe", according to criteria established by Burge et al. and Ringpfeil et al. ${ }^{4,56}$

"Disease severity in Hailey-Hailey disease: disease severity was scored as either "mild", "moderate" or "severe" according to criteria further explained in the methods section.

$8(17 \%)$ patients, of whom 7 familial cases came from 2 families. AKV with other DD symptoms was diagnosed in 3 individuals (6\%), one with guttate leukoderma, one with moderate and one patient with severe DD. Longitudinal leukonychia was found in 13 (25\%) individuals, $\mathrm{V}$-shaped notches in $5(10 \%)$, palmar pits in $5(10 \%)$ and palmoplantar keratoderma in 3 (7\%) DD patients. Learning disabilities were found in 3 (6\%) patients. 
Dyslexia, psychosis, depressive symptoms and bipolar disorder were found in one patient each. We did not find any individuals with the acral-haemorrhagic or comedonal DD phenotype. Comparable figures were reported earlier ${ }^{4}$.

In our case series, we were not able to relate disease severity or specific symptoms to specific variants, mutation type, or location in ATP2A2. However, two families and one sporadic patient suffered from AKV rather than generalised DD, caused by mutations p.(Pro602Leu) and p.(Leu590Pro), respectively (see table 4.1). These mutations, as well as variant p.(Ala698Val), have been reported in association with the AKV phenotype before ${ }^{5,9,131,132}$. All mutations are found in exon 14, encoding the ATP binding domain of SERCA2. The other reported 21 unique variants in exon 14 (see the LOVD database, references ${ }^{1,6,42,56,66,67,75,133-135}$ ) are associated with the classic DD phenotype without AKV. The mutations p.(Leu590Pro), p.(Pro602Leu) and p.(Ala698Val) have not been described in patients with classic DD. This may suggest that mutations in these two specific areas of ATP2A2 cause a predominant AKV phenotype.

Our observations are in line with, most studies, which have not found a robust genotype-phenotype-correlation in DD as well. Although an association between missense mutations and particular severe presentation of DD has been reported ${ }^{6}$, and one study identified a non-random clustering of mutations in the 3' end of ATP2A2 associated with neuropsychiatric disease $\mathrm{e}^{42}$, the majority of studies with larger patient series did not find an association between mutation type or location and DD phenotype/ severity $^{30,31,56,65,66,76}$ or neuropsychiatric symptoms ${ }^{6}$. Given the results from functional analysis of ATP2A2 variants, a genotype-phenotype correlation is not to be expected for several reasons. Most variants markedly reduced expression of SERCA2, independent of mutation type or localization ${ }^{62,97,98}$. Although some variants in specific SERCA2 domains could be related to specific levels of SERCA2 dysfunction (e.g. diminished phosphorylation associated with missense mutations in the P-domain, etc.), all expressed variants ultimately reduced $\mathrm{Ca}^{2+}$ transport activity, again independent of variant type or location ${ }^{62,97,98}$. The level of SERCA2 dysfunction, i.e. reduction in $\mathrm{Ca}^{2+}$ transport activity could not be correlated with the phenotype ${ }^{97}$.

Establishing a genotype-phenotype-correlation in DD is difficult for several other reasons. Most studies report small cohorts (up to 30 individuals) of DD patients, which is likely to bias findings. No standardised and reproducible scoring system for disease severity exists, although semi-quantitative systems have been described ${ }^{1,4,56}$. This fact 


\section{CHAPTER 4 DARIER DISEASE AND HAILEY-HAILEY DISEASE}

limits the possibility to adequately evaluate the natural course of exacerbations elicited by external factors and spontaneous remissions in $\mathrm{DD}^{4}$.

The low prevalence of the other clinical subtypes of DD (acral-haemorrhagic and comedonal DD) makes defining a genotype-phenotype correlation even more difficult. Two studies identified the p.(Asn767Ser) missense mutation in four unrelated patients with acral-haemorrhagic DD ${ }^{6,72}$. However, other DD patients with the p.(Asn767Ser) mutation did not suffer from acral haemorrhagic blistering ${ }^{42,66,71,74}$, arguing against this particular genotype-phenotype-correlation in DD. Comedonal DD has been reported in 9 patients to date ${ }^{8}$. One study found the c.120_122delGTT (p.(Leu41del)) variant in a patient with comedonal DD and suggested a genotype-phenotype-correlation for comedonal $\mathrm{DD}^{7}$. However, in a patient with a comparable phenotype, no variants in ATP2A2 were found ${ }^{136}$. Patients with a similar frameshift mutation in the adjacent codon 40 (c.119_120delAG, p.(Glu40Valfs $\left.{ }^{\star} 4\right)$ ) showed the classical DD phenotype ${ }^{6,137}$.

\subsubsection{Genotype-phenotype-correlation in HHD}

Clinical data from 13 HHD patients was available for analysis (see table 4.2, 4.3 and 4.4). Mild disease was found in 4 (31\%), moderate disease in 2 (15\%) and severe disease in 7 (54\%) patients. Nail changes or mucosal disease were not noted. We were not able to find any relation between age of onset, pattern of skin symptoms, disease severity or progression of HHD and mutation type or location of mutation in ATP2C1. These findings are in line with earlier studies that tried to address a genotype-phenotypecorrelation in $\mathrm{HHD}^{2,17,90,138,139}$. As in $\mathrm{DD}$, any type or location of ATP2C1 variant seems to disrupt Golgi Ca ${ }^{2+}$ homeostasis, which is enough to develop $\mathrm{HHD}^{88,106,107}$. The extensive phenotypic variation suggests the influence of other as of now unknown modifying genes. In a comparable manner to $\mathrm{DD}, \mathrm{HHD}$ is also exacerbated by external factors that cause friction in predisposed body sites ${ }^{11,140,141}$.

All studies that tried to address a genotype-phenotype-correlation in HHD did not find any relation between age of onset, pattern of skin symptoms, disease severity or progression of HHD and mutation type or location of mutation in ATP2C1, $17,90,138,139$. The extensive phenotypic variation suggests the influence of other as of now unknown external triggers or modifying genes. In a comparable manner to DD, HHD is also exacerbated by external factors that cause friction in predisposed body sites ${ }^{11,140,141}$. 


\subsubsection{Absence of ATP2A2 and ATP2C1 variants}

We did not find mutations in 17 patients (24\%) with DD and 3 patients (17\%) with

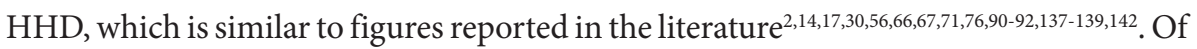
interest though, one of our DD patient showed skipping of exon 4 of ATP2A2 on mRNA level, which indicates that, for instance, larger deletions or cryptic splice site mutations may account for the disease phenotype. Furthermore, mutations may be present in gene regions that are not routinely screened (e.g. promoter regions) or other regions or genes regulating $A T P 2 A 2$ and $A T P 2 C 1$ transcription. For example, both deletion of the promoter region of $A T P 2 A 2$ and $A T P 2 C 1$ or knockdown of the upregulating transcription factor Sp1 lead to reduced levels of ATP2A2 and ATP2C1 mRNA ${ }^{143,144}$. These patients either suffer from an inherited skin disorder caused by gene defects in a gene other than $A T P 2 A 2$ or $A T P 2 C 1$, or from acquired skin diseases with a phenotype resembling DD and HHD, such as pemphigus foliaceus ${ }^{66,76,144,145}$.

\subsection{Future prospects}

Further research needs to focus on ascertainment of clinical features, pitfalls in molecular testing and evaluation of current and new treatment strategies in larger groups of DD and HHD patients.

Although there is probably no genotype-phenotype relation in DD and HHD, most data on phenotypic variability are too inaccurate to draw firm conclusions. The consensus disease severity classification used in some studies is not a validated means of assessing clinical severity, which makes comparison of different studies impossible $e^{1,2,456}$. Establishing a reliable and reproducible disease severity scoring system for DD and HHD should be one of the goals of further research into the two disorders. It would allow clinicians to more accurately follow disease progression and variation as well as assess efficacy of therapeutic interventions.

The diagnosis of DD and HHD relies on the occurrence of typical clinical symptoms and histopathological examination of skin lesions. Mutation analysis of ATP2A2 and $A T P 2 C 1$ can confirm the diagnosis and provides necessary information for genetic counseling. For patients in whom no variants in ATP2A2 and ATP2C1 can be found, other diagnostic strategies such as MLPA analysis, RNA analysis or whole genome 


\section{CHAPTER 4 DARIER DISEASE AND HAILEY-HAILEY DISEASE}

sequencing may help to elucidate the genetic cause of their disease. Our results in the DD patient in whom genomic DNA sequencing did not yield an ATP2A2 variant, but RNA analysis showed absence of ATP2A2 exon 4. This strongly indicates the need for more advanced diagnostic investigations in DD and HHD patients without obvious pathogenic variants in the coding sequence.

Currently, DD and HHD cannot be cured and symptomatic treatment is often difficult. For DD, topical and systemic retinoids are the mainstay of therapy ${ }^{146-148}$. Bacterial superinfection frequently warrants use of systemic antibiotics. Furthermore, laser ablation of refractory lesions may be indicated ${ }^{149}$. Retinoids do not have the same beneficial effects in $\mathrm{HHD}^{11}$. In most patients, a combination of topical steroids and topical antibiotics is sufficient to control disease symptoms. As in DD, laser ablation of areas unresponsive to treatment may yield significant results ${ }^{150,151}$. Lesional Botulinum toxin A injection or subcutaneous administration of the $\alpha-\mathrm{MSH}$ analogue afamelanotide have been reported in small case series as an effective alternative in refractory $\mathrm{HHD}^{152,153}$.

Extrapolating on data from ATP2A2 and ATP2C1 variants as described above and experimental studies, interesting therapeutic approaches may arise. In the LSDBs for both genes, $8.5 \%$ of DD patients and $11 \%$ of HHD patients are identified with nonsense mutations in $A T P 2 A 2$ and $A T P 2 C 1$, respectively. These patients are potentially eligible for "read-through therapy" of premature termination codons (PTC) by aminoglycosides or Ataluren (PTC124) ${ }^{154,155}$. A proof-of-principle study using topical gentamycin in a HHD patient with the p.(Arg468*) mutation in ATP2C1 has shown an increase of fulllength SPCA1 and a beneficial effect on HHD skin symptoms ${ }^{156}$. Experimental data has shown that the consequences of SERCA2 haploinsufficiency can be abolished by miglustat, an a-glucosidase inhibitor registered for treatment of Gaucher disease ${ }^{101}$. However, miglustat has not yet been used in DD patients, and its use is compromised by sometimes severe side effects and high costs. Last, gene therapy may be a future solution to overcome haploinsufficiency of SERCA2 and SPCA1. Although suitable SERCA2b vectors have not been developed yet, gene therapy restoring SERCA2a expression in cardiomyocytes is currently being developed for heart failure. This disease is associated with decreased SERCA2a expression and activity in cardiac myocytes similar to SERCA2b haploinsufficiency in $\mathrm{DD}^{157-159}$.

At last, gene editing and RNA-based therapies may prove to be a viable option in treatment of DD and HHD. These interventions have not reached testing in a clinical 
setting, however. The emergence of site-specific gene editing technologies, especially the clustered regularly interspaced short palindromic repeats (CRISPR)-CRISPR associated (Cas9) system (CRISPR/Cas9) offer the possibility of correction of the underlying genetic defect with a reduced risk of off-target mutagenesis associated with viral gene delivery ${ }^{160}$. It remains to be seen whether RNA interference (RNAi)-based gene therapy may be a viable therapeutic option in DD and HHD, since knockdown of the mutant alleles by RNAi does not overcome haploinsufficiency of ATP2A2 or ATP2C1. Furthermore, both RNAi-therapy and site-specific gene editing is hindered by poor transfection performance, lack of tissue specificity and potential cytotoxicity ${ }^{158,160,161}$. Furthermore, as can be concluded from our data and review, variants associated with $\mathrm{DD}$ and HHD are heterogeneous. This implies that gene editing interventions need to be tailor made to the specific underlying genetic defect in most patients and underlines the need for obtaining a molecular diagnosis in DD and HHD.

In conclusion, $\mathrm{DD}$ and $\mathrm{HHD}$ are chronic skin diseases caused by defective epidermal calcium homeostasis that severely affect quality of life in affected individuals. Both clinical symptoms and underlying genetic defects are highly variable, with no genotypephenotype relations observed. Diagnosis can be difficult, and therapeutic options are limited. Therefore, further research efforts are warranted and should be aimed at identification of clinical and genotypic characteristics that help our understanding of both diseases and point out directions towards new treatment options. 


\section{Acknowledgments}

\# Professionals who have provided patient samples:

Netherlands:

- M.F. Jonkman, M.C. Bolling, A.S. Aalfs, J.L. Dickinson-Blok, S. van Hattem, M. Hoekstra, G. van der Wier, W.Y.Yuen, Department of Dermatology, University Medical Centre Groningen, Groningen

- P.C. van den Akker, de Waard, Department of Clinical Genetics, University Medical Centre Groningen, Groningen

- K. Mosterd, I.F. Nagtzaam, Department of Dermatology, Maastricht University Medical Centre, Maastricht

- D. Marcus-Soekarman, Department of Clinical Genetics, Maastricht University Medical Centre, Maastricht

- M. Nielsen, Department of Clinical Genetics, Leiden University Medical Centre, Leiden

- U. Badrising, Department of Neurology, Van Weel-Bethesda Ziekenhuis, Dirksland

- V. Sigurdsson, Department of Dermatology, University Medical Centre Utrecht, Utrecht

- B. Jagtman, Department of Dermatology, Viecuri Hospital, Venlo

- J.A.J. van Rooijen, Department of Gynaecology and Obstetrics, TweeSteden Ziekenhuis, Tilburg

- M.W. Elting, Department of Clinical Genetics, VU Medical Centre, Amsterdam

- J.J. van der Smagt, F.A. Beemer, Department of Clinical Genetics, University Medical Centre Utrecht, Utrecht

- T. Kleefstra, Department of Clinical Genetics, University Medical Centre Nijmegen, Nijmegen

- W.J.A. de Kort, Department of Dermatology, Amphia Hospital, Breda

- J.G. Geerdink, Department of Dermatology, Academic Medical Centre, Amsterdam

- S. Maas, A.S. Plomp, M. Hänkel, Department of Clinical Genetics, Academic Medical Centre, Amsterdam

Germany:

- H. Hamm, Department of Dermatology, University Hospital Würzburg, Würzburg

- U. Schreyer, Koln 
- R. Fölster-Holst, Department of Dermatology, University Hospital SchleswigHolstein, Campus Kiel, Kiel

Belgium:

- G. Matthijs, Centrum voor Menselijke Erfelijkheid, University Hospital Leuven, Leuven

- J. Desir, Institut de Pathologie et de Génétique, Charleroi Gosselies, Charleroi

- S. Bulk, Department of Clinical Genetics, CHU Liege, Liege

- D. de Smedt, Department of Clinical Genetics, University Hospital Brussels, Brussels

Finland:

- H. Mäkinen, Department of Genetics, University of Turku, Turku

- E. Rahikkala, Department of Clinical Genetics, Oulu University Hospital and University of Oulu, Oulu

- R. Karhu, M. Kähkönen, Department of Clinical Genetics, Tampere University Hospital, Tampere

Cyprus:

- G.A. Tanteles, Department of Clinical Genetics, The Cyprus Institute of Neurology and Genetics, Nicosia

Norway:

- K. Heimdal, Department of Clinical Genetics, Universitetssykehus Oslo, Oslo

Austria:

- D. Kotzot, Department of Clinical Genetics, University Hospital Innsbrück

UK:

- E. Blair, Department of Clinical Genetics, Churchill Hospital, Oxford

- J. Carmichael, Department of Clinical Genetics, Northampton General Hospital, Northampton

- A. Fryer, Department of Clinical Genetics, Countess of Chester Hospital, Chester

- V. Murday, West of Scotland Genetics Services Laboratory, Glasgow

We like to thank M. Kamps for technical assistance. 


\section{CHAPTER 4 DARIER DISEASE AND HAILEY-HAILEY DISEASE}

\section{References}

1 Sakuntabhai, A., Ruiz-Perez, V., Carter, S. et al. Mutations in ATP2A2, encoding a Ca2+ pump, cause Darier disease. Nat Genet 1999; 21: p. 271-7.

$2 \mathrm{Hu}, \mathrm{Z}$., Bonifas, J.M., Beech, J. et al. Mutations in ATP2C1, encoding a calcium pump, cause Hailey-Hailey disease. Nat Genet 2000; 24: p. 61-5.

3 Sudbrak, R., Brown, J., Dobson-Stone, C. et al. Hailey-Hailey disease is caused by mutations in ATP2C1 encoding a novel $\mathrm{Ca}(2+)$ pump. Hum Mol Genet 2000; 9: p. 1131-40.

4 Burge, S.M., Wilkinson, J.D. Darier-White disease: a review of the clinical features in 163 patients. J Am Acad Dermatol 1992; 27: p. 40-50.

5 Nellen, R.G.L., Arits, A.H.M.M., van Geel, M. et al. Darier disease: discrete phenotype in a Sinhalese patient with Darier disease. J Eur Acad Dermatol Venereol 2015; 29: p. 1641-2.

6 Ruiz-Perez, V.L., Carter, S.A., Healy, E. et al. ATP2A2 mutations in Darier's disease: variant cutaneous phenotypes are associated with missense mutations, but neuropsychiatric features are independent of mutation class. Hum. Mol. Genet. 1999; 8: p. 1621-30.

7 Tsuruta, D., Akiyama, M., Ishida-Yamamoto, A. et al. Three-base deletion mutation c.120_122delGTT in ATP2A2 leads to the unique phenotype of comedonal Darier disease. Br J Dermatol 2010; 162: p. 687-9.

8 Derrick, E.K., Darley, C.R., Burge, S. Comedonal Darier's disease. Br J Dermatol 1995; 132: p. 453-5.

9 Dhitavat, J., Macfarlane, S., Dode, L. et al. Acrokeratosis verruciformis of Hopf is caused by mutation in ATP2A2: evidence that it is allelic to Darier's disease. J Invest Dermatol 2003; 120: p. 229-32.

10 Castori, M., Barboni, L., Duncan, P.J. et al. Darier disease, multiple bone cysts, and aniridia due to double de novo heterozygous mutations in ATP2A2 and PAX6. Am J Med Genet A 2009; 149A: p. 1768-72.

11 Burge, S.M. Hailey-Hailey disease: the clinical features, response to treatment and prognosis. Br J Dermatol 1992; 126: p. 275-82.

12 Dodiuk-Gad, R., Cohen-Barak, E., Ziv, M. et al. Health-related quality of life among Darier's disease patients. J Eur Acad Dermatol Venereol 2013; 27: p. 51-6.

13 Foggia, L., Hovnanian, A. Calcium pump disorders of the skin. Am J Med Genet C Semin Med Genet 2004; 131C: p. 20-31.

14 Godic, A., Korosec, B., Miljkovic, J. et al. Four novel ATP2A2 mutations in Slovenian patients with Darier disease. J Am Acad Dermatol 2010; 62: p. 819-23.

15 Tavadia, S., Mortimer, E., Munro, C.S. Genetic epidemiology of Darier's disease: a population study in the west of Scotland. Br J Dermatol 2002; 146: p. 107-9. 


\section{CHAPTER 4 DARIER DISEASE AND HAILEY-HAILEY DISEASE}

Wang, C.C., Chao, S.C., Tsai, T.H. Hailey-Hailey disease: a novel mutation of the ATP2C1 gene in a Taiwanese family with divergent clinical presentation. J Eur Acad Dermatol Venereol 2008; 22: p. 1145-6.

Ikeda, S., Shigihara, T., Mayuzumi, N. et al. Mutations of ATP2C1 in Japanese patients with Hailey-Hailey disease: intrafamilial and interfamilial phenotype variations and lack of correlation with mutation patterns. J Invest Dermatol 2001; 117: p. 1654-6.

Sakuntabhai, A., Dhitavat, J., Burge, S. et al. Mosaicism for ATP2A2 mutations causes segmental Darier's disease. J Invest Dermatol 2000; 115: p. 1144-7.

Hwang, L.Y., Lee, J.B., Richard, G. et al. Type 1 segmental manifestation of Hailey-Hailey disease. J Am Acad Dermatol 2003; 49: p. 712-4.

Wada, T., Shirakata, Y., Takahashi, H. et al. A Japanese case of segmental Darier's disease caused by mosaicism for the ATP2A2 mutation. Br J Dermatol 2003; 149: p. 185-8.

Folster-Holst, R., Nellen, R.G.L., Jensen, J.M. et al. Molecular genetic support for the rule of dichotomy in type 2 segmental Darier disease. Br J Dermatol 2012; 166: p. 464-6.

Poblete-Gutierrez, P., Wiederholt, T., Konig, A. et al. Allelic loss underlies type 2 segmental Hailey-Hailey disease, providing molecular confirmation of a novel genetic concept. J Clin Invest 2004; 114: p. 1467-74.

Happle, R. Segmental forms of autosomal dominant skin disorders: different types of severity reflect different states of zygosity. Am J Med Genet 1996; 66: p. 241-2.

Happle, R. A rule concerning the segmental manifestation of autosomal dominant skin disorders. Review of clinical examples providing evidence for dichotomous types of severity. Arch Dermatol 1997; 133: p. 1505-9.

(1)

Itin, P.H., Buchner, S.A., Happle, R. Segmental manifestation of Darier disease. What is the genetic background in type 1 and type 2 mosaic phenotypes? Dermatology 2000; 200: p. 254-7.

Rodriguez-Pazos, L., Gomez-Bernal, S., Loureiro, M. et al. Type 2 segmental Darier disease with twin spot phenomenon. J Eur Acad Dermatol Venereol 2011; 25: p. 496-7.

Hall, J.G. Review and hypotheses: somatic mosaicism: observations related to clinical genetics. Am J Hum Genet 1988; 43: p. 355-63.

Happle, R. Loss of heterozygosity in human skin. J Am Acad Dermatol 1999; 41: p. 143-64.

Frank, J., Happle, R. Cutaneous mosaicism: right before our eyes. J Clin Invest 2007; 117: p. 1216-9.

Klausegger, A., Nischler, E., Wagner, R.N. et al. Seven novel mutations in the ATP2A2 gene of Austrian patients with Darier's disease. Arch Dermatol Res 2011; 303: p. 371-4. 


\section{CHAPTER 4 DARIER DISEASE AND HAILEY-HAILEY DISEASE}

31 Godic, A., Strazisar, M., Zupan, A. et al. Darier disease in Slovenia: spectrum of ATP2A2 mutations and relation to patients' phenotypes. Eur J Dermatol 2010; 20: p. 271-5.

32 Li, C.R., Cui, P.G., Jia, H. et al. Identification of a novel mutation in a Chinese patient with mild Darier's disease. Int J Dermatol 2010; 49: p. 1286-8.

33 Ren, Y.Q., Gao, M., Liang, Y.H. et al. Five mutations of ATP2A2 gene in Chinese patients with Darier's disease and a literature review of 86 cases reported in China. Arch Dermatol Res 2006; 298: p. 58-63.

34 Goh, B.K., Ang, P., Goh, C.L. Darier's disease in Singapore. Br J Dermatol 2005; 152: p. 284-8.

35 Terrom, M., Dhaille, F., Baltazard, T. et al. Guttate leukoderma in Darier disease: case report and review. J Eur Acad Dermatol Venereol 2016.

36 Clemens, T.L., Adams, J.S., Henderson, S.L. et al. Increased skin pigment reduces the capacity of skin to synthesise vitamin D3. Lancet 1982; 1: p. 74-6.

37 Foggia, L., Aronchik, I., Aberg, K. et al. Activity of the hSPCA1 Golgi Ca2+ pump is essential for Ca2+-mediated Ca2+ response and cell viability in Darier disease. J Cell Sci 2006; 119: p. 671-9.

38 Savignac, M., Edir, A., Simon, M. et al. Darier disease : a disease model of impaired calcium homeostasis in the skin. Biochim Biophys Acta 2011; 1813: p. 1111-7.

39 Wong, S.N., Chua, S.H. Spectrum of subepidermal immunobullous disorders seen at the National Skin Centre, Singapore: a 2-year review. Br J Dermatol 2002; 147: p. 476-80.

40 Dodiuk-Gad, R., Lerner, M., Breznitz, Z. et al. Learning disabilities in Darier's disease patients. J Eur Acad Dermatol Venereol 2014; 28: p. 314-9.

41 Gordon-Smith, K., Jones, L.A., Burge, S.M. et al. The neuropsychiatric phenotype in Darier disease. Br J Dermatol 2010; 163: p. 515-22.

42 Jacobsen, N.J., Lyons, I., Hoogendoorn, B. et al. ATP2A2 mutations in Darier's disease and their relationship to neuropsychiatric phenotypes. Hum Mol Genet 1999; 8: p. 1631-6.

43 Wuytack, F., Raeymaekers, L., Missiaen, L. Molecular physiology of the SERCA and SPCA pumps. Cell Calcium 2002; 32: p. 279-305.

44 Dodiuk-Gad, R.P., Cohen-Barak, E., Khayat, M. et al. Darier disease in Israel: combined evaluation of genetic and neuropsychiatric aspects. Br J Dermatol 2016; 174: p. 562-8.

45 Cederlof, M., Bergen, S.E., Langstrom, N. et al. The association between Darier disease, bipolar disorder, and schizophrenia revisited: a population-based family study. Bipolar Disord 2015; 17: p. 340-4.

46 Cederlof, M., Karlsson, R., Larsson, H. et al. Intellectual disability and cognitive ability in Darier disease: Swedish nation-wide study. Br J Dermatol 2015; 173: p. 155-8. 


\section{CHAPTER 4 DARIER DISEASE AND HAILEY-HAILEY DISEASE}

Munro, C.S. The phenotype of Darier's disease: penetrance and expressivity in adults and children. Br J Dermatol 1992; 127: p. 126-30.

Benmously-Mlika, R., Bchetnia, M., Deghais, S. et al. Hailey-Hailey disease in Tunisia. Int J Dermatol 2010; 49: p. 396-401.

Korner, J., Rietschel, M., Nothen, M.M. et al. Familial cosegregation of affective disorder and Hailey-Hailey disease. Br J Psychiatry 1993; 163: p. 109-10.

Wilk, M., Rietschel, M., Korner, J. et al. [Pemphigus chronicus benignus familiaris (HaileyHailey disease) and bipolar affective disease in 3 members of a family]. Hautarzt 1994; 45: p. 313-7.

Behne, M.J., Tu, C.L., Aronchik, I. et al. Human keratinocyte ATP2C1 localizes to the Golgi and controls Golgi Ca2+ stores. J Invest Dermatol 2003; 121: p. 688-94.

Vanoevelen, J., Dode, L., Van Baelen, K. et al. The secretory pathway Ca2+/Mn2+-ATPase 2 is a Golgi-localized pump with high affinity for Ca2+ ions. J Biol Chem 2005; 280: p. 22800-8.

Dowlatshahi, E.A., Wakkee, M., Arends, L.R. et al. The prevalence and odds of depressive symptoms and clinical depression in psoriasis patients: a systematic review and meta-analysis. J Invest Dermatol 2014; 134: p. 1542-51.

Nelson, P.A., Ashcroft, D.M., Bundy, C. et al. The IMPACT Programme in Psoriasis: Phase I - where we are now and future directions. Dermatological Nursing 2015; 14: p. 37-44.

van Steenbergen-Weijenburg, K.M., van der Feltz-Cornelis, C.M., van Benthem, T.B. et al. [Collaborative care for co-morbid major depressive disorder in chronically ill outpatients in a general hospital]. Tijdschr Psychiatr 2015; 57: p. 248-57.

Ringpfeil, F., Raus, A., DiGiovanna, J.J. et al. Darier disease--novel mutations in ATP2A2 and genotype-phenotype correlation. Exp Dermatol 2001; 10: p. 19-27.

van Steensel, M.A., van Geel, M.V., Steijlen, P.M. Mal de Meleda without mutations in the ARS coding sequence. Eur J Dermatol 2002; 12: p. 129-32.

den Dunnen, J.T., Antonarakis, S.E. Mutation nomenclature extensions and suggestions to describe complex mutations: a discussion. Hum Mutat 2000; 15: p. 7-12.

den Dunnen, J.T., Dalgleish, R., Maglott, D.R. et al. HGVS Recommendations for the Description of Sequence Variants: 2016 Update. Hum Mutat 2016; 37: p. 564-9.

60 Dally, S., Corvazier, E., Bredoux, R. et al. Multiple and diverse coexpression, location, and regulation of additional SERCA2 and SERCA3 isoforms in nonfailing and failing human heart. J Mol Cell Cardiol 2010; 48: p. 633-44.

61 Moller, J.V., Olesen, C., Winther, A.M. et al. The sarcoplasmic Ca2+-ATPase: design of a perfect chemi-osmotic pump. Q Rev Biophys 2010; 43: p. 501-66. 


\section{CHAPTER 4 DARIER DISEASE AND HAILEY-HAILEY DISEASE}

62 Dode, L., Andersen, J.P., Leslie, N. et al. Dissection of the functional differences between sarco(endo)plasmic reticulum Ca2+-ATPase (SERCA) 1 and 2 isoforms and characterization of Darier disease (SERCA2) mutants by steady-state and transient kinetic analyses. J Biol Chem 2003; 278: p. 47877-89.

63 Vangheluwe, P., Raeymaekers, L., Dode, L. et al. Modulating sarco(endo)plasmic reticulum Ca2+ ATPase 2 (SERCA2) activity: cell biological implications. Cell Calcium 2005; 38: p. 291-302.

64 Wallis, Y., Payne, S., McAnulty, C. et al. Practice guidlines for the evaluation of pathogenecity and reporting of sequence variants in clinical molecular genetics. ACGS and DSCGLS 2013: p.http://www.acgs.uk.com/media/774853/evaluation_and_reporting_of_sequence_variants_ bpgs_june_2013_-_finalpdf.pdf.

65 Bchetnia, M., Charfeddine, C., Kassar, S. et al. Clinical and mutational heterogeneity of Darier disease in Tunisian families. Arch Dermatol 2009; 145: p. 654-6.

66 Green, E.K., Gordon-Smith, K., Burge, S.M. et al. Novel ATP2A2 mutations in a large sample of individuals with Darier disease. J Dermatol 2013; 40: p. 259-66.

67 Ikeda, S., Mayuzumi, N., Shigihara, T. et al. Mutations in ATP2A2 in patients with Darier's disease. J Invest Dermatol 2003; 121: p. 475-7.

68 Onozuka, T., Sawamura, D., Yokota, K. et al. Mutational analysis of the ATP2A2 gene in two Darier disease families with intrafamilial variability. Br J Dermatol 2004; 150: p. 652-7.

69 Shi, H.J., Li, M., Zhang, G.L. et al. Novel splice-site and frameshift ATP2A2 mutations in Chinese patients with Darier disease. Clin Exp Dermatol 2012; 37: p. 677-9.

70 Chao, S.C., Yang, M.H., Lee, J.Y. Mutation analysis of the ATP2A2 gene in Taiwanese patients with Darier's disease. Br J Dermatol 2002; 146: p. 958-63.

71 Fu, X., Liu, H., Yan, X. et al. Mutation analysis of the ATP2A2 gene in Chinese patients with Darier's disease. J Eur Acad Dermatol Venereol 2011; 25: p. 370-1.

72 Hamada, T., Yasumoto, S., Karashima, T. et al. Recurrent p.N767S mutation in the ATP2A2 gene in a Japanese family with haemorrhagic Darier disease clinically mimicking epidermolysis bullosa simplex with mottled pigmentation. Br J Dermatol 2007; 157: p. 605-8.

73 Mac Manus, M.P., Cavalleri, G., Ball, D.L. et al. Exacerbation, then clearance, of mutationproven Darier's disease of the skin after radiotherapy for bronchial carcinoma: a case of radiation-induced epidermal differentiation? Radiat Res 2001; 156: p. 724-30.

74 Pedace, L., Barboni, L., Pozzetto, E. et al. Molecular characterization of 11 Italian patients with Darier disease. Eur J Dermatol 2011; 21: p. 334-8.

75 Racz, E., Csikos, M., Benko, R. et al. Three novel mutations in the ATP2A2 gene in Hungarian families with Darier's disease, including a novel splice site generating intronic nucleotide change. J Dermatol Sci 2005; 38: p. 231-4. 


\section{CHAPTER 4 DARIER DISEASE AND HAILEY-HAILEY DISEASE}

Sakuntabhai, A., Burge, S., Monk, S. et al. Spectrum of novel ATP2A2 mutations in patients with Darier's disease. Hum Mol Genet 1999; 8: p. 1611-9.

Li, C.R., Zhang, Y., Jia, W.X. et al. Severe Darier's disease patient with mutation of ATP2A2. Postepy Dermatol Alergol 2014; 31: p. 338-40.

Shi, B.J., Xue, M., Zhu, Y.J. et al. Exon 12 of the ATP2A2 gene in patients with Darier disease: one novel mutation and one previously described. J Eur Acad Dermatol Venereol 2015; 29: p. 394-6.

Amichai, B., Karpati, M., Goldman, B. et al. Novel mutations in two families with Darier's disease. Int J Dermatol 2007; 46: p. 64-7.

Ellegren, H., Smith, N.G., Webster, M.T. Mutation rate variation in the mammalian genome. Curr Opin Genet Dev 2003; 13: p. 562-8.

Krawczak, M., Ball, E.V., Cooper, D.N. Neighboring-nucleotide effects on the rates of germline single-base-pair substitution in human genes. Am J Hum Genet 1998; 63: p. 474-88.

Gruenbaum, Y., Stein, R., Cedar, H. et al. Methylation of CpG sequences in eukaryotic DNA. FEBS Lett 1981; 124: p. 67-71.

Kaneko, S., Aki, I., Tsuda, K. et al. Origin and evolution of processed pseudogenes that stabilize functional Makorin1 mRNAs in mice, primates and other mammals. Genetics 2006; 172: p. 2421-9.

Razin, A., Webb, C., Szyf, M. et al. Variations in DNA methylation during mouse cell differentiation in vivo and in vitro. Proc Natl Acad Sci U S A 1984; 81: p. 2275-9.

Ollila, J., Lappalainen, I., Vihinen, M. Sequence specificity in CpG mutation hotspots. FEBS Lett 1996; 396: p. 119-22.

Rogozin, I.B., Malyarchuk, B.A., Pavlov, Y.I. et al. From context-dependence of mutations to molecular mechanisms of mutagenesis. Pac Symp Biocomput 2005: p. 409-20.

Rogozin, I.B., Pavlov, Y.I., Bebenek, K. et al. Somatic mutation hotspots correlate with DNA polymerase eta error spectrum. Nat Immunol 2001; 2: p. 530-6.

88 Fairclough, R.J., Dode, L., Vanoevelen, J. et al. Effect of Hailey-Hailey Disease mutations on the function of a new variant of human secretory pathway Ca2+/Mn2+-ATPase (hSPCA1). J Biol Chem 2003; 278: p. 24721-30.

89 Missiaen, L., Dode, L., Vanoevelen, J. et al. Calcium in the Golgi apparatus. Cell Calcium 2007; 41: p. 405-16.

Cheng, T.S., Ho, K.M., Lam, C.W. Heterogeneous mutations of the ATP2C1 gene causing Hailey-Hailey disease in Hong Kong Chinese. J Eur Acad Dermatol Venereol 2010; 24: p. 1202-6. 


\section{CHAPTER 4 DARIER DISEASE AND HAILEY-HAILEY DISEASE}

91 Li, H., Sun, X.K., Zhu, X.J. Four novel mutations in ATP2C1 found in Chinese patients with Hailey-Hailey disease. Br J Dermatol 2003; 149: p. 471-4.

92 Yokota, K., Yasukawa, K., Shimizu, H. Analysis of ATP2C1 gene mutation in 10 unrelated Japanese families with Hailey-Hailey disease. J Invest Dermatol 2002; 118: p. 550-1.

93 Cooper, D.N., Bacolla, A., Ferec, C. et al. On the sequence-directed nature of human gene mutation: the role of genomic architecture and the local DNA sequence environment in mediating gene mutations underlying human inherited disease. Hum Mutat 2011; 32: p. 1075-99.

94 Du, X., Gertz, E.M., Wojtowicz, D. et al. Potential non-B DNA regions in the human genome are associated with higher rates of nucleotide mutation and expression variation. Nucleic Acids Res 2014; 42: p. 12367-79.

95 Kondrashov, A.S., Rogozin, I.B. Context of deletions and insertions in human coding sequences. Hum Mutat 2004; 23: p. 177-85.

96 Kamat, M.A., Bacolla, A., Cooper, D.N. et al. A Role for Non-B DNA Forming Sequences in Mediating Microlesions Causing Human Inherited Disease. Hum Mutat 2016; 37: p. 65-73.

97 Ahn, W., Lee, M.G., Kim, K.H. et al. Multiple effects of SERCA2b mutations associated with Darier's disease. J Biol Chem 2003; 278: p. 20795-801.

98 Miyauchi, Y., Daiho, T., Yamasaki, K. et al. Comprehensive analysis of expression and function of 51 sarco(endo)plasmic reticulum Ca2+-ATPase mutants associated with Darier disease. J Biol Chem 2006; 281: p. 22882-95.

99 Sato, K., Yamasaki, K., Daiho, T. et al. Distinct types of abnormality in kinetic properties of three Darier disease-causing sarco(endo)plasmic reticulum Ca2+-ATPase mutants that exhibit normal expression and high Ca2+ transport activity. J Biol Chem 2004; 279: p. 35595-603.

100 Leinonen, P.T., Myllyla, R.M., Hagg, P.M. et al. Keratinocytes cultured from patients with Hailey-Hailey disease and Darier disease display distinct patterns of calcium regulation. $\mathrm{Br}$ J Dermatol 2005; 153: p. 113-7.

101 Savignac, M., Simon, M., Edir, A. et al. SERCA2 dysfunction in darier disease causes endoplasmic reticulum stress and impaired cell-to-cell adhesion strength: rescue by Miglustat. J Invest Dermatol 2014; 134: p. 1961-70.

102 Hetz, C. The unfolded protein response: controlling cell fate decisions under ER stress and beyond. Nat Rev Mol Cell Biol 2012; 13: p. 89-102.

103 Dhitavat, J., Cobbold, C., Leslie, N. et al. Impaired trafficking of the desmoplakins in cultured Darier's disease keratinocytes. J Invest Dermatol 2003; 121: p. 1349-55.

104 Celli, A., Mackenzie, D.S., Zhai, Y. et al. SERCA2-controlled Ca(2)+-dependent keratinocyte adhesion and differentiation is mediated via the sphingolipid pathway: a therapeutic target for Darier's disease. J Invest Dermatol 2012; 132: p. 1188-95. 


\section{CHAPTER 4 DARIER DISEASE AND HAILEY-HAILEY DISEASE}

105 Celli, A., Mackenzie, D.S., Crumrine, D.S. et al. Endoplasmic reticulum Ca2+ depletion activates XBP1 and controls terminal differentiation in keratinocytes and epidermis. $\mathrm{Br} \mathrm{J}$ Dermatol 2011; 164: p. 16-25.

106 Fairclough, R.J., Lonie, L., Van Baelen, K. et al. Hailey-Hailey disease: identification of novel mutations in ATP2C1 and effect of missense mutation A528P on protein expression levels. J Invest Dermatol 2004; 123: p. 67-71.

107 Ton, V.K., Rao, R. Expression of Hailey-Hailey disease mutations in yeast. J Invest Dermatol 2004; 123: p. 1192-4.

108 Matsuda, M., Hamada, T., Numata, S. et al. Mutation-dependent effects on mRNA and protein expressions in cultured keratinocytes of Hailey-Hailey disease. Exp Dermatol 2014; 23: p. 514-6.

109 Ramos-Castaneda, J., Park, Y.N., Liu, M. et al. Deficiency of ATP2C1, a Golgi ion pump, induces secretory pathway defects in endoplasmic reticulum (ER)-associated degradation and sensitivity to ER stress. J Biol Chem 2005; 280: p. 9467-73.

110 Lissandron, V., Podini, P., Pizzo, P. et al. Unique characteristics of Ca2+ homeostasis of the trans-Golgi compartment. Proc Natl Acad Sci U S A 2010; 107: p. 9198-203.

111 Sepulveda, M.R., Vanoevelen, J., Raeymaekers, L. et al. Silencing the SPCA1 (secretory pathway $\mathrm{Ca} 2+-\mathrm{ATPase}$ isoform 1) impairs Ca2+ homeostasis in the Golgi and disturbs neural polarity. J Neurosci 2009; 29: p. 12174-82.

112 Raiko, L., Siljamaki, E., Mahoney, M.G. et al. Hailey-Hailey disease and tight junctions: Claudins 1 and 4 are regulated by ATP2C1 gene encoding $\mathrm{Ca}(2+) / \mathrm{Mn}(2+)$ ATPase SPCA1 in cultured keratinocytes. Exp Dermatol 2012; 21: p. 586-91.

113 Kellermayer, R. Hailey-Hailey disease as an orthodisease of PMR1 deficiency in Saccharomyces cerevisiae. FEBS Lett 2005; 579: p. 2021-5.

114 Kellermayer, R. Hailey-Hailey disease from a clinical perspective. Cell Calcium 2008; 43: p. 105-6.

115 Locke, E.G., Bonilla, M., Liang, L. et al. A homolog of voltage-gated $\mathrm{Ca}(2+)$ channels stimulated by depletion of secretory $\mathrm{Ca}(2+)$ in yeast. Mol Cell Biol 2000; 20: p. 6686-94.

116 Vandecaetsbeek, I., Vangheluwe, P., Raeymaekers, L. et al. The Ca2+ pumps of the endoplasmic reticulum and Golgi apparatus. Cold Spring Harb Perspect Biol 2011; 3.

117 Periasamy, M., Reed, T.D., Liu, L.H. et al. Impaired cardiac performance in heterozygous mice with a null mutation in the sarco(endo)plasmic reticulum Ca2+-ATPase isoform 2 (SERCA2) gene. J Biol Chem 1999; 274: p. 2556-62.

118 Liu, L.H., Boivin, G.P., Prasad, V. et al. Squamous cell tumors in mice heterozygous for a null allele of Atp2a2, encoding the sarco(endo)plasmic reticulum Ca2+-ATPase isoform 2 Ca2+ pump. J Biol Chem 2001; 276: p. 26737-40. 


\section{CHAPTER 4 DARIER DISEASE AND HAILEY-HAILEY DISEASE}

119 Prasad, V., Boivin, G.P., Miller, M.L. et al. Haploinsufficiency of Atp2a2, encoding the sarco(endo)plasmic reticulum Ca2+-ATPase isoform $2 \mathrm{Ca} 2+$ pump, predisposes mice to squamous cell tumors via a novel mode of cancer susceptibility. Cancer Res 2005; 65: p. 8655-61.

120 Zhao, X.S., Shin, D.M., Liu, L.H. et al. Plasticity and adaptation of $\mathrm{Ca} 2+$ signaling and Ca2+dependent exocytosis in SERCA2(+/-) mice. EMBO J 2001; 20: p. 2680-9.

121 Mayosi, B.M., Kardos, A., Davies, C.H. et al. Heterozygous disruption of SERCA2a is not associated with impairment of cardiac performance in humans: implications for SERCA2a as a therapeutic target in heart failure. Heart 2006; 92: p. 105-9.

122 Tavadia, S., Tait, R.C., McDonagh, T.A. et al. Platelet and cardiac function in Darier's disease. Clin Exp Dermatol 2001; 26: p. 696-9.

123 Xiang, M., Mohamalawari, D., Rao, R. A novel isoform of the secretory pathway Ca2+, $\mathrm{Mn}(2+)$ ATPase, hSPCA2, has unusual properties and is expressed in the brain. J Biol Chem 2005; 280: p. 11608-14.

124 Lapinskas, P.J., Cunningham, K.W., Liu, X.F. et al. Mutations in PMR1 suppress oxidative damage in yeast cells lacking superoxide dismutase. Mol Cell Biol 1995; 15: p. 1382-8.

125 Antebi, A., Fink, G.R. The yeast $\mathrm{Ca}(2+)$-ATPase homologue, PMR1, is required for normal Golgi function and localizes in a novel Golgi-like distribution. Mol Biol Cell 1992; 3: p. 63354.

126 Durr, G., Strayle, J., Plemper, R. et al. The medial-Golgi ion pump Pmr1 supplies the yeast secretory pathway with $\mathrm{Ca} 2+$ and $\mathrm{Mn} 2+$ required for glycosylation, sorting, and endoplasmic reticulum-associated protein degradation. Mol Biol Cell 1998; 9: p. 1149-62.

127 Ton, V.K., Mandal, D., Vahadji, C. et al. Functional expression in yeast of the human secretory pathway $\mathrm{Ca}(2+), \mathrm{Mn}(2+)$-ATPase defective in Hailey-Hailey disease. J Biol Chem 2002; 277: p. 6422-7.

128 Praitis, V., Simske, J., Kniss, S. et al. The secretory pathway calcium ATPase PMR-1/SPCA1 has essential roles in cell migration during Caenorhabditis elegans embryonic development. PLoS Genet 2013; 9: p. e1003506.

129 Okunade, G.W., Miller, M.L., Azhar, M. et al. Loss of the Atp2c1 secretory pathway Ca(2+)ATPase (SPCA1) in mice causes Golgi stress, apoptosis, and midgestational death in homozygous embryos and squamous cell tumors in adult heterozygotes. J Biol Chem 2007; 282: p. 26517-27.

130 Shull, G.E., Miller, M.L., Prasad, V. Secretory pathway stress responses as possible mechanisms of disease involving Golgi Ca2+ pump dysfunction. Biofactors 2011; 37: p. 150-8.

131 Berk, D.R., Taube, J.M., Bruckner, A.L. et al. A Sporadic Patient with Acrokeratosis Verruciformis of Hopf and a Novel ATP2A2 Mutation. British Journal of Dermatology 2010; 9999. 


\section{CHAPTER 4 DARIER DISEASE AND HAILEY-HAILEY DISEASE}

132 Bergman, R., Sezin, T., Indelman, M. et al. Acrokeratosis verruciformis of Hopf showing P602L mutation in ATP2A2 and overlapping histopathological features with Darier disease. Am J Dermatopathol 2012; 34: p. 597-601.

133 Quan, C., Liang, Y.H., Zhang, Z.Z. et al. Two novel frame-shift mutations of ATP2A2 gene in Chinese patients with Darier's disease. J Eur Acad Dermatol Venereol 2008; 22: p. 745-6.

134 Takahashi, H., Atsuta, Y., Sato, K. et al. Novel mutations of ATP2A2 gene in Japanese patients of Darier's disease. J Dermatol Sci 2001; 26: p. 169-72.

135 Ueo, D., Hamada, T., Hashimoto, T. et al. Late-onset Darier's disease due to a novel missense mutation in the ATP2A2 gene: a different missense mutation affecting the same codon has been previously reported in acrokeratosis verruciformis. J Dermatol 2013; 40: p. 280-1.

136 Lora, V., Cota, C., Grammatico, P. et al. Comedonal Darier disease: report of 2 cases. J Am Acad Dermatol 2013; 69: p. e307-9.

137 Bchetnia, M., Benmously, R., Ben Brick, A.S. et al. New mutations of Darier disease in Tunisian patients. Arch Dermatol Res 2009; 301: p. 615-9.

138 Dobson-Stone, C., Fairclough, R., Dunne, E. et al. Hailey-Hailey disease: molecular and clinical characterization of novel mutations in the ATP2C1 gene. J Invest Dermatol 2002; 118: p. 338-43.

139 Hamada, T., Fukuda, S., Sakaguchi, S. et al. Molecular and clinical characterization in Japanese and Korean patients with Hailey-Hailey disease: six new mutations in the ATP2C1 gene. $J$ Dermatol Sci 2008; 51: p. 31-6.

140 Szigeti, R., Chao, S.C., Szasz, O. et al. Premenstrual exacerbation in calcium ATPase disorders of the skin. J Eur Acad Dermatol Venereol 2007; 21: p. 412-3.

141 Szigeti, R., Kellermayer, R. Autosomal-dominant calcium ATPase disorders. J Invest Dermatol 2006; 126: p. 2370-6.

142 Zhang, F., Yan, X., Jiang, D. et al. Eight novel mutations of ATP2C1 identified in 17 Chinese families with Hailey-Hailey disease. Dermatology 2007; 215: p. 277-83.

143 Kawada, H., Nishiyama, C., Takagi, A. et al. Transcriptional regulation of ATP2C1 gene by Sp1 and YY1 and reduced function of its promoter in Hailey-Hailey disease keratinocytes. J Invest Dermatol 2005; 124: p. 1206-14.

144 Takagi, A., Nishiyama, C., Maeda, K. et al. Role of Sp1 in transcription of human ATP2A2 gene in keratinocytes. J Invest Dermatol 2008; 128: p. 96-103.

145 James, K.A., Culton, D.A., Diaz, L.A. Diagnosis and clinical features of pemphigus foliaceus. Dermatol Clin 2011; 29: p. 405-12, viii.

146 Christophersen, J., Geiger, J.M., Danneskiold-Samsoe, P. et al. A double-blind comparison of acitretin and etretinate in the treatment of Darier's disease. Acta Derm Venereol 1992; 72: p. 150-2. 


\section{CHAPTER 4 DARIER DISEASE AND HAILEY-HAILEY DISEASE}

147 Letule, V., Herzinger, T., Ruzicka, T. et al. Treatment of Darier disease with oral alitretinoin. Clin Exp Dermatol 2013; 38: p. 523-5.

148 Steijlen, P.M., Reifenschweiler, D.O., Ramaekers, F.C. et al. Topical treatment of ichthyoses and Darier's disease with 13-cis-retinoic acid. A clinical and immunohistochemical study. Arch Dermatol Res 1993; 285: p. 221-6.

149 Krakowski, A.C., Nguyen, T.A., Eichenfield, L.F. Treatment of segmental keratosis follicularis (Darier disease) using ablative fractional laser resurfacing. Dermatol Surg 2015; 41: p. 516-8.

150 Falto-Aizpurua, L.A., Griffith, R.D., Yazdani Abyaneh, M.A. et al. Laser therapy for the treatment of Hailey-Hailey disease: a systematic review with focus on carbon dioxide laser resurfacing. J Eur Acad Dermatol Venereol 2015; 29: p. 1045-52.

151 Hunt, K.M., Jensen, J.D., Walsh, S.B. et al. Successful treatment of refractory Hailey-Hailey disease with a 595-nm pulsed dye laser: a series of 7 cases. J Am Acad Dermatol 2015; 72: p. 735-7.

152 Biolcati, G., Aurizi, C., Barbieri, L. et al. Efficacy of the melanocortin analogue Nle4-D-Phe7alpha-melanocyte-stimulating hormone in the treatment of patients with Hailey-Hailey disease. Clin Exp Dermatol 2014; 39: p. 168-75.

153 Koeyers, W.J., Van Der Geer, S., Krekels, G. Botulinum toxin type A as an adjuvant treatment modality for extensive Hailey-Hailey disease. J Dermatolog Treat 2008; 19: p. 251-4.

154 Bidou, L., Allamand, V., Rousset, J.P. et al. Sense from nonsense: therapies for premature stop codon diseases. Trends Mol Med 2012; 18: p. 679-88.

155 Karijolich, J., Yu, Y.T. Therapeutic suppression of premature termination codons: mechanisms and clinical considerations (review). Int J Mol Med 2014; 34: p. 355-62.

156 Kellermayer, R., Szigeti, R., Keeling, K.M. et al. Aminoglycosides as potential pharmacogenetic agents in the treatment of Hailey-Hailey disease. J Invest Dermatol 2006; 126: p. 229-31.

157 Del Monte, F., O'Gara, P., Poole-Wilson, P.A. et al. Cell geometry and contractile abnormalities of myocytes from failing human left ventricle. Cardiovasc Res 1995; 30: p. 281-90.

158 Sikkel, M.B., Hayward, C., MacLeod, K.T. et al. SERCA2a gene therapy in heart failure: an anti-arrhythmic positive inotrope. Br J Pharmacol 2014; 171: p. 38-54.

159 Jessup, M., Greenberg, B., Mancini, D. et al. Calcium Upregulation by Percutaneous Administration of Gene Therapy in Cardiac Disease (CUPID): a phase 2 trial of intracoronary gene therapy of sarcoplasmic reticulum Ca2+-ATPase in patients with advanced heart failure. Circulation 2011; 124: p. 304-13.

160 LaFountaine, J.S., Fathe, K., Smyth, H.D. Delivery and therapeutic applications of gene editing technologies ZFNs, TALENs, and CRISPR/Cas9. Int J Pharm 2015; 494: p. 180-94.

161 Jeong, E.H., Kim, H., Jang, B. et al. Technological development of structural DNA/RNA-based RNAi systems and their applications. Adv Drug Deliv Rev 2016; 104: p. 29-43. 
CHAPTER 4 DARIER DISEASE AND HAILEY-HAILEY DISEASE 


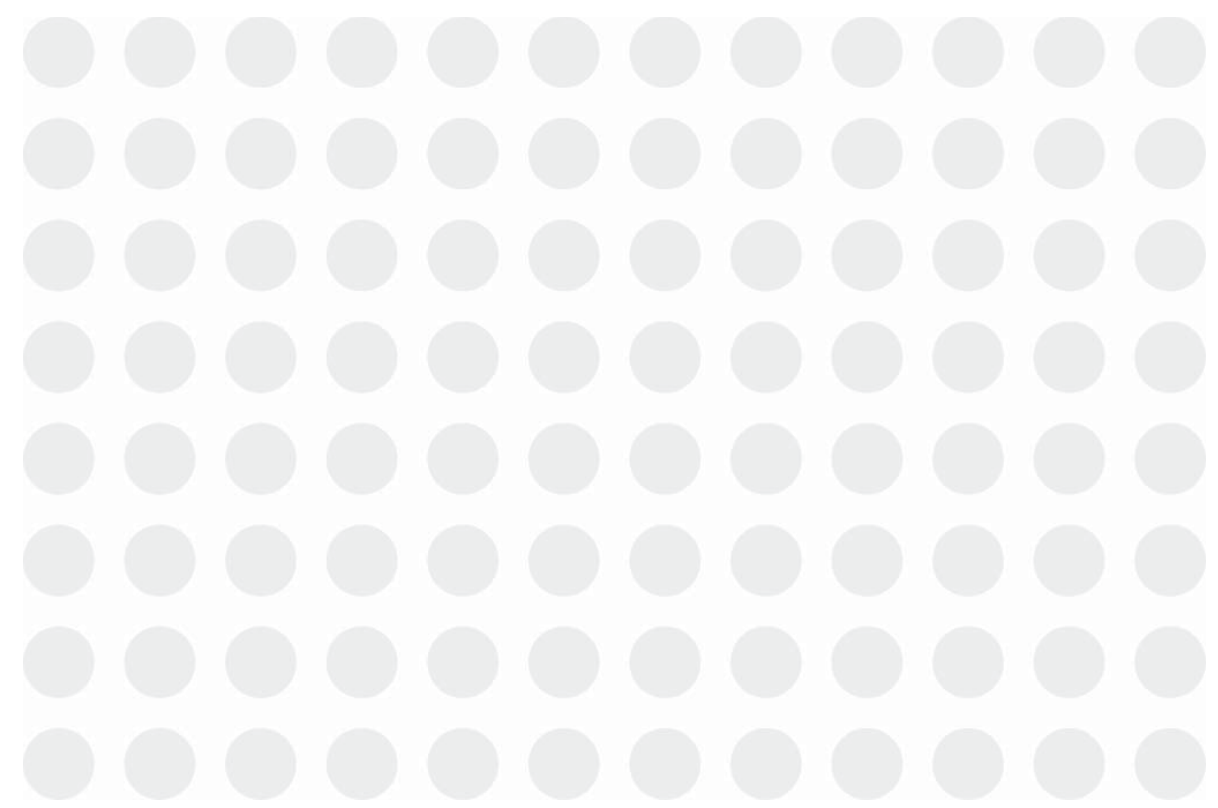




\section{Chapter V}

Conclusions, discussion and valorisation 


\subsection{Conclusions and general discussion}

The Mendelian disorders of cornification (MEDOC) are a clinically and genetically heterogeneous group of hereditary skin disorders affecting homeostasis of the epidermis. Among the diseases counted as MEDOC are the ichthyoses, palmoplantar keratodermas (PPK), Darier disease (DD) and Hailey-Hailey disease (HHD). This thesis focuses on clinical and genetic heterogeneity and possible genotype-phenotype correlations in these MEDOC. We describe the clinical and molecular genetic characteristics of patients with mal de Meleda (MDM), Epidermolytic Ichthyosis (EI), Darier disease (DD) and Hailey-Hailey disease (HHD). The aims of this thesis were to assess clinical and genetic variability in MDM, EI, DD and HHD and to define genotype-phenotype correlations in MDM, EI, DD and HHD.

\subsubsection{Mal de Meleda}

MDM is a rare autosomal recessive PPK, caused by mutations in the Secreted Ly-6/ uPar related protein-1 gene $(S L U R P 1)^{1}$. Clinical features are progressive transgredient hyperkeratosis of the palms and soles, hyperhidrosis, malodourous scent due to bacterial superinfection ${ }^{2,3}$. Minor symptoms such as perioral erythema, mild ichthyosiform hyperkeratosis on elbows and knees, pseudo-ainhum and nail abnormalities may develop in a limited number of patients ${ }^{2,3}$. Symptoms are somewhat variable due to exogenous factors (heat, manual labor) and tend to worsen with age ${ }^{4}$. Of interest, SLURP1 mutations have been found in patients with palmoplantar keratoderma of the Gamborg-Nielsen type (PPK-GN), a PPK with similar characteristics as MDM ${ }^{5}$. It was argued that PPK-GN is allelic to MDM due to the less severe disease course observed in a series of patients.

To assess clinical and genotypic variability in MDM, we semi-quantatively summarized all reported phenotypes reported in the literature, described the phenotype and genotype of four Dutch, one German and two Indian patients with MDM, performed haplotype analysis in MDM patients with the p.(Trp15Arg) variant. We commented on the status of PPK-GN ${ }^{6-9}$.

\subsubsection{Clinical variability}

Review of the literature on clinical features in MDM and examination of our patients revealed that all MDM patients show the following major symptoms: a transgredient 


\section{CHAPTER 5 CONCLUSIONS, DISCUSSION AND VALORISATION}

(i.e. extending to dorsal surfaces of hands and feet) and progressive (progrediens i.e. progression of hyperkeratosis during the years) palmoplantar keratoderma that starts in the first year of life, hyperhidrosis and concurrent fungal and bacterial superinfection (see chapter II, table 2.3). Minor symptoms are nail deformities (pale, pink discoloration, subungual hyperkeratosis, koilonychia and dystrophy), perioral erythema, mild ichthyosiform hyperkeratosis on elbows and knees, pseudo-ainhum and conical tapering of the distal phalanges. The severity of symptoms varies between patients, mainly in severity and extent of palmoplantar hyperkeratosis. The main contributing factors to disease severity seem to be heat exposure, mechanical stress and age. The phenotype of the Dutch and Indian MDM patients described in this thesis did not differ from descriptions in the literature. However, our review of clinical symptoms in MDM does not give a complete view of phenotypic variation in MDM. In most reports, only a synopsis of clinical symptoms is provided, especially when large families are described ${ }^{1,4,10}$. Furthermore, most studies are "cross-sectional", i.e. report clinical findings at the time of consultation/examination but do not or do not adequately describe whether or not disease progression is present. The number of described MDM patients in most case series is too small to yield robust results. Last, there are no instruments to reliably quantify disease severity in MDM, which makes comparison of reported phenotypes in different studies difficult.

\subsubsection{Genetic variability}

We describe four Dutch patients, one German family with an affected mother and three affected children and two Indian siblings with MDM. The Dutch patient was compound heterozygous for the p.(Trp15Arg) and the unreported p.(Arg71Pro) mutation and the two Indian patients homozygous for the unreported c.58+5G $>\mathrm{T}$ variant, predicted to lead to the frameshift mutation p.(Val17Metfs $\left.{ }^{\star} 16\right)$. Our results confirm the relation between homozygous mutations in SLURP1 and MDM and expand the mutation spectrum in MDM: to date, 18 variants in SLURP1 have been reported, including the novel p.(Arg71Pro) and c.58+5G>T/p.(Val17Metfs ${ }^{\star} 16$ ) variants (see chapter II, table 2.1).

The three other Dutch patients and German family members with cardinal features of MDM were homozygous for the p.(Trp15Arg) mutation. Haplotype analysis indicates that the most prevalent SLURP1 mutation in the Western-European population, p.(Trp15Arg), was introduced by a common ancestor into the population rather than 


\section{CHAPTER 5 CONCLUSIONS, DISCUSSION AND VALORISATION}

being a chance event. The p.(Trp15Arg) variant is the third mutation for which a founder effect is demonstrated, apart from p.(Cys28fs32*) and p.(Arg96 $\left.6^{\star}\right)$. The founder effect described for the p.(Cys28fs32*) and p. $($ Arg96*) mutation is reported in families with a high incidence of consanguinity, which may account for the high prevalence of MDM. Although consanguinity was not reported in our patients, the high incidence of the p. (Trp15Arg) variant may be attributable to the fact that the Dutch and German patients were members of a homogenous population. Incidental migration may have spread this variant to other parts of Northern Europe and may be an explanation for the occurrence of the p.(Trp15Arg) mutation in Sweden ${ }^{5}$. However, the Swedish MDM patients originate from an isolated part of Sweden, and therefore, the possibility that the p.(Trp15Arg) variant originated independently from the other Northern European p.(Trp15Arg) variant cannot be ruled out. The fact that this variant is the most common SLURP1 mutation reported in the Western-European population, indicates that p.(Trp15Arg) can be considered as a population specific mutation for MDM. This provides valuable information for screening and diagnostic strategies in PPK.

\subsubsection{Genotype-phenotype correlation}

We were not able to establish a genotype-phenotype correlation in MDM, other than the complete penetrance of homozygous or compound heterozygous SLURP1 mutations. Clinical variability seems to rely on influencing factors (age) and external factors (heat and manual labor) and not on specific mutation types (e.g. missense mutations etc.) or location of variants. Based on this conclusions, we cannot support the proposed relation between SLURP1 variant p.(Trp15Arg) and the phenotype of PPK-GN ${ }^{5}$. Rather, PPKGN merely represents the mild end of the MDM spectrum. We therefore propose that the classification of PPK-GN as a separate genodermatosis be abandoned.

\subsubsection{Epidermolytic Ichthyosis}

Epidermolytic Ichthyosis (EI) is a rare autosomal dominant skin disorder caused by mutations in the genes coding for keratin 1 (KRT1) and 10 (KRT10). The classic symptoms of EI are either widespread blistering and erythroderma during infancy that develops into generalized ichthyosis, often more pronounced in the flexural areas (severe phenotype) or blistering upon mechanical trauma, but no ichthyosis (mild phenotype). If KRT1 mutations are the cause of EI, a palmoplantar keratoderma will develop as well. A 
strong phenotype-genotype correlation has been reported in patients harboring a KRT1 mutation. Mutations associated with a severe phenotype occur in the helix boundary motifs (HBM) of the protein ${ }^{11,12}$. Mutations causing milder phenotypes occur in the linker (L12) domain ${ }^{13,14}$.

To further delineate clinical and genetic variability in EI, we describe the phenotypes found in a large family with EI in whose members the p.(Met339Lys) mutation in KRT1 was found. Furthermore, we analyzed the mutation's impact on keratin filament formation.

\subsubsection{Clinical variability}

In our described family, EI manifests with a remarkable phenotypic variation among affected members, in whom we found the p.(Met339Lys) variant in KRT1. The index patient presented with a diffuse palmoplantar keratoderma, severe ichthyosis with a cobblestone appearance in flexural areas and distal parts of the extremities and mild ichthyosis on the trunk, in the absence of congenital blistering and erythroderma. On the other hand, the other patients, harbouring the same mutation, and sharing a common ancestor with the first patient, only developed a diffuse palmoplantar keratoderma and occasional friction blisters. The mechanisms that underlie such phenotypic differences are not well understood. We do not think that environmental factors can explain them. Our index patient was not excessively exposed to exacerbating factors. Furthermore, the other affected patients had no different exposition to these environmental factors and only developed PPK with mild blistering after trauma. We excluded the 5 most frequently found Western European FLG mutations (c.1501C>T (p.Arg501*), c.2282_2285del4, c.3702delG, c.7339C>T (p.Arg2447*) and c.9740C>A (p.Ser3247*)) in our index patient as explanation for the observed difference in phenotypes ${ }^{15}$. Differences in posttranslational processing of mutated $\mathrm{K} 1$ between individuals, such as phosphorylation in reaction to mechanical stress, or endoplasmic reticulum stress responses following improper processing of keratin aggregates may be a theoretical explanation for the observed intrafamilial variation. The intrafamilial phenotypic variation has not been reported before in EI patients with mutations in the L12 domain, although intrafamilial clinical heterogeneity in EI has been reported for the p.(Ser185Pro) mutation in the rod $1 \mathrm{~A}$ domain of $K R T 1^{16}$ and p.(Leu153Met) mutation in the rod $1 \mathrm{~A}$ domain of KRT10 ${ }^{17}$. 


\section{CHAPTER 5 CONCLUSIONS, DISCUSSION AND VALORISATION}

\subsubsection{Genetic variability}

Mutation analysis revealed the missense mutation c.1016T >A (p.(Met339Lys)). This mutation is an addition to the reported variants in KRT1 associated with EI. Index patients were related through a common ancestor five generations in the past. Results from transfection experiments indicate pathogenicity of the p.(Met339Lys) mutation: $\mathrm{HaCaT}$ cells expressing the mutant EGFP-KRT1 fusion construct showed increased keratin clumping and decreased keratin filament formation compared to wild-type transfected cells, in particular after hyperosmotic shock. These observations are in concordance with transfection experiments for the p.(Asp340Gly) variant, where increased keratin clumping and a similarly diminished keratin filament network was observed $^{13}$. However, the results of our transfection experiments do not provide an explanation for the intrafamilial phenotypic variation.

\subsubsection{Genotype-phenotype correlations}

The observed variable severity of skin symptoms in our patients is not consistent with the supposedly strict genotype-phenotype correlations in KRT1-associated skin disease. Mutations in the helix boundary motifs of KRT1 and KRT10 can cause the severe EI phenotype consisting of neonatal erythroderma and blistering that progress to generalized ichthyosis ${ }^{11,12,18,19}$. A less severe phenotype of mild neonatal blistering, adult PPK and mild blistering upon trauma in absence of neonatal erythroderma and generalized ichthyosis is supposed to be associated with mutations in the linker (L12) domain ${ }^{13,14}$. However, we find the extensive ichthyosis in the index patient, whereas we do observe relatively mild PPK and blistering in the other patients. Both this phenotype and the strong intrafamilial clinical variability have not been described in patients with mutations in the L12 domain before. It remains to be seen which additional genetic, epigenetic or environmental factors are responsible for the observed intrafamilial phenotypic variation in EI.

The occurrence of either severe or mild EI caused by mutations in the $2 \mathrm{~B}$ domain seems to be related to the position of the affected amino acid in the keratin rod domain. Mutations of interface residues, which disrupt K1-K10 dimer interaction, are associated with severe phenotypes, whereas residues in surface-exposed positions on the keratin rod domain are associated with mild phenotypes ${ }^{20,21}$. Furthermore, there are incidental reports that not only the position, but the nature of the amino acid change is 


\section{CHAPTER 5 CONCLUSIONS, DISCUSSION AND VALORISATION}

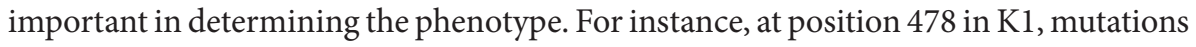
p.(Glu478Gln $)^{18}$ and p.(Glu478Lys) ${ }^{22}$ are associated with severe EI, whereas variant

p.(Glu478Asp) $)^{19,23,24}$ is associated with mild disease. In the two former variants, the negatively charged glutamic acid is replaced by the neutral glutamine and the positively charged lysine amino acid, respectively. In the latter variant, glutamic acid is replaced by aspartate, which is a negatively charged amino acid as well. Furthermore, the side chains of glutamate and aspartate only differ one carbon atom in length. Therefore, it is thought that this variant has a less detrimental influence on the tertiary structure of $K 1$ than the other variants, as residual filament formation was demonstrated in cells transfected with mutant KRT1:p.(Glu478Asp) ${ }^{24}$. In our family, the hydrophobic uncharged methionine is changed into the positively charged lysine. It is interesting to note that this amino acid substitution is, apparently, responsible for not only the expected more severe EI phenotype, but a mild EI phenotype as well.

Several other transfection studies have shown similar results: KRT1 or KRT10 mutations that cause severe EI showed cytoplasmic keratin clumping and absence of a keratin filament network, whereas KRT1 or KRT10 mutations associated with mild EI led to perinuclear keratin filament collapse without formation of keratin clumping ${ }^{11,20}$. It is interesting to note that HaCaT cells transfected with KRT1:p.(Met339Lys), found in our family, and KRT1:p.(Asp340Gly) showed both features: keratin filament formation was diminished and keratin aggregates occurred ${ }^{13,25}$, where absence of aggregates was expected. Aggregate formation was less than observed in severe EI. The functional consequences of these observations, especially the apparent occurrence of three different transfection phenotypes (keratin aggregates, diminished keratin network, combined aggregates/diminished network) remain unclear. One study found increased apoptosis in keratinocytes with the KRT10:p.(Arg156Cys) mutation associated with severe EI and keratin aggregate formation, and an increased mitotic index in keratinocytes with the KRT10:p.(Gln441del) mutation associated with mild EI and perinuclear keratin filament formation ${ }^{20}$. These findings may be related to increased epidermolysis and may possibly explain blister formation and widespread skin involvement in severe EI on the one hand, and increased susceptibility to development of an ichthyosiform phenotype in mild EI on the other hand. Again, this functional data does not explain the intrafamilial variation seen in our EI family. 


\section{CHAPTER 5 CONCLUSIONS, DISCUSSION AND VALORISATION}

\subsubsection{Darier disease and Hailey-Hailey disease}

The two disorders of cornification associated with mutations in genes coding for intracellular calcium pumps are Darier disease (DD) and Hailey-Hailey disease (HHD). Both are inherited as autosomal dominant traits and are relatively common. DD is mainly defined by warty papules in seborrheic and flexural areas $^{26}$, whereas the major symptoms of HHD are vesicles and erosions in flexural skin ${ }^{27}$. Both phenotypes are highly variable. Cases of either type I or type II segmental disease have been reported for both disorders ${ }^{28-30}$. DD seems to be associated with a higher prevalence of neuropsychiatric disease ${ }^{31,32}$.

$\mathrm{DD}$ is caused by mutations in the ATP2A2 gene ${ }^{33}$, while the $A T P 2 C 1$ gene is associated with $\mathrm{HHD}^{34,35}$. Both genes encode ATP-dependent pumps that transport $\mathrm{Ca}^{2+}$ or $\mathrm{Ca}^{2+} /$ $\mathrm{Mn}^{2+}$ from the cytosol to the lumen of the endoplasmic reticulum (SERCA2) or the Golgi (SPCA1), respectively. However, in $12-40 \%$ of DD patients and $12-55 \%$ of HHD patients no mutations in ATP2A2 (DD) or ATP2C1 (HHD) are found ${ }^{34,36-50}$.

\subsubsection{Clinical variability}

We describe two DD patients with a less frequently encountered phenotype and provide comment on the relation between DD and psychiatric disease. The first patient is a 1-year-old Caucasian boy with type II segmental DD. He developed erosive patches confined to the right side of the abdomen, following the lines of Blaschko. His mother, maternal uncle and maternal grandmother were known to have classic, generalised DD. More importantly, we were able to, for the first time, provide molecular genetic support for the type II segmental manifestation in DD, which has not been done before. Sequencing analysis of $A T P 2 A 2$ revealed a novel germline missense mutation in exon 8, c.1030G $>$ A, p.(Gly343Asp). In the PCR product containing exon 8 of the ATP2A2 gene derived from lesional skin, we found the p.(Gly343Asp) mutation as well, and saw a marked decrease of the wild-type G-signal when compared with the heterozygous germline mutation, indicative of loss of heterozygosity $(\mathrm{LOH})$. All findings together may be taken as supporting evidence in favour of the proposed aetiological concept of type 2 mosaicism.

The second patient was a 25-year-old female, born in Sri Lanka, with DD caused by missense mutation p.(Leu590Pro). She developed a diffuse palmoplantar keratoderma with palmar pits during childhood. During puberty she developed flat, skin-coloured papules on the dorsum of her hands and a small number of discrete, disseminated, 
pigmented papules and depigmented macules 5-7 $\mathrm{mm}$ in diameter on her trunk. Although this case may be an example of the normal variability of symptoms in $\mathrm{DD}^{33}$, we hypothesise that the skin type of our patient is the main contributing factor to the mild appearance of the disease. Dark skin type protects against UVB-irradiation, which is an important exacerbating factor in DD. Also, (desmosomal) adhesion of keratinocytes of DD patients with Fitzpatrick skin type V possibly differs from patients with skin type I-III, as can be concluded, for example, from the relatively low incidence of blistering diseases such as bullous pemphigoid. In contrast to the abundant reports on DD in patients with skin type I-IV, the literature on DD patients with skin type V-VI is scarce ${ }^{51}$. We suggest that this may be due to DD having a mitigated course in dark skin, leading to underdiagnosis.

It remains difficult to establish a causal relationship between ATP2A2 variants and the neuropsychiatric phenotype. Given the fact that ATP2A2 is expressed in brain neurons ${ }^{33,52}$, ATP2A2 mutations may possibly have a causal role in the development of neuropsychiatric disease. There is experimental evidence that implies a role for (aberrant) calcium signaling in the pathophysiology of intellectual disability, bipolar disorder and schizophrenia $^{53}$. However, this deterministic view on the aetiologic role of ATP2A2 variants underestimates the multifactorial nature of these psychiatric disorders. With regard to the high prevalence of depression and depressive symptoms in $\mathrm{DD}$, it seems not very likely that psychiatric symptoms are only attributable to ATP2A2 mutations. Although higher than in the general population, lifetime depression prevalence in DD is not remarkably different from psoriasis or other chronic diseases ${ }^{54}$ ( $5.4 \%$ for clinical depression, $22.9 \%$ for depressive symptoms in $\mathrm{DD}^{31}$, vs. $10 \%$ and $28 \%$ in psoriasis, respectively). This suggests that having a chronic, extensive and debilitating skin disease is a major determinant for the development of mood disorders in DD. Furthermore, the theoretical possibility that ATP2A2 mutations segregate with susceptibility loci for development of neuropsychiatric disease has not been ruled out as an explanation for the observed relation. That said, these observations emphasise that the burden of psychological suffering is an important part of DD.

\subsubsection{Genetic variability}

In this thesis, we review the locus-specific database (LSDB) we created for all mutations in ATP2A2 and ATP2C1 using the Leiden Open Variation Database (LOVD v3.0, www. 


\section{CHAPTER 5 CONCLUSIONS, DISCUSSION AND VALORISATION}

lovd.nl). This allows us to analyse all variants reported in the literature as well as future inclusions. The existing set for variations of ATP2A2 contains 350 entries with 253 unique variants, while the one for ATP2C1 contains 209 entries with 167 unique variants. The variants for both genes are located throughout the respective coding sequences and include missense, nonsense, and splice site mutations in addition to insertions and deletions causing frameshifts. Furthermore, we analysed 80 cases of DD and 20 cases of HHD, whose data were added to the database. We found 43 different ATP2A2 mutations in $60 \mathrm{DD}$ patients (75\%) and 13 different ATP2C1 mutations in $17 \mathrm{HHD}$ patients (85\%), of which 24 ATP2A2 variants and 10 ATP2C1 variants are novel, respectively. Mutations are scattered throughout the genes and are in all mutation categories.

In our case series, we did not find mutations in $25 \%$ of DD and $15 \%$ of $\mathrm{HHD}$ patients, which is consistent with other reports. In these patients without a mutation in the associated gene, variants might be present in gene regions not screened (e.g. deep intronic, promoter regions), or consist of exon deletions or duplications. One DD patient showed skipping of exon 4 of ATP2A2 on mRNA level, which indicates that, for instance, larger deletions or cryptic splice site mutations may account for the disease phenotype. Other diagnostic strategies such as MLPA analysis, RNA analysis or whole genome sequencing should be considered to elucidate the underlying genetic variation if conventional diagnostic strategies (e.g. Sanger sequencing as performed in this thesis) do not yield results. Alternatively, some patients might have phenotypes that resemble DD or HHD, but are caused by different gene defects. For example, a phenotype of impaired epidermal adhesion reminiscent of the acantholysis found in DD and HHD is observed in zebrafish in association with mutations in atp $1 b 1$. The atp $1 b 1$ gene encodes a $\beta$-subunit of a $\mathrm{Na}^{+}, \mathrm{K}^{+}$-ATPase, an ion pump that drives the directional transport of $\mathrm{Na}^{+}$and $\mathrm{K}^{+}$ions across cell membranes thus maintaining ionic homeostasis in tissues. In humans, variants in the homologue $A T P 1 B 1$ are thought to be a susceptibility locus for hypertension, although skin changes have not been reported in association with ATP1B1 variants.

\subsubsection{Genotype-phenotype correlation}

The data collected in both LSDBs for ATP2A2 and ATP2C1 allowed us to draw the following conclusions regarding the genotype-phenotype correlation in DD and HHD. For DD there are data suggesting that mutations in the ATP-binding region of SERCA2 


\section{CHAPTER 5 CONCLUSIONS, DISCUSSION AND VALORISATION}

could be associated with the development of Acrokeratosis Verruciformis of Hopf (AKV). The mutations p.(Leu590Pro), p.(Pro602Leu) and p.(Ala698Val) have been found in patients with AKV, but not in patients with classic DD. The p.(Pro602Leu) variant is found in two unrelated families with AKV (this thesis). This may suggest that mutations in these two specific areas of ATP2A2 cause a predominant AKV phenotype. However, the other 18 variants found in the ATP-binding region, among which the p.(Ala698Pro) mutation, are associated with the classic DD phenotype. In the other patients with DD and the patients with HHD we could not discern a specific genotype-phenotype correlation between disease onset, disease course, and disease severity. Specifically for $\mathrm{DD}$, no relations between gene variant and the acral-haemorrhagic DD, comedonal DD or the neuropsychiatric phenotype associated with DD were found.

However, establishing a genotype-phenotype-correlation is difficult for several reasons. Most studies report small cohorts (up to 30 individuals) of DD or HHD patients, which is likely to bias findings. No standardised and reproducible scoring system for disease severity exists, although semi-quantitative systems have been described ${ }^{26,33,42}$. This fact limits the possibility to adequately evaluate the natural course of exacerbations elicited by external factors and spontaneous remissions in $\mathrm{DD}$ and $\mathrm{HHD}^{26}$.

\subsection{Future prospects}

The knowledge presented in this thesis may hopefully be helpful for improvement in diagnosis and treatment of patients with MEDOC and may prove to be a guideline for future research. The translation from the results in this thesis to clinical practice converges onto two topics: advancement in clinical and molecular diagnostics and advancement in developing new treatment options. Challenges in these areas are generally the same for MDM, EI, DD and HHD and will therefore be discussed together.

\subsubsection{Diagnostic challenges}

Expanding knowledge on clinical variation in MEDOC. For all discussed MEDOC in this thesis, further progress can be made in the delineation of phenotypic variety and disease course. The most obvious way to achieve this goal is the establishment of larger case series, in which patients are followed and symptoms are evaluated over time, with 


\section{CHAPTER 5 CONCLUSIONS, DISCUSSION AND VALORISATION}

special emphasis on external exacerbating factors. Collecting this data should be a multicentre, perhaps even trans-national effort. Preferably, data should be centrally registered in an open-access database. This is especially relevant in MEDOC with great phenotypic variability, such as EI. Defining the highly variable phenotype and sometimes unclear genotype-phenotype correlation will only succeed in a large-scale effort.

To adequately assess disease course in MEDOC, reliable disease severity scoring systems should be developed. These will enable harmonised scientific reporting and standardised evaluation of treatment outcomes. This scoring system should take into account the extent of affected skin on one hand, and on the other hand, extent of hyperkeratosis in DD (e.g. hyperkeratotic papules vs. confluated hyperkeratotic patches) or blistering and reactive hyperkeratosis in HHD to give an estimate of disease severity. These features are the most significant determinants of health related quality of life in $\mathrm{DD}^{55}$. This makes such a scoring system not only a more objective measure of disease severity than the current classification ${ }^{33,42}$, but also measures the more relevant aspects of disease for patients. The disease severity scoring system for MDM proposed in this thesis should be validated in order to standardise evaluation of the extent of MDM.

A special aspect of at least DD that should receive much more emphasis is the occurrence of psychological and psychiatric disease. The disease burden from these symptoms remains high in a large number of DD patients ${ }^{31,56}$. Interestingly, an association between psychiatric disease and HHD has not been reported ${ }^{57-59}$, although SPCA1 is expressed in brain nerve cells comparable to SERCA2 cells ${ }^{34,60,61}$. A thorough (neuro-) psychological and psychiatric evaluation in HHD patients is therefore needed to see if such a correlation is present. Furthermore, the attention should shift from a focus on aetiological aspects to a more clinically oriented approach: "integrative" or "collaborative" care, i.e. evaluation, counseling and treatment of psychiatric disease should be an integral part of care in DD, at least for mood disorders. This view should be extended to other MEDOC as well. The (health related) quality of life is also compromised in other genetic skin diseases, such as EI and other forms of ichthyosis ${ }^{62-64}$. It is unknown if this impaired quality of life is associated with a higher prevalence of clinical depression and depressive symptoms. However, a higher prevalence of these disorders may be expected, as the other MEDOC are chronic, debilitating skin diseases as well. Therefore, collaborative care should be considered in the treatment of other MEDOC as well, as this has proven to be of great value in other chronic disorders ${ }^{65}$. 


\section{CHAPTER 5 CONCLUSIONS, DISCUSSION AND VALORISATION}

Expanding knowledge on genetic variation in MEDOC. This thesis underlines the value of collecting and categorising disease-causing variants for monogenic skin disorders. First of all, LSDBs are a quick reference tool for evaluating variants found in newly diagnosed patients. Secondly, the creation of a locus-specific database (LSDB) for ATP2A2 and ATP2C1 in the Leiden Open Variation Database (LOVD, www.lovd. nl) enabled us, as pointed out before, to address the genotype-phenotype correlation in DD and HHD in greater detail than has been done before (see chapter IV, paragraph 4.5). Furthermore, data that can only be retrieved by analysing all variants in LSDBs, such as relative prevalence of specific mutation types, mutation position, the presence or absence of mutation hotspots, may be beneficial for future treatment.

A specific problem in genetic diagnosis of DD and HHD is the fact that a substantial number of patients do not show variants in ATP2C1 or ATP2C1. The finding of a deletion of exon 4 revealed by RNA sequence analysis in one of our DD patients and the reported $2.5 \mathrm{Mb}$ deletion in a HHD patient ${ }^{34}$ indicates that other DNA defects than base substitutions, small deletions, insertions and insertion-deletions are responsible for the DD and HHD disease phenotype. Further research should evaluate the value of other diagnostic tests, such as MLPA, RNA analysis or whole exome sequencing, when ATP2A2 and ATP2C1 variants are not found.

Addressing the question of intrafamilial variation in disease severity. This thesis describes, but unfortunately does not explain the considerable intrafamilial phenotypic variability in MDM, EI, DD and HHD. In all investigated MEDOC, external factors seem to be relevant (for instance, $\mathrm{UV}$ radiation in $\mathrm{DD}^{26}$, heat and manual labor in $\mathrm{MDM}^{4,66}$ ), but cannot explain the full spectrum of the observed intrafamilial differences. Further research should be aimed at identifying the underlying contributing mechanisms. For instance, in $\mathrm{DD}$ and $\mathrm{HHD}$, in vitro experiments point out the important role of ER-stress responses following SERCA2 and SPCA1 dysfunction ${ }^{67,68}$, but this has not been shown in vivo. Little is known about inter-individual variation in efficacy of these processes that may explain the intrafamilial clinical variability ${ }^{69}$. Dramatic differences in KRT1 allele expression in leukocytes related to 5 single nucleotide polymorphisms (SNP) all favouring upregulation of KRT1 transcription have been reported ${ }^{70}$. It remains to be investigated if these factors are relevant to the observed phenotypic variation in EI.

Molecular diagnosis of MEDOC in the age of next generation sequencing (NGS). The development of NGS (whole genome or exome sequencing) has dramatically changed the 


\section{CHAPTER 5 CONCLUSIONS, DISCUSSION AND VALORISATION}

field of clinical and molecular genetics. It has increased the ability to identify new disease causing genes in patients without a molecular diagnosis, when conventional strategies such as linkage analysis have failed or were not feasible. An example of the power of NGS is the identification of germline EGFR mutations in a patient with inflammatory pustules and papules, erosions, dry scaling, and alopecia ${ }^{71}$. In patient care, NGS may allow screening for gene defects if a precise clinical or molecular diagnosis cannot be made. However, variants found with NGS can only be successfully interpreted in relation to the phenotype, especially when mutations are found in genes with unknown function. Advancement in delineation of phenotypes in "known" syndromes are equally important in the evaluation of NGS. Precise phenotyping therefore remains an important part of care for genetic diseases and MEDOC as well.

\subsubsection{Therapeutic challenges}

Establishing evidence based treatment for MEDOC. Although this thesis was not aimed at evaluation of treatment modalities for MEDOC, there are some remarks to be made on this subject. In short, as reviewed in the introductory parts of chapters II and IV, therapeutic options are limited (see paragraphs 2.1.2 and 4.6). MEDOC cannot be cured. Treatment is mainly symptomatic: emollients and keratolytics for hyperkeratosis in PPK and ichthyosis and anti-microbial treatment for concurrent bacterial and fungal superinfection in $\mathrm{MDM}, \mathrm{DD}$ and $\mathrm{HHD}^{72,73}$. Traditionally, acitretin is the mainstay of systemic therapy in MDM, EI and DD if more conservative measures are not sufficient. Although reasonably effective and tolerable, acitretin is associated with side-effects such as xerosis, skin tenderness and the possibility of teratogenicity in woman of childbearing age $^{66,74}$. These side effects may be overcome by the use of alitretinoin (9-cis retinoic acid), which is associated with less severe side effects. It has successfully been used in one patient with MDM and several patients with $\mathrm{DD}^{75,76}$.

It is impossible to provide recommendations for evidence-based management of MEDOC as most therapeutic interventions are poorly evaluated: most interventions are only described in small case series or case reports ${ }^{66,74-76}$ and measurement of efficacy remains inaccurate due to absence of reliable disease severity assessment. As pointed out before, these issues can be addressed only by delineating the clinical and genetic variability in MEDOC by establishment of larger studies aimed at standardised evaluation of clinical and genetic characteristics of MEDOC. This will hopefully enable us, 


\section{CHAPTER 5 CONCLUSIONS, DISCUSSION AND VALORISATION}

in turn, to better assess efficacy of new treatment modalities. For instance, although the effect of alitretinoin in MEDOC seems promising, it should be preferably evaluated in randomized non-inferiority studies, comparing alitretinoin not only to placebo, but also to standard-of-care (i.e. acitretin). The value of such trials is highly dependent on the evaluation of relevant disease parameters, whose identification is only possible through studies as performed in this thesis.

Future treatment strategies. Identification of genetic variants in MEDOC may prove to be of great importance for future therapies aimed at correction of the underlying genetic defect. According to our review, nonsense mutations cause the disease in $10-15 \%$ of DD and HHD patients. These patients may therefore be eligible for read-through therapy with (topical) aminoglycosides ${ }^{77}$, Ataluren (PTC124) or other compounds ${ }^{78-80}$. RNA interference (RNAi)-based gene therapy is tested for the autosomal dominant disorder pachyonycha congenita ${ }^{81}$, and it may be a viable therapeutic option in EI. Specific siRNAs designed for EI should be able to abolish the expression of the mutated KRT1 or KRT10 allele. A promising development in treatment of the underlying genetic defect is the emergence of site-specific gene editing technologies. The clustered regularly interspaced short palindromic repeats (CRISPR) - CRISPR associated endonuclease (Cas9) system (CRISPR/Cas9) offer the possibility of correction of the underlying genetic defect with a possible reduced risk of off-target mutagenesis associated with viral gene delivery ${ }^{82}$. However, RNAi-based gene therapy and gene editing strategies are hindered by poor transfection performance, lack of tissue specificity and potential cytotoxicity ${ }^{83}$. However, this approach may be viable for correcting gene defects in readily accessible tissue and organs, such as the skin. Monogenic skin disorders such as MEDOC may therefore prove to be an excellent indication for gene therapy. It is therefore of great importance to provide a molecular diagnosis in individuals with MEDOC.

As it is becoming increasingly clear that ER stress is a direct consequence of improper calcium homeostasis in keratinocytes and the possible mechanism of action that elicits disease symptoms, strategies aimed relieving ER stress could be beneficial in DD and $\mathrm{HHD}^{67,68}$. Miglustat, a pharmacological chaperone, is able to restore adherens junction and desmosome formation by alleviating the retention of E-cadherin and desmosomal cadherins in the ER of DD keratinocytes ${ }^{68}$. The use of Miglustat, as well as other molecular chaperones, remains to be investigated in a clinical setting, which is the case for all above described experimental therapeutic strategies. 


\section{CHAPTER 5 CONCLUSIONS, DISCUSSION AND VALORISATION}

\subsection{Valorisation}

There are ample reasons to study rare diseases such as the Mendelian disorders of cornification (MEDOC) and the clinical and genetic heterogeneity in MEDOC. First of all, people have them; they are affected by and suffer from MEDOC. Without research on the clinical and pathophysiologic aspects of their disease, it is impossible to deliver appropriate care to these patients. The low prevalence of MEDOC is not an argument to ignore the needs of these patients. Secondly, the study of MEDOC grants us insight in fundamental principles of epidermal functioning. Our knowledge of skin disease is severely limited, mostly because we understand very little about how normal human skin works. By studying the models that nature is offering us, we might attain some comprehension. This understanding may be helpful, in a strict sense, in the development of refined diagnostic strategies and (targeted) therapies for MEDOC. In a broader sense, the extent of the expanding comprehension of epidermal homeostasis may reach as far as areas as the pathophysiology of non-genetic, multifactorial and more common skin diseases such as auto-immune blistering disorders, psoriasis or wound healing. Thirdly, the value of describing clinical and genetic variability lies mainly in the field of patient management: our study provides tools to dermatologists and clinical geneticist that will hopefully improve diagnosis and treatment of MEDOC. Lastly, fundamental research or research without direct apparent benefits for large numbers of individuals is valuable by itself.

The disease burden of MEDOC. MEDOC are rare diseases with few individuals affected in absolute numbers, but the lives of patients are influenced in a profound way. In this regard, MEDOC patients differ from the general dermatological population. Skin diseases are a significant health problem. The disease burden of dermatologic disorders is high in the general population: all skin conditions combined were the fourth leading cause of non-fatal disease burden at the global level ${ }^{84,85}$. However, this is mainly due to the high prevalence of dermatologic disease. The disability rate of most skin diseases is relatively low ${ }^{84,85}$. The opposite is the case for MEDOC. These skin diseases are rare - the reported prevalence for DD is $1: 30,000-100,000^{86}$, for EI $1: 200,000^{87,88}$ and for MDM $<1: 1,000,000$ (estimated $^{1}$ ) - but they have a significant impact on health related quality of life (HRQL). Several studies identified a substantial impairment of quality of life in patients with $\mathrm{DD}^{55,89}, \mathrm{HHD}^{89,90}$ and $\mathrm{EI}^{62-64}$. Furthermore, the mean health care related costs associated with congenital ichthyosis, among which EI, is estimated 


\section{CHAPTER 5 CONCLUSIONS, DISCUSSION AND VALORISATION}

at $\$ 3,192$ per annum ${ }^{62,91}$. Up to $30 \%$ of these costs is borne out of pocket by patients. Although no cost analysis studies have been performed for DD, HHD and MDM, it can be expected that these costs may be in the same order of magnitude as for ichthyosis. Research efforts and improving knowledge are important steps in optimizing care and treatment to alleviate the burden of patients with MEDOC and reduce health care costs for patients and society.

The advancement of our understanding of the skin. The study of these disorders has provided much insight in epidermal homeostasis. In the past two decades, almost all MEDOC have been linked to defects in various proteins associated with keratinocyte function and differentiation. The prevailing view on epidermal physiology was the "bricks and mortar"-model. Improper functioning of structural proteins due to mutations in their coding genes was thought to impair either the keratinocytes (bricks) or proteins connecting the keratinocytes (mortar). The discovery of defects in genes encoding structural proteins such as keratin 1, causing EI, supported this view. With the discovery of mutations in ATP2A2, ATP2C1 and SLURP1 as the cause of DD, HHD and $\mathrm{Mal}$ de Meleda (MDM) respectively, the "brick and mortar"-model proved to be an insufficient metaphor for epidermal homeostasis ${ }^{92}$. ATP2A2 and ATP2C1 encode intracellular calcium pumps and SLURP1 encodes a protein enhancing the function of an epidermal nicotinic receptor. These proteins are parts of signaling pathways that coordinate cell differentiation and underlie the crucial role of keratinocytes in skin integrity. Research on these pathways revealed complex networks of interacting signal molecules in keratinocytes, and defects of these proteins heavily impair proper epidermal differentiation and function. Patients with MEDOC provide a great opportunity to study the biological consequences of gene mutations affecting epidermal biology in humans. To study a human disease model of MEDOC would otherwise be impossible.

Improvement of patient care. Diagnosis of MEDOC can sometimes be difficult, as we have shown in chapter III and IV for Epidermolytic Ichthyosis (EI), Darier disease (DD) or Hailey-Hailey disease (HHD). Research on MEDOC extends our understanding of the phenotype of these diseases and the disease course. This, in turn, helps physicians in their care for patients with a genodermatosis, which is often difficult. Treatment options are often limited, but almost all patients are helped significantly with a right diagnosis ${ }^{93,94}$. Making the right diagnosis often ends a period of doubt and uncertainty. 


\section{CHAPTER 5 CONCLUSIONS, DISCUSSION AND VALORISATION}

The physician therefore must be able to discriminate these rare diseases from more common skin ailments, and should be able to recognize atypical presentation of these diseases. 


\section{CHAPTER 5 CONCLUSIONS, DISCUSSION AND VALORISATION}

\section{References}

1 Fischer, J., Bouadjar, B., Heilig, R. et al. Mutations in the gene encoding SLURP-1 in Mal de Meleda. Hum Mol Genet 2001; 10: p. 875-80.

2 Fischer, J., Bouadjar, B., Heilig, R. et al. Genetic linkage of Meleda disease to chromosome 8qter. Eur J Hum Genet 1998; 6: p. 542-7.

3 Schnyder, U.W., Franceschetti, A., Ceszarovic, B. et al. La maladie de Meleda autochtone. Ann Derm Syph 1969; 96: p. 517-30.

$4 \quad$ Eckl, K.M., Stevens, H.P., Lestringant, G.G. et al. Mal de Meleda (MDM) caused by mutations in the gene for SLURP-1 in patients from Germany, Turkey, Palestine, and the United Arab Emirates. Hum Genet 2003; 112: p. 50-6.

5 Zhao, L., Vahlquist, A., Virtanen, M. et al. Palmoplantar Keratoderma of the GamborgNielsen Type is Caused by Mutations in the SLURP1 Gene and Represents a Variant of Mal de Meleda. Acta Derm Venereol 2014; 94: p. 707-10.

6 Nellen, R.G.L., Steijlen, P.M., Hennies, H.C. et al. Haplotype analysis in western European patients with mal de Meleda: founder effect for the W15R mutation in the SLURP1 gene. $\mathrm{Br}$ J Dermatol 2013; 168: p. 1372-4.

7 Nellen, R.G.L., Steijlen, P.M., van Geel, M. et al. Comment on Zhao et al. "Palmoplantar keratoderma of the Gamborg-Nielsen type is caused by mutations in the SLURP1 gene and represents a variant of Mal de Meleda". Acta Derm Venereol 2015; 95: p. 1034-5.

8 Nellen, R.G.L., van Geel, M., Steijlen, P.M. et al. Compound heterozygosity for ARS component B mutations in a Dutch patient with mal de Meleda. Br J Dermatol 2009; 160: p. 878-80.

9 Nellen, R.G.L., Claessens, T., Subramaniam, R. et al. A novel mutation in SLURP1 in patients with mal de Meleda from the Indian subcontinent. J Dermatol Sci 2015; 80: p. 76-8.

$10 \mathrm{Hu}$, G., Yildirim, M., Baysal, V. et al. A recurrent mutation in the ARS (component B) gene encoding SLURP-1 in Turkish families with mal de Meleda: evidence of a founder effect. $J$ Invest Dermatol 2003; 120: p. 967-9.

11 Syder, A.J., Yu, Q.C., Paller, A.S. et al. Genetic mutations in the K1 and K10 genes of patients with epidermolytic hyperkeratosis. Correlation between location and disease severity. J Clin Invest 1994; 93: p. 1533-42.

12 Porter, R.M., Lane, E.B. Phenotypes, genotypes and their contribution to understanding keratin function. Trends Genet 2003; 19: p. 278-85.

13 Bolling, M.C., Bladergroen, R.S., van Steensel, M.A. et al. A novel mutation in the L12 domain of keratin 1 is associated with mild epidermolytic ichthyosis. Br J Dermatol 2010; 162: p. 875-9. 


\section{CHAPTER 5 CONCLUSIONS, DISCUSSION AND VALORISATION}

14 Kremer, H., Lavrijsen, A.P., McLean, W.H. et al. An atypical form of bullous congenital ichthyosiform erythroderma is caused by a mutation in the L12 linker region of keratin $1 . J$ Invest Dermatol 1998; 111: p. 1224-6.

15 Chen, H., Common, J.E., Haines, R.L. et al. Wide spectrum of filaggrin-null mutations in atopic dermatitis highlights differences between Singaporean Chinese and European populations. Br J Dermatol 2011; 165: p. 106-14.

16 McLean, W.H., Eady, R.A., Dopping-Hepenstal, P.J. et al. Mutations in the rod 1A domain of keratins 1 and 10 in bullous congenital ichthyosiform erythroderma (BCIE). J Invest Dermatol 1994; 102: p. 24-30.

17 Abdul-Wahab, A., Takeichi, T., Liu, L. et al. Intrafamilial phenotypic heterogeneity of epidermolytic ichthyosis associated with a new missense mutation in keratin 10. Clin Exp Dermatol 2016; 41: p. 290-3.

18 Arin, M.J., Oji, V., Emmert, S. et al. Expanding the keratin mutation database: novel and recurrent mutations and genotype-phenotype correlations in 28 patients with epidermolytic ichthyosis. Br J Dermatol 2011; 164: p. 442-7.

19 Hotz, A., Oji, V., Bourrat, E. et al. Expanding the Clinical and Genetic Spectrum of KRT1, KRT2 and KRT10 Mutations in Keratinopathic Ichthyosis. Acta Derm Venereol 2016; 96: p. 473-8.

20 Mirza, H., Kumar, A., Craiglow, B.G. et al. Mutations Affecting Keratin 10 Surface-Exposed Residues Highlight the Structural Basis of Phenotypic Variation in Epidermolytic Ichthyosis. J Invest Dermatol 2015; 135: p. 3041-50.

21 Sung, J.Y., Oh, S.W., Kim, S.E. et al. Mild phenotype of epidermolytic hyperkeratosis mimicking ichthyosis bullosa of Siemens is related to specific mutation in 2B domain of KRT1. J Dermatol Sci 2013; 70: p. 220-2.

22 Sun, X.K., Ma, L.L., Xie, Y.Q. et al. Keratin 1 and keratin 10 mutations causing epidermolytic hyperkeratosis in Chinese patients. J Dermatol Sci 2002; 29: p. 195-200.

23 Tsubota, A., Akiyama, M., Sakai, K. et al. Congenital ichthyosiform erythroderma mimicking ichthyosis bullosa of Siemens. Br J Dermatol 2008; 158: p. 191-4.

24 Yang, J.M., Nam, K., Kim, H.C. et al. A novel glutamic acid to aspartic acid mutation near the end of the $2 \mathrm{~B}$ rod domain in the keratin 1 chain in epidermolytic hyperkeratosis. J Invest Dermatol 1999; 112: p. 376-9.

25 Nellen, R.G.L., Nagtzaam, I.F., Hoogeboom, A.J. et al. Phenotypic variation in epidermolytic ichthyosis: clinical and functional evaluation of the novel p.(Met339Lys) mutation in the L12 domain of KRT1. Exp Dermatol 2015; 24: p. 883-5.

26 Burge, S.M., Wilkinson, J.D. Darier-White disease: a review of the clinical features in 163 patients. J Am Acad Dermatol 1992; 27: p. 40-50. 


\section{CHAPTER 5 CONCLUSIONS, DISCUSSION AND VALORISATION}

Burge, S.M. Hailey-Hailey disease: the clinical features, response to treatment and prognosis. Br J Dermatol 1992; 126: p. 275-82.

Poblete-Gutierrez, P., Wiederholt, T., Konig, A. et al. Allelic loss underlies type 2 segmental Hailey-Hailey disease, providing molecular confirmation of a novel genetic concept. J Clin Invest 2004; 114: p. 1467-74.

Sakuntabhai, A., Dhitavat, J., Burge, S. et al. Mosaicism for ATP2A2 mutations causes segmental Darier's disease. J Invest Dermatol 2000; 115: p. 1144-7.

Hwang, L.Y., Lee, J.B., Richard, G. et al. Type 1 segmental manifestation of Hailey-Hailey disease. J Am Acad Dermatol 2003; 49: p. 712-4.

Dodiuk-Gad, R.P., Cohen-Barak, E., Khayat, M. et al. Darier disease in Israel: combined evaluation of genetic and neuropsychiatric aspects. Br J Dermatol 2016; 174: p. 562-8.

Cederlof, M., Bergen, S.E., Langstrom, N. et al. The association between Darier disease, bipolar disorder, and schizophrenia revisited: a population-based family study. Bipolar Disord 2015; 17: p. 340-4.

Sakuntabhai, A., Ruiz-Perez, V., Carter, S. et al. Mutations in ATP2A2, encoding a Ca2+ pump, cause Darier disease. Nat Genet 1999; 21: p. 271-7.

Hu, Z., Bonifas, J.M., Beech, J. et al. Mutations in ATP2C1, encoding a calcium pump, cause Hailey-Hailey disease. Nat Genet 2000; 24: p. 61-5.

Sudbrak, R., Brown, J., Dobson-Stone, C. et al. Hailey-Hailey disease is caused by mutations in ATP2C1 encoding a novel $\mathrm{Ca}(2+)$ pump. Hum Mol Genet 2000; 9: p. 1131-40.

Bchetnia, M., Benmously, R., Ben Brick, A.S. et al. New mutations of Darier disease in Tunisian patients. Arch Dermatol Res 2009; 301: p. 615-9.

Godic, A., Korosec, B., Miljkovic, J. et al. Four novel ATP2A2 mutations in Slovenian patients with Darier disease. J Am Acad Dermatol 2010; 62: p. 819-23.

Green, E.K., Gordon-Smith, K., Burge, S.M. et al. Novel ATP2A2 mutations in a large sample of individuals with Darier disease. J Dermatol 2013; 40: p. 259-66.

Klausegger, A., Nischler, E., Wagner, R.N. et al. Seven novel mutations in the ATP2A2 gene of Austrian patients with Darier's disease. Arch Dermatol Res 2011; 303: p. 371-4.

Sakuntabhai, A., Burge, S., Monk, S. et al. Spectrum of novel ATP2A2 mutations in patients with Darier's disease. Hum Mol Genet 1999; 8: p. 1611-9.

1 Fu, X., Liu, H., Yan, X. et al. Mutation analysis of the ATP2A2 gene in Chinese patients with Darier's disease. J Eur Acad Dermatol Venereol 2011; 25: p. 370-1.

Ringpfeil, F., Raus, A., DiGiovanna, J.J. et al. Darier disease--novel mutations in ATP2A2 and genotype-phenotype correlation. Exp Dermatol 2001; 10: p. 19-27. 


\section{CHAPTER 5 CONCLUSIONS, DISCUSSION AND VALORISATION}

43 Ikeda, S., Mayuzumi, N., Shigihara, T. et al. Mutations in ATP2A2 in patients with Darier's disease. J Invest Dermatol 2003; 121: p. 475-7.

44 Cheng, T.S., Ho, K.M., Lam, C.W. Heterogeneous mutations of the ATP2C1 gene causing Hailey-Hailey disease in Hong Kong Chinese. J Eur Acad Dermatol Venereol 2010; 24: p. 1202-6.

45 Dobson-Stone, C., Fairclough, R., Dunne, E. et al. Hailey-Hailey disease: molecular and clinical characterization of novel mutations in the ATP2C1 gene. J Invest Dermatol 2002; 118: p. 338-43.

46 Ikeda, S., Shigihara, T., Mayuzumi, N. et al. Mutations of ATP2C1 in Japanese patients with Hailey-Hailey disease: intrafamilial and interfamilial phenotype variations and lack of correlation with mutation patterns. J Invest Dermatol 2001; 117: p. 1654-6.

47 Hamada, T., Fukuda, S., Sakaguchi, S. et al. Molecular and clinical characterization in Japanese and Korean patients with Hailey-Hailey disease: six new mutations in the ATP2C1 gene. J Dermatol Sci 2008; 51: p. 31-6.

$48 \mathrm{Li}, \mathrm{H} .$, Sun, X.K., Zhu, X.J. Four novel mutations in ATP2C1 found in Chinese patients with Hailey-Hailey disease. Br J Dermatol 2003; 149: p. 471-4.

49 Yokota, K., Yasukawa, K., Shimizu, H. Analysis of ATP2C1 gene mutation in 10 unrelated Japanese families with Hailey-Hailey disease. J Invest Dermatol 2002; 118: p. 550-1.

50 Zhang, F., Yan, X., Jiang, D. et al. Eight novel mutations of ATP2C1 identified in 17 Chinese families with Hailey-Hailey disease. Dermatology 2007; 215: p. 277-83.

51 Goh, B.K., Ang, P., Goh, C.L. Darier's disease in Singapore. Br J Dermatol 2005; 152: p. 284-8.

52 Wuytack, F., Raeymaekers, L., Missiaen, L. Molecular physiology of the SERCA and SPCA pumps. Cell Calcium 2002; 32: p. 279-305.

53 Cederlof, M., Karlsson, R., Larsson, H. et al. Intellectual disability and cognitive ability in Darier disease: Swedish nation-wide study. Br J Dermatol 2015; 173: p. 155-8.

54 Dowlatshahi, E.A., Wakkee, M., Arends, L.R. et al. The prevalence and odds of depressive symptoms and clinical depression in psoriasis patients: a systematic review and meta-analysis. J Invest Dermatol 2014; 134: p. 1542-51.

55 Dodiuk-Gad, R., Cohen-Barak, E., Ziv, M. et al. Health-related quality of life among Darier's disease patients. J Eur Acad Dermatol Venereol 2013; 27: p. 51-6.

56 Gordon-Smith, K., Jones, L.A., Burge, S.M. et al. The neuropsychiatric phenotype in Darier disease. Br J Dermatol 2010; 163: p. 515-22.

57 Benmously-Mlika, R., Bchetnia, M., Deghais, S. et al. Hailey-Hailey disease in Tunisia. Int J Dermatol 2010; 49: p. 396-401. 


\section{CHAPTER 5 CONCLUSIONS, DISCUSSION AND VALORISATION}

Korner, J., Rietschel, M., Nothen, M.M. et al. Familial cosegregation of affective disorder and Hailey-Hailey disease. Br J Psychiatry 1993; 163: p. 109-10.

Wilk, M., Rietschel, M., Korner, J. et al. [Pemphigus chronicus benignus familiaris (HaileyHailey disease) and bipolar affective disease in 3 members of a family]. Hautarzt 1994; 45: p. 313-7.

Behne, M.J., Tu, C.L., Aronchik, I. et al. Human keratinocyte ATP2C1 localizes to the Golgi and controls Golgi Ca2+ stores. J Invest Dermatol 2003; 121: p. 688-94.

Vanoevelen, J., Dode, L., Van Baelen, K. et al. The secretory pathway Ca2+/Mn2+-ATPase 2 is a Golgi-localized pump with high affinity for Ca2+ ions. J Biol Chem 2005; 280: p. 22800-8.

Dreyfus, I., Pauwels, C., Bourrat, E. et al. Burden of inherited ichthyosis: a French national survey. Acta Derm Venereol 2015; 95: p. 326-8.

Ganemo, A. Quality of life in Swedish children with congenital ichthyosis. Dermatol Reports 2010; 2: p. e7.

Ganemo, A., Sjoden, P.O., Johansson, E. et al. Health-related quality of life among patients with ichthyosis. Eur J Dermatol 2004; 14: p. 61-6.

van Steenbergen-Weijenburg, K.M., van der Feltz-Cornelis, C.M., van Benthem, T.B. et al. [Collaborative care for co-morbid major depressive disorder in chronically ill outpatients in a general hospital]. Tijdschr Psychiatr 2015; 57: p. 248-57.

Gruber, R., Hennies, H.C., Romani, N. et al. A novel homozygous missense mutation in SLURP1 causing Mal de Meleda with an atypical phenotype. Arch Dermatol 2011; 147: p. 748-50.

Shull, G.E., Miller, M.L., Prasad, V. Secretory pathway stress responses as possible mechanisms of disease involving Golgi Ca2+ pump dysfunction. Biofactors 2011; 37: p. 150-8.

Savignac, M., Simon, M., Edir, A. et al. SERCA2 dysfunction in darier disease causes endoplasmic reticulum stress and impaired cell-to-cell adhesion strength: rescue by Miglustat. J Invest Dermatol 2014; 134: p. 1961-70.

Hetz, C. The unfolded protein response: controlling cell fate decisions under ER stress and beyond. Nat Rev Mol Cell Biol 2012; 13: p. 89-102.

Tao, H., Cox, D.R., Frazer, K.A. Allele-specific KRT1 expression is a complex trait. PLoS Genet 2006; 2: p. e93.

Campbell, P., Morton, P.E., Takeichi, T. et al. Epithelial inflammation resulting from an inherited loss-of-function mutation in EGFR. J Invest Dermatol 2014; 134: p. 2570-8.

Braun-Falco, M. Hereditary palmoplantar keratodermas. J Dtsch Dermatol Ges 2009; 7: p. 971-84; quiz 84-5. 


\section{CHAPTER 5 CONCLUSIONS, DISCUSSION AND VALORISATION}

73 Schiller, S., Seebode, C., Hennies, H.C. et al. Palmoplantar keratoderma (PPK): acquired and genetic causes of a not so rare disease. J Dtsch Dermatol Ges 2014; 12: p. 781-8.

74 van de Kerkhof, P.C., van Dooren-Greebe, R.J., Steijlen, P.M. Acitretin in the treatment of mal de Meleda. Br J Dermatol 1992; 127: p. 191-2.

75 Park, H.K., Kim, E.J., Ko, J.Y. Alitretinoin: treatment for refractory palmoplantar keratoderma. Br J Dermatol 2016; 174: p. 1143-4.

76 Letule, V., Herzinger, T., Ruzicka, T. et al. Treatment of Darier disease with oral alitretinoin. Clin Exp Dermatol 2013; 38: p. 523-5.

77 Kellermayer, R., Szigeti, R., Keeling, K.M. et al. Aminoglycosides as potential pharmacogenetic agents in the treatment of Hailey-Hailey disease. J Invest Dermatol 2006; 126: p. 229-31.

78 Bidou, L., Allamand, V., Rousset, J.P. et al. Sense from nonsense: therapies for premature stop codon diseases. Trends Mol Med 2012; 18: p. 679-88.

79 Karijolich, J., Yu, Y.T. Therapeutic suppression of premature termination codons: mechanisms and clinical considerations (review). Int J Mol Med 2014; 34: p. 355-62.

80 Gomez-Grau, M., Garrido, E., Cozar, M. et al. Evaluation of Aminoglycoside and NonAminoglycoside Compounds for Stop-Codon Readthrough Therapy in Four Lysosomal Storage Diseases. PLoS One 2015; 10: p. e0135873.

81 Leachman, S.A., Hickerson, R.P., Schwartz, M.E. et al. First-in-human mutation-targeted siRNA phase Ib trial of an inherited skin disorder. Mol Ther 2010; 18: p. 442-6.

82 LaFountaine, J.S., Fathe, K., Smyth, H.D. Delivery and therapeutic applications of gene editing technologies ZFNs, TALENs, and CRISPR/Cas9. Int J Pharm 2015; 494: p. 180-94.

83 Jeong, E.H., Kim, H., Jang, B. et al. Technological development of structural DNA/RNA-based RNAi systems and their applications. Adv Drug Deliv Rev 2016; 104: p. 29-43.

84 Hollestein, L.M., Nijsten, T. An insight into the global burden of skin diseases. J Invest Dermatol 2014; 134: p. 1499-501.

85 Murray, C.J., Vos, T., Lozano, R. et al. Disability-adjusted life years (DALYs) for 291 diseases and injuries in 21 regions, 1990-2010: a systematic analysis for the Global Burden of Disease Study 2010. Lancet 2012; 380: p. 2197-223.

86 Godic, A., Strazisar, M., Zupan, A. et al. Darier disease in Slovenia: spectrum of ATP2A2 mutations and relation to patients' phenotypes. Eur J Dermatol 2010; 20: p. 271-5.

87 Muller, F.B., Huber, M., Kinaciyan, T. et al. A human keratin 10 knockout causes recessive epidermolytic hyperkeratosis. Hum Mol Genet 2006; 15: p. 1133-41.

88 DiGiovanna, J.J., Bale, S.J. Clinical heterogeneity in epidermolytic hyperkeratosis. Arch Dermatol 1994; 130: p. 1026-35. 


\section{CHAPTER 5 CONCLUSIONS, DISCUSSION AND VALORISATION}

89 Harris, A., Burge, S.M., Dykes, P.J. et al. Handicap in Darier's disease and Hailey-Hailey disease. Br J Dermatol 1996; 135: p. 959-63.

90 Gisondi, P., Sampogna, F., Annessi, G. et al. Severe impairment of quality of life in HaileyHailey disease. Acta Derm Venereol 2005; 85: p. 132-5.

91 Styperek, A.R., Rice, Z.P., Kamalpour, L. et al. Annual direct and indirect health costs of the congenital ichthyoses. Pediatr Dermatol 2010; 27: p. 325-36.

92 Peacocke, M., Christiano, A.M. Bumps and pumps, SERCA 1999. Nat Genet 1999; 21: p. 252-3.

93 Cnossen, M.H., van der Est, M.N., Breuning, M.H. et al. Deletions spanning the neurofibromatosis type 1 gene: implications for genotype-phenotype correlations in neurofibromatosis type 1? Hum Mutat 1997; 9: p. 458-64.

94 Lipinski, S.E., Lipinski, M.J., Biesecker, L.G. et al. Uncertainty and perceived personal control among parents of children with rare chromosome conditions: the role of genetic counseling. Am J Med Genet C Semin Med Genet 2006; 142C: p. 232-40. 


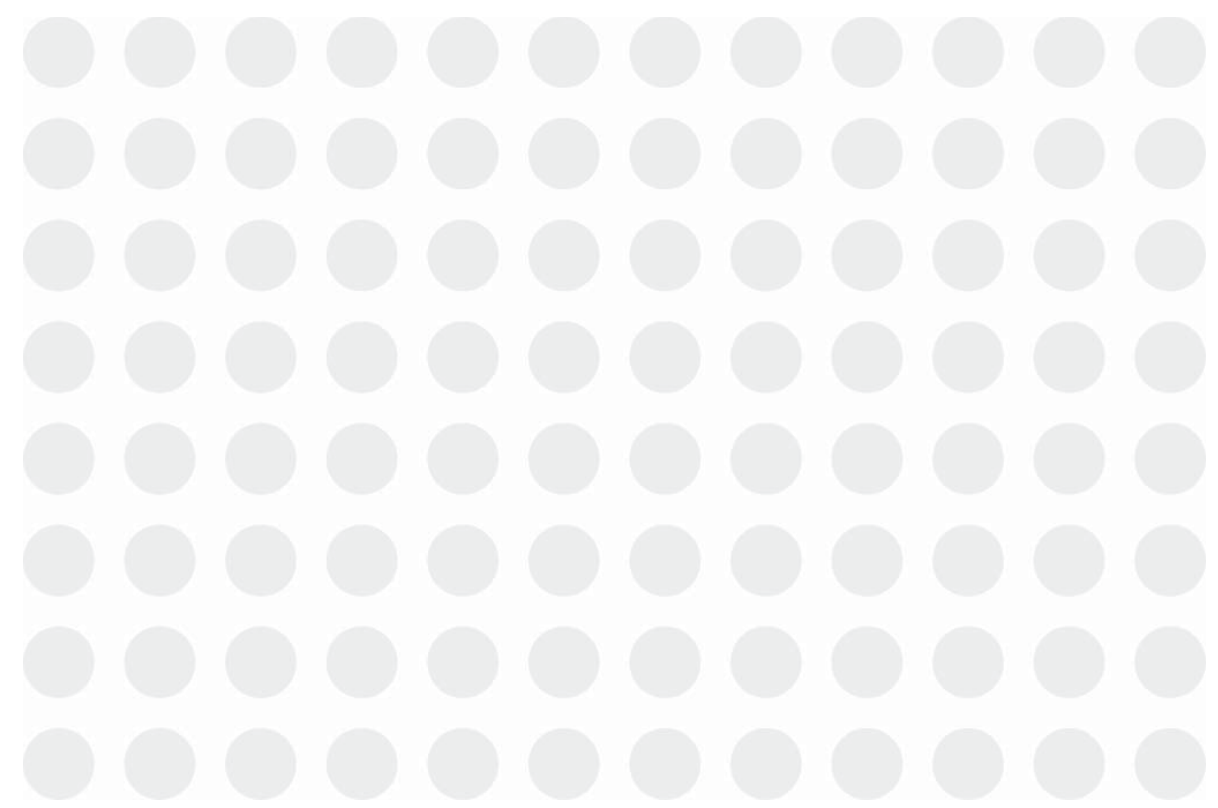




\section{Chapter VI}

Summary

Samenvatting 


\section{CHAPTER 6 SUMMARY/SAMENVATTING}

\subsection{Summary}

This thesis describes the results of the research we performed to address the problems of genotypic and phenotypic variation and genotype-phenotype correlations in four Mendelian disorders of cornification (MEDOC): mal de Meleda (MDM), Epidermolytic Ichthyosis (EI), Darier disease (DD) and Hailey-Hailey disease (HHD).

Chapter II discusses the clinical and genetic aspects of mal de Meleda (MDM). This autosomal recessive palmoplantar keratoderma (PPK) is caused by mutations in the Secreted Ly-6/uPar related protein-1 (SLURP1). It is defined by a progressive transgredient hyperkeratosis of the palms and soles, hyperhidrosis, malodourous scent due to bacterial superinfection and minor symptoms such as perioral erythema, mild ichthyosiform hyperkeratosis on elbows and knees, pseudo-ainhum and nail abnormalities. To assess clinical and genotypic variability in MDM, we summarised all phenotypes reported in the literature and created a semi-quantative disease scoring system that can be used in further research. We described the phenotype and genotype of four Dutch families, one German and one Indian family with MDM, in whom we found heterozygosity for the p.(Trp15Arg) and p.(Arg71Pro) mutation (one Dutch patient), homozygosity for the p.(Trp15Arg) mutation (the other Dutch patients, all German patients) and the c. $58+5 \mathrm{G}>\mathrm{T} / \mathrm{p}$.(Val17Metfs $\left.{ }^{\star} 16\right)$ variant (the Indian patients). We performed haplotype analysis in MDM patients with the p. (Trp15Arg) variant and found a shared core haplotype of $125 \mathrm{Kbp}$ segregating with p.(Trp15Arg), indicating a founder effect. With the results of our literature study, we re-evaluate the conclusions of a recent report that described p.(Trp15Arg) variants in SLURP1 in palmoplantar keratoderma of the Gamborg-Nielsen type (PPK-GN). The authors consider PPKGN to be a separate disease allelic to MDM. We argue that the PPK-GN phenotype represents the milder end of the disease severity spectrum of MDM and that PPK-GN is not therefore a separate disease entity.

Chapter III describes clinical variance in Epidermolytic Ichthyosis (EI), which is a rare autosomal dominant skin disorder caused by mutations in the genes coding for keratin 1 (KRT1) and 10 (KRT10). Mutations associated with a severe phenotype (widespread blistering and erythroderma during infancy that develops into generalised ichthyosis) affect the helix boundary motifs (HBM) of the protein. Mutations causing milder phenotypes (blistering upon mechanical trauma, but no ichthyosis) occur in the central $\alpha$-helical region (1B, 2B) and linker (L12) domain. We describe a large family 


\section{CHAPTER 6 SUMMARY/SAMENVATTING}

with EI in whose affected members we found the p.(Met339Lys) mutation in the L12 domain of KRT1 associated with a remarkable intrafamilial phenotypic variation. The index patient presented with a diffuse palmoplantar keratoderma and severe ichthyosis, in absence of congenital blistering and erythroderma. The other patients, having the same mutation and sharing a common ancestor with the first patient, only developed a diffuse palmoplantar keratoderma and occasionally friction blisters. HaCaT cells expressing the mutant p.(Met339Lys) EGFP-KRT1 fusion construct showed increased keratin clumping compared to wild-type transfected cells, supporting pathogenicity of the p.(Met339Lys) variant. We speculate on the probable mechanisms that underlie the intrafamilial differences in EI phenotype, but are unable to explain this observed difference.

Chapter IV describes clinical and genetic variability in the two disorders of cornification associated with mutations in genes coding for intracellular calcium pumps: Darier disease (DD) and Hailey-Hailey disease (HHD). Both are inherited as autosomal dominant traits. DD is mainly defined by warty papules in seborrheic and flexural areas and associated with mutations in the ATP2A2 gene, whereas the major symptoms of HHD are vesicles and erosions in flexural skin, caused by ATP2C1 mutations. Both phenotypes are highly variable. $12-40 \%$ of DD patients and $12-55 \%$ of HHD patients have no mutations in ATP2A2 (DD) or ATP2C1 (HHD). We describe two DD patients with a less frequently encountered phenotype. The first patient is a 1-year-old Caucasian boy with type II segmental DD, in whom we found the p.(Gly343Asp) mutation in ATP2A2. We were able to provide molecular genetic support for the type II segmental manifestation in DD, which has not been done before. The second patient was a 25-yearold female, born in Sri Lanka, with unusually mild DD caused by a missense mutation p.(Leu590Pro). We hypothesise that the skin type of our patient holds the key to the mild appearance of the disease. We also commented on the observed high prevalence of depression and depressive symptoms in DD. We argue that this may be the result of the psychological burden of a chronic skin disease, rather than a neuropsychiatric manifestation of SERCA2b dysfunction and advocate a more clinically oriented approach towards psychiatric and psychological care in DD. We reviewed all reported mutations in ATP2A 2 and ATP2C1 and created a database for all mutations in ATP2A2 and ATP2C1 using the Leiden Open Variation Database (LOVD v2.0), for variants reported in the literature as well as to allow future inclusions. The existing set for variations of ATP2A2 contains 350 entries with 253 unique variants, while the one for ATP2C1 contains 209 


\section{CHAPTER 6 SUMMARY/SAMENVATTING}

entries with 167 unique variants. The variants for both genes are located throughout the respective coding sequences and include missense, nonsense and splice site mutations in addition to insertions and deletions causing frame shifts. Furthermore, we analysed 80 unreported cases of DD and 20 cases of HHD. We found 43 different ATP2A2 mutations in $60 \mathrm{DD}$ patients (75\%) and 13 different $A T P 2 C 1$ mutations in $17 \mathrm{HHD}$ patients (85\%), of which 24 ATP2A2 variants and 10 ATP2C1 variants are novel. Mutations are scattered throughout the genes and occur in all mutation categories. In DD and HHD patients with no mutation in the associated gene, variants might be present in gene regions not screened (e.g. deep intronic, promoter regions) or consist of exon deletions or duplications. This is further illustrated by the fact that we found skipping of exon 4 of ATP2A2 by RNA analysis in a DD patient, in whom we were unable to identify ATP2A2 variants using conventional diagnostic strategies. Alternatively, DD and HHD could be caused by mutations in other genes that give rise to comparable phenotypes. We could not discern a specific genotype-phenotype correlation between disease severity, disease course and mutation type or location in DD and HHD. There is limited data that suggests that a correlation between mutations in the ATP-binding region of SERCA2 could be associated with the development of Acrokeratosis Verruciformis of Hopf (AKV).

Chapter V reflects on the findings described in the previous chapters and addresses the aims of this thesis as put forward in the introduction. This thesis extends our knowledge on clinical and genetic variability in MEDOC. Considering clinical variability, we were either able to show that our observations are in concordance with earlier reports (MDM, DD, HHD) or are able to describe unusual features not previously reported (intrafamilial variation in EI, type II segmental disease in DD and a mild DD phenotype in a patient with skintype V). Considering genetic variability, we significantly expand the mutation spectrum in MDM, EI, DD and HHD. With regard to genotype-phenotype correlations, we can conclude that genotype-phenotype correlations in EI are not always as strong as thought. Our data suggests a probable genotype-phenotype correlation in $\mathrm{AKV}$. In MDM, DD and HHD, no other relation than segregation of variants with the disease phenotype was observed. The limitations of this study are the absence of reliable disease scoring systems to objectively evaluate disease phenotypes. This compromises the establishment of genotype-phenotype correlations and the fact that we are unable to explain the pathophysiologic mechanisms underlying our observations. However, our findings are a relevant contribution to patient care and management in MEDOC. 


\subsection{Samenvatting}

De term "Mendelian disorders of cornification" (Mendeliaans overervende verhoorningsstoornissen, MEDOC) is de naam voor de groep erfelijke huidziekten die zich kenmerkt door een verstoring van de normale verhoorning van de opperhuid. Dat deze verstoring tot een uitgebreid palet aan verschillende ziektebeelden kan leiden, blijkt uit het feit dat alle vormen van ichthyosis ("vissenhuid") en palmoplantaire keratodermieën (PPK, overmatige verhoorning van handpalmen en voetzolen), naast de ziekte van Darier en de ziekte van Hailey-Hailey tot deze groep worden gerekend. Hoewel het zeldzame ziekten betreft, is dit geen reden om hier geen onderzoek naar te doen. De kwaliteit van leven van deze patiënten is vaak in ernstige mate verminderd. Er is (nog) geen genezing mogelijk en er zijn helaas weinig behandelmogelijkheden die de symptomen adequaat kunnen bestrijden (hetgeen bijdraagt aan de verminderde kwaliteit van leven). Daarnaast geven de MEDOC inzicht in de basale principes van het functioneren van de huid. Deze kennis kan ook van belang zijn voor huidziekten die veel vaker voorkomen, zoals constitutioneel eczeem, psoriasis vulgaris en huidkanker. Onderzoek vergroot de kennis over MEDOC, hetgeen essentieel is voor het verbeteren van de behandeling en begeleiding van deze patiënten.

De laatstgenoemde zaken, behandeling en begeleiding van patiënten met een MEDOC, beginnen bij het stellen van de juiste diagnose. Dit is niet altijd eenvoudig. De meeste MEDOC zijn uniforme, vast omschreven ziektebeelden en daarnaast is er bij de meeste een duidelijke relatie tussen het klinisch beeld (het fenotype) en het onderliggend genetisch defect (het genotype). Zo leiden homozygote of compound heterozygote mutaties in het SLURP1 gen tot de ziekte mal de Meleda (MDM). Soms is er sprake van een weliswaar variabel klinisch beeld, maar ook een sterke genotype-fenotype correlatie, hetgeen het geval is in Epidermolytische Ichthyosis (EI). Mutaties in het gedeelte van het KRT1 gen dat codeert voor de helix boundary motifs veroorzaken uitgebreide blaarvorming rond de geboorte die in de loop van de tijd verandert in een uitgebreide ichthyosis met een PPK. Mutaties in de overige gebieden van KRT1 veroorzaken een veel milder beeld dat bestaat uit een PPK met blaarvorming na beschadiging of belasting van de huid. Bij sommige ziektebeelden bestaat een uitgebreide variatie in klinische presentatie. Naast verschillen in ziekte-ernst, die overigens bij elke erfelijke (huid-)ziekte voor kunnen komen, zijn er ook verschillen in symptomen die patiënten ontwikkelen. Het laatste lijkt het geval te zijn bij de ziekte van Darier (DD) en de ziekte 


\section{CHAPTER 6 SUMMARY/SAMENVATTING}

van Hailey-Hailey (HHD), die veroorzaakt worden door mutaties in respectievelijk het ATP2A2 en ATP2C1 gen. Mutaties in beide genen veroorzaken weliswaar in alle dragers symptomen (complete penetrantie), maar de ontwikkelde symptomen en ziekte-ernst kunnen enorm variëren, zelfs in familieleden die drager zijn van dezelfde mutatie. Deze soms uitgebreide variatie in klinische kenmerken en ziekte-ernst maakt het lastig om een ziektebeeld goed te definiëren. Een onduidelijke definitie van een ziektebeeld maakt het moeilijk om een klinische diagnose te stellen. Het moge duidelijk zijn dat er zonder een diagnose geen verder aanvullend (genetisch) onderzoek en voorlichting over de prognose en behandeling kan plaatsvinden. Het is daarom, zeker binnen het vakgebied van de erfelijke huidziekten, van essentieel belang dat er intensief onderzoek gedaan wordt naar de klinische en genetische variatie van deze zeldzame ziektebeelden.

De doelen van dit proefschrift kunnen daarom als volgt worden beschreven. Het eerste doel is het beschrijven van de klinische variabiliteit ofwel het fenotype, dat wil zeggen de variatie in symptomen en ziekte-ernst van MDM, EI, DD en HHD. Het tweede doel is het beschrijven van de genetische variabiliteit ofwel het genotype, dat wil zeggen de aard van de genetische defecten die ten grondslag liggen aan de beschreven ziektebeelden, van deze MEDOC. Het derde doel van het onderzoek is het analyseren van een relatie tussen het fenotype en het genotype in deze erfelijke huidziekten.

Hoofdstuk II beschrijft de klinische en genetische variabiliteit in mal de Meleda (MDM). MDM is een autosomaal recessieve genodermatose die gekenmerkt wordt door een verhoorningsstoornis van handpalmen en voetzolen (palmoplantaire keratodermie, PPK), waarbij de abnormale verhoorning zich uitstrekt to de hand- en voetruggen (transgrediens) en zich in de loop der tijd verder uitbreidt (progrediens). Door overmatig zweten ontstaat een overgroei van huidbacteriën en schimmels, waardoor een penetrante, onwelriekende geur ontstaat. Andere symptomen die kunnen ontstaan zijn roodheid rondom de mond (perioraal erytheem), schilfering op ellebogen en knieën, ringvormige vernauwingen van de huid van de vingers (pseudo-ainhum) en nagelafwijkingen. Het aangedane gen, SLURP1, codeert voor het Secreted Ly-6/uPar related protein-1. Dit eiwit is betrokken bij de normale groei, uitrijping (differentiatie) en functioneren van de opperhuid. Om de huidige stand van zaken met betrekking tot de klinische en genetische variabiliteit te inventariseren, hebben wij alle eerdere klinische beschrijvingen van MDM samengevat. Dit stelde ons in staat een semi-kwantitatieve score voor ziekte-ernst in MDM te ontwikkelen. Daarmee konden we vervolgens de verschillende 


\section{CHAPTER 6 SUMMARY/SAMENVATTING}

fenotypes vergelijken. Wij beschrijven het fenotype en genotype van vier Nederlandse patiënten, één Duitse familie en twee Indiase patiënten met MDM. Het klinisch beeld van deze patiënten komt overeen met de eerder beschreven casuïstieken. Genetische analyse toonde heterozygositeit voor de p.(Trp15Arg) en p.(Arg71Pro) mutatie (één Nederlandse patiënt), homozygositeit voor de p.(Trp15Arg) mutatie (de overige Nederlandse en alle Duitse patiënten) en de c.58+5G>T/p.(Val17Metfs $\left.{ }^{\star} 16\right)$ variant (de Indiase patiënten) aan. In alle patiënten met de p.(Trp15Arg) mutatie vonden we een gedeeld haplotype van $125 \mathrm{Kbp}$. Dit resultaat toont aan dat de p.(Trp15Arg) mutatie hoogstwaarschijnlijk door een gemeenschappelijke voorouder in de Westeuropese populatie is geïntroduceerd. Na analyse van de klinische en de genetische gegevens van onze patiënten en die gerapporteerd in de literatuur kunnen we concluderen dat er geen genotype-fenotypecorrelatie is in MDM. Mede hierom kunnen we beargumenteren dat de palmoplantaire keratodermie van het Gamborg-Nielsen type (PPK-GN), eveneens veroorzaakt door homozygote mutaties in SLURP1, geen aparte genodermatose is, maar slechts een milde manifestatie van MDM.

Hoofdstuk III behandelt de klinische variabiliteit van Epidermolytische Ichthyosis (EI). EI is een zeldzame autosomaal dominant overervende verhoorningsstoornis die veroorzaakt wordt door mutaties in de genen die coderen voor de structuureiwitten keratine 1 en 10 (KRT1 en KRT10). Er zijn ernstige en minder ernstige vormen van EI. De ernstige vorm kenmerkt zich door uitgebreide blaarvorming en uitgebreide, (vrijwel) volledige roodheid van de huid (erythrodermie) rond de geboorte, die in de loop van de vroege kinderjaren veranderd in ichthyosis over het gehele lichaam. Het onderliggend genetisch defect bevindt zich in de helix boundary motifs van keratine 1 of 10 . Deze gedeelten vormen de belangrijkste punten waaraan keratines aan elkaar verbonden worden om zo hun structuurfunctie te kunnen vervullen. Het mildere beeld bestaat uit oppervlakkige blaarvorming na beschadiging of belasting van de huid, zonder dat er sprake is van neonatale roodheid, blaarvorming of ichthyosis. Mutaties in de centrale a-helices (1B, 2B) domeinen en het linker (L12) domein veroorzaken het milde EI fenotype. Indien de mutaties zich in KRT1 bevinden, dan zal er ook een PPK ontstaan (NB. dit geldt voor zowel de milde als ernstige vorm). In dit proefschrift beschrijven wij de fenotypes in een grote familie met meerdere EI patiënten, bij wie wij de p.(Met339Lys) mutatie in het L12 domein van KRT1 hebben aangetoond in alle aangedane familieleden. In deze familie was er sprake van een aanzienlijke variatie in het klinisch beeld. De 


\section{CHAPTER 6 SUMMARY/SAMENVATTING}

indexpatiënt ontwikkelde in de vroege jeugd een diffuse PPK en uitgebreide ichthyosis, met name in de lichaamsplooien. Er was geen sprake van aangeboren blaarvorming of roodheid. De overige aangedane familieleden, die allen dezelfde mutatie hadden als de indexpatiënt, kregen alleen een PPK en blaren na belasting of beschadiging van de huid. Wij waren in staat om het mutante keratine 1 eiwit tot expressie te brengen in $\mathrm{HaCaT}$ cellen en aan te tonen dat cellen met dit mutante eiwit minder goed tegen stress bestand waren dan cellen met het normale (wildtype) keratine 1 eiwit. Dit toont aan dat deze mutatie hoogst waarschijnlijk een negatieve invloed heeft op de structuur en stevigheid van de opperhuidcellen waarin dit keratine tot expressie komt, en dat deze mutatie het ziektebeeld in de door ons beschreven familie veroorzaakt. Dit experiment biedt echter geen verklaring voor het verschil in klinisch beeld tussen de familieleden. Wel is deze intrafamiliale variatie niet eerder beschreven bij mutaties in het L12 domein van KRT1 of KRT10. Daarnaast is een ernstige vorm van EI veroorzaakt door een mutatie in het L12 domein niet eerder beschreven. Dat betekent dat de genotype-fenotypecorrelatie in EI minder sterk lijkt te zijn dan is gedacht.

Hoofdstuk IV bespreekt de klinische en genetische variatie in de ziekte van Darier (DD) en de ziekte van Hailey-Hailey (HHD). Beide genodermatosen worden veroorzaakt door autosomaal dominante mutaties in genen die coderen voor eiwitten die functioneren als calciumpomp in de opperhuidcellen (keratinocyten). Deze calciumpompen zijn niet verantwoordelijk voor de structuur en stevigheid van keratinocyten, maar zijn van belang voor het goed functioneren van het endoplasmatisch reticulum (ER) en het Golgi-apparaat. Het ER en het Golgi-apparaat kunnen worden beschouwd als de machinefabriek van een cel, waar alle eiwitten van een cel in elkaar worden gezet. Indien deze machinerie vastloopt doordat de calciumpompen niet goed functioneren, dan zullen de eiwitten die nodig zijn voor het goed functioneren van de cel niet meer worden gemaakt en gaat de keratinocyt, en het weefsel dat uit deze cellen bestaat, uiteindelijk te gronde. DD erft autosomaal dominant over en wordt veroorzaakt door mutaties in het ATP2A2 gen. De belangrijkste symptomen zijn wratachtige pukkels (papels) op de romp, met name de borst en tussen de schouderbladen (de seborroïsche gebieden), en de lichaamsplooien. HHD is een autosomaal dominant overervende ziekte waarbij oppervlakkige blaren en beschadigingen (erosies) optreden in de lichaamsplooien. HHD wordt veroorzaakt door mutaties in het $A T P 2 C 1$ gen. Er is een grote variatie van het klinisch beeld bij beide ziekten. Externe factoren zoals UV-blootstelling en mechanische 


\section{CHAPTER 6 SUMMARY/SAMENVATTING}

irritatie kunnen een verergering van het ziektebeeld uitlokken. In $12-40 \%$ van de DD patiënten en $12-55 \%$ van de HHD patiënten worden er geen mutaties in ATP2A2 (DD) of ATP2C1 (HHD) gevonden. Met name bij DD kan de klinische variabiliteit uitgebreid zijn. Wij beschrijven twee DD patiënten met een zeldzaam DD fenotype. De eerste patient is een 1-jarige blanke jongen met een type II segmentale DD. Wij toonden de p.(Gly343Asp) mutatie in ATP2A2 aan en vonden sterke aanwijzingen dat in het aangedane gebied het gezonde allel eveneens gemuteerd was. Dergelijk moleculair bewijs voor een type II segmentale distributie van DD is nog niet eerder gegeven. De tweede casus betrof een 25 jaar oude patiënte afkomstig uit Sri Lanka, die een ongewoon milde presentatie van DD liet zien, veroorzaakt door de p.(Leu590Pro) mutatie in ATP2A2. Mogelijk is het huidtype van deze patiënte de verklaring voor het milde fenotype. Tenslotte beargumenteren we dat het vaker voorkomen van depressie en depressieve symptomen bij patiënten met DD eerder berust op het feit dat deze patiënten de last van een chronische en invaliderende huidziekte moeten dragen, dan dat er een directe relatie is met ATP2A2 mutaties, zoals sommige studies suggereren. In onze optiek verdienen psychiatrische symptomen meer aandacht in de behandeling van DD patiënten. Om de genetische variabiliteit van DD en HHD in kaart te brengen hebben wij een database gecreëerd waarin alle tot op heden gerapporteerde mutaties in ATP2A2 en ATP2C1 zijn verzameld. Aan deze databases kunnen nieuwe varianten worden toegevoegd en deze databases kunnen als referentie voor toekomstig onderzoek gebruikt worden. De huidige set mutaties in ATP2A2 bevat 350 ingangen met 253 unieke varianten, en de set van ATP2C1 209 ingangen met 167 unieke varianten. De mutaties bevinden zich verspreid over de gehele coderende basevolgorde van beide genen. Alle typen mutaties zijn vertegenwoordigd. Naast deze gegevens hebben wij ook de genetische varianten in een cohort DD en HHD patiënten in kaart gebracht. Deze groepen bestonden uit 74 nog niet eerder gerapporteerde DD en $18 \mathrm{HHD}$ casus. Wij vonden 39 verschillende ATP2A2 mutaties in 57 DD patiënten (77\%) en 13 verschillende ATP2C1 mutaties in $15 \mathrm{HHD}$ patiënten (78\%). Van deze mutaties zijn 25 ATP2A2 varianten en 10 ATP2C1 varianten nog niet eerder beschreven. Ook in deze patiëntenserie zijn de mutaties verspreid over de gehele genen en worden alle type mutaties gezien. In de patiënten met DD en HHD, bij wie we geen mutatie in het aangedane gen vinden, kunnen andere genetische defecten aanwezig zijn, die we met de door ons gebruikte methode niet aan kunnen tonen. In een DD patiënt vonden we bij analyse van het RNA (nadat het "klassieke" DNA onderzoek 


\section{CHAPTER 6 SUMMARY/SAMENVATTING}

geen mutatie had opgeleverd) dat het volledige exon 4 van ATP2A2 verdwenen was. Wij konden geen genotype-fenotype correlatie aantonen tussen symptomen, ziektebeloop en ziekte-ernst en mutatietype of locatie van de mutatie in DD en HHD. Er is mogelijk een aanwijzing dat mutaties in exon 14 van ATP2A2 verantwoordelijk zijn voor het ontwikkelen van Acrokeratosis Verruciformis van Hopf (AKV).

Hoofdstuk V biedt een reflectie op de resultaten die in eerdere hoofdstukken van dit proefschrift beschreven zijn en komt terug op de doelen die in het inleidende hoofdstuk zijn gesteld. Dit proefschrift breidt onze kennis over klinische en genetische variabiliteit in MEDOC uit. Ten aanzien van de klinische variabiliteit kunnen we stellen dat enerzijds onze conclusies in overeenstemming zijn met eerdere bevindinge (MDM, DD, HHD) en dat wij anderzijds ongebruikelijke aspecten die niet eerder beschreven zijn rapporteren (de intrafamiliale variatie in EI, type II segmentale ziekte in DD, mild DD fenotype in een patient met huidtype V). Ten aanzien van de genetische variabiliteit kunnen we stellen dat we nieuwe, nog niet eerder gerapporteerde varianten toevoegen aan de huidig bestaande kennis omtrent mutaties in MDM, EI, DD en HHD. Ten aanzien van genotype-fenotypecorrelaties kunnen we stellen dat deze relaties in EI minder sterk zijn dan eerder vermoed en dat er een mogelijke genotype-fenotypecorrelatie bestaat in AKV. Bij MDM, DD en HHD is er geen duidelijke genotype-fenotypecorrelatie. Deze gegevens kunnen van belang zijn voor diagnostiek en behandeling van patiënten met MEDOC. 
CHAPTER 6 SUMMARY/SAMENVATTING 


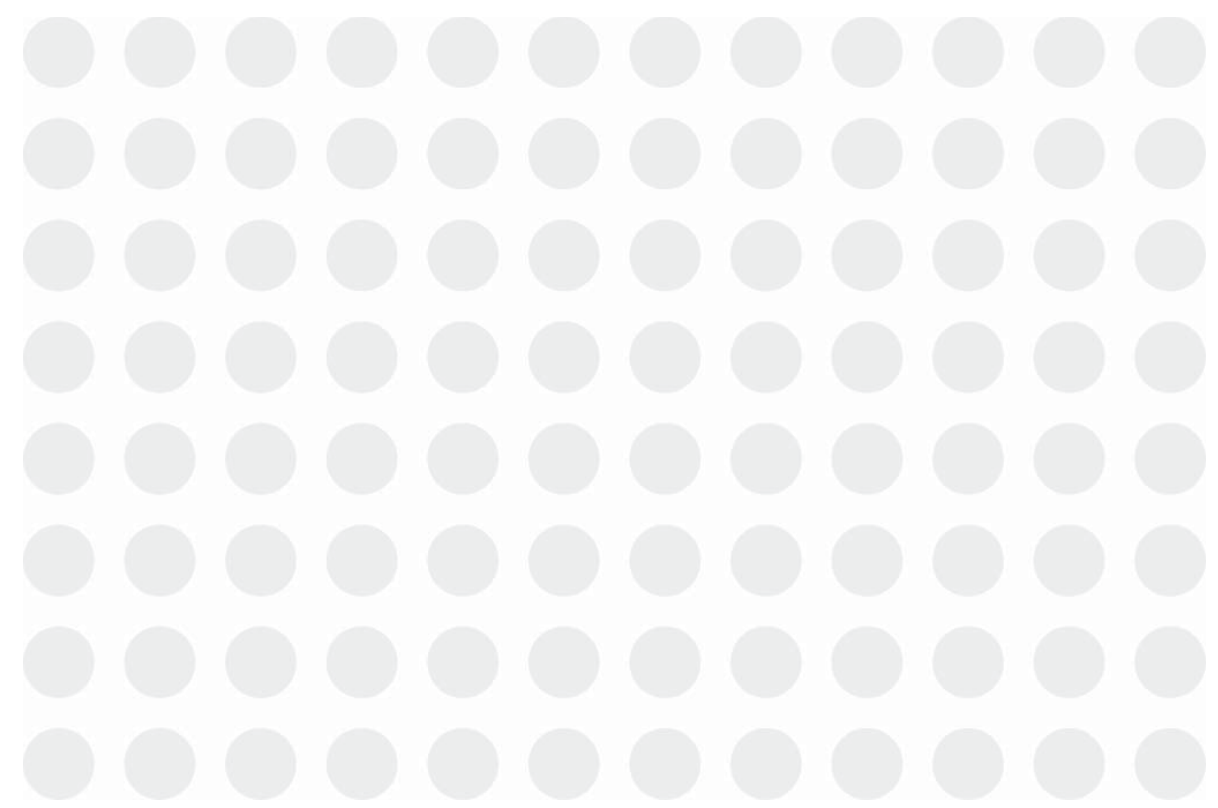




\section{Appendix}

Curriculum vitae List of publications Dankwoord (Acknowledgements) 


\section{Curriculum vitae}

The author of this thesis was born on July 12th, 1980, in Roosendaal en Nispen, the Netherlands. From 1992 to 1998, he attended the Gymnasium at the Norbertuscollege, Roosendaal. His interest in science was sparked during the extracurricular astronomy classes. He did not pursue a career in unraveling the mysteries of the universe, but instead went to medical school.

He studied medicine at Leiden University, starting in 1998. His first research internship he did at the department of Geriatrics and Gerontology of the Leiden University Medical Centre (LUMC, head: prof. dr. R.G.J. Westendorp) under supervision of dr. J. Gussekloo and dr. A.J.M. de Craen on the association of HFE genotype, serum ferritin levels and cognitive function in the oldest old (there is none). He did a second research internship at the department of Dermatology of the LUMC (head: prof. dr. R. Willemze). Supervised by dr. F.R. de Gruijl, drs. Y.G.L. de Graaf, H. Rebel and dr. J.N. Bouwes Bavinck, he received his training in laboratory research, which resulted in his master's thesis "Methods of mutation detection in p53-patches in squamous cell carcinomas and excision margins form renal transplant recipients". He did his clinical internship (oudste co-schap) at the department of Dermatology of the Erasmus MC, Rotterdam under supervision of prof. dr. H.A.M. Neumann.

After obtaining his medical degree in april 2005, he started his clinical residency in dermatology at the department of Dermatology of the Maastricht University Medical Centre+ that same month (opleider: prof. dr. P.M. Steijlen). He received specialised training in genodermatology and Mohs' micrographic surgery and was awarded the "Mentorstipendium" of the Dutch Society for Dermatology and Venerology. He used this grant for a fellowship with drs. K. Munte, department of Dermatology, Erasmus MC, Rotterdam, to further sharpen his skills in reconstructive surgery after Mohs' surgery of facial skin cancer. In the evening hours he performed the research described in this thesis, with prof. dr. P.M. Steijlen and prof. dr. M.A.M. van Steensel as promotores and dr. M. van Geel and prof. dr. J. Frank as copromotores.

In 2010 he finished his residency and started his dermatology practice in the IJsselland Hospital, Capelle aan den IJssel, in association with drs. G.M. van den Berg, drs. A.L. Gerretsen and drs. A. Okkerse. As of 2016, he collaborates with prof. dr. S.G.M.A. Pasmans in the outpatient clinic for genodermatoses in the Erasmus MC, Rotterdam, with a focus on the adult patient with a genodermatosis.

$\mathrm{He}$ is married to Annieke Nijssen and lives in Rotterdam. 


\section{List of publications}

\section{Publications on which this thesis is based:}

R.G.L. Nellen, M. van Geel, P.M. Steijlen, M.A.M. van Steensel. Compound heterozygosity for ARS component $B$ mutations in a Dutch patient with mal de Meleda. $\mathrm{Br} J$ Dermatol 2009 Apr;160(4):878-80.

R. Fölster-Holst*, R.G.L. Nellen ${ }^{\star}$ J.M. Jensen, P. Poblete-Gutiérrez, P.M. Steijlen, T. Schwarz, R. Happle, M. van Geel, J. Frank. Molecular genetic support for the rule of dichotomy in type 2 segmental Darier disease. Br J Dermatol 2012 Feb;166(2):464-6.

R.G.L. Nellen, P.M. Steijlen, H.C. Hennies, J. Fischer, C.S. Munro, M.F. Jonkman, M.A.M. van Steensel, M. van Geel. Haplotype analysis in western European patients with mal de Meleda: founder effect for the W15R mutation in the SLURP1 gene. Br J Dermatol 2013 Jun;168(6):1372-4.

R.G.L. Nellen, A.H.M.M. Arits, M. van Geel, P.M. Steijlen, M.A.M. van Steensel. Darier disease: discrete phenotype in a Sinhalese patient with Darier disease. J Eur Acad Dermatol Venereol 2015 Aug;29(8):1641-2.

R.G.L. Nellen, I.F. Nagtzaam, A.J.M. Hoogeboom, R.S. Bladergroen, M.F. Jonkman, P.M. Steijlen, M.A.M. van Steensel, M. van Geel. Phenotypic variation in epidermolytic ichthyosis: clinical and functional evaluation of the novel p.(Met339Lys) mutation in the L12 domain of KRT1. Exp Dermatol 2015 Nov;24(11):883-5.

R.G.L. Nellen, P.M. Steijlen, M. van Geel, M.A.M. van Steensel. Comment on Zhao et al. "Palmoplantar keratoderma of the Gamborg-Nielsen type is caused by mutations in the SLURP1 gene and represents a variant of Mal de Meleda”. Acta Derm Venereol 2015 Nov;95(8):1034-5.

R.G.L. Nellen, T. Claessens, R. Subramaniam, J. Betkerur, A. Prashanth, P.M. Steijlen, M. van Geel. A novel mutation in SLURP1 in patients with mal de Meleda from the Indian subcontinent. J Dermatol Sci 2015 Oct;80(1):76-8.

R.G.L. Nellen, M. van Geel, K.M.L. Huijbregts. Response to 'Darier disease in Israel: combined evaluation of genetic and neuropsychiatric aspects'. Br J Dermatol 2016 Jul;175(1):223-4. 


\section{APPENDIX}

R.G.L. Nellen, P.M. Steijlen, M.A.M. van Steensel, M. Vreeburg, European professional contributors, J. Frank, M. van Geel. Mendelian disorders of cornification caused by defects in intracellular calcium pumps: mutation update and database for variants in ATP2A2 and ATP2C1 associated with Darier disease and Hailey-Hailey disease. Under revision for publication in Human Mutation.

\section{Other publications on genodermatology:}

M. Vreeburg, E.A. de Zwart-Storm, M.I. Schouten, R.G.L. Nellen, D. MarcusSoekarman, M. Devies, M. van Geel, M.A.M. van Steensel. Skin changes in oculodento-digital dysplasia are correlated with C-terminal truncations of connexin 43. Am J Med Genet A 2007 Feb 15;143(4):360-3.

J.J.A.J. van der Velden, M. van Geel, R.G.L. Nellen, M.F. Jonkman, J.A. McGrath, A. Nanda, E. Sprecher, M.A.M. van Steensel, W.H.I. McLean, A.J. Cassidy. Novel TGM5 mutations in acral peeling skin syndrome. Exp Dermatol 2015 Apr;24(4):285-9.

A.R.J.V. Vossen, L.S. Boesten, P.D. Siersema, R.G.L Nellen. Porphyria cutanea tarda: nut van aanvullende diagnostiek. Ned Tijdschr Geneeskd 2016;160:A9166.

\section{Other publications:}

Y.G.L. de Graaf, H. Rebel, A. Elghalbzouri, P. Cramers, R.G.L. Nellen, R. Willemze, J.N. Bouwes Bavinck, F.R. de Gruijl. More epidermal p53 patches adjacent to skin carcinomas in renal transplant recipients than in immunocompetent patients: the role of azathioprine. Exp Dermatol 2008 Apr;17(4):349-55.

R.G.L. Nellen, J.J. Rijzewijk, J. Frank, P. Poblete-Gutiérrez. Juvenile amyopathic dermatomyositis with concomitant heart disease. Int J Dermatol 2007 Nov;46 Suppl 3:22-4.

R.G.L. Nellen, J. Frank. Diagnose in beeld (365). Een man met hyperpigmentatie in het gelaat. Ned Tijdschr Geneeskd 2008 Mar 15;152(11):615.

R.G.L. Nellen, A.M. van Marion, J. Frank, P. Poblete-Gutiérrez, P.M. Steijlen PM. Eruption of lymphocyte recovery or autologous graft-versus-host disease? Int J Dermatol 2008 Nov;47 Suppl 1:32-4. 
K. Mosterd, R.G.L. Nellen ${ }^{\star}$, M. van Engeland, M. van Geel, M.A.M. van Steensel. Defects in DNA mismatch repair do not account for early-onset basal cell carcinoma. Br J Dermatol 2008 Sep;159(3):751-3.

L.J.M.T. Parren, R.G.L. Nellen, A.M. van Marion, C.J.M. Henquet, J. Frank, P. PobleteGutiérrez. Penile pyoderma gangrenosum: successful treatment with colchicine. Int $J$ Dermatol 2008 Nov;47 Suppl 1:7-9. 


\section{Dankwoord (Acknowledgements)}

Dit proefschrift was niet tot stand gekomen zonder de hulp van velen.

Allereerst dank ik de patiënten, hun familieleden, de personen uit de controlepopulatie en de verwijzende collegae voor hun medewerking.

De leden van de promotiecommissie, prof. dr. P.M. Steijlen, prof. dr. M.A.M. van Steensel, dr. M. van Geel en prof. dr. J. Frank wil ik hartelijk bedanken voor de begeleiding de afgelopen jaren. Beste Peter, ik heb met erg veel plezier met je samengewerkt tijdens mijn opleiding en het onderzoek; onze discussies over werk en wereldlijke zaken blijven een inspiratie. Beste Maurice, bedankt dat ik de afgelopen jaren op elk moment van je kennis en kunde aangaande de genodermatologie en het wetenschappelijk bedrijf gebruik heb mogen maken. Beste Michel, bedankt voor je dagelijkse begeleiding tijdens mijn onderzoek: zonder je niet aflatende steun, adviezen en begeleiding in het laboratorium had ik dit onderzoek niet kunnen doen en was dit boekje nooit meer dan een hersenschim geweest. Beste Jorge, je stilistische en retorische aanwijzingen hebben veel van mijn eerste versies voor artikelen uit het moeras van de middelmatigheid getrokken.

Speciale dank gaat uit naar Reno Bladergroen, Tijs Claessens en Miriam Kamps voor de talloze uren hulp met alle experimenten. Het is jullie bijna gelukt een moleculair bioloog van me te maken.

De leden van de beoordelingscommissie en de corona wil ik hartelijk bedanken voor de beoordeling van het manuscript en de moeite die zij zich troosten af te reizen naar Maastricht voor de verdediging van mijn proefschrift.

De secretaresses van de afdeling Dermatologie van het MUMC en het IJsselland Ziekenhuis wil ik bedanken voor al hun hulp bij het regelen van de praktische zaken die komen kijken bij mijn promotie.

Adriaan Zwiers en Nathalie de Schipper, bedankt voor de hulp bij de opmaak van het omslag en het redigeren van de tekst.

Mijn oud-collega's uit de opleiding in Maastricht en mijn huidige collega's in Capelle wil ik bedanken voor de fijne samenwerking al deze jaren. Annemarie, Bart en Gerdien, ik waardeer het enorm dat we in een hele prettige sfeer samenwerken waarin we een mooie praktijk voeren en elkaar onze eigen persoonlijke ontwikkeling gunnen.

Mijn familie en vrienden ben ik dankbaar voor de hulp en de steun al deze jaren, ook op de momenten dat er op het persoonlijk vlak hele andere zaken speelden dan een proefschrift.

Annieke, bedankt voor alles. 